Inheritance and genetic variation of shoot elongation before winter in oilseed rape (Brassica napus L.)

Mohammad Ghanbari

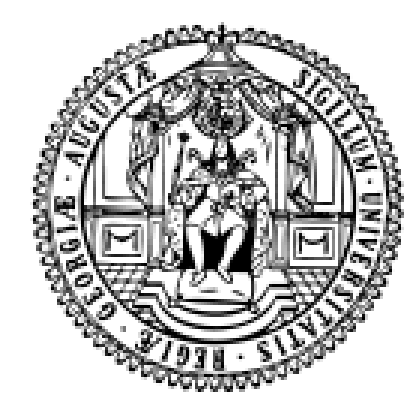

Göttingen 2016 


\title{
Inheritance and genetic variation of shoot elongation before winter in oilseed rape (Brassica napus L.)
}

\author{
Dissertation \\ to obtain the Ph.D. degree, \\ in the International Ph.D. Program for Agricultural Sciences in Göttingen (IPAG), \\ at the Faculty of Agricultural Sciences, \\ Georg-August-University Göttingen, \\ Germany
}

Presented by

Mohammad Ghanbari

born in Zahedan, Iran

Göttingen, Germany, 12 May 2016 
D7

1. Name of supervisor: Dr. Christian Möllers

2. Name of co-supervisor: Prof. Dr. Konstantin Krutovsky

Date of dissertation: 14 July 2016 
Dedicated to

My mother's soul in Paradise 


\section{Contents}

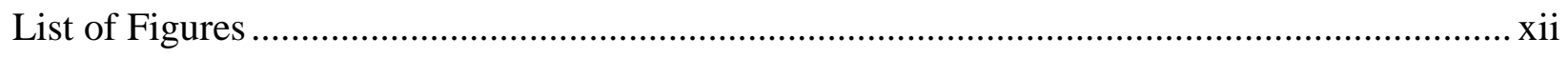

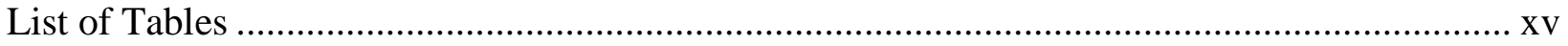

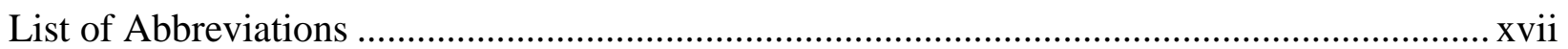

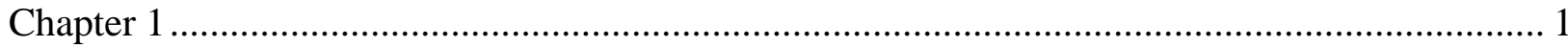

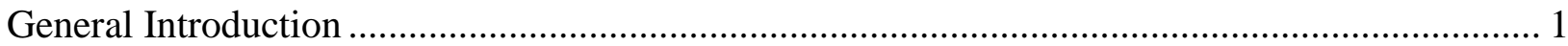

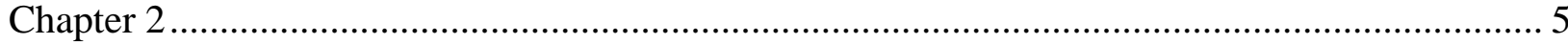

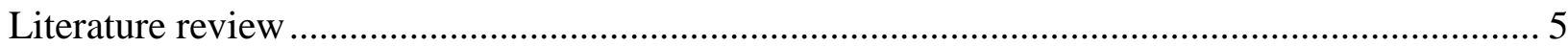

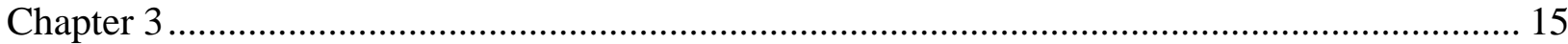

Genetic variation of shoot elongation before winter and its correlation with vernalization requirement in winter oilseed rape cultivars (Brassica napus L.) ........................................... 15

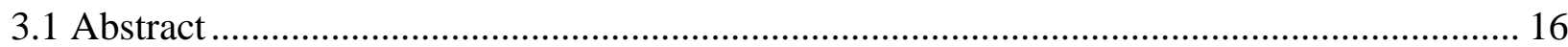

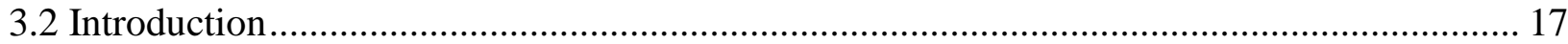

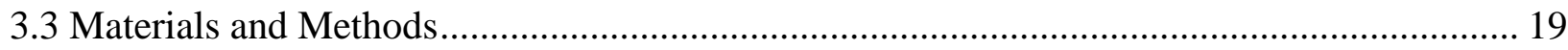

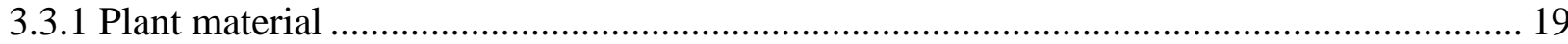

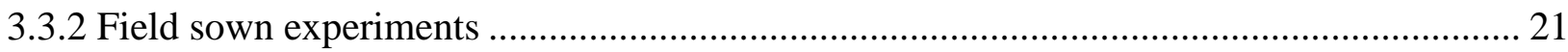

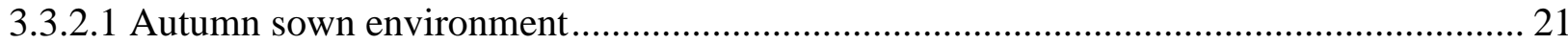

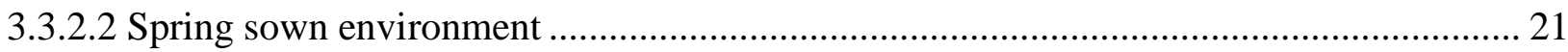

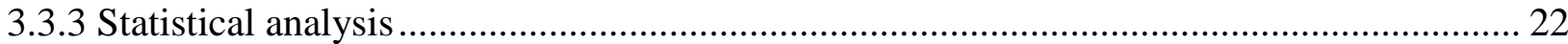

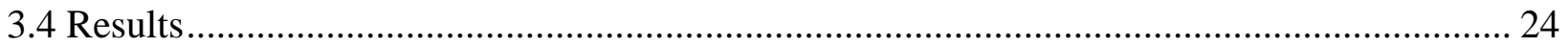

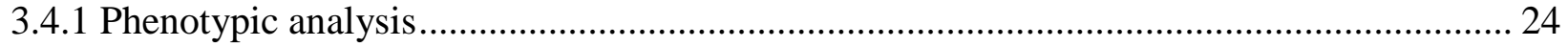

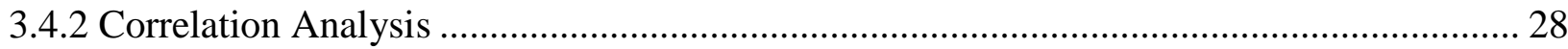

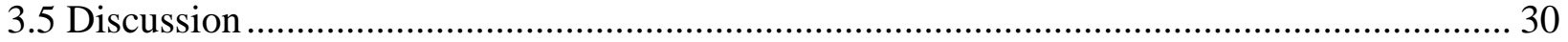

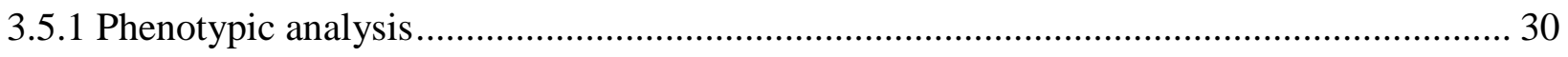

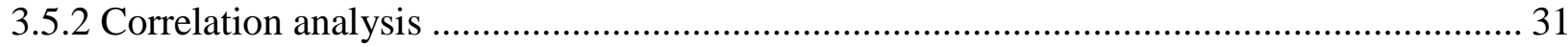

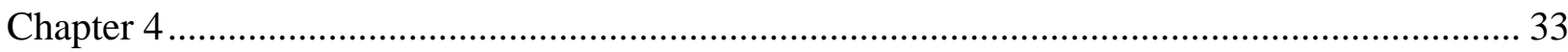

Genetic analysis and inheritance of shoot elongation before winter and its relation with other traits in the doubled haploid population L16 x Express617 (Brassica napus L.)....................... 33 


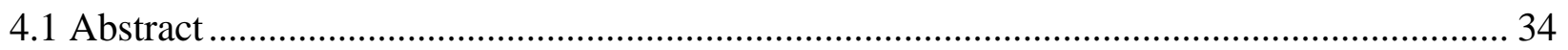

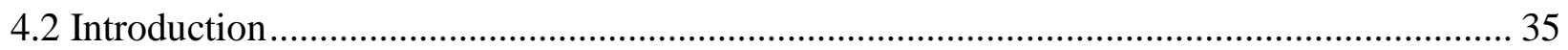

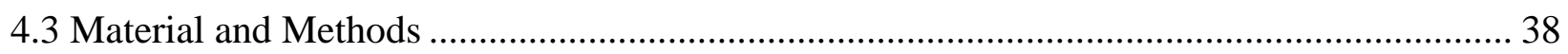

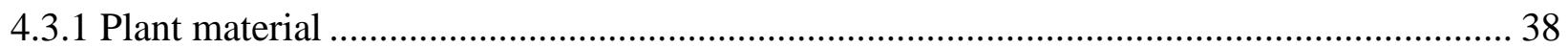

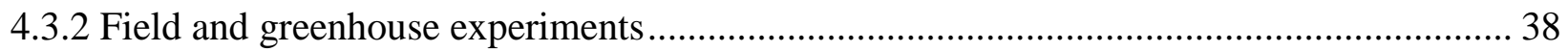

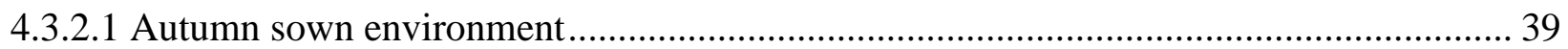

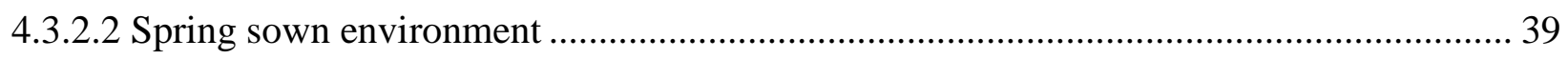

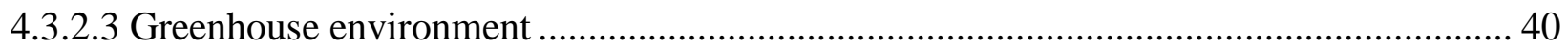

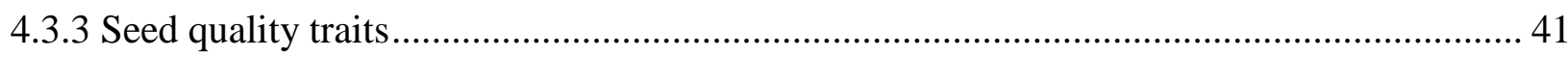

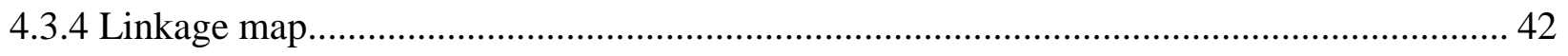

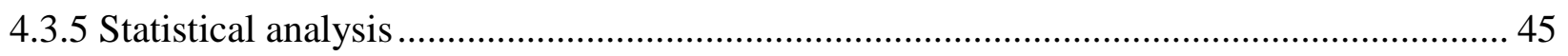

4.3.6 QTL mapping and identification of candidate genes .......................................................... 46

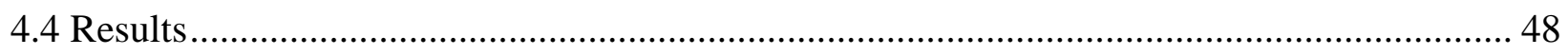

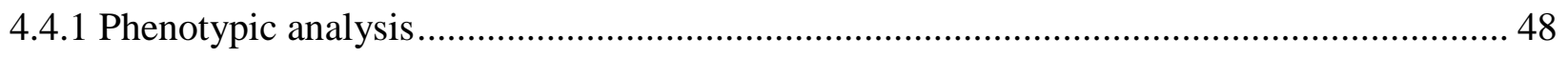

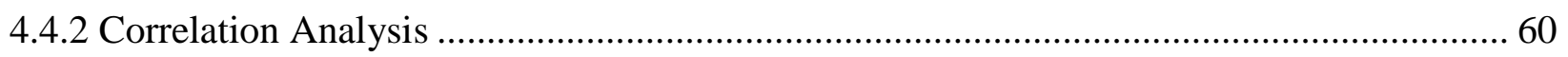

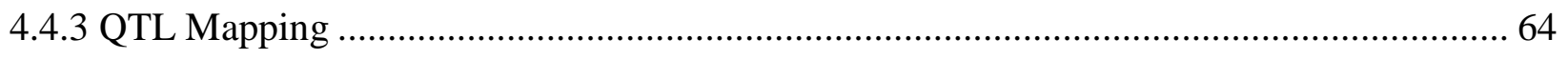

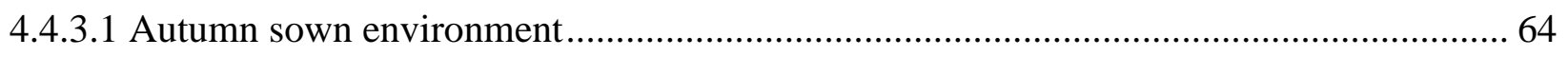

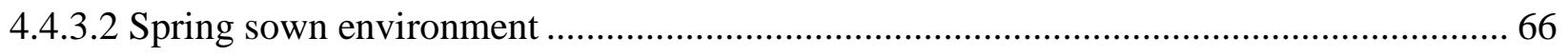

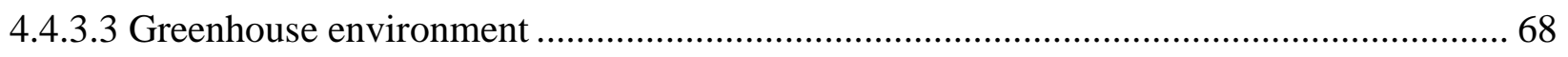

4.4.3.4 Seed quality traits........................................................................................................ 71

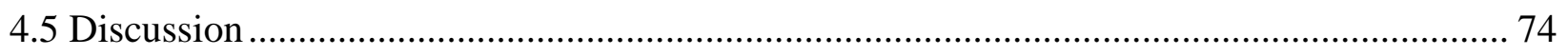

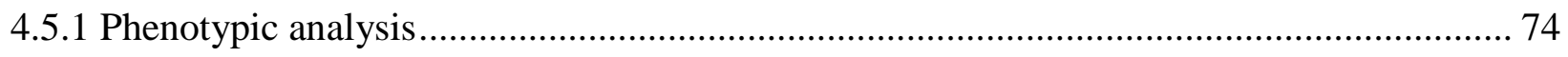

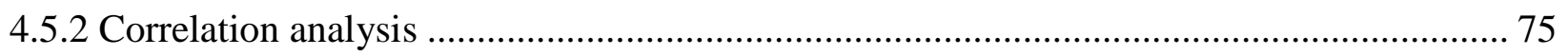

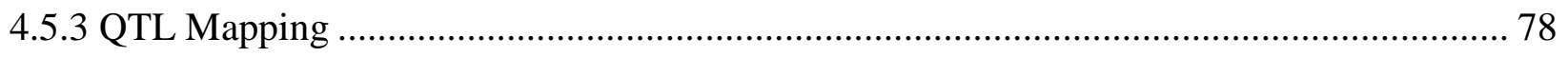

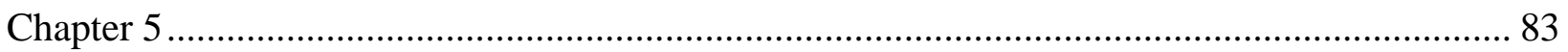

Genetic analysis and inheritance of shoot elongation before winter and its relation with other traits in a doubled haploid population Sansibar x Oase (Brassica napus L.) …………….......... 83

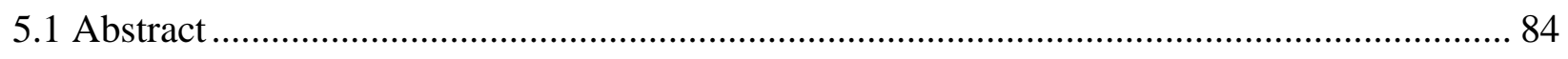

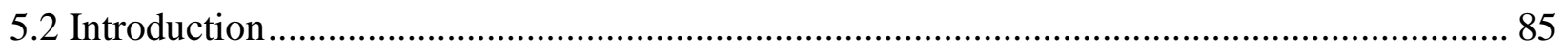

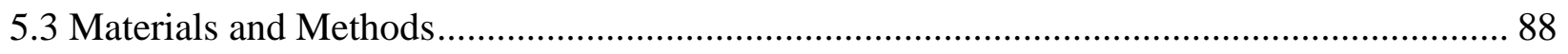




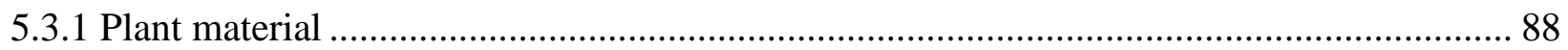

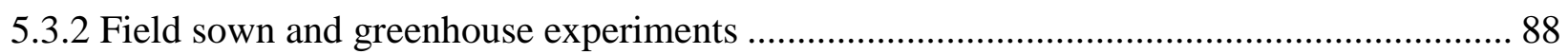

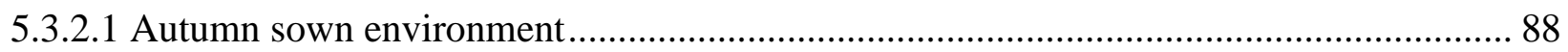

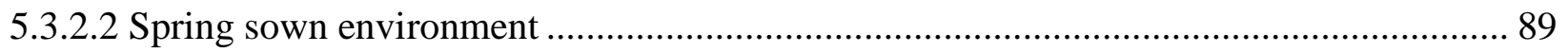

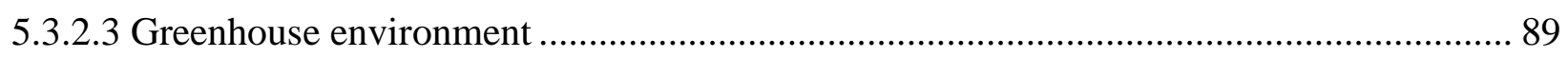

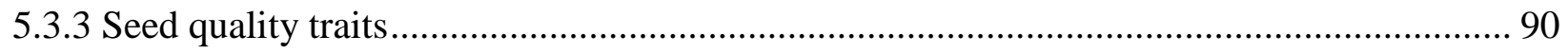

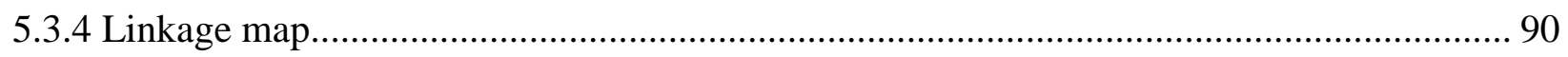

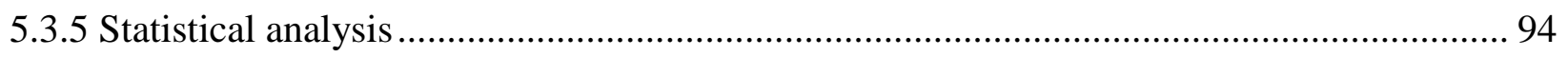

5.3.6 QTL mapping and Identification of candidate genes...................................................... 94

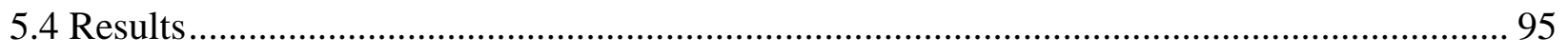

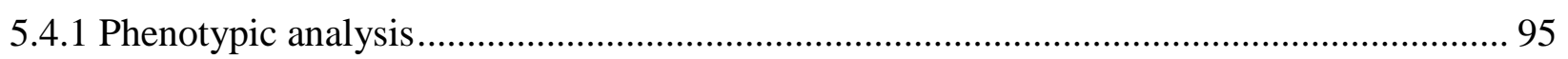

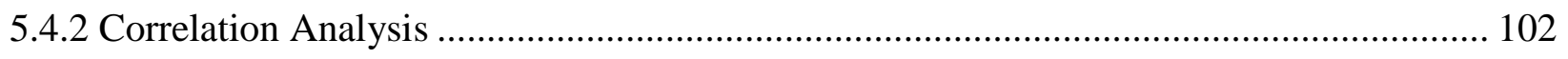

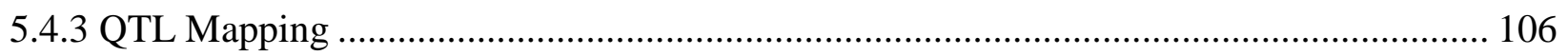

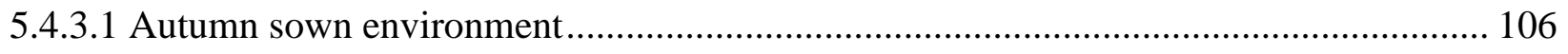

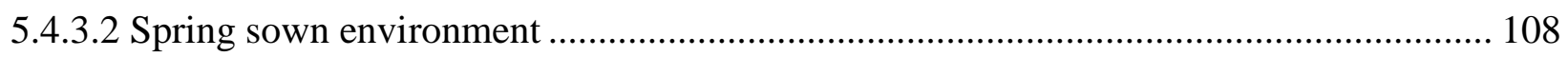

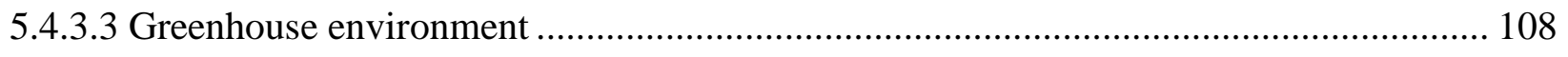

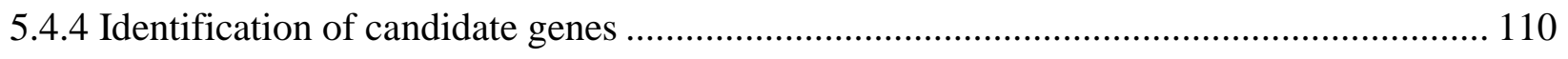

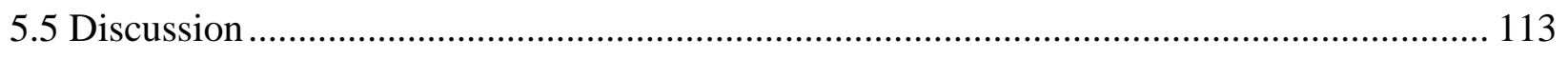

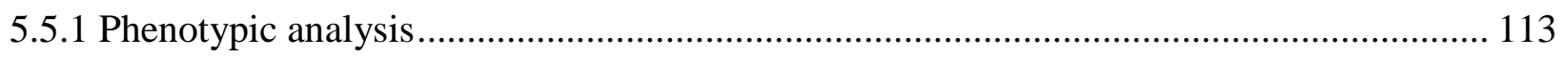

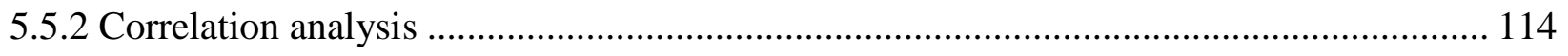

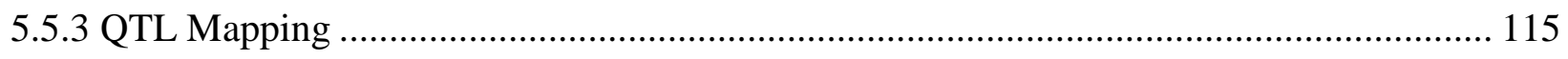

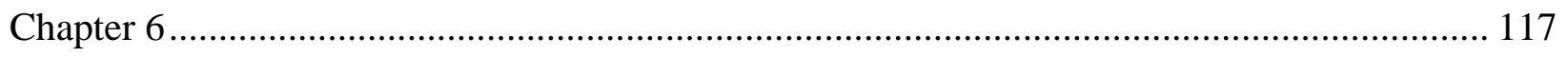

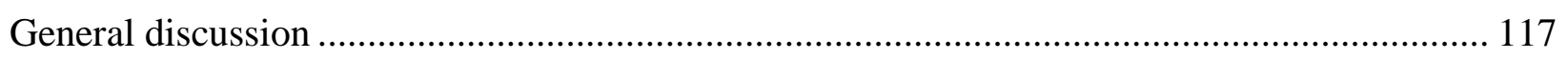

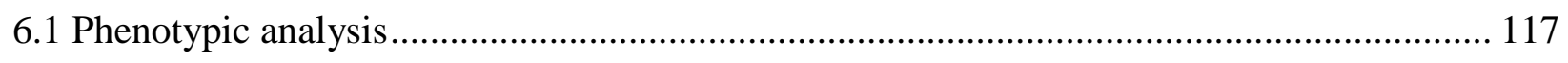

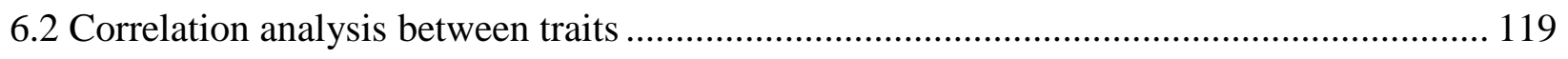

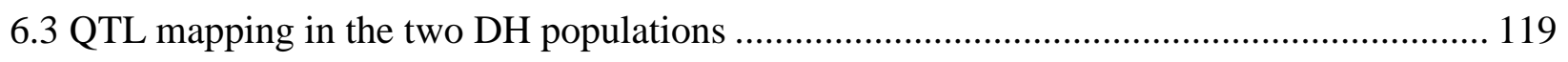

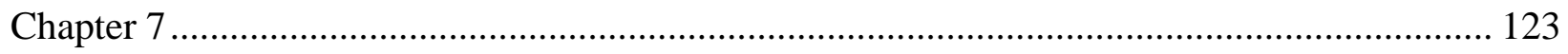

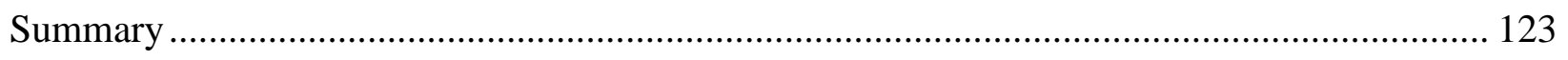

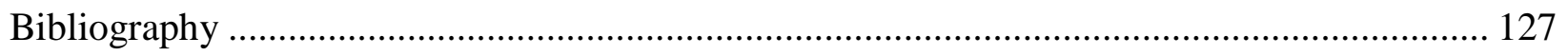




\section{List of Figures}

Figure 2.1: World Supply and distribution of major vegetable oils in 2014/2015 (in million tons). Source: USDA Foreign Agriculture Service;

http://apps.fas.usda.gov/psdonline/circulars/oilseeds.pdf (site visited February 25, 2016)

Figure 2.2: World supply and distribution of oilseed rape in 2014/2015 (in million tons). Source: USDA Foreign Agriculture Service; http://apps.fas.usda.gov/psdonline/circulars/oilseeds.pdf (site visited February 25, 2016)

Figure 3.1.1: Mean comparison of 19 genotypes of winter oilseed rape for shoot length in the autumn sown environment.

Figure 3.1.2: Mean comparison of 19 genotypes of winter oilseed rape for shoot length in the spring environment.

Figure 3.2: Scatter plot of 19 oilseed line and OP cultivars between shoot length before winter and shoot length in the spring sown environment

Figure 4.1: Estimated recombination fractions (upper left) and LOD scores (Lower right) for all pairs of markers in the DHLE population. Dark red indicates pairs of markers that appear to be tightly linked (very low recombination), dark blue indicates pairs that are not completely linked (very high recombination). Green points (combination of red and blue points) indicated marker's pairs ranging from very high recombination to very low recombination.

Figure 4.2: Genetic framework map of the DHLE population, with approximately 5 to $10 \mathrm{cM}$ marker spacing.

Figure 4.3: Genotype data for the DHLE population. Blue and red pixels correspond to alleles coming from L16 and Express617, respectively. White pixels indicate missing genotype data.. 45

Figure 4.4.1: Frequency distribution of shoot length, shoot diameter, begin of flowering, plant height in the DHLE population in the autumn sown environment. Arrows indicate the parents mean across the field experiments. (continued on the next page)

Figure 4.4.1: (continued from the previous page) Frequency distribution of shoot length, shoot diameter and visible buds in the DHLE population in the spring sown environment. Arrows indicate the parents mean across the field experiments.

Figure 4.4.2: Frequency distribution of shoot length and shoot diameter in zero, four and eight weeks vernalization treatment. Begin of flowering in the eight weeks vernalization treatment in the DHLE population. Arrows indicate the parents mean across experiments. 
Figure 4.4.3: Frequency distribution of oil content, protein of the defatted meal, thousand kernel weight, glucosinolates, fatty acid composition, fibre seed fraction in the DHLE population. Arrows indicate the parents mean across the experiments. (continued on the next page)........... 58 Figure 4.4 .3 (continued from previous page) Frequency distribution of oil content, protein of defatted meal, seed weight, glucosinolates, fatty acid composition, seed fibre fraction, in the DHLE population. Arrows indicate parents mean across the experiments.

Figure 4.5: Genetic and physical map positions of markers within the QTL genomic region (125$131 \mathrm{cM})$ on C09 in the DHLE. Left: QTL for shoot length and percentage of visible buds in the spring sown, shoot length and in the 4 week vernalization treatment and begin of flowering in the greenhouse with eight weeks vernalization treatment. Middle: Additional markers mapped within the QTL genomic region in the full map. Right: The corresponding physical positions of additional markers and the candidate gene $(B n F L C 9 b)$ in $B$. napus genome

Figure 4.6: Genetic and physical map positions of markers within the QTL genomic region (48.5-55.1cM) on A02 in the DHLE. Left: QTL for begin of flowering and plant height at end of flowering in the autumn sown, shoot length Figure 4.7: Additive effect of two flanking markers Bn-A02-p8215285 and Bn-C09-p482119394 linked to the two major QTL on A02 and C09 for the shoot length in the spring sown environment in the DHLE population.

Figure 4.7: Additive effect of two flanking markers Bn-A02-p8215285 and Bn-C09-p482119394 linked to the two major QTL on A02 and C09 for the shoot length in the spring sown environment in the DHLE population. Red points indicate missing data. Red boxplot shows standard error and higher phenotypic mean and blue boxplot shows standard error and lower phenotypic mean for shoot length in the spring sown environment in each genotypic combination

Figure 5.1: Estimated recombination fractions (upper left) and LOD scores (Lower right) for all pairs of markers in the DHSO population. Dark red indicates pairs of markers that appear to be tightly linked (very low recombination), dark blue indicates pairs that are not completely linked (very high recombination). Green points (combination of red and blue points) indicated marker's pairs ranging from very high recombination to very low recombination.

Figure 5.2: Genetic framework map of the DHSO population, with average density 1 marker per $7.4 \mathrm{cM}$

Figure 5.3: Genotype data for the DHSO population. Red and blue pixels correspond to alleles coming from Sansibar and Oase, respectively. White pixels indicate missing genotype data.... 93

Figure 5.4.1: Frequency distribution of shoot length, shoot diameter, begin of flowering, end of flowering, duration of flowering and plant height at end of flowering in the autumn sown environment in the DHSO population. Parental mean values are indicated by arrows 98 
Figure 5.4.2: Frequency distribution of shoot length, visible buds and shoot diameter in the spring sown environment and shoot length, shoot diameter in the greenhouse environment in the DHSO population. Parental mean values are indicated by arrows

Figure 5.5: Genetic and physical map positions of markers within the QTL genomic region (14.6-23.6 cM) on A02. Left: QTL for shoot length, shoot diameter, begin of flowering, end of flowering, duration of flowering, plant height at end of flowering, percentage of visible buds, oil content and thousand kernel weight in the DHSO population. Middle: Additional markers mapped within the QTL genomic region in full map of the DHSO population Right: The corresponding physical positions of additional markers and the candidate gene (BnFLC2) in $B$.

napus genome

Figure 5.6: Additive effect of flanking marker 3091433|F|0 linked to the major QTL on A02 for the shoot length in the spring sown environment in the DHSO population. Red points indicate missing genotype data. Red boxplot shows standard error and higher phenotypic mean and blue boxplot shows standard error and lower phenotypic mean for shoot length in the spring sown environment.

Figure 5.7: Genetic and physical map positions of markers within the QTL genomic region (22.1-29.7 cM) on C06. Left: QTL for begin of flowering, end of flowering, duration of flowering, plant height at end of flowering, percentage of visible buds in the DHSO population. Middle: Additional markers mapped within the QTL genomic region in full map of the DHSO population Right: The corresponding physical positions of additional markers and the candidate gene (Bn.C6.FT.b) in B. napus genome. 


\section{List of Tables}

Table 3.1: Name and features of the 19 breeding lines and cultivars of winter oilseed rape ....... 20

Table 3.2: Variance components and heritability of the traits in 19 oilseed cultivars in the two

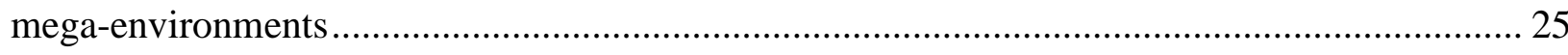

Table 3.3: Descriptive statistics of the traits in 19 cultivars of winter oilseed rape in the two mega

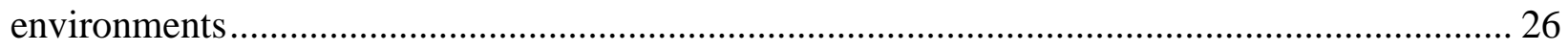

Table 3.4: Spearman's rank correlation of the traits in 19 cultivars of winter oilseed in two mega

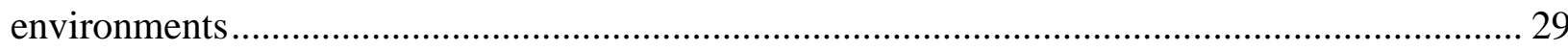

Table 4.1: Marker distribution, size and marker density between markers of each linkage group in the linkage map of the DHLE population (Brandes 2016) ................................................ 43

Table 4.3.1: Descriptive statistics of the parents and the DHLE population $(n=151)$ in the autumn

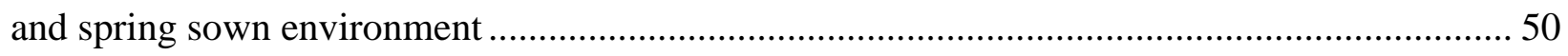

Table 4.3.2: Descriptive statistics of the parents and the DHLE population $(n=151)$ in greenhouse

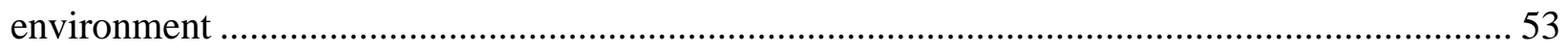

Table 4.2.2: Variance components and heritability of the seed quality traits in the DHLE

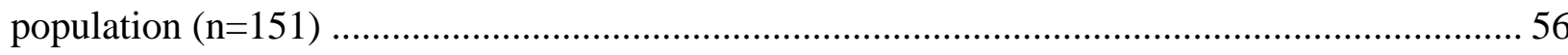

Table 4.3.3: Descriptive statistics of the parents and the DHLE population $(n=151)$ for the seed

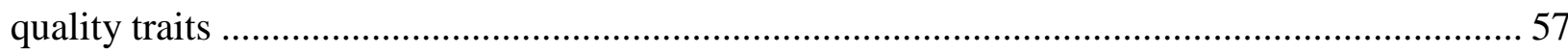

Table 4.4.1: Spearman's rank correlation of the traits in the DHLE population $(n=151) \ldots \ldots \ldots . . .61$

Table 4.4.2: Spearman's rank correlation of the seed quality traits in the DHLE population

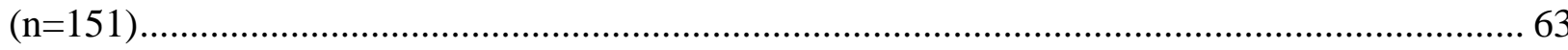

Table 4.5.1: QTL mapped for the traits in the autumn sown environment in the DHLE population $(\mathrm{n}=151)$ 65

Table 4.5.2: QTL mapped for the traits in the spring sown environment in the DHLE population $(\mathrm{n}=151)$

Table 4.5.3: QTL mapped for the traits in the greenhouse environment in the DHLE population $(\mathrm{n}=151)$ 70

Table 4.6.4: QTL mapped for seed quality traits in the DHLE population ............................. 72

Table 5.1: Marker distribution, size and marker density between markers of each linkage group in the linkage map of DHSO population. (data taken from Teh and Möllers 2016) 91 
Table 5.2.1: Variance components and heritability of the DHSO population in the three mega environments.

Table 5.3.1: Descriptive statistics of the parents and the DHSO population in the autumn sown environment

Table 5.3.2: Descriptive statistics of the parents and the DHSO population $(n=226)$ in spring and

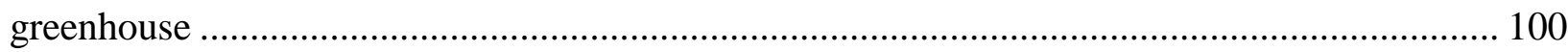

Table 5.4.1: Spearman's rank correlation of the studied traits in the DHSO population $(n=226)$

Table 5.4.2: Spearman's rank correlation of seed quality traits in the DHSO population $(\mathrm{n}=226)$

Table 5.5.1: QTL mapped for the studied traits in the autumn sown environment in the DHSO population.

Table 5.5.2: QTL mapped for the studied traits in the spring sown and greenhouse environment in the DHSO population

Table 6.1: Number of QTL mapped in the DHLE and DHSO for the studied traits in three mega environments. 


\section{List of Abbreviations}

ADFm acid detergent fibre of the defatted meal

ADLm acid detergent lignin of the defatted meal

AFLP amplified fragment length polymorphisms

AP1 APETALA1 gene

BOF begin of flowering

CBC cap-binding Complex

CBF c binding Factor

CCT CONSTANCE, CONSTANCE-like, TIMING of C

C18:1 oleic acid

C18:2 linoleic acid

C18:3 linolenic acid

DArT diversity arrays technology

DH doubled haploid

DHLE doubled haploid of L16 x Express617

DHSO doubled haploid of Sansibar $\times$ Oase

DOF duration of flowering

EFS early flowering in short days

EOF end of flowering

FLC FLOWERING LOCUS C

FRI FRIGIDA gene

FT FLOWERING LOCUS T

GC gas chromatography

GSL glucosinolates content

$\mathbf{H}^{2}$ broad sense heritability

KASP KBioscience competitive Allele-Specific PCR

LT 50\% lethality rate at 50\%

LFY: LEAFY gene

MIM multiple interval mapping

NDFm neutral detergent fibre of the defatted meal

NIRS near-infrared reflectance spectroscopy

PH plant height

PodM protein content of the defatted meal

QTL quantitative trait locus

$\mathbf{R}^{2}$ coefficient of determination

SD shoot diameter at root crown

SL shoot length from root crown to shoot apex

SNP single nucleotide polymorphisms

SSR simple sequence repeats 


\section{Chapter 1}

\section{General Introduction}

Oilseed rape or rapeseed (Brassica napus L.) is the world's third-leading crop of vegetable oil (http://apps.fas.usda.gov). Oilseed rape cultivars are mainly cultivated for human nutrition and recently as animal feed and biodiesel production. Predominant oilseed rape genotypes that were released and commercialized in the last decades are double low cultivars. The term "double low" or "double zero" is commonly used to refer to oilseed rape with $<2 \%$ erucic acid in the oil and $<25 \mu_{m o l g}^{-1}$ glucosinolates in the seed (Bundessortenamt 2014). Oilseed rape is highly recognized for its nearly ideal fatty-acid profile that is, having low level of saturated fatty acids, high mono-unsaturated fatty acids and a good proportion of omega-3 and omega-6 polyunsaturated fatty acids (Schmidt and Bancroft 2011). B. napus is an amphidiploid species with 2 n=38 (AACC) chromosomes derived from crosses between B. rapa, represented by AA genome, and B. oleracea, represented by CC genome. B. napus varieties are grown in different regions across the world, including Central and Western Europe, Canada, China and other parts of the world. This large adaptation has been achieved by spring and winter growth types, enabling genotypes to grow in diverse climates. The classification is based on vernalization requirement and not on the level of frost tolerance. However, winter types, also named biennial types, are generally assumed to have better winter survival which is correlated with cold acclimation and mechanisms preventing stem elongation before winter (Teutonico et al. 1993, Rapacz 1999). As any other crop, the yield potential of oil seed rape is also limited by environmental conditions such as biotic and abiotic factors hampering the successful production of this crop. Abiotic factors, like extreme low and high temperature are most significant constraints for the production of this crop in Central and Western Europe. Moreover in temperate regions, extreme low temperatures may occur in winter which may require enhanced stress tolerance of crop plants. For example, in 2012 following a rather normal winter, extreme low temperatures of up to $-25{ }^{\circ} \mathrm{C}$ occurred in February in North Western Germany (https://www.wunderground.com, site visited March 3, 2016). Since at that time crops were not covered by snow, this caused severe frost damage in winter wheat, oilseed rape and other crops 


\section{General introduction}

(Christiane Möllers, personal communication). In addition, in January 2016 temperature dropped to $-17{ }^{\circ} \mathrm{C}$ after a long warm period in December 2015 , resulting in frost damage of initially formed buds in oilseed rape (own personal observation). Low temperatures have significantly limited plant reproduction and geographical distribution in North Europe and Canada. Therefore, plants have evolved variety of adaptive mechanisms to survive after exposure to freezing temperature and resume growth when threat of frost stress is passed (Fowler et al. 1981). Cold acclimation and vernalization requirement are both survival mechanisms adopted by winter type crops to cope with extreme freezing conditions during overwintering (Rapacz 2002a,b). In Brassica napus and other biennials plants, winter survival is a decisive attribute for favored overwintering that depends on the expression of many interacting traits (Kole et al. 2002). Plant breeders are striving for improving winter hardiness in the breeding material in order to secure yield stability in years with risk of frost damage. However, selection for improved winter hardiness is a difficult task, because firstly, efficient selection can only be performed in extreme winters, like e.g. in 2012, which in principle is not accessible and predictable in all regions. Secondly, winter hardiness is a complex trait, which consists of frost tolerance per se, disease resistance - especially under snow cover, flooding tolerance - after heavy rain falls on frozen soil, drought tolerance at long periods with frozen soil, and tolerance against soil movements due to rapidly changing temperatures. The reason for winterkill vary greatly from region to region and from year to year. It is discussed that vernalization genes and plant development stage are, also, interacting with winter hardiness, for instance, it is suggested that higher degree of vernalization leads to more winter hardy plants (Fowler et al. 1996a,b, Sãulescu and Braun 2001).Vernalization is a complex physiological process that plays a determining role to accelerate floral transition in oilseed rape after enough exposure to nonfreezing low temperatures during rosette stage in the field sown conditions (Prásil et al. 2004). Although all winter oilseed rape varieties require vernalization, this requirement is not always correlated with winter hardiness. For instance, Teutonico et al. (1993), Rapacz and Chilmonik (2000) observed spring oilseed rape lines whose frost tolerance were the same as that of winter lines. Nonetheless, transition to the generative phase occurred earlier in spring types, which then at the bolting and flowering stage frequently suffer frost damage. As matter of fact, spring type plants have low capability to reduce and stop growth and shoot development when temperatures rise above $0{ }^{\circ} \mathrm{C}$ before and during winter (Rapacz 1999, Rapacz et al. 2001). Consequently, less assimilates are 
accessible to increase concentration of cell constituents to prevent formation of of ice crystals in plant tissues under freezing conditions (Laroche et al. 1992, Fowler et al. 1996a). Cessation of growth during cold acclimation (Levitt 1972) and compact plant morphology have long been considered as one of the main requirements for overwintering (Rapacz 2002b). Too early elongation of the shoot before and during winter is particularly considered by oilseed rape breeders as a potential trait for selection of winter-hardy genotypes (Schulz 2007). Genotypes that show an enhanced shoot elongation before and during winter are very much prone to frost damage. However, so far, little is known about genetic variation and inheritance of shoot elongation before winter and its correlation to vernalization that is important mechanism for winter survival in oilseed rape. Furthermore, correlation between seed quality trait, that are economically important, and winter hardiness related traits are ambiguous in oilseed rape.

The present study aimed at performing field and greenhouse trials followed by statistical analysis and QTL mapping in two bi-parental doubled haploid (DH) populations of Brassica napus to shed light on genetic base and inheritance of shoot elongation before winter and its relation to vernalization requirement, flowering time and seed quality traits. Furthermore, a collection of 19 European winter oilseed rape breeding lines and open pollination (OP) cultivars were used to evaluate genetic variation of shoot elongation before winter and vernalization requirement in replicated field trials. The first DH population comprising $226 \mathrm{DH}$ lines derived from a cross between the two winter oilseed rape cultivars "Sansibar" and "Oase", called DHSO population (Teh and Möllers 2016). The second DH population comprising 151 DH lines derived from a cross between the resynthesized line L16 and the inbred line 617 of the cultivar Express (Express617, Brandes 2016), called DHLE population. The two DH populations were selected from prior field tests regarding shoot length before winter and flowering time (Christian Möllers, personal communication). Furthermore, for the both populations genetic maps with sequence informative markers were available (Teh and Möllers 2016, Brandes 2016). The two DH populations and their parental lines were assessed in three different mega environments: (I) autumn sown environment, (II) spring sown environment, and (III) greenhouse environment with vernalized and non-vernalized plants. Multiple Interval Mapping (MIM, Kao et al. 1999) was applied for QTL mapping based on genetic maps previously constructed for each of the two populations (Teh and Möllers 2016, Brandes 2016). 
Therefore, the specific objectives of the present study were:

(1) To study genetic variation and inheritance of shoot elongation before winter in the 19 breeding lines and OP cultivars and two DH populations (DHLE \& DHSO) in the autumn sown environment.

(2) To study genetic variation and inheritance of shoot elongation and tendency to form inflorescence in the 19 breeding lines and OP cultivars and two DH populations (DHLE \& DHSO) in the spring sown environment.

(3) To study genetic variation and inheritance of shoot elongation in the two DH populations (DHLE \& DHSO) in the greenhouse environment with vernalized and nonvernalized plants.

(4) To study correlation between studied traits in three different mega environments.

(5) To map and compare QTL identified for the studied traits in the two DH populations (DHLE \& DHSO) in the three different mega environments.

(6) To identify candidate genes in genomic regions with major QTL for the traits of interest in the two DH populations (DHLE \& DHSO). 


\section{Chapter 2}

\section{Literature review}

Oilseed rape or rapeseed (Brassica napus L.) is a major oil crop in many parts of the world and is well adapted to cold, dry and moist growing conditions and is extensively cultivated in Europe, China, Canada and India (Downey and Rakow 1987). Today, oilseed rape is the world's third-leading source of vegetable oil and the second most important oilseed in the world after soybean (http://apps.fas.usda.gov). In 2014/15, oil production from oilseed rape amounted to 27.2 million tons, accounting for $15.5 \%$ of the world's vegetable oil supply (Figure 2.1). The main oilseed rape producing countries are China, Canada and India (Figure 2.2). In the EU-28 countries, 10.52 million tons of oilseed rape were produced in 2014/15, accounting for $38.6 \%$ of worldwide oilseed rape production. Cultivation acreage of oilseed rape is predicted to expand, particularly in European regions where demand is growing for renewable fuels such as biodiesel (Britz and Hertel 2011).

Oilseed rape varieties that meet the requirements of less than $2 \%$ erucic acid in the oil and less than $25 \mu \mathrm{mol} / \mathrm{g}$ glucosinolates in the seeds are called "canola" in Canada or "double low" (double zero) in Europe to distinguish them from traditional varieties that do not meet this standard (Bundessortenamt 2014). Depending on the fatty acid profile found in the seed of particular cultivars, oilseed rape is used for both edible and industrial purposes (Schmidt and Bancroft 2011). Typically, the fatty acid profile of edible modern oilseed rape (" 00 ") oil contains $60 \%$ of oleic acid (18:1), 20\% linoleic acid (18:2), 10\% linoleic acid (18:3), 7\% saturated fats and 1-2\% erucic acid (Wittkop et al. 2009). For many years, grain yield has been the major breeding goal for oilseed rape researchers. However, since 1970 other breeding objectives have gained importance, such as early and simultaneous maturity, diseases resistance, oil and protein content, fatty acid composition, reduced fiber content, anti-nutritional factors and abiotic stresses tolerance 


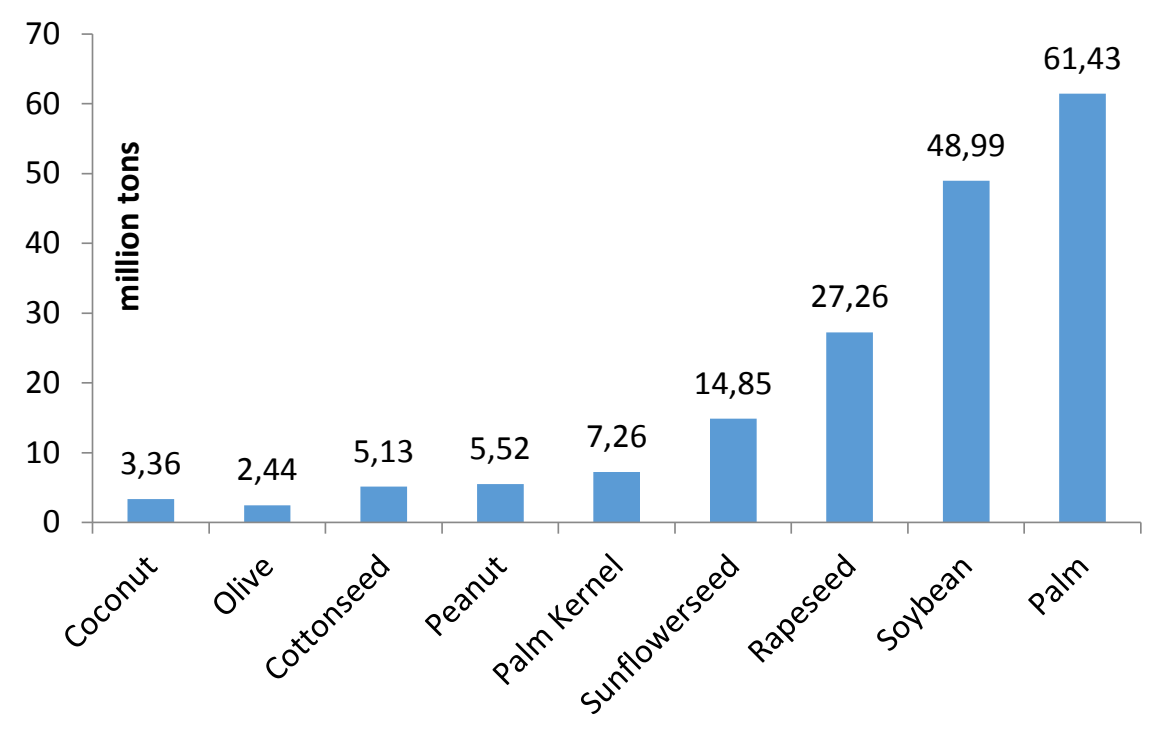

Figure 2.1: World Supply and distribution of major vegetable oils in 2014/2015 (in million tons). Source: USDA Foreign Agriculture Service; http://apps.fas.usda.gov/psdonline/circulars/oilseeds.pdf (site visited February 25, 2016)

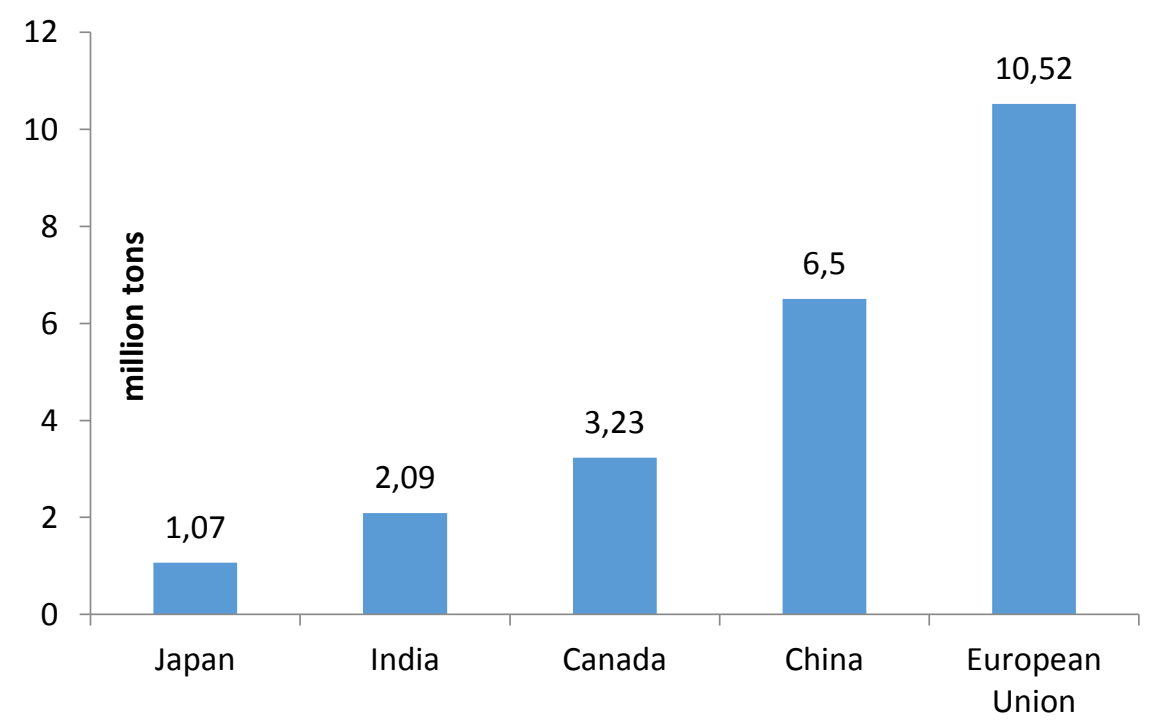

Figure 2.2: World supply and distribution of oilseed rape in 2014/2015 (in million tons). Source: USDA Foreign Agriculture Service; http://apps.fas.usda.gov/psdonline/circulars/oilseeds.pdf (site visited February 25, 2016) 


\section{Literature review}

Winter stress is one of the major common abiotic stresses that adversely influence plant growth and productivity in winter-type crops which are typically sown either in late summer or early fall (Chinnusamy et al. 2007). Plants overwinter as juvenile in rosette growth form and continue their development in the following spring (Kole et al. 2002). As other winter type crops, winter oilseed rape has to be winter hardy to endure unfavorable extreme low temperatures during overwintering, but the level of winter hardiness is not constant and dependent on both genotype and environment (Kole et al. 2002). The term winter or cold hardiness in a general sense is, the capability of a plant to withstand freezing temperatures. Collectively, the adaptive mechanisms associated with this ability are quite diverse; including cold acclimation to survive sub-zero temperatures and vernalization requirement to delay flowering (Gusta and Wisniewski 2013). It is well established, cold acclimation that typically occurs in autumn is an essential step to induce frost tolerance in acclimated plants and ideally, genotypes can maintain high level of winter hardiness over winter (Levitt 1980). The effect of cold acclimation can be understood when in the early fall, winter plants will not survive sub-freezing temperatures any better than spring plants (Rapacz and Chilmonik 2000, Waalen et al. 2014, Trischuk et al. 2014). However, cold acclimation is a complex multi-step process involving series of concrete physiological and biochemical changes and it is extremely influenced by environment and growing stage of the plant genotype (Rapacz and Janowiak 1998, Theocharis et al. 2012). It has been suggested that for cold acclimation to occur in winter cereals the plants must be in their vegetative state in order to respond to the environmental clues, however this has not been proven unequivocally (Andrews et al. 1960, Mahfoozi et al. 2001). The cold acclimation process results in the rapid accumulation of storage carbohydrates and high photosynthetic rate for the expression of freezing tolerance in different plants tissues (Levitt 1980, Livingston and Henson 1998, Rapacz et al. 2001). Recent studies of overwintering in cereals have shown that frost tolerance is strongly correlated with the capacity to increase photosynthesis and soluble carbohydrate pools during cold acclimation (Tognetti et al. 1990, Öquist et al. 1993). In field-grown oilseed rape cultivars some properties of photosynthetic apparatus, observed during winter, are correlated with growth rate and the progress of the cold acclimation (Rapacz 1998ab). It is shown that oilseed rape cultivars with higher photosynthetic electron transport rate maintained the cessation of elongation growth for a longer period, resulting in better preparation for overwintering (Rapacz and Chilmonik 2000). In addition, they found that less efficient photosynthetic electron 


\section{Literature review}

transport in autumn was observed in the spring cultivars in which the elongation of generative shoots was observed already during the first warm break in winter. The observation is in agreement with higher net assimilation rates and higher in situ $\mathrm{CO}$, exchange rates in winter wheat cultivars than the respective cold-grown spring cultivars (Hurry et al. 1995). Such conditions may be described as conditions of elevated photosystem II (PSII) excitation pressure. Plants showed elevated PSII excitation pressure reflecting imbalances between energy supply and consumption when exposed to either high light intensity or low temperature (Rapacz 2002a,b). Both pre-hardening and growth under high PSII excitation pressure resulted in acclimation of the photosynthetic apparatus and the decrease in elongation growth rate, but it was not involved directly in the development of frost resistance (Rapacz 1998a,b).

From research point of view, frost stress is the main factor influencing winter survival in winter cereals and winter oilseed rape (Rapacz and Markowski 1999). Hence, artificial frost tests are exploited to select tolerant genotypes to frost in breeding projects. Although in some studies the correlation coefficients for frost tolerance between field and laboratory were between $0.77^{* *}$ and $0.92^{* *}$, (Caradus and Christie 1980) the selected genotypes did not maintain winter hardiness in consecutive years, because freezing stress is assessed only under lab conditions while winter survival consists of others stresses such as disease, drought, etc., making selection of tolerant genotypes less efficient. In fact, controlled freezing tests obviously have an advantage over fieldtesting in which the evaluations are faster, give greater control of environmental conditions and provide the opportunity for application over time (Pomeroy and Fowler 1973), yet laboratory tests do not allow estimation of winter hardiness, which is a more relevant trait than freezing tolerance for winter survival. Also Rapacz et al. (2015) stated that cold acclimation under natural field conditions activates a greater array of freezing tolerance mechanisms than cold acclimation performed in under controlled environmental conditions in a laboratory. All the above barriers makes improvement of frost tolerance with less pace compared to breeding for biotic stresses with high correlation between field and controlled conditions. Also in the regions with harsh winters, spring cultivars of oilseed rape are alternative types for farmers to cultivate oilseeds.

In temperate regions, vernalization is the second important mechanism, after cold acclimation, for winter survival in winter crops (Trischuk et al. 2014). Vernalization prevents frost damage by prohibiting floral transition before winter and promoting transition to reproductive growth when optimum conditions are met (Zografos and Sung 2012). Vernalization enables a developmental 
switch at the shoot apical meristem upon exposure to low temperatures making it competent to initiate floral apex. Vernalization is a quantitative response which is proportional to the duration of low temperature conditions, until a species or genotype specific requirement is reached (vernalization requirement), and further exposure to low temperature has no effect on accelerating the transition from vegetative to reproductive stage (Mahfoozi et al. 2001).

Several studies were undertaken to dissect genetic variation of vernalization requirement in winter crops. Early results on B. napus cultivars indicated that two recessive genes control vernalization (Thurling et al. 1979). In contrast, similar studies with B. oleracea indicated a polygenic inheritance with the annual growth habit being dominant (Kennard et al. 1994). QTL studies have shown that the vernalization requirement in B. napus is controlled by as many as three QTL (Ferreira et al. 1995). Very little is still known about the relationship between vernalization and frost tolerance. The relationship varies in different plant tissues and might have genetic association but the metabolic pathway is separated. Work on Arabidopsis thaliana suggested that completely separate pathways control freezing tolerance and vernalization (Chandler et al. 1996). In wheat, winter type varieties usually have a greater vernalization requirement and higher sensitivity to short days than spring type varieties, which enable them to survive in the vegetative phase over winter. Molecular markers have shown genes controlling vernalization in wheat are closely linked with frost tolerance genes (Galiba et al. 1995). It was indicated by Fowler et al. (2001) and Danyluk (2003) that genes that regulate vegetative/generative transition $(\mathrm{Vrn}, \mathrm{Ppd})$, also act to control genes affecting the expression of low temperature-induced genes associated with frost tolerance. Prásil et al. (2004) reported that genes controlling vernalization requirement act as master switch regulating genes of low temperature induced frost tolerance. They concluded that after saturation of vernalization requirement, winter wheat establishes only a low level of frost tolerance. It was also discussed that saturation of the vernalization requirement is main factor for the gradual loss in lowtemperature tolerance observed in winter cereals after a long period at low temperatures (Fowler et al. 1996b). In such cases, vernalization genes may have a regulatory influence on low temperature gene expression in winter cereals since these genes were identified as key factors responsible for the duration of expression of low temperature-induced genes (Fowler et al. 1996a). 


\section{Literature review}

Despite the fact that some studies have reported a positive correlation between the degree of vernalization requirement and winter hardiness (Andersson and Olsson 1961, Kole et al. 2002, Hawkins et al. 2002, Casao et al. 2011), recently published results demonstrated that spring-type oilseed rape is, also, able to be winter hardy to a level comparable with winter-type, but only after cold pre-hardening which results in both the increase of photosynthetic activity and growth cessation during cold acclimation (Rapacz 1998a,b). The findings were confirmed with results obtained from field trials where some spring cultivars were characterized by frost tolerance similar to less tolerant winter cultivars (Teutonico et al. 1993). At the DNA level, Lorche et al. (1992) have found that low temperature induced amplification of rDNA and the differential methylation of EcoRI sites may possibly be related to the vernalization process but may not be related to the development of freezing tolerance. The above contradictory findings indicate that there is no simple relationship between frost tolerance and the degree of vernalization in plants.

Despite unknown genetic interaction between vernalization and winter hardiness, it is straightforward that due to lack of vernalization requirement, spring oilseed rape varieties are not able to cease plant growth in long warm-breaks before and during winter. Also winter varieties with low vernalization requirement may resume growth and break winter dormancy under such conditions and then are killed by freezing temperatures (Andersson and Olsson 1961). Therefore, in such situations vernalization requirements is highly correlated with frost damage. In Brassica species, further studies illustrated different linkage groups exist in both B. napus and B. rapa for capacity to attain freezing tolerance and vernalization (Ferreira et al. 1995, Teutonico et al. 1995). Teutonico et al. (1995) showed that freezing tolerance in the Brassicaceae might be controlled by number of genes in number of linkage groups throughout the genome. They also observed that regions linked to freezing tolerance in B. rapa did not appear to be linked with freezing tolerance in B. napus.

During the last decades, double low cultivars of winter oilseed rape replaced traditional types in the cultivation acreage and they are subjected for enhancement oil and meal quality. Breeding for reduction in erucic acid and glucosinolates contents involved crossing with spring forms (Niewiadomski 1990), which may have influenced the correlation between winter hardiness and vernalization as well as the level of vernalization and frost tolerance in commercial oilseed rape cultivars. One major hazard for winter crops is when plants start bolting or flowering in a period during the winter when the temperature rises to spring-like level (Rapacz and Markowski 1999). 
The situation is now more common, due to global warming phenomenon and serious loss in yield may occur if freezing temperatures follow. Therefore, understanding the genetic basis of the control of flowering time in B. napus is important for plant breeders in order to optimize crop performance in specific environments (Schmidt and Bancroft 2011). The time that a crop takes to flower is crucial and can affect seed yield, especially if one takes into account an ever-changing climate scenario. In winter type wheat, flowering time is induced by vernalization treatment. However, flowering is delayed during winter until favorable growth conditions in spring (Mahfoozi et al. 2001). Floral transition is profoundly affected in the process of vernalization (Chinnusamy et al. 2007). From physiology point of view, intermittent cold treatment delays flowering and induce FLOWERIMG LOCUS C (FLC) gene expression by approximately three folds (Seo et al. 2009). By contrast, prolonged expose to cold temperatures promotes flowering by suppressing the FLC gene (Sung and Amasino 2004, Kim et al. 2009).

In the model species Arabidopsis thaliana, four main floral transition pathways are vernalization, gibberellin, photoperiods and autonomous pathway, regulating the timing of flowering in response to different environmental and endogenous clues (Amasino 2010, Amasino and Michaels 2010). The key regulator of vernalization requirement is the MADS box transcription factor gene FLOWERING LOCUS C (FLC), which is a repressor of FLOWERING LOCUS T (FT) but is down-regulated by vernalization, thus enabling promotion of flowering by expression of FT in shoot apex (Amasino and Michaels 2010). Both FLC and its upstream regulator FRIGIDA (FRI) are major determinants of natural variation in flowering time (Irwin et al. 2012). Dominant alleles of $F R I$ confer vernalization requirement causing plants to overwinter in vegetative stage, and several loss-of-function mutations are associated with early flowering (Johanson et al. 2000). FRI was suggested to up regulate $F L C$ expression through interaction with the histone methyltransferase EARLY FLOWERING IN SHORT DAYS (EFS), which results in the modification of FLC chromatin (Ko et al. 2010, Irwin et al. 2012), and interaction with a nuclear cap-binding complex $(C B C)$ with concomitant effects on FLC transcription and splicing (Geraldo et al. 2009). Photoperiod is another important ambient cue, affecting flowering time in oilseed rape. The key regulator in the photoperiodic pathway, which mediates the effect of day length on flowering time, is the CCT (CONSTANS, CONSTANS-LIKE, TIMING OF CAB EXPRESSION 1) domain transcription factor gene CONSTANS (CO) (Nelson et al. 2014). Under long-day conditions, $C O$ protein accumulates at the end of the light phase and promotes 
flowering by activating the expression of $F T$ that is a central integrator of input signals from different pathways whose protein product is a major component of the mobile signal that moves to the shoot apical meristem and initiates flowering (Turck et al. 2008).

QTL mapping is intensively performed by researchers to find out the quantitative trait loci for flowering time in the natural or segregating populations. In B. rapa QTL linked to known function genes for flowering time (VFR1,VFR2 and VFR3 FR1, FR2 and $F R 3$ ) were mapped in a segregating F2 population and a recombinant inbred line (RIL) population derived from a cross between an annual and a biennial oilseed type (Teutonico and Osborn 1994, Osborn et al. 1997), $V F R 2$ was estimated to have large effect and was suggested to be orthologue of $F L C$ gene in Arabidopsis. A further study confirmed that VFR2 locates at the BrFLC1 locus, FR1 at the position of BrFLC2 and FR2 at BrFLC5 (Lou et al. 2007). The three B. rapa flowering time genes BrFLC2, BrFLC3 and BrFLC1 were assigned to linkage groups A02, A03 and A10, respectively (Kole et al. 2001). In addition, VFR1 was mapped on A02 close to region syntenic to the MAF (MADS Affecting Flowering) region at the bottom of chromosome 5 in Arabidopsis.

Bolting time, as relevant trait for flowering time has also been analyzed under different conditions in a population derived from a cross between two heading Chinese cabbage (Zhang et al. 2006). 10 QTLs mapped to 6 linkage groups, however the linkage groups were not assigned to the chromosomes of reference genome in B. oleracea, therefore it was not possible to compare the mapped QTL to other flowering time QTL. Long et al. (2007) investigated flowering time in oilseed rape in 11 field environments and detected 5-18 QTL in each environment. When Brassica napus QTL were aligned with hundreds of flower transition genes in Arabidopsis by in silico mapping, 28\% of the genes aligned with QTL regions, and 9\% were consistent in interacting loci. The natural variation of the splicing site in $B r F L C l$ was thought to contribute to flowering time in a study using 121 B. rapa accession (Yuan et al. 2009). Co-localization of the flowering-time QTL with flowering-related genes, including $b r F L C 1$ and $b r F L C 2$ in multiple segregating populations of $B$. rapa suggests that the function of $B r F L C$ genes has changed due to genetic variation in vernalization requirement (Lou et al. 2007). Zou et al. (2012) identified nine FLC homologs in Brassica napus and found the coding sequences of all BnFLC were relatively conserved but the intron and promoter regions were more divergent.

Little is known about how flowering time is affected by frost stress, as main element of winter hardiness, and cold acclimation, which typically occurs before winter and it has been debating 
whether there is simple correlation between them or complex models are involved. However, almost all researchers emphasized that cultivation time, shoot elongation before winter and shoot apex development are significantly correlated with frost damage in different field crops (Prásil et al. 2004, Velicka et al. 2005, Asghari et al. 2014). Under typical Western European growing conditions, elongation before winter to some extent is determined by sowing time in late summer or early autumn, therefore sowing date may play a decisive role in optimizing winter hardiness in winter type crops. Results of some investigations showed that successful over-wintering of oilseed rape was observed after they developed 6 to 8 leaves, a root collar diameter of 8 to 10 $\mathrm{mm}$ and a height of shoot not exceeding $30 \mathrm{~mm}$ in autumn (Cramer 1990). It is discussed that promotion of elongation growth leads to consumption of accumulated photosynthetic products, e.g. sugars and loss of frost tolerance (Levitt 1972). Rapacz et al. (2001) stated that decrease in frost tolerance observed in spring- type plants was associated with the beginning of elongation growth of petioles and epicotyl and expansion of leaf area. Also Waalen et al. (2014) showed that carbohydrate level and water content in the shoot apex of oilseed rape genotypes, during mid to late winter, are better predictors for winter hardiness than levels of theses parameters in leaves, especially sucrose, in the shoot apex meristem is good predictor of LT50 and shoot regrowth after freezing stress over winter. Prásil et al. (2004) concluded that the initial growth of shoot apex was not associated with a loss in frost tolerance in wheat varieties; however, a much more advanced shoot length resulted in a decrease in the frost tolerance. Photoperiod is the second important factor after vernalization in winter type crop to resume growth during growing period. It is shown that vernalization requirement, solely, is not sufficient to induce reproductive transition in wheat (Triticum aestivum L.), but other ambient cues, such as the day length and temperature are, also, involved (Bergjord et al. 2009). In a research conducted on barley $(H$. vulgare) shoot apex development, flowering time and inflorescence development were accelerated when vernalized plants were grown in longer days (Sasani et al. 2009). As a result, onset of flowering was delayed in short days compared to plants grown in long days, after equivalent vernalization treatment. When considering the effect of photoperiod on shoot elongation before and after winter on T. aestivum. Prásil et al. (2014) found that vernalized plants followed by long days required less days to heading and shoot apex differentiation, while the length of the photoperiod (Long days vs. short days) during vernalization and cold acclimation did not influence the course of frost tolerance significantly. The results achieved by 
Waalen et al. (2014), suggested that in winter oilseed, cells of the shoot apical meristem are initially differentiated by vernalization, then long day conditions induce the shoot apex to form flower primordial.

With respect to result of the QTL mapping for shoot development in winter crop a few studies have been conducted. Chen et al. (2010) reported that three major QTL were found to control variation in the developmental process of T.aestivum, and each of them was tightly linked with flowering genes, $V R N-A 1, P P D-D 1$ and $V R N-D 3$ on chromosomes 5A, 2D and 7D respectively. Dechaine et al. (2014) characterized the genetic architecture of vegetative traits and begin of reproduction in different developmental stages in a recombinant inbred lines of Brassica rapa in the field and glasshouse. They detected 10 QTLs in different environments for the vegetative and generative traits during life cycle in a bi-parental population of B. rapa. The results showed differential expression of QTL for stem length over developmental time, indicting a three-way interaction between QTL, environment and ontogeny stage. So far, no scientific attempt was reported to study genetic variation and QTL mapping on shoot elongation before winter in oilseed rape. The present study aimed to shed light on genetic basis and inheritance of shoot elongation before winter and its correlation with vernalization requirement, flowering time and seed quality trait in a set of 19 winter oilseed rape breeding lines and open pollination (OP) cultivars and two bi-parental DH populations of Brassica napus in three mega environments. 


\section{Chapter 3}

Genetic variation of shoot elongation before winter and its correlation with vernalization requirement in winter oilseed rape cultivars (Brassica napus L.) 


\subsection{Abstract}

Complexity of winter hardiness and low efficiency of laboratory test has propelled breeding strategies toward the contributing traits for improved winter hardiness. Shoot elongation before winter is a decisive feature that contributes to the winter hardiness of oilseed rape. The present study was carried out to investigate genetic variation of shoot elongation before winter and its correlation with vernalization requirement in 19 European breeding lines and open pollination (OP) cultivars of winter oilseed rape. All 19 genotypes were tested in field experiments in two different mega environments: autumn sown and spring sown. Shoot length from root neck (crown) to shoot apex and shoot diameter at the root neck were measured around three months after sowing date in respective environments. Large phenotypic variation with significant genotypic variance was found for shoot length in the autumn sown and spring sown environment which were named shoot length before winter and shoot length in the spring environment, respectively. Broad sense heritability was quite high $\left(h^{2}=97 \%\right)$ for shoot length in the spring sown environment, while medium heritability $\left(h^{2}=62 \%\right)$ was observed for shoot length before winter. Spearman's rank correlation gave rather medium positive correlation $\left(\mathrm{r}_{s}=0.48^{*}\right)$ between shoot length before winter and shoot length in the spring sown environment. Scatter plot of Spearmen's rank correlation distributed the genotypes in two clusters; first cluster consisted of genotypes with short shoot length in the autumn sown and spring sown environment, including R53 and L16, Mohican, Lorenz and Sollux, Zenith, Apex and Akela. Second cluster consisted of cultivars which were short before winter but long in the spring sown environment including Montego, Tenor, Adriana, Sansibar, Oase, Express 617, SGEDH13, SGDH14, King 10 and hybrid cultivar Visby. Gaoyou was the only cultivar representing the longest shoot length in the both environments. Rather low vernalization requirement was found in the majority of genotypes which increases risk of frost damage in the regions with long warm periods before and during winter. Shoot length before winter differed between the genotypes, however no serious frost damage was observed during implementation of this study at the four locations. Two resynthesized lines R53 and L16 with short shoot length in the two environment, were recognized from the traditional oilseed genotypes. Whereas no substantial differentiation was found between double low and double high quality genotypes among traditional oilseed genotypes. 


\subsection{Introduction}

Oilseed rape (Brassica napus L.) is a major oilseed in many parts of the world with well adaptation to cold, dry and moist growing conditions and is extensively cultivated in Northern Europe, China, Canada and India (Downey and Rakow 1987). Despite large adaptation, winter canola survival is a limiting factor to the success of the crop in the regions with extreme freezing temperatures. Therefore in the countries with Northern latitudes such as Canada and Norway spring types of oilseed rape are mainly grown on farmlands. However, in temperate regions such as Central and Northern Europe winter stress is one of the main common abiotic stresses that adversely affect plant growth and productivity in winter type crops which are typically sown either in late summer or early fall (Chinnusamy et al. 2007). Many variables affect winter hardiness and the inability to control these variables severely restricts the usefulness of natural environments in the evaluation of cold hardiness of potential genotypes in breeding programs (Gusta et al. 1977). Moreover, winter hardiness is not a stable attribute in oilseed rape varieties making less efficiency of selection for enhanced winter hardiness. In temperate regions, vernalization is the second important mechanism for winter survival in winter crops (Trischuk et al. 2014). Vernalization prevents frost damage by repressing floral transition before winter and promoting transition to reproductive growth when optimum conditions are met (Zografos and Sung 2012). Some studies have reported a positive correlation between the degree of vernalization requirement and winter hardiness in winter type crops, suggesting that selection of genotypes with higher vernalization requirement leads to more winter hardy plants in breeding programs (Andersson and Olsson 1961, Kole et al. 2002, Hawkins et al. 2002, Casao et al. 2011). However, recently published results demonstrated that spring type oilseed rape is able to be winter hardy to a level comparable with winter type, but only after cold hardening which results in both the increase of photosynthetic activity and growth cessation during cold acclimation (Rapacz 1998a,b). These observations were confirmed with results obtained from field trials in which some spring oilseed varieties were characterized by frost tolerance similar to less tolerant winter cultivars (Teutonico et al. 1993). However, winter survival frequency in spring type plants, which typically lack vernalization requirement, is usually very low compared to winter cultivars, because of frost damage (Teutonico et al. 1993, Fowler et al. 1979). One of the possible reasons of low frost tolerance might be due to the limited capability to prevent shoot 
elongation during winter when temperature rises only slightly above $0{ }^{\circ} \mathrm{C}$ during overwintering (Laroche et al. 1992, Murelli et al. 1995, Fowler et al. 1996b). Consequently, less energy is available for processes associated with cold acclimation (Fowler et al. 1996a, Stanca et al. 2003). Further studies suggested that spring type plants cannot recover high photosynthetic activity after shift from warm to cold acclimating temperatures, while the high photosynthetic rate during cold acclimation is a prerequisite for the expression of freezing tolerance in frost tolerant plants as it provides carbohydrates for cold acclimation (Hurry et al. 1995 and Rapacz 1999).

One major hazard for winter crops is when plants start bolting or flowering in long warm periods during the winter when the temperature rises to spring like levels. The situation is now more common, due to climate changes and global warming phenomenon that may result in serious yield losses if freezing temperature follows. Therefore, investigating the genetic basis of vernalization requirement is important for understanding variation in flowering time and winter survival in B. napus (Schmidt and Bancroft 2011). During the last 25 to 30 years, double low cultivars of winter oilseed rape replaced traditional oilseed rape types in cultivation. Reduction in erucic acid and glucosinolates involved crossing with spring forms (Finlayson et al. 1973, Niewiadomski 1990), which may have influenced the correlation between winter hardiness and vernalization as well as the level of vernalization and frost tolerance of currently cultivated oilseed rape. It is discussed that intensive selection on double zero quality cultivars led to lower vernalization requirement, earlier shoot elongation and flowering and at least in some areas with long warm periods in winter this could be a cause of serious winter damage (Rapacz and Markowski 1999). Therefore, the present study aimed to study genetic variation for the elongation of shoot before winter and its correlation with vernalization requirement in 19 winter oilseed genotypes including breeding line and OP cultivars with different genetic and quality background. 


\subsection{Materials and Methods}

\subsubsection{Plant material}

The seed material consisted of 19 European breeding lines and open pollination (OP) cultivars of winter oilseed rape with different quality background, ranging from double zero $(0,0)$ to double high $(+,+)$ quality (Table 3.1). All cultivars are inbred lines except Visby that is a hybrid cultivar. The line SGDH14 is a doubled haploid line that was developed based on F1-microspore culture technic from a cross between the old German cultivar Sollux and the Chinese cultivar Gaoyou (Zhao et al. 2005). Furthermore, SGEDH13 is a doubled haploid line derived of a cross between line SGDH14 and the cultivar Express. The seed material was obtained from breeding companies and the Department of Crop Sciences at Göttingen University. 
Table 3.1: Name and features of the 19 breeding lines and cultivars of winter oilseed rape

\begin{tabular}{|c|c|c|}
\hline Genotype name & Seed quality & Genetic background \\
\hline Adriana & 00 & Line cultivar \\
\hline Akela & 00 & Line cultivar \\
\hline Apex & 00 & Line cultivar \\
\hline Express 617 & 00 & Line cultivar, inbred line \\
\hline Gaoyou & ++ & Chinese Line cultivar \\
\hline King10 & 00 & Line cultivar \\
\hline L16 & $0+$ & Resynthesized line \\
\hline Lorenz & 00 & Line cultivar \\
\hline Mohican & 00 & Line cultivar \\
\hline Montego & 00 & Line cultivar \\
\hline Oase & 00 & Line cultivar \\
\hline R53 & ++ & Resynthesized line \\
\hline Sansibar & 00 & Line cultivar \\
\hline SGDH14 & ++ & DH line \\
\hline SGEDH13 & ++ & DH line \\
\hline Sollux & ++ & Line cultivar \\
\hline Tenor & 00 & Line cultivar \\
\hline Visby & 00 & Hybrid cultivar \\
\hline Zenith & 00 & Line cultivar \\
\hline
\end{tabular}

00 less than $2 \%$ erucic acid in the oil and less than $25 \mu \mathrm{molg}^{-1}$ glucosinolates in the seed

$0+$ less than $2 \%$ erucic acid in the oil and more than $25 \mu \mathrm{molg}^{-1}$ glucosinolates in the seed ++ more than $2 \%$ erucic acid in the oil and more than $25 \mu \mathrm{molg}^{-1}$ glucosinolates in the seed 


\subsubsection{Field sown experiments}

All 19 breeding lines and cultivars, named 19 genotypes in this study, were phenotypically tested in field sown experiments in the two different environments: autumn sown and spring sown. Since the two environments diffed, they were named the two mega environments.

\subsubsection{Autumn sown environment}

The seed material of 19 genotypes were sown in North-Western Germany at four locations with two replicates during growing seasons $2014 / 15$ and no replicate in 2015/16. In 2014/15 the locations were Peine (Limagrain GmbH), sown on 21 August, and Einbeck (KWS Saat SE), sown on 4 September. In 2015/16 the locations were Peine (Limagrain GmbH), sown on 20 August, and Göttingen-Reinshof, sown on 28 August. Hundred seeds from each line were sown in small field-plots with double rows in Peine and Göttingen with $2 \mathrm{~m}$ length, $0.5 \mathrm{~m}$ space between plots and plant-to-plant distance in the row was $10 \mathrm{~cm}$. In Einbeck, seeds were sown as one row with $3 \mathrm{~m}$ length and $0.8 \mathrm{~m}$ space between the rows and plant-to-plant distance in the row was $6 \mathrm{~cm}$. All agronomic practices, such as fertilizer, herbicide and insecticides were applied at each location according to common practices. Three to four months after sowing date, five representative plants were harvested by cutting the stem below the root neck (crown). Harvesting time in 2014/15 for Peine and Einbeck were 8 and 24 December 2014 and in 2015/16 for Peine and Göttingen were 30 November 2015 and 11 January 2016, respectively. Shoot length from root neck (crown) to shoot apex and shoot diameter at the root neck were measured using a slide gauge and a metering rule and they were called in this study shoot length before winter and shoot diameter before winter.

\subsubsection{Spring sown environment}

The seed material of 19 genotypes were sown with two replicates at four location in 2013 and 2014 and with no replicate at two locations in 2015. Four locations were Göttingen-Reinshof, sown on 19 and 30 April 2013, 20 March 2014 and 24 March 2015 (no replicate). Two locations were in Einbeck (KWS Saat SE), sown on 4 April 2014 and 10 April 2015 (no replicate). All 
plants were grown by sowing 100 seeds in $2 \mathrm{~m}$ long double rows and $0.5 \mathrm{~m}$ space between plots with $10 \mathrm{~cm}$ distance between plants in the row in Göttingen and $3 \mathrm{~m}$ single row and $8 \mathrm{~cm}$ space in Einbeck. Three to four months after sowing date (Göttingen 18.07.2013, 7.08.2013, 02.07.2014, 26.06.2016; Einbeck 06.07.2014, 13.07.2015), seven representative plants were harvested by cutting the stem below the root neck (crown). Shoot length from root neck to shoot apex and shoot diameter, at the root neck, were measured using metering rule and slide gauge. Percentage of tendency to form inflorescence was scored as $100 \%$ for visible buds or flower and $0 \%$ for lack of buds in each of the seven plants.

\subsubsection{Statistical analysis}

Analysis of variance and descriptive statistics were done by PLABSTAT (Utz 2011) and R (i386 3.0.3). Analysis of variance was done for the autumn sown and spring sown environment, separately. In each mega environment, location and year were defined as experiment, meaning four experiments in the autumn sown environment and six experiments in the spring sown environment. Due to unbalance replicates at different locations, genotype's mean over replicates were used for ANOVA. Linear mixed-effect model (R package \{nlme $\}$ version 3.1-125) was applied to test significant difference for the studied traits. Therefore, experiment and sample plants were random factor versus, genotypes were fixed factor. The statistic model used for ANOVA is shown as follow:

$$
X_{i \mathrm{jk}}=\mu+g_{i}+e_{j}+g_{i} e_{j}+p_{k}: g_{i} e_{j}
$$

where $X_{i j k}$ is phenotypic observation of genotype $i$ in experiment $j$ and plant $k, \mu$ is overall mean, $g_{i}$ and $e_{j}$ are effects of genotype $i$ and experiment $j$, respectively, $g_{i} e_{j}$ is residual error to test $g_{i}$ and $e_{j}$ and $p_{k}: g_{i} e_{j}$ is sampling residual error to test $g_{i} e_{j}$ effect. Broad sense heritability $\left(h^{2}\right)$ of genotypes mean over experiments was calculated by following equations suggested by Hill et al. (1998)

$$
h^{2}=\sigma_{G}^{2} /\left(\sigma_{G}^{2}+\sigma_{G E}^{2} / E+\sigma^{2} p: g e / E P\right)
$$


where $\sigma_{G}^{2}$ and $\sigma_{G E}^{2}$ are genetic and genetic x experiment variance components, respectively. $E$ is number of experiments and $P$ is number of sample plants. Least significant difference (LSD) was utilized for mean comparisons at $\mathrm{P}<0.05$ for shoot length before winter and shoot length in the spring sown environment. Mean values of the genotypes across the experiments were used to calculate Spearman's rank correlation coefficients between the traits that was done by R software (i386 3.0.3). 


\subsection{Results}

\subsubsection{Phenotypic analysis}

The analysis of variance indicated significant genotypic variance components for the all studied traits in the two mega environments (Table 3.2). Significant variance components were observed for experiment and genotype $\mathrm{x}$ experiment interaction $(\mathrm{G} \times \mathrm{E})$ that was bigger than genotypic variance for shoot length before winter and shoot diameter in the spring sown environment, that caused medium heritability for respective traits, while for shoot length and the appearance of visible buds in the spring sown environment high heritability was found in the 19 oilseed rape genotypes.

Large phenotypic variability was found among the plant material for the measured traits in the two mega environments (Table 3.3). Shoot diameter before winter ranged from 7 to $12 \mathrm{~mm}$, while it ranged from 18 to $26 \mathrm{~mm}$ in the spring sown environment. Shoot length before winter ranged from 23 to $66 \mathrm{~mm}$, in contrast shoot length ranged from 187 to $1296 \mathrm{~mm}$ in the spring sown environment. In the two environments, the Chinese cultivar Gaoyou showed the maximum value for shoot length. Tendency to from inflorescence, shown by percentage of buds, was observed for almost all genotypes, nonetheless Akela was the only genotype with no visible buds during implementation of the study. Results of mean comparisons (LSD) demonstrated that no significant difference was found between genotypes with less than $11.7 \mathrm{~mm}$ difference for shoot length in the autumn sown environment and less than $203.4 \mathrm{~mm}$ difference in the spring sown environment (Figure 5.1.1 and Figure 5.1.2). For instance, the two cultivars Sansibar and Oase showed significant difference for shoot length in the autumn sown environment, while no significant difference was observed for shoot length in the spring sown environment. 
Table 3.2: Variance components and heritability of the traits in 19 oilseed cultivars in the two mega-environments

\begin{tabular}{|c|c|c|c|c|c|}
\hline \multirow{2}{*}{$\begin{array}{l}\text { Environmen } \\
\qquad \mathrm{t}\end{array}$} & \multirow{2}{*}{ Trait } & \multicolumn{3}{|c|}{ Variance components } & \multirow{2}{*}{$\begin{array}{l}\text { Heritability } \\
(\%)\end{array}$} \\
\hline & & Genotype (G) & $\begin{array}{l}\text { Experiment } \\
\text { (E) }\end{array}$ & $\mathrm{G} \times \mathrm{E}$ & \\
\hline \multirow{2}{*}{$\begin{array}{l}\text { Autumn } \\
\text { sown }\end{array}$} & Shoot length $^{a}$ & $100.97^{* *}$ & $128.9^{* *}$ & $166.43^{* *}$ & 62 \\
\hline & $\begin{array}{c}\text { Shoot } \\
\text { diameter }^{a}\end{array}$ & $0.88^{* *}$ & $0.49^{* *}$ & $1.91^{* *}$ & 69 \\
\hline \multirow{3}{*}{$\begin{array}{l}\text { Spring } \\
\text { sown }\end{array}$} & Shoot length $^{a}$ & $152235^{* *}$ & $31595^{*}$ & $23070^{* *}$ & 97 \\
\hline & $\begin{array}{c}\text { Shoot } \\
\text { diameter }^{a}\end{array}$ & $4.75^{* *}$ & $7.54^{* *}$ & $7.54^{* *}$ & 73 \\
\hline & Buds $^{b}$ & $0.99^{*}$ & $0.09^{* *}$ & $0.9^{* *}$ & 87 \\
\hline
\end{tabular}

${ }^{*}$ and ${ }^{* *}$ denote significance at $\mathrm{P}<0.05$ and $\mathrm{P}<0.01$, respectively.

${ }^{a}$ and ${ }^{b}$ denote millimeter $(\mathrm{mm})$ and percentage $(\%)$, respectively. 
Table 3.3: Descriptive statistics of the traits in 19 cultivars of winter oilseed rape in the two mega environments

\begin{tabular}{|c|c|c|c|c|c|}
\hline \multirow{3}{*}{ Genotype $^{*}$} & \multicolumn{2}{|c|}{ Autumn sown } & \multicolumn{3}{|l|}{ Spring sown } \\
\hline & $\begin{array}{c}\text { Shoot } \\
\text { diameter }^{\mathrm{a}}\end{array}$ & $\begin{array}{l}\text { Shoot } \\
\text { length }^{\mathrm{a}}\end{array}$ & Shoot diameter ${ }^{\mathrm{a}}$ & $\begin{array}{r}\text { Shoot } \\
\text { length }^{\mathrm{a}}\end{array}$ & Buds ${ }^{\mathrm{b}}$ \\
\hline & $\mathrm{LSD} 5 \%=2.1$ & LSD5 $\%=11.7$ & LSD5\%=3.7 & $\begin{array}{c}\text { LSD5 } \%=20 \\
3.4\end{array}$ & $\begin{array}{c}\text { LSD5\% } \%= \\
34\end{array}$ \\
\hline L16 & 12 & 23 & 24 & 259 & 39 \\
\hline R53 & 10 & 24 & 25 & 200 & 32 \\
\hline Apex & 9 & 25 & 26 & 668 & 60 \\
\hline Adriana & 11 & 26 & 22 & 1186 & 82 \\
\hline Mohican & 11 & 26 & 25 & 298 & 27 \\
\hline Tenor & 8 & 26 & 19 & 1009 & 100 \\
\hline Lorenz & 11 & 27 & $26^{c}$ & 334 & 32 \\
\hline Montego & 10 & 28 & 20 & 1017 & $100^{c}$ \\
\hline Sansibar & 11 & 29 & 26 & 844 & 76 \\
\hline Sollux & 11 & 29 & 21 & $187^{d}$ & 14 \\
\hline King10 & 10 & 33 & 23 & 990 & 80 \\
\hline SGEDH13 & $12^{c}$ & 35 & 23 & 1204 & 86 \\
\hline SGDH14 & 12. & 38 & 23 & 1089 & $100^{c}$ \\
\hline Express617 & 10 & 39 & 25 & 991 & 80 \\
\hline Oase & 11 & 43 & 21 & 733 & 80 \\
\hline Akela & 9 & 48 & 20 & 232 & $0^{d}$ \\
\hline Visby & 10 & 48 & 21 & 1216 & 98 \\
\hline Zenith & $7^{d}$ & $23^{d}$ & 23 & 579 & 26 \\
\hline Gaoyou & 9 & $66^{c}$ & $18^{d}$ & $1296^{c}$ & $100^{c}$ \\
\hline
\end{tabular}

LSD 5\%: least significant difference at level of $\mathrm{P}<0.05$

${ }^{a}$ and ${ }^{b}$ denote millimeter $(\mathrm{mm})$ and percentage (\%) respectively

${ }^{c}$ and ${ }^{d}$ denote maximum and minimum mean for each trait, respectively

* genotypes are ascending sorted for shoot length in the autumn sown 


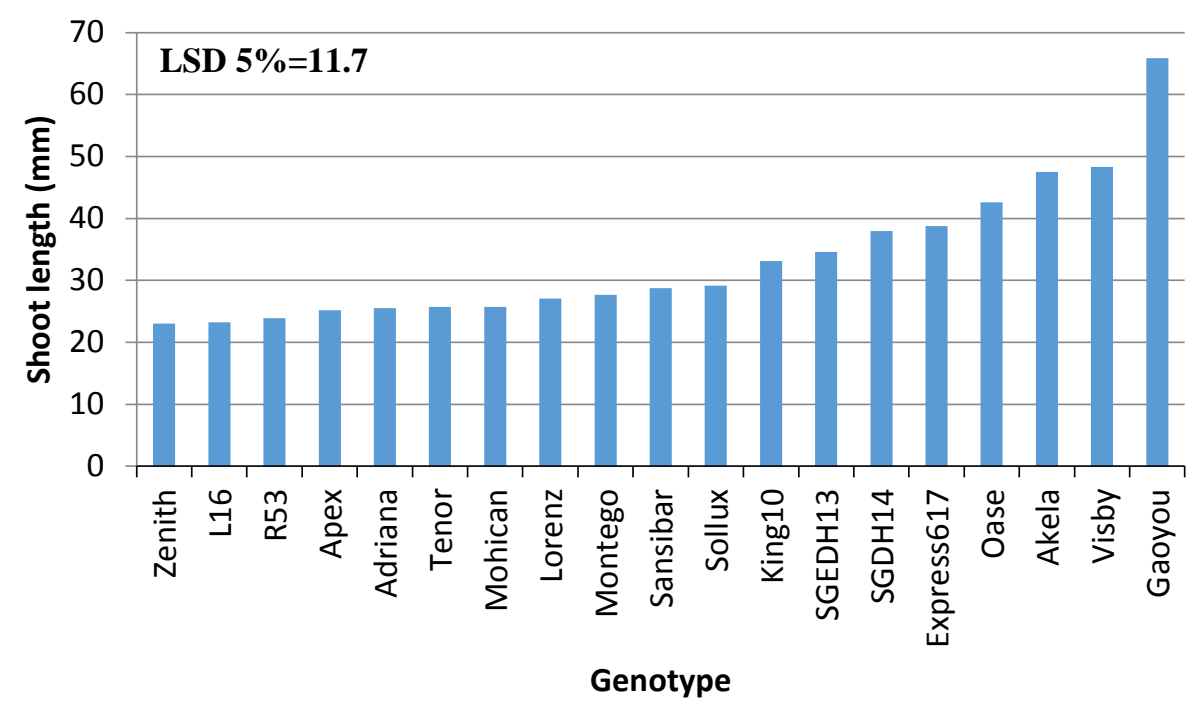

Figure 3.1.1: Mean comparison of 19 genotypes of winter oilseed rape for shoot length in the autumn sown environment.

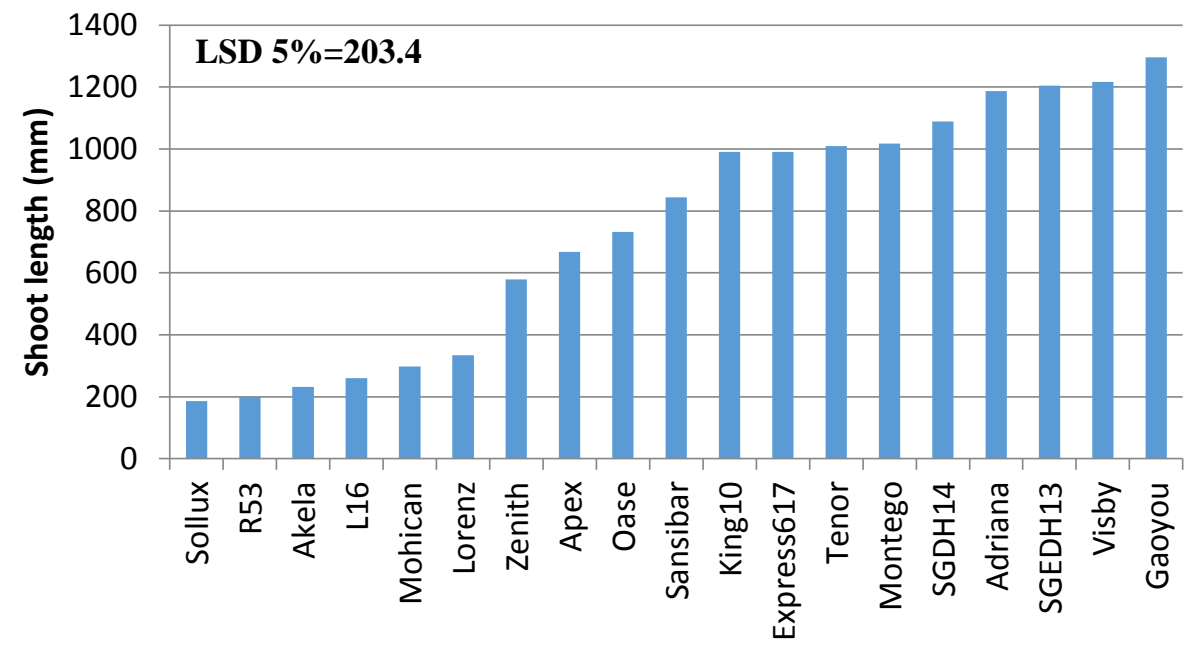

Genotype

Figure 3.1.2: Mean comparison of 19 genotypes of winter oilseed rape for shoot length in the spring environment. 


\subsubsection{Correlation Analysis}

Spearman's rank correlation analysis illustrated low to high phenotypic correlation ranging from 0.1 to 0.88 between the studied traits in 19 genotypes (Table 3.4). No significant correlation was found between shoot length and shoot diameter in the autumn sown environment, whereas a negative significant correlation $\left(r_{s}=-0.42^{* *}\right)$ was found between them in the spring sown environment. Furthermore, no significant correlation was found between the shoot diameters in two mega-environments. Highly positive correlation was found between shoot length and visible buds in the spring sown environment $\left(\mathrm{r}_{\mathrm{s}}=0.88^{* * *}\right)$, showing that shoot elongation was significantly followed by tendency to form inflorescence in the spring sown environment. Spearman correlation revealed a positive correlation $\left(\mathrm{r}_{\mathrm{s}}=0.48^{*}\right)$ between shoot length before winter and shoot length in the spring sown environment. Likewise, shoot length before winter had a rather low positive correlation with buds in the spring environment $\left(r_{\mathrm{s}}=0.45^{*}\right)$. Scatter plot of spearman's rank correlation depicted moderate positive correlation $\left(r_{s}=0.48^{*}\right)$ between shoot length before winter and shoot length in the spring sown environment (Figure 3.2). The two resynthesized lines L16 and R53 and three cultivars Mohican, Lorenz and Sollux had the shortest shoot length at both mega environments. In contrast, the two cultivars Gaoyou and Visby showed the longest shoot length at both mega environments. The cultivar Oase had a relatively long shoot before winter and a moderate shoot length in the spring sown environment. Cultivar SGDH14 was found in the middle between its parents Sollux and Gaoyou. However, SGEDH13 was at the same position as its parents Express and SGDH14. 
Table 3.4: Spearman's rank correlation of the traits in 19 cultivars of winter oilseed in two mega environments

\begin{tabular}{cccccc}
\hline \multirow{2}{*}{ Environment } & Trait & Autumn sown & \multicolumn{3}{c}{ Spring sown } \\
\cline { 3 - 5 } & & Shoot length & Shoot diameter & Shoot length & Shoot diameter \\
\hline Autumn sown & Shoot diameter & 0.15 & & \\
Spring sown & Shoot length & $0.48^{*}$ & 0.1 & \\
& Shoot diameter & $-0.52^{*}$ & 0.15 & $-0.42^{*}$ & \\
& Buds & $0.45^{*}$ & 0.03 & $0.88^{* *}$ & $-0.44^{*}$ \\
\hline
\end{tabular}

"and"* denote significance at $\mathrm{P}<0.05$ and $\mathrm{P}<0.01$, respectively

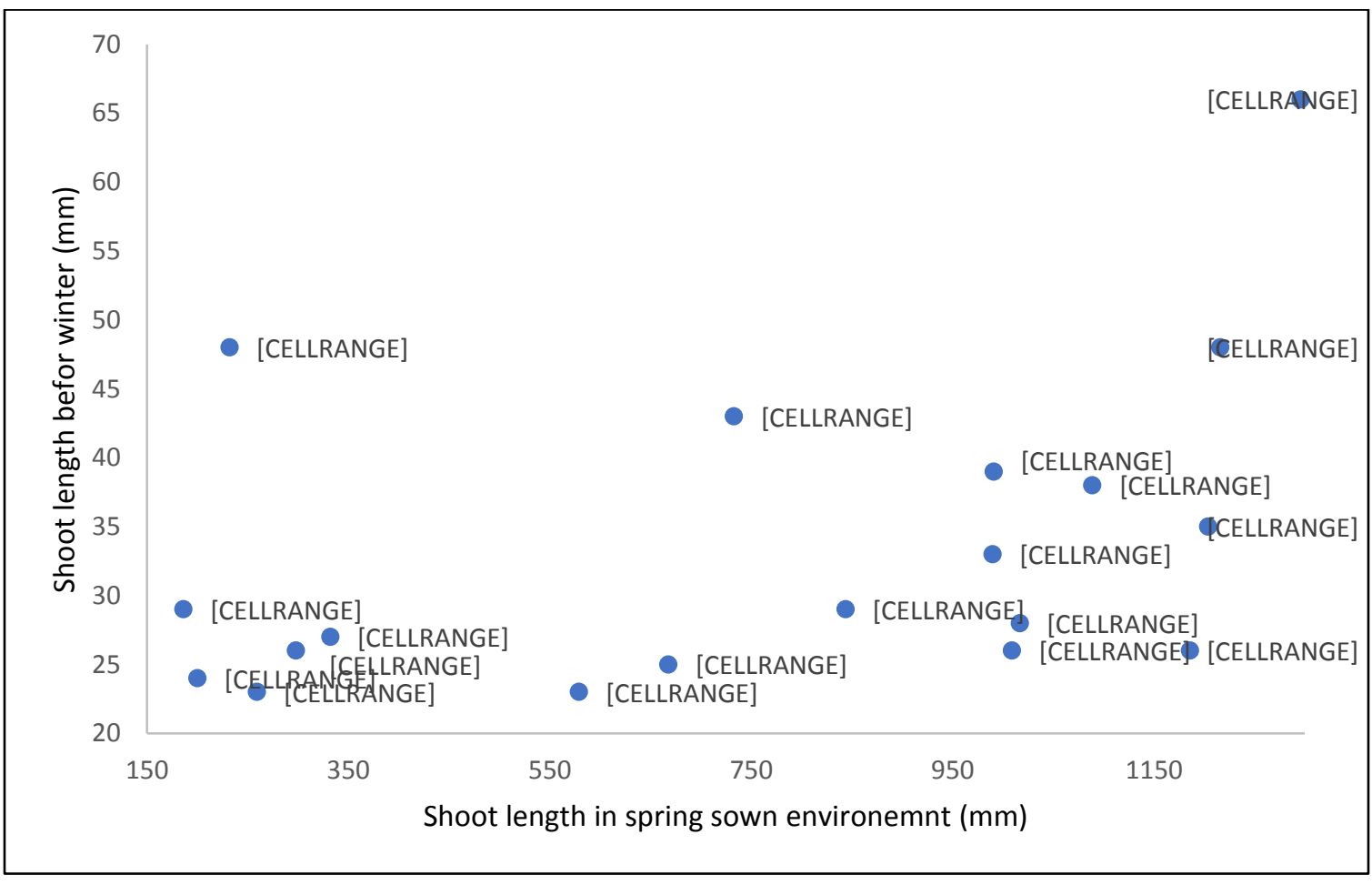

Figure 3.2: Scatter plot of 19 winter oilseed rape genotypes between shoot length before winter and shoot length in the spring sown environment 


\subsection{Discussion}

\subsubsection{Phenotypic analysis}

Significant genotypic difference for shoot length before winter in 19 winter oilseed rape genotypes indicates large genetic variation in the current genepool of winter oilseed rape. This variation was described earlier by Schulz (2007) in a set of 15 winter oilseed rape cultivars. He stated that with respect to frost tolerance of winter oilseed rape, the too early elongation of the epicotyl before and during winter is considered a particularly relevant trait. Low heritability for shoot length and shoot diameter before winter corresponds to a phenomenon in plant development process, called plant plasticity. Plasticity often involves altering gene expression and plant physiology in response to environmental cues (El-Soda et al. 2014). As a result of phenotypic plasticity, the magnitude of genetic variation between plants in the initial steps of plant development i.e. at the rosette stage is environment-specific, whereas later in development and in adult plants it is more stable across environments (Dechaine et al. 2014). Large genetic variation along with high heritability found for vernalization requirement, determined by shoot length and tendency to from inflorescence in the spring sown environment, are frequently reported in long researches (Rapacz et al. 2001, Prásil et al. 2004, Waalen et al. 2014). High heritability shows stable genetic variability in different environments that is a desire feature to increase selection efficiency for traits of interest in plant breeding programs. Therefore, shoot length and the appearance of visible buds in the spring sown experiment can be exploited for selection of genotypes with low or high vernalization requirement. Gaoyou, SGDH14 and Montego showed $100 \%$ of visible buds, while Akela and Sollux had the lowest percentage of visible buds in the spring sown environment. As a result, using of segregating populations derived from cross between the above contrasting genotypes could increase the detection power of QTL mapping. Novickiene et al. (2010) compared growth parameters of three winter oil seed varieties during hardening period in autumn in growing seasons 2007 and 2008. They observed significant differences for leaf number, root diameter, leaf weight and root weight showing 
different acclimation response among cultivars. Additionally they concluded that apical bud and root crown diameter are important for winter hardiness.

\subsubsection{Correlation analysis}

With respect to the processes involved in winter kill and winter hardiness, it can be noticed that dynamics of freezing tolerance are characterized by three stages in wheat; a hardening period, a maintenance period, and a dehardening period (Prásil et al. 2014) and each stage is influenced by vernalization, photoperiod, developmental and other environmental factors (Sãulescu and Braun 2001). Genetic relationship between vernalization requirement and winter hardiness has been studied in different crops. However, no explicit correlation was found between them (Fowler et al. 2001, Danyluk 2003, Waalen et al. 2014). In oilseed rape opposite results are reported, Andersson and Olsson (1961) pointed out that higher vernalization caused more winter-hardy plants, while Markowski and Rapacz (1994) denied it and they reported a line with high vernalization requirement and low frost tolerance. In this study, moderate correlation was found between shoot length before winter and shoot length in the spring sown environment. The medium correlation suggested genetic association between two traits, however the magnitude of correlation was not high enough to conclude stable correlation in winter oilseed rape that might be the reason for no simple correlation reported by other studies (Rapacz and Markowski 1999, Prásil et al. 2004, Waalen et al. 2014). Also it can be speculated that independent regulator genes are involved for both traits as different generic pathways are shown between frost tolerance and vernalization requirement (Ferreira et al. 1995, Teutonico et al. 1995). Scatter plot classified eighteen genotypes into two groups; first group comprised of genotypes with short shoot length

in the two environments; including R53 and L16, Mohican, Lorenz and Sollux, Zenith, Apex and Akela. Second group consisted of cultivars with short length before winter and enhanced shoot length in the spring environment including Montego, Tenor, Adriana, Sansibar, Oase, Express617, SGEDH13, SGDH14, King10 and hybrid Visby. Gaoyou was the only genotype, which was long in both mega environment. Gaoyou is a Chinese semi-winter inbred line with (++) quality developed by Zhejiang Agriculture University (Zhao et al. 2005), thus, spring alleles in Gaoyou increased shoot length when temperature arose above $0{ }^{\circ} \mathrm{C}$ during winter. Two resynthesized lines L16 and R53 showed same and strong vernalization requirement and the 
minimum shoot length before winter, while traditional line and cultivars showed large variation for shoot length. Girke et al. (2011) observed large differences in the genetic distance of resynthesized lines to the winter oilseed rape genepool. The large difference can be used for integrating desired genes lost during domestication or intensive selection for improvement of oil quality traits in oilseed rape genepool. Genetic variation found among cultivars with double zero quality for shoot length in the two environments (see Table 3.1) can support the hypothesis that intensive selection has changed the relation between vernalization requirement and frost tolerance in modern oilseed cultivars. Rapacz and Markowski (1999) compared European winter oilseed rape cultivars cultivated in the 1970s and in the mid-1990. They reported that significant correlation between vernalization requirement and frost tolerance in old oilseed rape cultivars have been decreased due to improved winter hardiness in modern cultivars during last 20 years. Low vernalization recorded in this study for majority of lines and cultivars is a hazard in the current climates condition. In which global warming has caused long warm periods during winter especially in Northern hemisphere in the last decades. The warm breaks during before or during winter promotes shoot development and tendency to form inflorescence in cultivars with low vernalization that caused reduction in plant capacity to withstand following freezing temperature. Using QTL mapping on population derived from cross between genotypes with different shoot length before winter and spring sown environment gives more genetic variability to dissect genetic relationship between vernalization requirement and shoot length before winter. Therefore in the chapters 4 and 5, two doubled haploid populations L16 x Express617 (DHLE) and Sansibar x Oase (DHSO) whose parental lines showed significant difference for shoot length before winter are used to study inheritance of shoot length before winter and its association with vernalization requirement in winter oilseed rape. 


\section{Chapter 4}

Genetic analysis and inheritance of shoot elongation before winter and its relation with other traits in the doubled haploid population L16 x Express617 (Brassica napus L.) 


\subsection{Abstract}

Shoot elongation before winter is considered as a critical component of the complex trait winter hardiness in winter oilseed rape. Thereby genotypes with an enhanced shoot length before winter are very much prone to frost damage. The present work has been conducted to study the inheritance of shoot elongation in a $\mathrm{DH}$ population derived from a cross between the resynthesized line L16 and the winter rapeseed cultivar Express617 in three mega environments: (a) autumn sown (b) spring sown and (c) greenhouse with zero, four and eight weeks vernalization treatments. Shoot length and shoot diameter were measured around three months after sowing in each environment. Furthermore, begin of flowering, plant height at end of flowering and seed quality traits were measured in the autumn sown environment. Large and significant genotypic variance components were found for all the traits in the three environments. Shoot length in the autumn sown environment, also named shoot length before winter, was significantly positive correlated with shoot length in the three greenhouse treatments. However, no significant correlation was observed between shoot length before winter and shoot length in the spring sown environment. Shoot length before winter was, also, not correlated with begin of flowering neither in the autumn sown nor in the greenhouse environment. Six main QTL for shoot length before winter contributed $49.2 \%$ to the phenotypic variance. For shoot length in the spring sown environment a major QTL with $R^{2}=35.5 \%$ was localized on linkage group C09 which along with two QTL on A02 and A07 explained 68\% of the observed variance. No collocation of QTL were found between shoot length before winter and shoot length in the spring sown and greenhouse environment with zero and 8 weeks vernalization treatment. On linkage group A02 a hotspot comprised QTL for begin of flowering and plant height in the autumn sown environment, shoot length and visible buds in the spring sown environment, shoot length and shoot diameter in 4 weeks vernalized conditions in the greenhouse environment. An identified candidate gene for the hotspot on A02 is a copy of the FT gene. Identification of candidate gene in the vicinity of the biggest QTL for shoot length in the spring sown environment indicated a paralogue of gene FLC on linkage group C09. QTL analysis in the present study also revealed that linkage groups A07 and C09 consisted of genomic regions influencing both seed quality traits and the studied traits in three different environments. 


\subsection{Introduction}

The seed oil of B. napus, in comparison with other oilseeds, contains low levels of saturated fatty acids, a high percentage of oleic acid and an optimal ratio of polyunsaturated fatty acids for human nutrition (Schmidt and Bancroft 2011). Moreover, after oil extraction the remaining meal is a valuable feedstuff for animal feeding and a potential protein source for human consumption. The favourable composition of amino acids in the meal, including comparatively high contents of the essential sulphuric amino acids methionine and cysteine has placed rapeseed meal as substitute for soybean meal (Downey 1990). All above benefits along with growing demand for biodiesel production has dramatically increased cultivation acreage of oilseed rape cultivars with in the last decades. However, the genetic base of oilseed rape (Brassica napus) is quite narrow due to its limited geographic range and intensive breeding (Girke et al. 2012). Resynthesized lines could be employed to give more chance to find desired alleles or to increase the genetic distance for optimal utilization of heterosis (Girke et al. 2012). Becker et al. (1995) investigated genetic distances between resynthesized lines and B. napus varieties with RFLP and allozyme markers and stated that resynthesized lines might be a valuable source for broadening the genetic base of the present breeding material of B. napus.

Intensive selection for improvement oil quality in oilseed rape cultivars is believed to have decreased vernalization requirement in double zero cultivars while frost tolerance has improved in modern cultivars (Rapacz and Markowski 1999). Low vernalization increases risk of frost damage in some areas with long warm periods during winter, because plants may break growth cessation and then are killed by subsequent freezing temperatures (Andersson and Olsson 1961).Under typical Western European growing conditions, shoot elongation before winter to some extent is determined by sowing time in late summer or early autumn, therefore sowing date may play a decisive role in optimizing winter hardiness in winter type crops (Crosatti et al. 2008). Results of some investigations showed that successful overwintering of oilseed rape was observed after they developed 6 to 8 leaves, a root collar diameter of 8 to $10 \mathrm{~mm}$ and a height of shoot not exceeding $30 \mathrm{~mm}$ in autumn (Cramer 1990). Rapacz et al. (2001) stated that decrease in frost tolerance observed in spring type plants was associated with the beginning of elongation growth of petioles and epicotyls and also expansion of leaf area. Promotion of stem elongation 
leads to consumption of accumulated photosynthetic products, e.g. sugars and loss of frost tolerance (Levitt 1972). Also Waalen et al. (2014) showed that carbohydrate level and water content in the shoot apex of oilseed rape genotypes, during mid to late winter, are better predictors for winter hardiness than levels of theses parameters in leaves. Furthermore, their results highlighted that the potential of water content and carbohydrate content, especially sucrose, in the shoot apex meristem is good predictor of LT50 and shoot regrowth after freezing stress over winter. Prásil et al. (2004) concluded that the initial growth of shoot apex was not associated with a loss in frost tolerance in wheat varieties, however, a much more advanced shoot length resulted in a decrease in tolerance. From above literatures, vernalization and cessation of shoot elongation before winter are considered by breeder as survival mechanisms for optimal overwintering in winter type crops. However, correlation between them are not considered properly. Regarding the QTL mapping for genes regulating shoot development in winter type crops few studies have been conducted. Chen et al. (2010) reported that three major QTL were found to control variation in the developmental process of T. aestivum, and each of them was tightly linked with flowering genes, $V R N-A 1, P P D-D 1$ and $V R N-D 3$ on chromosomes 5A, 2D and 7D respectively. Dechaine et al. (2014) detected QTL x environment interaction for the vegetative traits and onset of reproduction over ontogeny in a bi-parental population of Brassica rapa.

Modern oilseed rape possess less than $2 \%$ amount of anti-nutritional fatty acid erucic acid (C22:1) in oil. Oil from low erucic-acid oilseed rape has a desirable fatty acid composition with oleic acid replacing erucic acid as the main component. Typically, the fatty acid profile of edible modern oilseed rape (“00") oil contains $60 \%$ of oleic acid (18:1), 20\% linoleic acid (18:2), 10\% linoleic acid (18:3), 7\% saturated fats and 1-2\% erucic acid (Wittkop et al. 2009). The development of cultivars combining high oleic acid and low linolenic acid is a breeding goal to provides a higher oxidative stability at high cooking temperatures, is related to mutations in the Fatty Acid Desaturase genes FAD2 and FAD3, which control the enzymes involved in desaturation of oleic (C18:1) to linoleic acid (C18:2) and linoleic to linolenic acid (C18:3), respectively (Wittkop et al. 2009, Abbadi and Leckband 2011). Modern oilseed cultivars are characterized not only for the favourable composition of fatty acid but also for an increase in the oil content. However, complex genetic structure of oil content in B. napus is only poorly understood due to complex polyploidy level in the genome. One approach to address this 
complexity is QTL mapping, which is used to identify significant genomic regions associated with quantitative traits on a molecular linkage map. The QTL associated with oil content in oilseed rape (Brassica napus L.) have been identified using different populations and different mapping methods (Zhao et al. 2005, Teh and Möllers 2016). The number of QTL involved in oil content reported ranged from 1 to 18 . Moreover, it was revealed that a single QTL could explain from 1.2 to $15.7 \%$ of the phenotypic variance that collectively with other QTL could explain up to $51 \%$ of the total phenotypic variance for oil content (Ecke et al. 1995) or up to $80 \%$ of oil content variation based on additive effects of QTL and additive $\times$ additive epistatic loci (Zhao $e t$ al. 2005). Additional investigations are essential to achieve a deeper knowledge of this trait in order to further improve oil content in high-yielding cultivars. In this context, the identification and utilization of genes contributing to oil content via comparative QTL mapping in different genetic backgrounds could help to identify gene loci with a key influence on this complex trait in oilseed rape (Chen et al. 2010). In a first such comparative study, Delourme et al. (2006) identified orthologous genomic regions involved in oil content in different genetic backgrounds and identified novel alleles in individual lines. Although genetic studies for seed quality traits and developmental traits are extensively conducted in different population of B. napus, little is known regarding the correlation between developmental processes and economic traits. The present study was carried out to investigate the inheritance and genetic basis of shoot elongation before winter and its relation to vernalization requirement, flowering time and seed quality traits in a DH population constructed from a cross between the resynthesized line L16 and the winter rapeseed cultivars Express617. The two parents differed in their vernalization requirement and flowering time. L16 is late flowering whereas Express617 is comparatively early flowering (Brandes 2016, and personal communication). In addition genetic variation of 19 different winter oilseed rape genotypes represented significant difference between L16 and Express617 for shoot length before winter and vernalization requirement (See chapter 3). It is anticipated that by the use of the DHLE population, higher number of major and minor QTL could be detected. 


\subsection{Material and Methods}

\subsubsection{Plant material}

A doubled haploid bi-parental population, consisting of 151 inbred lines, derived from a cross between the resynthesized line L16 and the winter rapeseed line Express617 was used for a series of field and greenhouse trials. The resynthesized line "L16" is an interspecific hybrid between a Chinese broccoli (B. oleracea convar. botrytis var. alboglabra) as a mother and a Chinese cabbage (B. rapa ssp. pekinensis) as a father. L16 has high glucosinolate $\left(\sim 50 \mu \mathrm{molg}^{-1}\right)$ content in the seed and less than $2 \%$ of erucic acid in the oil (Brandes 2016). This may indicate that L16 is not a true resynthesized line but rather a semi-synthesized line derived from a cross with a low erucic acid line or cultivar. On the other hand, Express617 is characterized as double low quality in Europe or "canola" in Canada, meaning less than $2 \%$ erucic acid in the oil and less than $25 \mu_{\mathrm{molg}}^{-1}$ glucosinolates in the seed. The two parents were selected from their contrasting characteristics. L16 is late flowering with short shoot length before winter, whereas Express617 is comparatively early flowering with enhanced shoot length before winter (Brandes 2016; personal communication). Furthermore, results of spring sown experiments of 19 winter oilseed breeding lines and cultivars indicated that L16 has significant higher vernalization requirement than Express617 (See Table 3.3, Chapter 3). The doubled haploid population was developed through microspore culture using F1 plants of the cross between L16 x Express617 as microspore donors, and was named as DHLE population (Doubled Haploid of L16 and Express617; Brandes 2016).

\subsubsection{Field and greenhouse experiments}

The DHLE population and the parental lines were phenotypically characterized in field and greenhouse experiments. The field experiments were performed in two different mega environments. Those included the normal sowing experiments at end of August/beginning of September and spring sowing experiments at end of March/ beginning of April. Since the greenhouse, autumn and spring sown experiments represented very different environments; they were called mega environments. 


\subsubsection{Autumn sown environment}

The DHLE population and its parental inbred lines were sown at four locations in observation field-plots during growing seasons 2014/15 and 2015/16. In 2014/15 the locations were Peine (Limagrain $\mathrm{GmbH}$ ), sown on 21 August, and Einbeck (KWS Saat SE), sown on 4 September. In 2015/16 the locations were Peine, sown on 20 August, and Göttingen-Reinshof, sown on 28 August. All locations were in North Western Germany. Hundred seeds from each line were sown in small field-plots with double rows in Peine and Göttingen with $2 \mathrm{~m}$ length, $50 \mathrm{~cm}$ space between plots and plant-to-plant distance in the row was $10 \mathrm{~cm}$. In Einbeck seeds were sown as one row with $3 \mathrm{~m}$ length and $80 \mathrm{~cm}$ space between plots and plant-to-plant distance in the row was $6 \mathrm{~cm}$. All agronomic practices, such as fertilizer, herbicide and insecticide were applied at each location according to common practices. Three to four months after sowing, five representative plants were selected and harvested by cutting the stem below the root neck (crown). Harvesting time in 2014 for Peine and Einbeck were 8 and 24 December and in 2015 for Peine and Reinshof were 30 November 2015 and 11 January 2016. Shoot length before winter from root neck to shoot apex and shoot diameter before winter at the root neck were measured using a slide gauge and a metering rule. Begin of flowering from first of January and plant height at end of flowering were recorded in the following spring at four locations. In addition, data for begin of flowering and plant height at end of flowering was kindly provided by Haiko Brandes for the two autumn sown experiments Reinshof, sown on 3 September 2012 and Peine sown on 1 September 2012 (Brandes 2016).

\subsubsection{Spring sown environment}

The DHLE population and its parental inbred lines were sown at four locations in North Western Germany. Two locations were in Göttingen-Reinshof, sown on 20 March 2014 and 24 March 2015 and two locations were in Einbeck (KWS Saat SE), sown on 4 April 2014 and 10 April 2015.

All plants were grown by sowing 100 seeds using $2 \mathrm{~m}$ double rows and $50 \mathrm{~cm}$ space between plots and $10 \mathrm{~cm}$ between plants in Göttingen and $3 \mathrm{~m}$ single row with $80 \mathrm{~cm}$ between plots and plant-to-plant distance in the row was $6 \mathrm{~cm}$ in Einbeck. Three to four months after sowing, seven 
representative plants were selected and harvested by cutting the stem below the root neck (crown). Harvesting time for Göttingen and Einbeck in 2014 were 3 and 7 July and in 2015 were 26 June and 13 July, respectively. Shoot length from root neck to shoot apex and shoot diameter, at the root neck, were measured using metering rule and slide gauge. Percentage of tendency to form inflorescence was scored as $100 \%$ for presence of visible buds or flower and $0 \%$ for lack of buds for each of the seven plants.

\subsubsection{Greenhouse environment}

The greenhouse experiments were conducted during December 2014 to July 2015 in Göttingen. The DHLE population and its parental lines were sown in 96-multipot trays, in compost soil. Four seeds, with one seed in each slot, were sown for each genotype. The greenhouse experiments were performed with three different vernalization treatments: 0,4 and 8 weeks chilling treatment. For 8 weeks vernalization treatment, the two independent experiments were sown with one week interval. The first experiment was sown on 12 December 2014 and the second experiment was sown on 19 December 2014. The plants of two experiments were allowed to grow to the four leaf stage and thereafter they were transferred to a vernalization chamber, set to $4{ }^{\circ} \mathrm{C}$ and 8 hours light, on 12 and 19 January 2015, respectively. The plants were taken out from the vernalization chamber after 8 weeks (12 and 19 March) and they were further cultivated in the greenhouse at around $20^{\circ} \mathrm{C}$, then they were harvested on 12 and 19 May 2015.

For the 4 weeks and 0 week vernalization treatments, the two experiments were sown by providing 1 week gap between the sowing dates, i.e. on 12 and 19 February 2015, respectively. In case of the 4 weeks vernalization treatment, the plants were allowed to grow until four leaf stage. Thereafter, plants were transferred to the vernalization chamber on 9 and 17 March 2015 for the two experiments, respectively. After around 4 weeks of vernalization, plants were taken out from the vernalization chamber on 7 and 14 April 2015 and they were further cultivated in the same greenhouse as mentioned above, then they were harvested on 7 and 14 June 2015. The plants without vernalization were sown on 12 and 19 February 2015 and kept constantly in the greenhouse without vernalization treatment and they were harvested on 12 and 19May 2015. Through this staggered arrangement, it was tried to grow all plants after vernalization treatment at the same time in the greenhouse that was possible for 8 weeks vernalized and non-vernalized 
plants (12 and 19 May). However, due to late sowing time, 4 weeks vernalized plants were harvested around 4 weeks later than other plants ( 7 and 14 June). Harvesting time was scheduled three month after sowing time in 0 week vernalized plants and two months following the transfer to the greenhouse in 4 and 8 weeks vernalized plants. In the all treatments, four plants per genotype were harvested by cutting the stem below the root neck (crown). Shoot length from root neck (crown) to shoot apex and shoot diameter at the root neck were measured using metering rule and slide gauge. Moreover, days to begin of flowering from sowing date was scored in the 8 weeks vernalized plants.

\subsubsection{Seed quality traits}

The DHLE population and the parental inbred lines were sown end of August /beginning of September at four locations in North Western Germany. Two locations were GöttingenReinshof, during growing seasons 2012/13 and 2013/14 and two locations were Einbeck (KWS Saat SE) and Peine (Limagrain GmbH) during growing season 2014/2015. Sowing condition and plots size are already mentioned in 4.3.2.1. At harvesting time, seeds of ten open pollinated plants from each line were harvested and bulked for analyses. Oil content, protein content, glucosinolates, were measured by near-infrared reflectance spectroscopy (NIRS) using commercial calibration raps2012.eqa provided by VDLUFA Qualitätssicherung NIRS GmbH (Teichstr. 65, D-34130 Kassel, Germany). Furthermore, neutral detergent fibre of defatted meal (NDFm), acid detergent fibre of defatted meal (ADFm) and acid detergent lignin of defatted meal content (ADLm) were measured by NIRS using calibration provided by Dimov et al. (2012). All the above traits are expressed on a seed basis at $91 \%$ dry matter content. Protein content of the defatted meal (PodM) was calculated as:

$\%$ Protein of the defatted meal $($ PodM $)=[\%$ Seed protein $/(100-\%$ Oil $)] * 100$

Fatty acid composition was initially measured by NIRS, then mean of genotypes across four experiments were used to select 25 genotypes with maximum content of oleic acid (C18:1) and 25 genotypes with minimum content of oleic acid (C18:2). Then seeds from the 50 genotypes were collected from each of four experiments (200 samples) and the fatty acid composition were 
analyzed by Gas Chromatography (GC) using method adapted from Thies (1971). Approximately $200 \mathrm{mg}$ of seed, $1 \mathrm{ml}$ of Na-methylate-methanol $\left(0.5 \mathrm{~mol} \mathrm{~L}^{-1}\right)$, and one stainless steel rod $(1.1 \mathrm{~cm}$ length; $0.4 \mathrm{~cm}$ diameter) were added in a propylene tube. The seeds were then homogenized using a custom-built vertical homogenizer (Institute of Applied Plant Nutrition, Georg-August-University Göttingen) for $3 \mathrm{~min}$. Following incubation for $20 \mathrm{~min}$ at room temperature, $300 \mu \mathrm{l}$ iso-octane and $100 \mu 1$ 5\% NaHSO4 in water were added, briefly vortexed, and centrifuged for $3 \mathrm{~min}$ at $4000 \mathrm{rpm}$. About $200 \mu \mathrm{l}$ of the upper phase was pipetted into a GC vial and $3 \mu \mathrm{l}$ was injected into a gas chromatograph (Thermo Trace GC Ultra), equipped with auto sampler, split injector (split ratio 70:1), flame ionization detector $\left(320^{\circ} \mathrm{C}\right)$, and capillary FFAP phase $(0.25 \mathrm{~mm} \times 25 \mathrm{~m}$; Macherey \& Nagel). Hydrogen (carrier gas) pressure was set at $100 \mathrm{kPa}$. Oven temperature was set at $210 \circ \mathrm{C}$. Total analytical time was $6 \mathrm{~min}$. Data from NIRS and GC was used to develop a new NIRS calibration equation to estimate fatty acid composition in the DHLE population in each field experiment separately. The fatty acids content reported in this study include oleic acid (C18:1), linoleic acid (C18:2), and linolenic acid (C18:3), expressed as percentage of total fatty acids in mature seeds. Thousand seed weight was measured from weight conversation of 500 seeds at all four locations.

\subsubsection{Linkage map}

Linkage map was constructed by Brandes (2016) using MAPMAKER/EXP 3.0 (Lincoln et al., 1992) (Table 4.1). The resulting linkage map for the DHLE population has 4003 SNP markers mapped to 19 linkage groups, representing 19 chromosomes in B. napus, and covered $2050.3 \mathrm{cM}$ with a mean interval distance of $0.5 \mathrm{cM}$ between markers (Brandes 2016). The map has an average density of 2.02 markers per $\mathrm{cM}$ with distribution of markers varied 0.2 to 3.8 marker/cM across the linkage groups. The A genome comprised more markers (2252) as compared to the C genome (1751), with a mean interval distance between markers of $2.3 \mathrm{cM}$ in the A genome and $1.6 \mathrm{cM}$ in the $\mathrm{C}$ genome. The number of markers mapped in an individual linkage group ranged from 52 (A08) to 389 (A03). Also pairwise recombination and LOD scores indicated that markers were well allocated to linkage groups based on LOD and recombination frequency (Figure 4.1). For QTL mapping, a subset of 788 markers were manually selected by Brandes (2016) (Figure 4.2 and Figure 4.3) from the high-fidelity markers on the basis that the distance 
between adjacent markers was about $5-10 \mathrm{cM}$. The term framework map was used to refer to the map used for QTL mapping.

Table 4.1: Marker distribution, size and marker density between markers of each linkage group in the linkage map of the DHLE population (Brandes 2016)

\begin{tabular}{|c|c|c|c|}
\hline Linkage group & $\begin{array}{l}\text { No. markers per } \\
\text { linkage group }\end{array}$ & Size $(\mathrm{cM})$ & Marker density $\left(\mathrm{cM}^{-1}\right)$ \\
\hline A01 & 187 & 83 & 2.25 \\
\hline A02 & 108 & 95.5 & 1.13 \\
\hline A03 & 389 & 138.8 & 2.80 \\
\hline A04 & 303 & 78.9 & 3.84 \\
\hline A05 & 139 & 116 & 1.20 \\
\hline A06 & 355 & 120.4 & 2.95 \\
\hline A07 & 312 & 92.4 & 3.38 \\
\hline A08 & 52 & 62.8 & 0.83 \\
\hline A09 & 176 & 112.4 & 1.57 \\
\hline A10 & 231 & 69.5 & 3.32 \\
\hline $\mathrm{C} 01$ & 207 & 108.7 & 1.91 \\
\hline $\mathrm{C} 02$ & 176 & 131.6 & 1.34 \\
\hline $\mathrm{C} 03$ & 286 & 196.1 & 1.46 \\
\hline $\mathrm{C} 04$ & 199 & 105.4 & 1.89 \\
\hline $\mathrm{C} 05$ & 160 & 121.6 & 1.32 \\
\hline $\mathrm{C} 06$ & 138 & 91.2 & 1.51 \\
\hline $\mathrm{C} 07$ & 209 & 108 & 1.94 \\
\hline $\mathrm{C} 08$ & 199 & 83.1 & 2.39 \\
\hline C09 & 177 & 134.8 & 1.31 \\
\hline A genome & 2252 & 969.8 & 2.33 \\
\hline C genome & 1751 & 1080.5 & 1.67 \\
\hline Whole genome & 4003 & 2050.3 & 2.02 \\
\hline
\end{tabular}




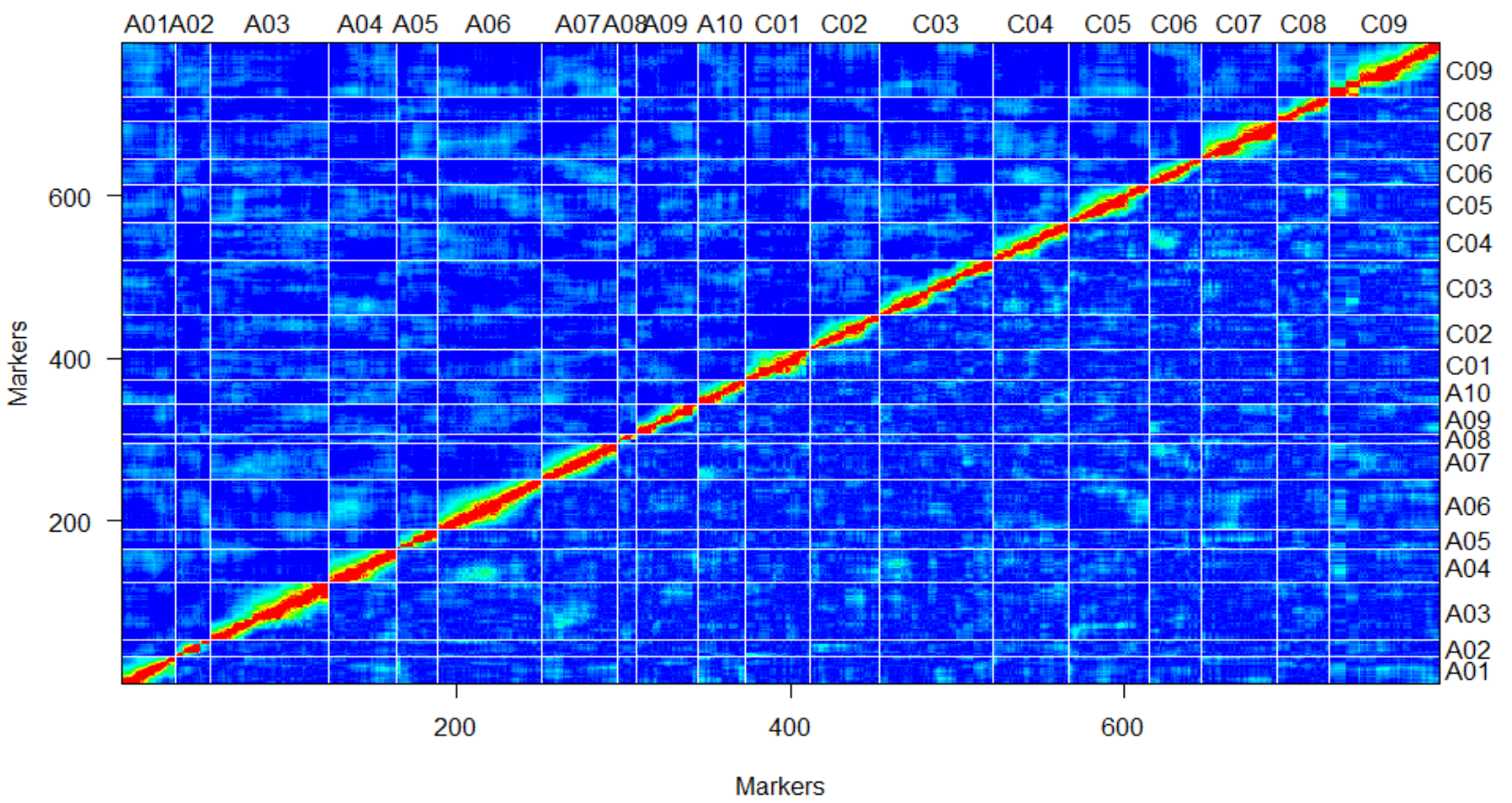

Figure 4.1: Estimated recombination fractions (upper left) and LOD scores (Lower right) for all pairs of markers in the DHLE population. Dark red indicates pairs of markers that appear to be tightly linked (very low recombination), dark blue indicates pairs that are not completely linked (very high recombination). Green points (combination of red and blue points) indicated marker's pairs ranging from very high recombination to very low recombination.

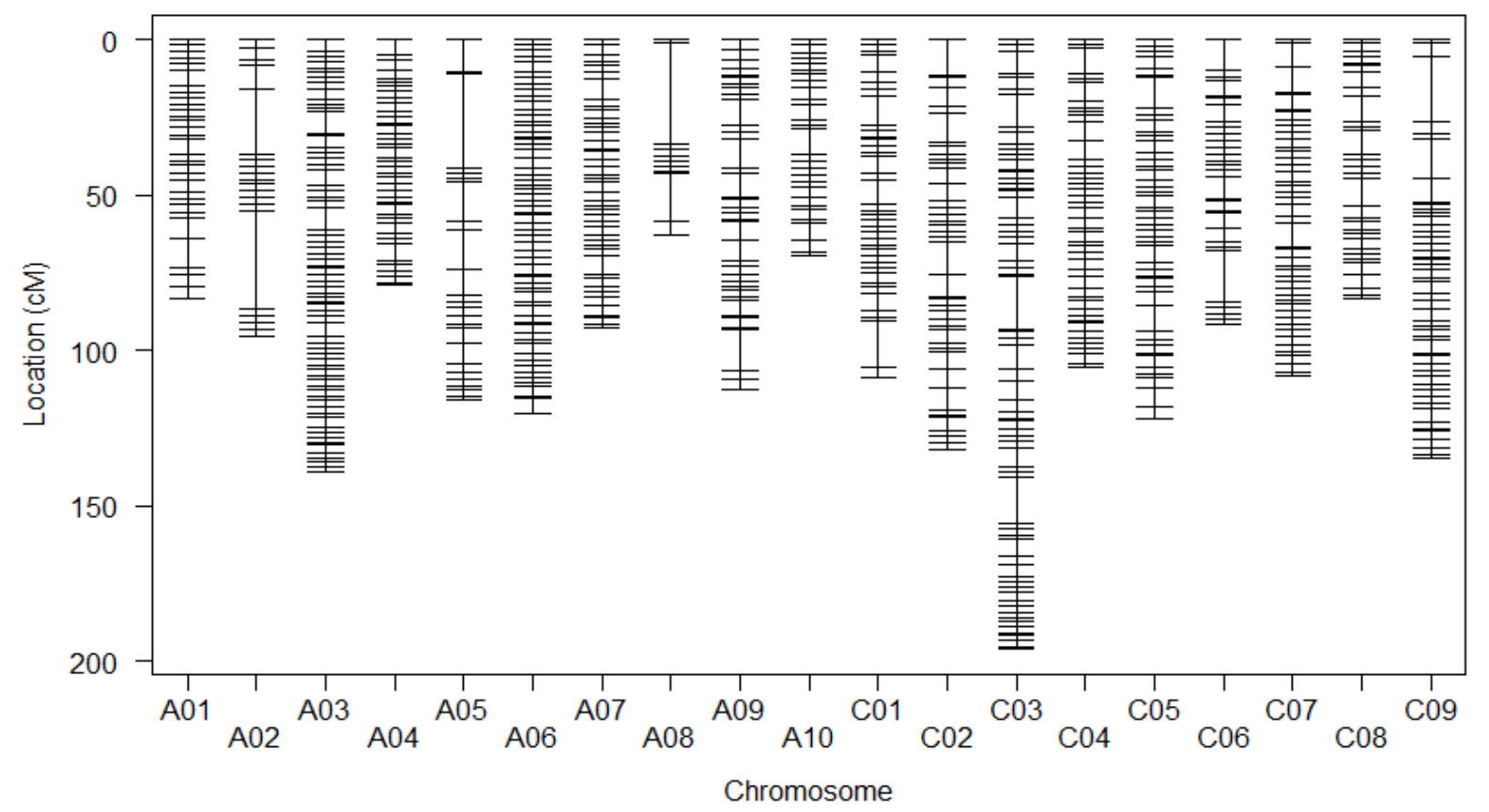

Figure 4.2: Genetic framework map of the DHLE population, with approximately 5 to $10 \mathrm{cM}$ marker spacing 


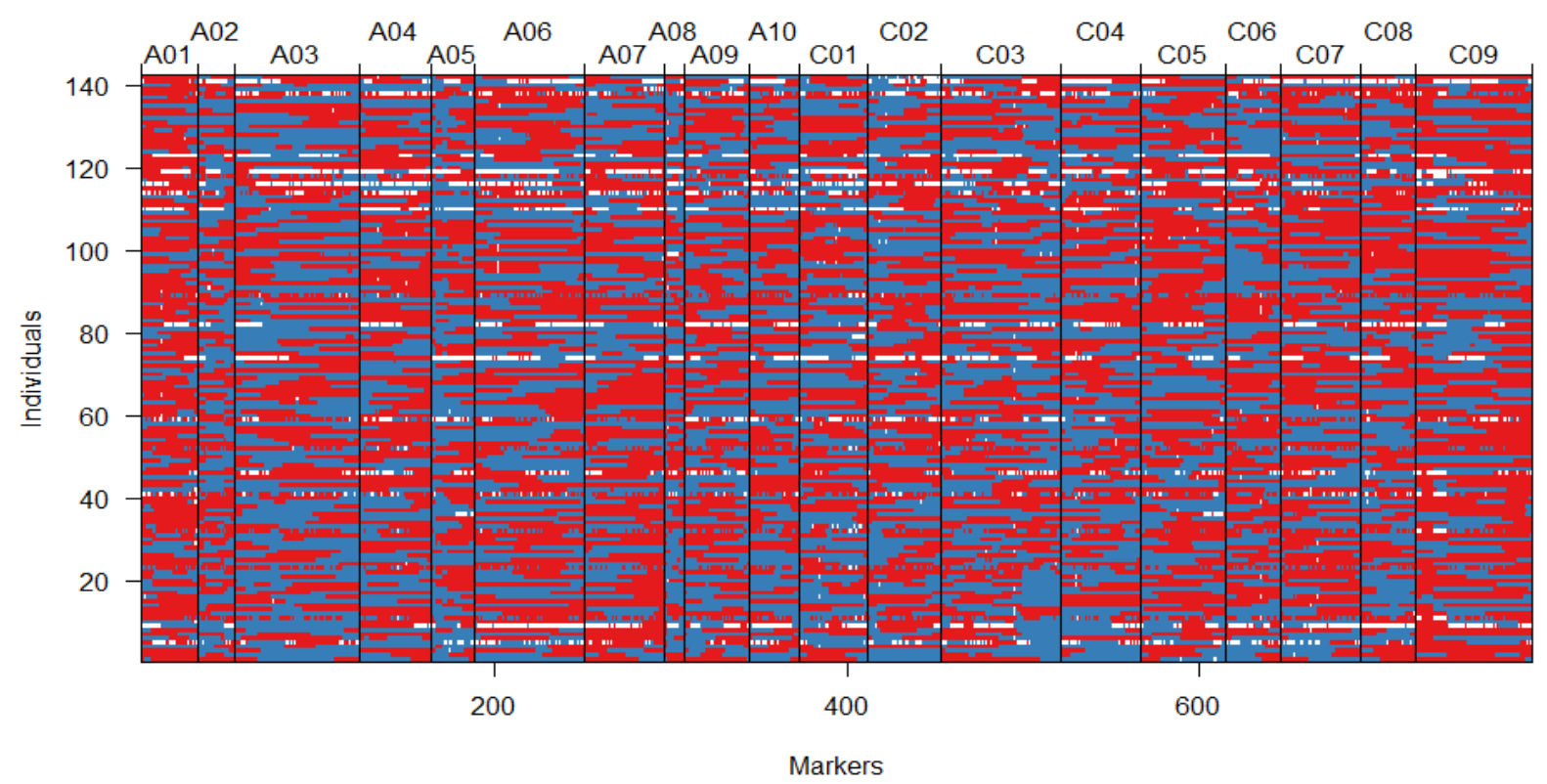

Figure 4.3: Genotype data for the DHLE population. Blue and red pixels correspond to alleles coming from L16 and Express617, respectively. White pixels indicate missing genotype data.

\subsubsection{Statistical analysis}

Analysis of variance and descriptive statistic were done by PLABSTAT (Utz 2011) and R (i386 3.0.3). Analysis of variance was separately done for each mega environment in which, location and year were treated as experiment factor in each mega environment. Linear mixed-effect model ( $\mathrm{R}$ version 3.1-125, package nnlme\}) was applied to test significant difference for the traits, hence experiment and plant sample (sub-sample) were defined as random factor and genotype was fixed factor. The statistic model used for ANOVA is shown below.

$$
X_{i \mathrm{jk}}=\mu+g_{i}+e_{j}+g_{i} e_{j}+p_{k} \cdot g_{i} e_{j}
$$

where $X_{i j k}$ is phenotypic observation of genotype $i$ in experiment $j$ and plant $k, \mu$ is a general mean, $g_{i}$ and $\mathrm{e}_{j}$ are effects of genotype $i$ and experiment $j, g_{i} e_{j}$ is residual error to test main effect of genotype $i$ and experiment $j$ and $p_{k}: g_{i} e_{j}$ is sampling residual error to test $g_{i} e_{j}$ effect. Broad sense heritability $\left(h^{2}\right)$ of genotypes mean over experiments were calculated as follow:

$$
h^{2}=\sigma_{G}^{2} /\left(\sigma_{G}^{2}+\sigma_{G E}^{2} / E+\sigma^{2} p: g e / E P\right)
$$


where $\sigma_{G}^{2}$ and $\sigma_{G E}^{2}$ are genotype and residual error variance components, respectively, $\mathrm{E}$ is the number of experiments and $\mathrm{P}$ is the number of measured plants. The following ANOVA model was used in variance analysis for seed quality traits and thousand kernel weight.

$$
X_{i j}=\mu+g_{i}+e_{j}+g_{i} e_{j}
$$

where $X_{i j}$ is observation of genotype $i$ in experiment $j, \mu$ is general mean, gi and $e j$ are effects of

genotype $i$ and experiment $j, g_{i} e_{j}$ is residual error of model. Broad sense heritability $\left(h^{2}\right)$ of mean values over experiments was calculated as follow:

$$
h^{2}=\sigma_{G}^{2} /\left(\sigma_{G}^{2}+\sigma_{G E}^{2} / E\right)
$$

where $\sigma_{G}^{2}$ and $\sigma_{G E}^{2}$ are genotype and residual error variance components, respectively, $\mathrm{E}$ is number of experiments. Genotypes mean across the experiments were used to calculate Spearman's rank correlation coefficients between the traits which was done by R software (i386 3.0.3).

\subsubsection{QTL mapping and identification of candidate genes}

QTL mapping was implemented using the software WinQTL Cartographer software (ver. 2.5) (Wang et al. 2012). QTL were initially detected with composite interval mapping (CIM) using stepwise regression model 6 (Silva et al. 2012) for each trait, the LOD significance threshold $(\alpha=0.05)$ was estimated by 1000 permutation tests. Five markers as default model for CIM were allowed as co-factor in forward and backward regression method in the analysis. If this was not done, other QTL would inflate the residual sum-of-squares, and reduce the power to detect a putative QTL in the region of interest. CIM tests were performed, at $1 \mathrm{cM}$ steps with a $10 \mathrm{cM}$ window size, to prevent any background markers within $10 \mathrm{cM}$ of a putative QTL from being included in the final results. Peaks were treated as separate QTL when the distance is more than $10 \mathrm{cM}$ and the minimum LOD value exceeds one between any two adjacent peaks. Subsequently, multiple interval mapping (MIM) (Kao et al. 1999, Silva et al. 2012) was applied to refine the QTL position, the QTL effect in detected QTL and also to search for more QTL, and to investigate epistatic effects among the detected QTL. The MIM model was built upon a priori 
model from CIM analysis and progressively refined using the BIC-M2 $=2 \ln (\mathrm{n})$ criterion. QTL positions that did not remain significant when fitted with others were then dropped from the model. QTL effects and their percentage of phenotypic variance explained by individual and all the QTL were estimated with the final model fitted in MIM. A one-LOD drop from the peak position was used as a confidence interval for each QTL.

To identify candidate genes in hotspot of genetic map, physical position of interval flanking markers (SNP) for was identified by performing a BLAST of marker's sequences against sequence reference genome of Brassica napus. (http://www.brassicadb.org/brad/). The position of the best hit was recorded only when the marker sequence from particular linkage group fell onto the same corresponding chromosome in Brassica napus. We used reference sequence genomes of Brassica rapa (http://www.brassicadb.org/brad/) and Brassica oleracea (http://www.ocri-genomics.org/bolbase/) to search for syntenic genes in B. napus. Then, the physical position of the syntenic genes were determined in the Brassica napus determined by BLAST search of genes sequence against reference sequence genome of Brassica napus. 


\subsection{Results}

\subsubsection{Phenotypic analysis}

For the DH population L16 x Express617 (DHLE), highly significant genotypic variance components were found for all traits in the three mega environments: autumn sown, spring sown and greenhouse (Table 4.2.1). The variance components of the experiment and genotype $\mathrm{x}$ experiment were significant for most traits in the three mega environments. Estimation of broadsense heritability classified traits in two groups. First group comprised traits with high heritability ranging from 73 to $94 \%$ including shoot length in the spring sown and greenhouse environment, plant height at end of flowering (EOF) and begin of flowering in the autumn sown environment and begin of flowering in the greenhouse with eight weeks vernalization treatment. Shoot length before winter and shoot diameter in the three mega environments were placed in the second group in which heritability ranged from 11 to $61 \%$, indicating high influence of genotype $\mathrm{x}$ environment interaction for the respective traits. Tendency to form influence in the spring sown environment, measured by the percentage of visible buds, showed high heritability $\left(h^{2}=80 \%\right)$. In the autumn sown environment, large phenotypic variation with normal or nearnormal distributions were found for shoot length, shoot diameter, begin of flowering and plant height at EOF (Fig. 4.4.1). Furthermore, transgressive segregation was observed with extreme values at both ends of the distributions exceeding the mean values of both parents. Parental differences for shoot length and begin of flowering were more pronounced than for other traits in the autumn sown environment (Table 4.3.1). Express617 with $61 \mathrm{~mm}$ shoot length and around five earlier days of begin of flowering differed from L16 with $34 \mathrm{~mm}$ shoot length. In the spring sown environment, parent L16 with $218 \mathrm{~mm}$ shoot length was significantly shorter than Express617 with $855 \mathrm{~mm}$ shoot length. In addition, large phenotypic variation was observed for shoot length that ranged from $87 \mathrm{~mm}$ to $1255 \mathrm{~mm}$, resulting in a bimodal frequency distribution of the DH population (Table 4.3.1 and Figure. 4.4.1). Bimodal frequency segregation suggested involvement of a major gene in inheritance of the trait. Also, comparison of frequency distribution of shoot length and the percentage of visible buds indicated that shoot elongation caused tendency to form buds in which, genotypes shorter than L16 showed lower tendency to 
form inflorescence, whereas genotypes longer than Express617 showed almost 100\% buds formation. For shoot diameter in the spring sown environment, no significant difference was found between parents L16 and Express617, however transgressive segregation and phenotypic variation ranged from $17 \mathrm{~mm}$ to 29 was found across spring sown field experiments.

Table 4.2.1: Variance components and heritability of the DHLE population in the three mega environments

\begin{tabular}{|c|c|c|c|c|c|}
\hline \multirow{2}{*}{$\begin{array}{l}\text { Environmen } \\
t\end{array}$} & \multirow[b]{2}{*}{ Trait } & \multicolumn{3}{|c|}{ Variance components $\left(\sigma^{2}\right)$} & \multirow{2}{*}{$\begin{array}{l}\text { Heritability } \\
(\%)\end{array}$} \\
\hline & & Genotype (G) & $\begin{array}{c}\text { Experiment(E } \\
)\end{array}$ & $\mathrm{G} \times \mathrm{E}$ & \\
\hline \multirow{4}{*}{$\begin{array}{l}\text { Autumn } \\
\text { Sown }\end{array}$} & Shoot length $^{a}$ & $35.9^{* *}$ & $468^{* *}$ & $151.9^{* *}$ & 51 \\
\hline & Shoot diameter ${ }^{a}$ & $0.2^{* *}$ & $9.01^{* *}$ & $0.9^{* *}$ & 29 \\
\hline & BOF & $4.1^{* *}$ & $46.15^{* *}$ & 4.14 & 84 \\
\hline & $\begin{array}{l}\text { Plant height at } \\
\text { EOF }^{a}\end{array}$ & $61.4^{* *}$ & $228^{* *}$ & 46.7 & 73 \\
\hline \multirow{3}{*}{$\begin{array}{l}\text { Spring } \\
\text { Sown }\end{array}$} & Shoot length ${ }^{a}$ & $132083^{*}$ & $53745^{* *}$ & 34581 & 94 \\
\hline & Shoot diameter ${ }^{a}$ & $10.93^{* *}$ & $1.03^{*}$ & $10.25^{* *}$ & 22 \\
\hline & Buds $^{b}$ & $0.12^{* *}$ & $0.01^{* *}$ & $0.08^{* *}$ & 80 \\
\hline \multirow{2}{*}{$\begin{array}{l}\text { Greenhouse } \\
0 \text { week }\end{array}$} & Shoot length ${ }^{a}$ & $53.4^{* *}$ & $5.9^{* *}$ & $20.7^{* *}$ & 77 \\
\hline & Shoot diameter ${ }^{\mathrm{a}}$ & $0.05^{* *}$ & $0.04^{* *}$ & $0.05^{* *}$ & 43 \\
\hline \multirow{2}{*}{$\begin{array}{l}\text { Greenhouse } \\
4 \text { weeks }\end{array}$} & Shoot length $4^{a}$ & $7129^{* *}$ & $5.8^{* *}$ & $3009^{* *}$ & 77 \\
\hline & Shoot diameter ${ }^{a}$ & $0.88^{* *}$ & 0.04 & $9.02^{*}$ & 11 \\
\hline \multirow[t]{3}{*}{$\begin{array}{l}\text { Greenhouse } \\
8 \text { weeks }\end{array}$} & Shoot length ${ }^{a}$ & $1670^{* *}$ & 5.52 & $2153^{* *}$ & 73 \\
\hline & Shoot diameter ${ }^{a}$ & $0.11^{* *}$ & 0.07 & $0.14^{* *}$ & 61 \\
\hline & BOF & $69^{* *}$ & 0.15 & $186^{* *}$ & 80 \\
\hline
\end{tabular}


Table 4.3.1: Descriptive statistics of the parents and the DHLE population $(n=151)$ in the autumn and spring sown environment

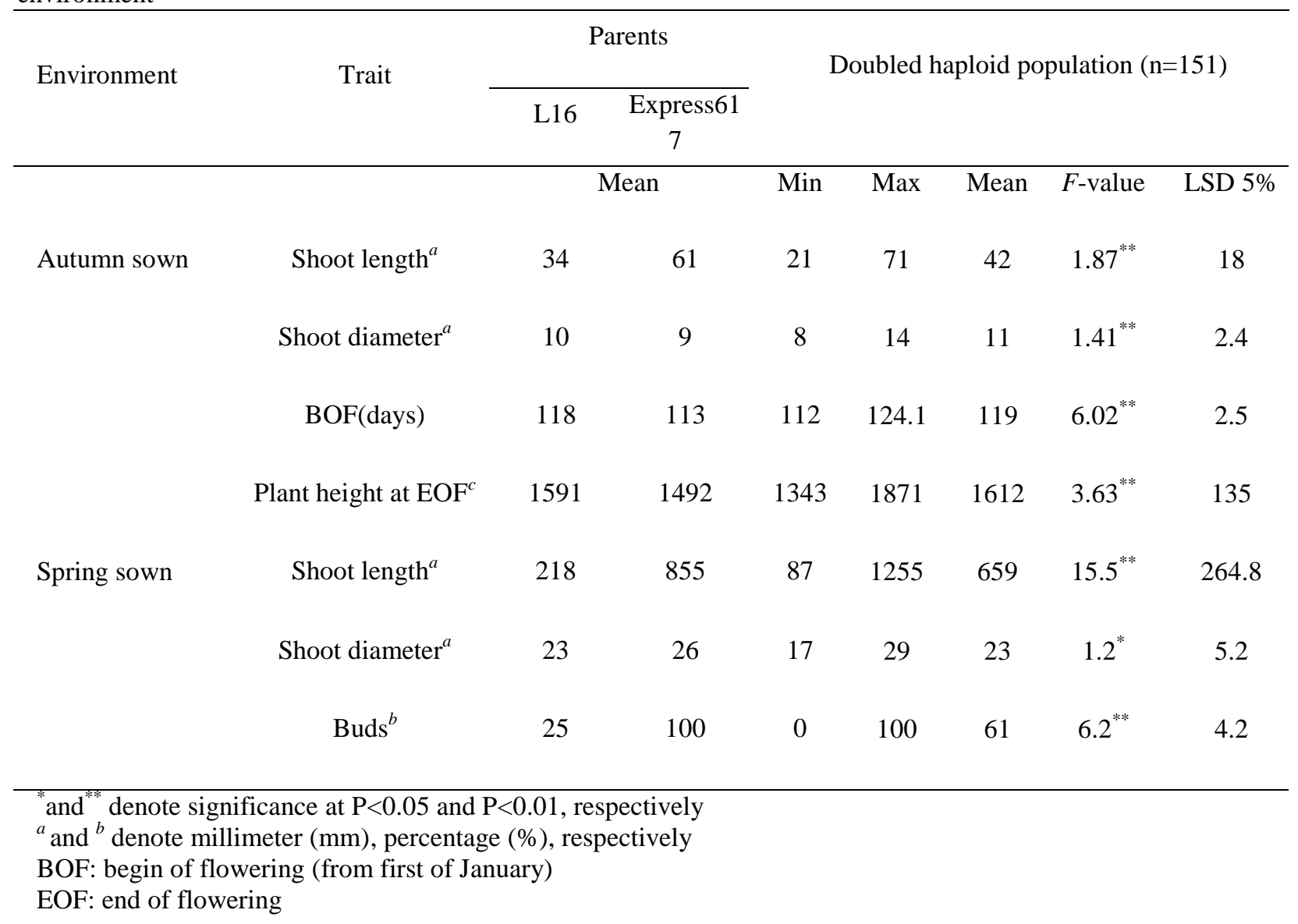




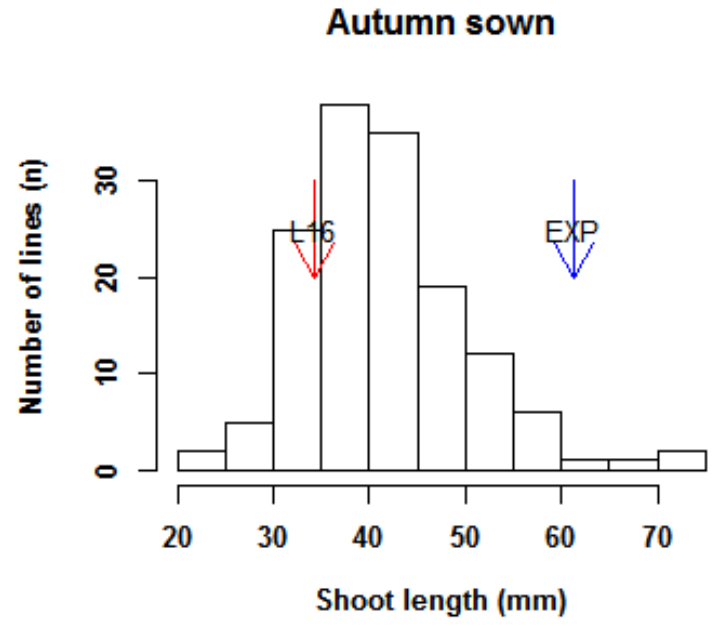

Autumn sown

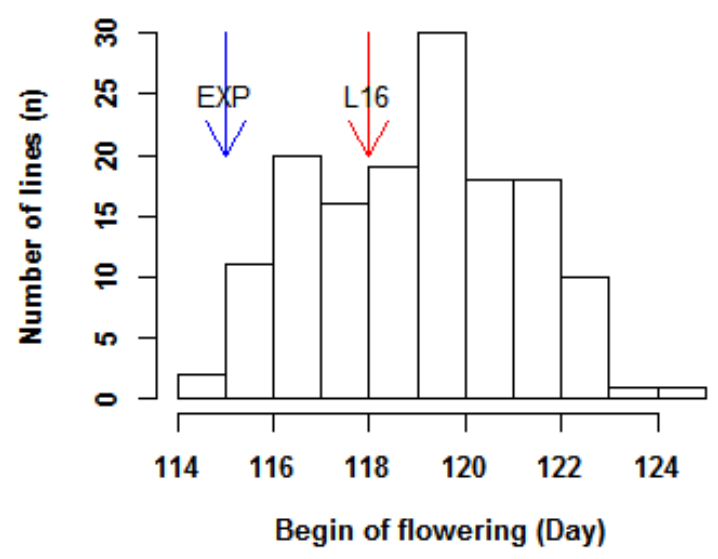

Autumn sown

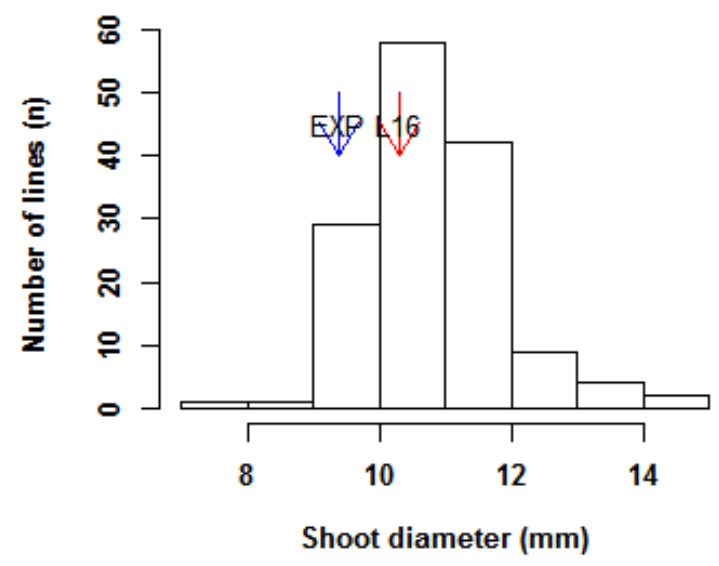

Autumn sown

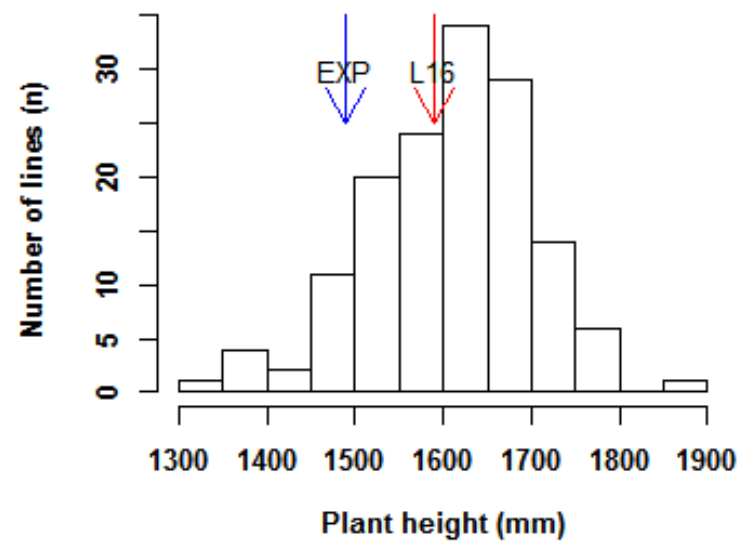

Figure 4.4.1: Frequency distribution of shoot length, shoot diameter, begin of flowering, plant height in the DHLE population in the autumn sown environment. Arrows indicate the parents mean across the field experiments. (continued on the next page) 
Spring sown

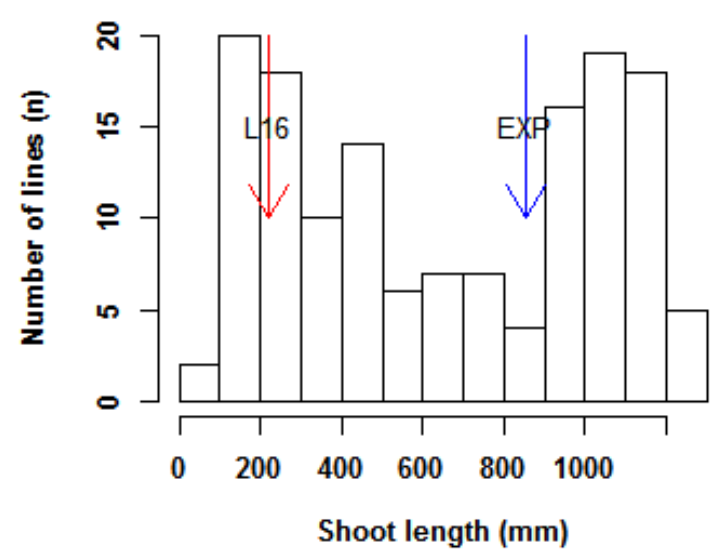

Spring sown

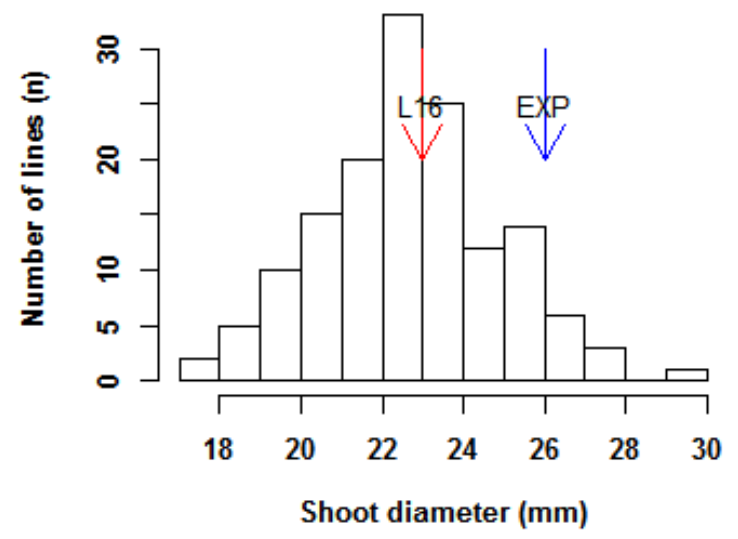

Spring sown

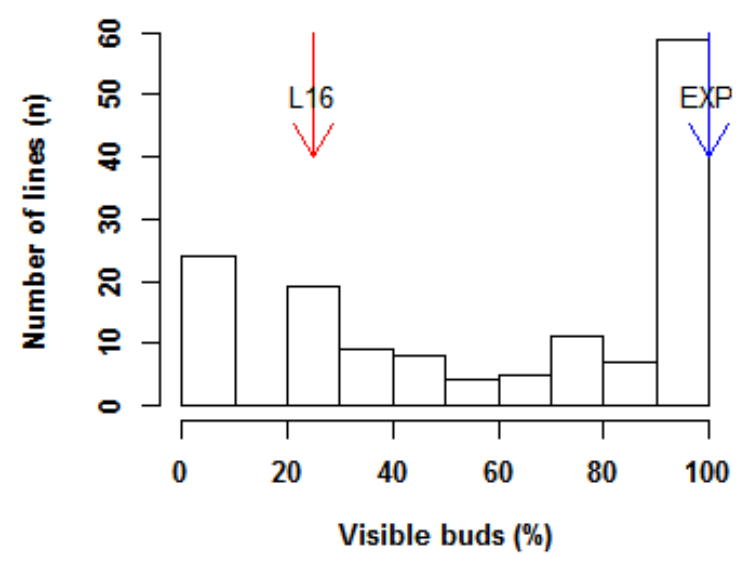

Figure 4.4.1: (continued from the previous page) Frequency distribution of shoot length, shoot diameter and visible buds in the DHLE population in the spring sown environment. Arrows indicate the parents mean across the field experiments. 
In the greenhouse environment, in which genotypes after zero (non-vernalized), four and eight weeks of vernalization were tested; large phenotypic variation with normal or near normal frequency distribution was found for shoot length which ranged from $15 \mathrm{~mm}$ to $71 \mathrm{~mm}$ for nonvernalized plants and ranged from $270 \mathrm{~mm}$ to $518 \mathrm{~mm}$ for 8 weeks vernalized plants (Table 4.3.2, Figure 4.4.2). A skewed frequency distribution with maximum difference between the parents was found for shoot length in 4weeks vernalized plants, demonstrating large variability in vernalization requirement between the DH lines. Significant difference for shoot length was found between the parental lines. L16 had shorter shoot length and thinner stem diameter than Express617 in all the greenhouse treatments. Population mean for shoot length in non vernalization treatment was $33 \mathrm{~mm}$ that was roughly 10 folds smaller than shoot length (370) in eight weeks vernalized plants. Begin of flowering was, also, observed in plants with eight weeks vernalization treatment which ranged from 120 to 160 days, implying that vernalization requirement was completed in the entire DHLE population, while begin of flowering was partially observed in plants with 4 weeks vernalization treatment (data not shown).

Table 4.3.2: Descriptive statistics of the parents and the DHLE population $(n=151)$ in greenhouse environment

Parents

Doubled haploid population $(\mathrm{n}=151)$

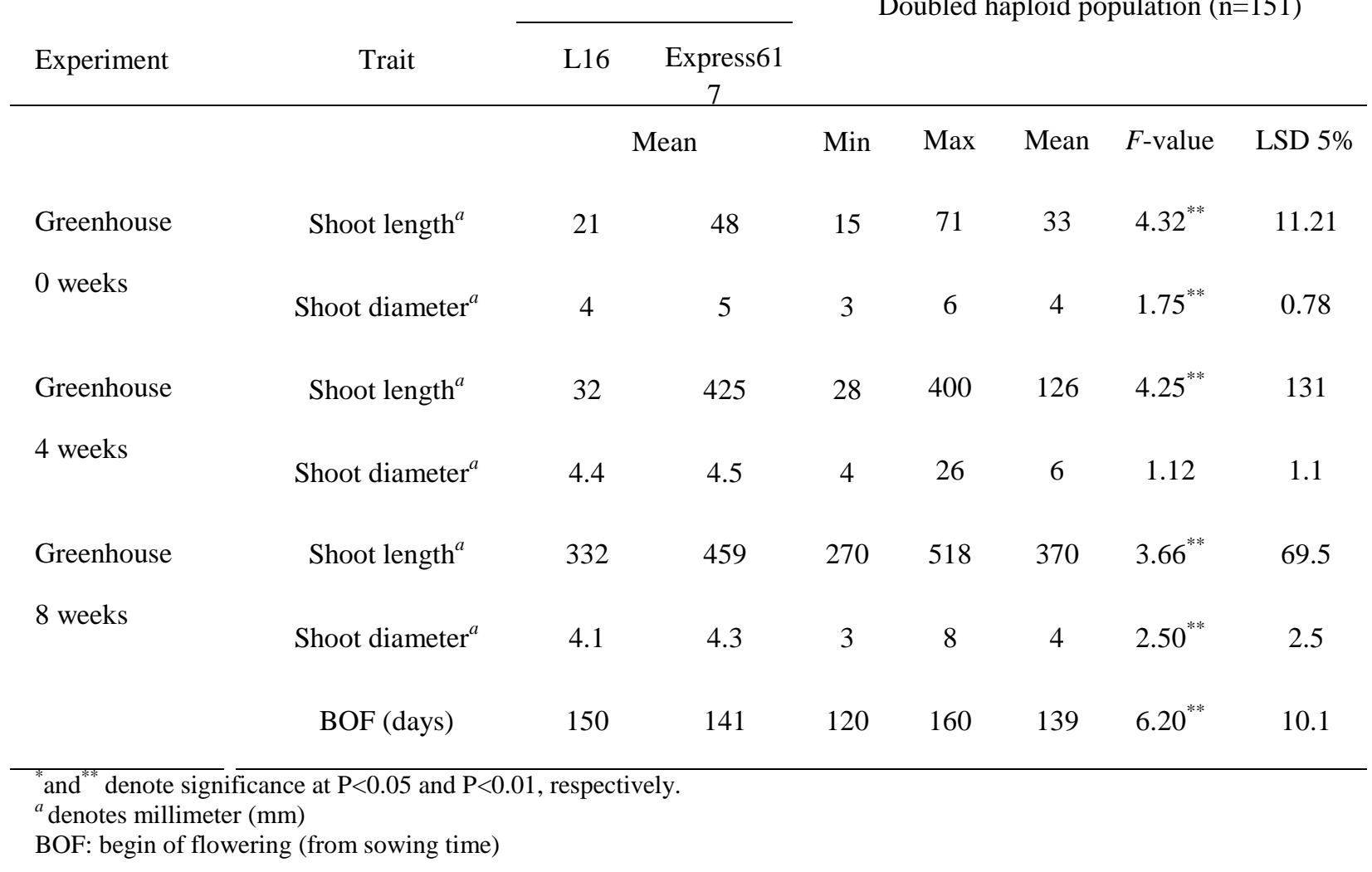



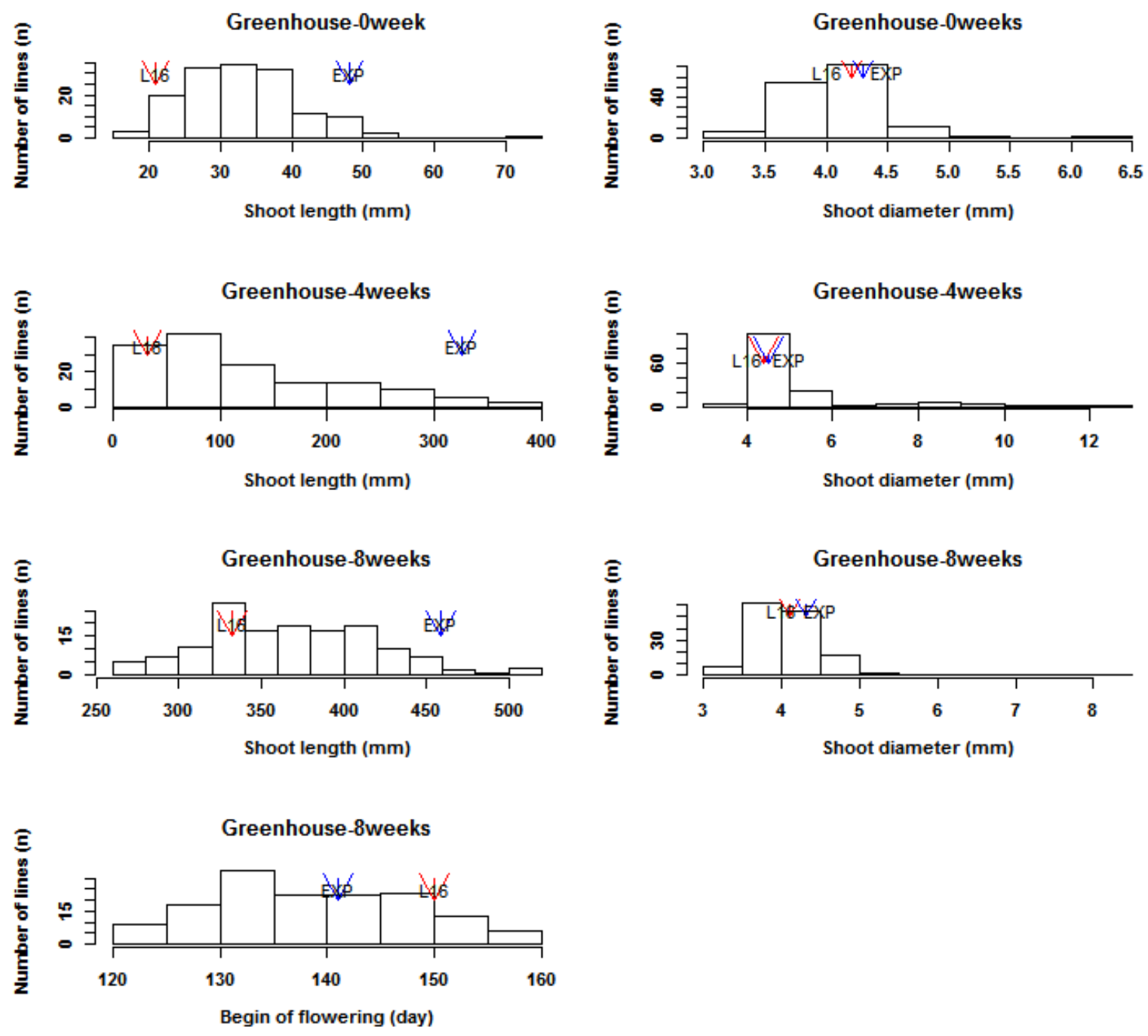

Figure 4.4.2: Frequency distribution of shoot length and shoot diameter in zero, four and eight weeks vernalization treatment. Begin of flowering in the eight weeks vernalization treatment in the DHLE population. Arrows indicate the parents mean across experiments. 
For seed quality traits, significant variance components for genotype and experiment were observed in the DHLE population (Table 4.2.2). Broad sense heritability was high, ranging from 74 to $96 \%$ implying the large genetic variance that was promising for identification of loci affecting seed quality traits in the DHLE population. Frequency distribution along with descriptive statistics showed normal or near normal distribution with large phenotypic variation exceeding form the parents mean for majority traits. Nevertheless, glucosinolate content with bimodal frequency distribution was recognized from others, suggesting involvement a major gene for this trait (Table 4.3.3 and Figure 4.4.3). Parent L16 had significantly higher contents of glucosinolate $(47.8 \mu \mathrm{mol} / \mathrm{g})$ and protein of defatted meal, in contrast Express617 had significantly higher content of oil, oleic acid (C18:1), linoleic acid (C18:2), linolenic acid (C18:3) and thousand kernel weight (TKW). 
Table 4.2.2: Variance components and heritability of the seed quality traits in the DHLE population $(n=151)$

\begin{tabular}{|c|c|c|c|c|}
\hline \multirow{2}{*}{ Trait } & \multicolumn{3}{|c|}{ Variance components } & \multirow{2}{*}{ Heritability (\%) } \\
\hline & Genotype (G) & Experiment (E) & $G \times E$ & \\
\hline $\mathrm{Oil}^{b}$ & $1.25^{* *}$ & $11.42^{* *}$ & 1.11 & 81 \\
\hline $\operatorname{PodM}^{b}$ & $2.85^{* *}$ & $17.31^{* *}$ & 1.69 & 87 \\
\hline $\mathrm{GSL}(\mu \mathrm{mol} / \mathrm{g})$ & $34.6^{* *}$ & $24.76^{* *}$ & 3.44 & 96 \\
\hline $\mathrm{C} 18: 1^{b}$ & $0.59^{* *}$ & $0.71^{* *}$ & 0.41 & 84 \\
\hline $\mathrm{C} 18: 2^{b}$ & $0.63^{* *}$ & $0.37^{* *}$ & 0.68 & 88 \\
\hline $\mathrm{C} 18: 3^{b}$ & $0.26^{* *}$ & $0.15^{* *}$ & 0.12 & 90 \\
\hline $\mathrm{NDFm}^{b}$ & $1.08^{* *}$ & $27.8^{* *}$ & 1.54 & 74 \\
\hline $\mathrm{ADFm}^{b}$ & $0.98^{* *}$ & $12.52^{* *}$ & 0.95 & 81 \\
\hline $\mathrm{ADLm}^{b}$ & $0.68^{* *}$ & $13.2^{* *}$ & 0.87 & 76 \\
\hline TKW(g) & $0.02^{* * *}$ & $0.11^{* *}$ & 0.03 & 78 \\
\hline $\begin{array}{l}{ }^{*}{ }^{* * *} \text { denote } \\
{ }^{b} \text { denote perce } \\
\text { PodM: protei } \\
\text { GSL: glucosin } \\
\text { C18:1: oleic a } \\
\text { C18:2: linolei } \\
\text { C18:3: linolen } \\
\text { NDFm: neutra } \\
\text { ADFm: acid d } \\
\text { ADLm: acid d } \\
\text { TKW: thousar }\end{array}$ & $\begin{array}{l}\text { of the defatted } \\
\text { the defatted me } \\
\text { of the defatted } \\
\text { ( } g \text { ) }\end{array}$ & tively & & \\
\hline
\end{tabular}


Table 4.3.3: Descriptive statistics of the parents and the DHLE population $(n=151)$ for the seed quality traits Parents

Doubled haploid population $(\mathrm{n}=151)$

\begin{tabular}{|c|c|c|c|c|c|c|c|}
\hline \multirow[t]{2}{*}{ Trait } & \multicolumn{3}{|c|}{ Express617 } & & & & \\
\hline & & & Min & Max & Mean & $F$-value & LSD 5\% \\
\hline $\mathrm{Oil}^{b}$ & 46.2 & 50.1 & 42.7 & 52.3 & 47.5 & $5.50^{* *}$ & 1.5 \\
\hline $\operatorname{PodM}^{b}$ & 41.2 & 36.9 & 32.7 & 43.3 & 38.4 & $7.47^{* *}$ & 1.81 \\
\hline $\mathrm{GSL}(\mu \mathrm{mol} / \mathrm{g})$ & 47.8 & 23.7 & 12.3 & 81.8 & 37.9 & $23.7^{* *}$ & 9.9 \\
\hline $\mathrm{C} 18: 1^{b}$ & 62.5 & 63.5 & 60.3 & 65.5 & 63.1 & $6.02^{* *}$ & 0.92 \\
\hline $\mathrm{C} 18: 2^{b}$ & 16.3 & 18.7 & 15.1 & 22.7 & 17.8 & $8.85^{* *}$ & 0.82 \\
\hline $\mathrm{C} 18: 3^{b}$ & 9.6 & 10.5 & 8.1 & 11.1 & 9.6 & $9.7^{* *}$ & 0.48 \\
\hline $\mathrm{NDFm}^{b}$ & 33.1 & 34.8 & 28.4 & 37.4 & 34.4 & $3.8^{* *}$ & 1.73 \\
\hline $\mathrm{ADFm}^{b}$ & 22.4 & 25 & 21.1 & 26.3 & 23.7 & $5.1^{* *}$ & 1.36 \\
\hline $\mathrm{ADLm}^{b}$ & 11.4 & 11.8 & 9.3 & 14.1 & 11.2 & $4.1^{*}$ & 1.3 \\
\hline TKW(g) & 4.1 & 5.4 & 3.7 & 5.9 & 4.5 & $4.42^{* *}$ & 0.25 \\
\hline
\end{tabular}

*and ${ }^{* *}$ denote significance at $\mathrm{P}<0.05$ and $\mathrm{P}<0.01$, respectively

${ }^{b}$ denotes percentage $(\%)$

PodM: protein of the defatted meal

GSL: glucosinolate content $(\mu \mathrm{mol} / \mathrm{g})$

C18:1: oleic acid

C18:2: linoleic acid

C18:3: linolenic acid

NDFm: neutral detergent fibre of the defatted meal

ADFm: acid detergent fibre of the defatted meal

ADLm: acid detergent lignin of the defatted meal

TKW: thousand kernel weight $(\mathrm{g})$ 

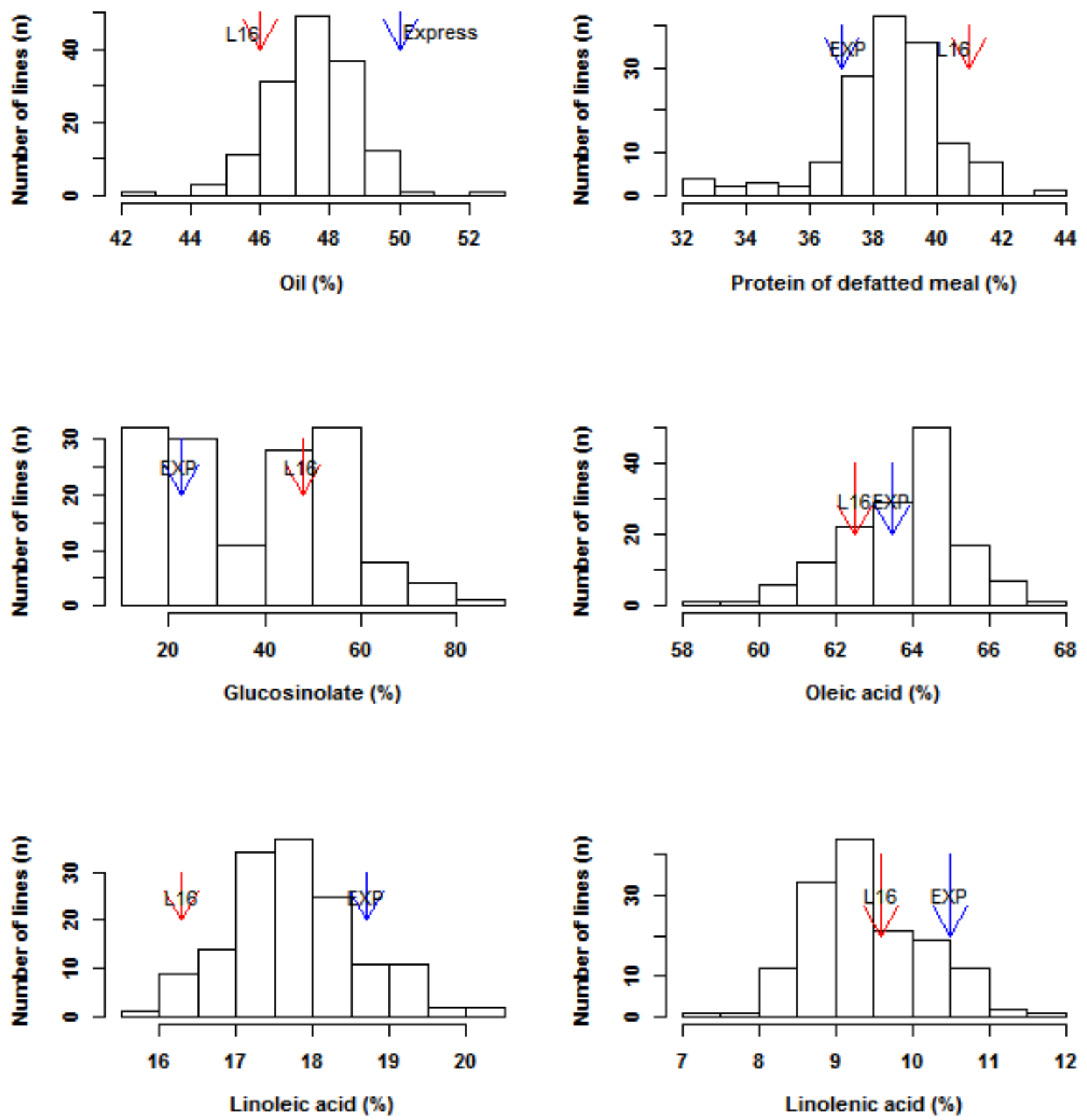

Figure 4.4.3: Frequency distribution of oil content, protein of the defatted meal, thousand kernel weight, glucosinolates, fatty acid composition, fibre seed fraction in the DHLE population. Arrows indicate the parents mean across the experiments. (continued on the next page) 

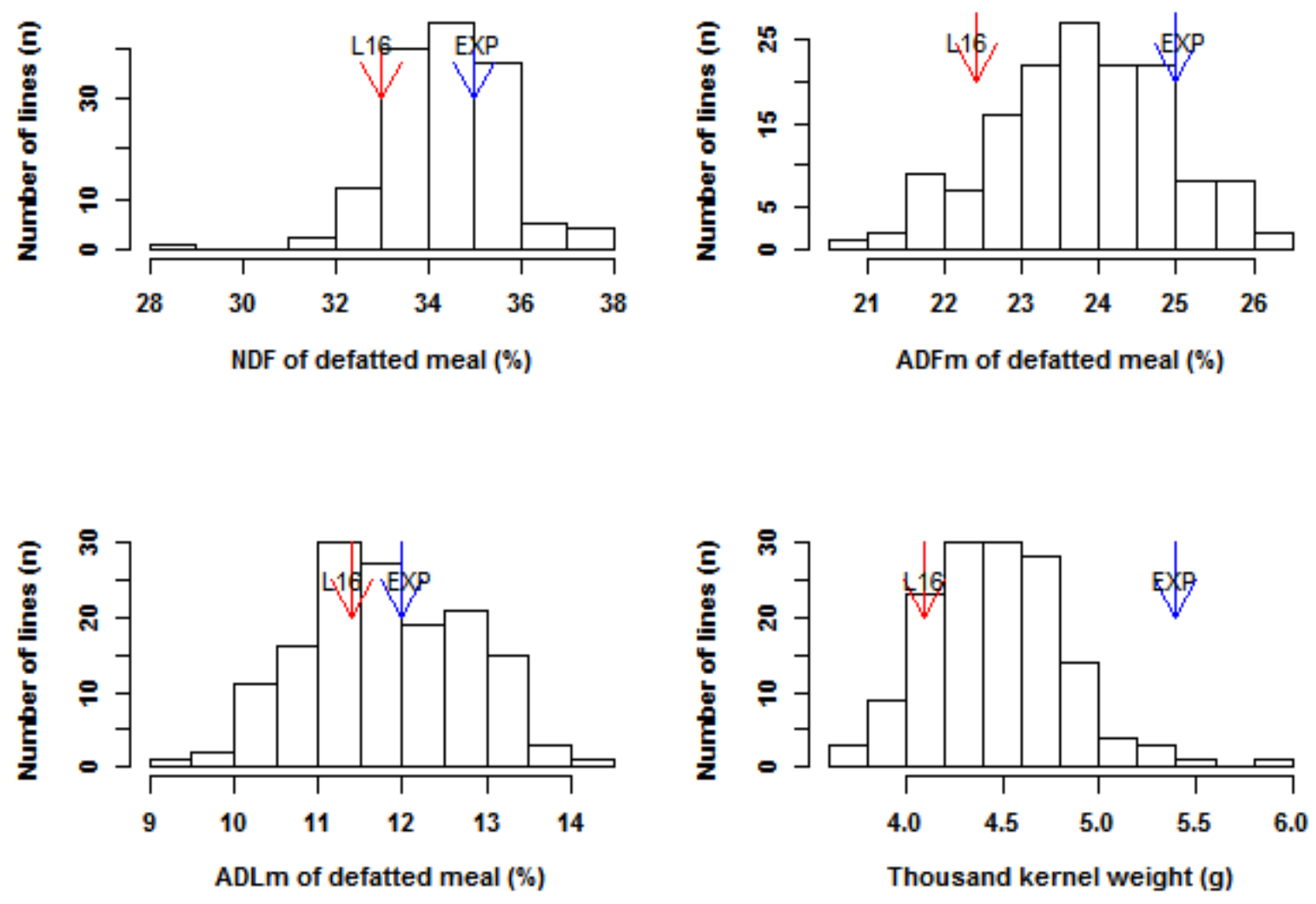

Figure 4.4.3 (continued from previous page) Frequency distribution of oil content, protein of defatted meal, seed weight, glucosinolates, fatty acid composition, seed fibre fraction, in the DHLE population. Arrows indicate parents mean across the experiments. 


\subsubsection{Correlation Analysis}

Spearman's rank correlation ranged from 0.01 to 0.93 for the studied traits in the three environments (Table 4.4.1). Shoot length before winter was weakly, but significantly positive correlated with shoot length in the all greenhouse treatments. However, no significant correlation was observed between shoot length before winter and shoot length in the spring sown environment. Shoot length in the autumn sown environment was also not correlated with begin of flowering neither in the autumn sown nor in the greenhouse environment. In the autumn sown environment, begin of flowering was positively correlated with plant height at end of flowering $\left(r_{s}=0.51^{* *}\right)$ which corresponds to the frequency distribution in which L16 with a late begin of flowering was longer than Express617 at end of flowering. Meanwhile, begin of flowering in the autumn sown environment had positive correlation $\left(\mathrm{r}_{s}=0.23^{* *}\right)$ with begin of flowering in eight weeks vernalized plants in the greenhouse and significant negative correlation with shoot length $\left(\mathrm{r}_{s}=-0.54^{* *}\right)$ and visible buds $\left(\mathrm{r}_{s}=-0.53^{* *}\right)$ in the spring sown environment. Shoot length in the spring sown environment had low to high positive correlations, ranging from $0.19^{*}$ to $0.74^{* *}$ with shoot length in the zero, four and eight weeks vernalization treatment. 
Table 4.4.1: Spearman's rank correlation of the traits in the DHLE population $(\mathrm{n}=151)$

\begin{tabular}{|c|c|c|c|c|c|c|c|c|c|c|c|c|c|c|c|}
\hline \multirow[t]{2}{*}{ Environment } & \multirow{2}{*}{ Trait } & \multicolumn{3}{|c|}{ Autumn sown } & \multicolumn{4}{|c|}{ Spring sown } & \multicolumn{2}{|c|}{$\begin{array}{l}\text { Greenhouse } \\
\text { 0week }\end{array}$} & \multicolumn{2}{|l|}{$\begin{array}{l}\text { Greenhouse } \\
\text { 4weeeks }\end{array}$} & \multicolumn{2}{|c|}{$\begin{array}{l}\text { Greenhouse } \\
\text { 8weeks }\end{array}$} & \multirow[b]{2}{*}{$\mathrm{F}^{\mathrm{BO}}$} \\
\hline & & SL & SD & $\mathrm{BOF}$ & $\mathrm{PH}$ & SL & SD & Buds & SL & SD & SL & $\mathrm{SD}$ & SL & $\begin{array}{c}\mathrm{S} \\
\mathrm{D}\end{array}$ & \\
\hline \multirow[t]{3}{*}{ Autumn sown } & SD & 0.10 & 1 & & & & & & & & & & & & \\
\hline & $\mathrm{BOF}$ & -0.02 & -0.08 & 1 & & & & & & & & & & & \\
\hline & $\mathrm{PH}$ & $0.25^{* *}$ & -0.13 & $0.51^{*}$ & 1 & & & & & & & & & & \\
\hline \multirow[t]{3}{*}{ Spring sown } & SL & 0.11 & 0.09 & $0.54^{-}$ & -0.27 & 1 & & & & & & & & & \\
\hline & SD & -0.12 & 0.06 & 0.11 & 0.15 & -0.29 & 1 & & & & & & & & \\
\hline & Buds & 0.08 & 0.08 & $0.53^{-}$ & $-0.3^{* *}$ & $0.93^{* *}$ & $0.29^{-}$ & 1 & & & & & & & \\
\hline \multirow[t]{2}{*}{$\begin{array}{l}\text { Greenhouse } \\
\text { 0week }\end{array}$} & SL & $0.31^{* *}$ & 0.01 & -0.1 & 0.01 & $0.22^{* *}$ & -0.17 & 0.17 & 1 & & & & & & \\
\hline & SD & $-0.18^{*}$ & $0.17^{*}$ & -0.12 & -0.04 & 0.02 & 0.17 & 0.02 & -0.06 & 1 & & & & & \\
\hline \multirow[t]{2}{*}{$\begin{array}{l}\text { Greenhouse } \\
\text { 4weeks }\end{array}$} & SL & $0.17^{*}$ & 0.08 & $0.4^{-}$ & $0.21^{-}$ & $0.74^{* *}$ & -0.3 & $0.71^{* *}$ & $0.37^{* *}$ & -0.03 & 1 & & & & \\
\hline & SD & -0.05 & $0.16^{*}$ & 0.02 & $0.16^{*}$ & -0.03 & 0.1 & -0.04 & -0.13 & $0.24^{* *}$ & $0.23^{*}$ & 1 & & & \\
\hline \multirow[t]{3}{*}{$\begin{array}{l}\text { Greenhouse } \\
\text { 8weeks }\end{array}$} & SL & $0.18^{*}$ & $0.22^{*}$ & -0.06 & 0.06 & $0.19^{*}$ & -0.04 & 0.18 & 0.16 & -0.02 & $0.33^{* *}$ & 0.06 & 1 & & \\
\hline & SD & -0.11 & 0.11 & -0.06 & -0.03 & $0.17^{*}$ & -.003 & 0.2 & -0.16 & $0.23^{* *}$ & 0.04 & 0.07 & 0.14 & 1 & \\
\hline & $\mathrm{BOF}$ & -0.06 & -0.08 & $\begin{array}{c}0.23 \\
*\end{array}$ & -0.01 & $0.33^{-}$ & 0.14 & $0.36^{\text {*** }}$ & $0.34^{-}$ & -0.05 & $-0.26^{* *}$ & 0.04 & $-0.36^{* *}$ & $\begin{array}{r}0 . \\
01\end{array}$ & 1 \\
\hline
\end{tabular}

${ }^{*}$ and ${ }^{* * *}$ denote significance at $\mathrm{P}<0.05$ and $\mathrm{P}<0.01$, respectively

$\mathrm{SL}=$ shoot length

$\mathrm{SD}=$ shoot diameter

$\mathrm{BOF}=$ begin of flowering (from first of January)

$\mathrm{PH}=$ plant height at the end of flowering 
For the seed quality traits, Spearman's rank correlation ranged from -0.02 to 0.96 (Table 4.4.2). Oil content was positively correlated with oleic acid (C18:1), NDFm, ADFm and ADLm content in the defatted meal and negatively correlated with glucosinolates, linoleic acid (C18:2), linolenic acid (C18:2) and protein content in the defatted meal (PodM). Negative and significant correlation, ranging from $-0.4^{* *}$ to $-0.7^{* *}$ was found between PodM and seed fiber fraction. Oleic acid had negative significant correlation with both linoleic acid and linolenic acid, while linoleic acid and linolenic acid were positive correlated to each other $\left(\mathrm{r}_{s}=0.54^{* *}\right)$. Thousand kernel weight (TKW) showed positive correlation with oil $\left(\mathrm{r}_{\mathrm{s}}=0.24^{* *}\right)$ and linolenic acid $\left(\mathrm{r}_{\mathrm{s}}=0.50^{* * *}\right)$, yet it was negatively correlated with PodM $\left(r_{s}=-0.26^{* *}\right)$ and oleic acid $\left(r_{s}=-0.33^{* *}\right)$. Positive significant correlation ranging from $0.63^{* *}$ to $0.96^{* * *}$ was found among NDFm, ADFm and ADLm, showing same genetic regulation for respective traits in the DHLE population.

Correlation between the seed quality traits with the studied traits in the three environment demonstrated positive correlation between shoot length before winter and contents of oil, protein of defatted meal, NDFm, ADFm, and ADLm. Shoot length and the percentage of buds in the spring sown environment, also, were correlated with oil content $\left(\mathrm{r}_{\mathrm{s}}=0.32^{* *}, \mathrm{r}_{\mathrm{s}}=0.30^{* * *}\right)$. Plant height at end of flowering was moderately positive correlated with oleic acid $\left(\mathrm{r}_{\mathrm{s}}=0.40^{* *}\right)$ and negatively correlated with linoleic and linolenic acid $\left(\mathrm{r}_{\mathrm{s}}=0.32^{* *}\right.$, $\mathrm{r}_{\mathrm{s}}=0.41^{* *}$ ). Thousand kernel weight (TKW) was positively correlated with shoot length in the greenhouse environment with 0 week $\left(r_{s}=0.29^{* *}\right)$ and four weeks $\left(r_{s}=0.29^{* * *}\right)$ vernalization treatment in the greenhouse environment. 
Table 4.4.2: Spearman's rank correlation of the seed quality traits in the DHLE population $(\mathrm{n}=151)$

\begin{tabular}{|c|c|c|c|c|c|c|c|c|c|c|c|c|c|c|c|}
\hline \multirow[b]{2}{*}{ Environment } & \multirow[b]{2}{*}{ Trait } & \multicolumn{4}{|c|}{ Autumn sown } & \multirow[b]{2}{*}{ Oil } & \multirow[b]{2}{*}{ PodM } & \multirow[b]{2}{*}{ GSL } & \multirow[b]{2}{*}{$\mathrm{C} 18: 1$} & \multirow[b]{2}{*}{$\mathrm{C} 18: 2$} & \multirow[b]{2}{*}{$\mathrm{C} 18: 3$} & \multirow[b]{2}{*}{ NDFm } & \multirow[b]{2}{*}{$\mathrm{ADFm}$} & \multirow[b]{2}{*}{ ADLm } & \multirow[b]{2}{*}{ TKW } \\
\hline & & SL & $\mathrm{SD}$ & $\mathrm{BOF}$ & $\mathrm{PH}$ & & & & & & & & & & \\
\hline & Oil & $0.3^{* *}$ & 0.0 & $-0.15^{*}$ & 0.13 & 1 & & & & & & & & & \\
\hline & PodM & $-0.4^{* *}$ & 0.0 & 0.11 & 0.0 & $-0.4 * *$ & 1 & & & & & & & & \\
\hline & GSL & $-0.24 * *$ & 0.0 & 0.0 & -0.1 & $-0.5 * *$ & 0.20 & 1 & & & & & & & \\
\hline & $\mathrm{C} 18: 1$ & 0.04 & -0.04 & 0.13 & $0.40 * *$ & $0.55 * *$ & 0.15 & -0.02 & 1 & & & & & & \\
\hline & $\mathrm{C} 18: 2$ & $0.17 *$ & $0.19 *$ & 0.09 & $-0.32 * *$ & $-0.38 * *$ & 0.19 & -0.05 & -0.5 & 1 & & & & & \\
\hline & $\mathrm{C} 18: 3$ & 0.06 & 0.06 & -0.29 & $-0.41 * *$ & $-0.41^{* *}$ & -0.05 & -0.11 & $-0.7 * *$ & $0.54 * *$ & 1 & & & & \\
\hline & NDFm & $0.44 * *$ & -0.04 & -0.16 & 0.11 & $0.5^{* *}$ & $-0.7 * *$ & -0.3 & $0.55^{* *}$ & $-0.27 * *$ & $-0.4 * *$ & 1 & & & \\
\hline & $\mathrm{ADFm}$ & $0.45^{* *}$ & -0.05 & $-0.2 * *$ & 0.09 & $0.5^{* *}$ & $-0.7 * *$ & -03 & $0.6^{* *}$ & $-0.33 * *$ & $-0.44 * *$ & $0.84 * *$ & 1 & & \\
\hline & ADLm & $0.35 * *$ & -0.08 & -0.16 & 0.04 & $0.20^{*}$ & $-0.4 * *$ & -0.2 & $0.6^{* *}$ & $-0.34 * *$ & $-0.44 * *$ & $0.63 * *$ & $0.96 * *$ & 1 & \\
\hline & TKW & 0.11 & $0.18^{*}$ & -0.1 & -0.02 & $0.24^{* *}$ & $-0.26^{* *}$ & 0.07 & $-0.33 * *$ & $0.22 *$ & $0.50 * *$ & -0.06 & -0.05 & -0.14 & 1 \\
\hline \multirow[t]{3}{*}{ Spring sown } & SL & 0.11 & 0.09 & $-0.54 * *$ & -0.27 & $0.32 * *$ & -0.14 & -0.11 & 0.02 & -0.05 & 0.11 & $0.19^{*}$ & 0.26 & $0.21^{*}$ & 0.07 \\
\hline & SD & -0.12 & 0.06 & 0.11 & 0.15 & 0.0 & 0.04 & 0.03 & -0.05 & 0.01 & 0.02 & -0.08 & -0.17 & $-0.21 *$ & $0.29 * *$ \\
\hline & Buds & 0.08 & 0.08 & $-0.53 * *$ & $-0.3 * *$ & $0.30 * *$ & -0.14 & -0.1 & 0.01 & -0.07 & 0.12 & $0.19^{*}$ & 0.26 & $0.21^{*}$ & 0.01 \\
\hline \multirow[t]{2}{*}{ Greenhouse 0week } & SL & $0.31 * *$ & 0.01 & -0.1 & 0.01 & 0.04 & -0.11 & -0.08 & 0.10 & 0.14 & $0.17 *$ & 0.12 & 0.18 & 0.14 & $0.29 * *$ \\
\hline & SD & $-0.18^{*}$ & $0.17 *$ & -0.12 & -0.04 & -0.12 & 0.11 & 0.0 & 0.01 & 0 & 0.0 & -0.11 & -0.13 & -0.07 & 0.05 \\
\hline \multirow[t]{2}{*}{ Greenhouse 4weeks } & SL & $0.17 *$ & 0.08 & $-0.4 * *$ & $-0.21 * *$ & $0.35 * *$ & $-0.27 * *$ & $0.22^{-}$ & 0.05 & -0.08 & 0.05 & 0.21 & 0.31 & $0.14^{*}$ & $0.18^{*}$ \\
\hline & SD & -0.05 & $0.16^{*}$ & 0.02 & $0.16^{*}$ & $0.24 * *$ & 0.13 & 0.0 & 0.04 & -0.08 & 0.05 & $-0.18^{*}$ & -0.15 & $-0.15^{*}$ & 0.05 \\
\hline \multirow[t]{3}{*}{ Greenhouse 8weeks } & SL & $0.18^{*}$ & $0.22 * *$ & -0.06 & 0.06 & $0.35^{* *}$ & $-0.16^{*}$ & $0.21^{-}$ & 01 & 0.02 & 0.09 & $0.16^{*}$ & 0.30 & $0.21 * *$ & $0.29 * *$ \\
\hline & SD & -0.11 & 0.11 & -0.06 & -0.03 & $0.24 * *$ & -0.10 & -0.13 & 0.08 & 0.111 & -0.08 & $0.19^{*}$ & 0.12 & -0.02 & 0.01 \\
\hline & BOF & -0.06 & -0.08 & $0.23^{*}$ & -0.01 & -0.15 & 0.11 & -0.02 & -0.05 & 0.08 & 0.02 & -0.16 & -0.21 & -0.16 & 00 \\
\hline
\end{tabular}

*and ${ }^{* *}$ denote significance at $\mathrm{P}<0.05$ and $\mathrm{P}<0.01$, respectively $\mathrm{SL}=$ shoot length $\mathrm{SD}=$ shoot diameter flowering
PodM: protein of the defatted meal

NDFm: neutral detergent fibre of the defatted meal

ADLm: acid detergent lignin of the defatted meal

TKW: thousand kernel weight (g)

ADFm: acid detergent fibre of the defatted meal
C18:3: linolenic acid

C18:1: oleic acid

C18:2: linoleic acid

GSL: glucosinolates 


\subsubsection{QTL Mapping}

Multiple interval mapping (MIM) was performed from mean of genotypes over experiments, in each mega environment separately (Table 4.5.1 and Table 4.5.2). Moreover, QTL mapping was done separately in each greenhouse experiment with zero, four and eight weeks vernalization treatment (Table 4.5.3). In total 52 QTL on A-genome linkage groups and 57 QTL on C-genome linkage groups were localized for the 25 studied traits in the DHLE population.

\subsubsection{Autumn sown environment}

Eighteen main QTL and one epistatic QTL were detected for shoot length, shoot diameter, begin of flowering, and plant height at EOF (Table 4.5.1). Six main QTL for shoot length before winter were localized on linkage groups A07, A08, A09, C01, C04 and C09 explaining individually 3.6 to $15.2 \%$ of the phenotypic variance. Moreover, an epistatic QTL with additive effect of $-2.1 \mathrm{~mm}$ was found between the QTL on A08 and C01, explaining $5.1 \%$ of the phenotypic variance that along with the six main QTL contributed $49.2 \%$ to the observed variance for shoot length before winter in the DHLE population. For shoot diameter before winter, two QTL with additive effect of $0.33 \mathrm{~mm}$ and $-0.27 \mathrm{~mm}$ and coefficients of determination of 7.1\% and 1.03\% were found on linkage groups A07 and C04. Four QTL were identified for begin of flowering on linkage groups A02, A03(2) and C04. The QTL at position $52.2 \mathrm{cM}$ on A02 was a major QTL $\left(R^{2}=23.7 \%\right)$ that along with the three other QTL cumulatively explained $47.1 \%$ of the phenotypic variance for begin of flowering. Six QTL for plant height at end of flowering were mapped to linkage groups $\mathrm{A} 02, \mathrm{C} 01, \mathrm{C} 03, \mathrm{C} 04, \mathrm{C} 05$ and $\mathrm{C} 08$ with additive effect ranging from -20.2 to $33 \mathrm{~mm}$. Additive effects of the mapped QTL for plant height indicated that alleles derived from L16 in the QTL mapped on C-genome increased plant height at end of flowering; in contrast alleles from L16 in the QTL mapped to A-genome decreased plant height. The six QTL together explained $47.8 \%$ of the phenotypic variance for plant height in the DHLE population. 
Table 4.5.1: QTL mapped for the traits in the autumn sown environment in the DHLE population $(\mathrm{n}=151)$

\begin{tabular}{|c|c|c|c|c|c|c|c|c|}
\hline Trait & QTL.name & $\begin{array}{l}\text { Linkage } \\
\text { group }\end{array}$ & $\begin{array}{l}\text { Position } \\
(\mathrm{cM})\end{array}$ & $\begin{array}{c}\mathrm{CI}^{a} \\
(\mathrm{cM})\end{array}$ & LOD & $\begin{array}{l}\text { Additive } \\
\text { Effect }^{b}\end{array}$ & $R^{2 c}$ & $T R^{2 d}$ \\
\hline \multirow[t]{7}{*}{ Shoot length } & Wi-Len-1 & A07 & 53.2 & $50.1-62.3$ & 5.31 & 2.42 & 5.1 & \multirow[t]{7}{*}{49.2} \\
\hline & Wi-Len-2 & A08 & 43.12 & $35.8-46.5$ & 2.78 & -1.88 & 3.6 & \\
\hline & Wi-Len-3 & A09 & 107.4 & $\begin{array}{l}102.1- \\
111.1\end{array}$ & 11.5 & -3.55 & 15.2 & \\
\hline & Wi-Len-4 & $\mathrm{C} 01$ & 5 & $1-7$ & 3.96 & -2.2 & 5 & \\
\hline & Wi-Len-5 & $\mathrm{CO} 4$ & 60.04 & $56.1-63.7$ & 5.75 & 2.64 & 8.3 & \\
\hline & Wi-Len-6 & $\mathrm{C} 09$ & 57.5 & $45-60.2$ & 3.85 & -2.1 & 7 & \\
\hline & Wi-Len-7 & $\mathrm{A} 08 * \mathrm{C} 01$ & & ------ & 5.46 & -2.02 & 5.1 & \\
\hline \multirow{2}{*}{$\begin{array}{c}\text { Shoot } \\
\text { diameter }\end{array}$} & Wi-Dim-1 & A07 & 67.2 & $66.2-69.2$ & 3.73 & 0.33 & 1.03 & \multirow[t]{2}{*}{8.13} \\
\hline & Wi-Dim-2 & $\mathrm{CO} 4$ & 1.01 & $0-6.1$ & 2.43 & -0.27 & 7.1 & \\
\hline \multirow[t]{4}{*}{$\begin{array}{l}\text { Begin of } \\
\text { flowering }\end{array}$} & Wi-Bflw-1 & $\mathrm{A} 02$ & 52.2 & $51.3-54.9$ & 9.24 & -0.93 & 23.7 & \multirow[t]{4}{*}{47.1} \\
\hline & Wi-Bflw-2 & A03 & 6.7 & $3.5-8$ & 3.79 & -0.41 & 2.7 & \\
\hline & Wi-Bflw-3 & A03 & 111.4 & $\begin{array}{l}111.3- \\
115.7\end{array}$ & 4.26 & 0.58 & 10.5 & \\
\hline & Wi-Bflw-4 & $\mathrm{C} 04$ & 100.9 & $97-102.7$ & 3.79 & 0.55 & 10.2 & \\
\hline \multirow[t]{6}{*}{$\begin{array}{l}\text { Plant height } \\
\text { at EOF }\end{array}$} & Wi-Het-1 & $\mathrm{A} 02$ & 50.7 & $42.1-52.9$ & 5.63 & -29 & 10.8 & \multirow[t]{6}{*}{47.8} \\
\hline & Wi-Het-2 & $\mathrm{C} 01$ & 12.4 & $6-15$ & 4.27 & 24 & 4 & \\
\hline & Wi-Het-3 & $\mathrm{C} 03$ & 187.2 & $\begin{array}{l}186.3- \\
188.8\end{array}$ & 7.15 & 33 & 13.8 & \\
\hline & Wi-Het-4 & $\mathrm{C} 04$ & 100.9 & $94.6-101.8$ & 4.81 & 28.2 & 8.5 & \\
\hline & Wi-Het-5 & $\mathrm{C} 05$ & 42.9 & $40.5-48.9$ & 5.23 & 28.2 & 8.5 & \\
\hline & Wi-Het-6 & $\mathrm{C} 08$ & 81.09 & $80.2-92.7$ & 2.86 & 20.2 & 2.2 & \\
\hline
\end{tabular}

\footnotetext{
${ }^{a}$ 1-LOD Confidence interval

${ }^{b}\{+\}$ or $\{-\}$ indicates that the trait value is increased by the allele derived from L16 or Express617, respectively ${ }^{c} R^{2}$ is the percentage of phenotypic variance explained by each QTL

${ }^{d} T R^{2}$ is the percentage of phenotypic variance explained by all QTL
} 


\subsubsection{Spring sown environment}

Twelve main QTL were mapped for shoot length, visible buds and shoot diameter in the spring sown environment (Table 4.5.2). As expected from three contiguous cohorts in the frequency plot of shoot length in the spring sown environment, two major QTL with $R^{2}=35.5 \%$ and $R^{2}=25.7 \%$ were localized on linkage group $\mathrm{C} 09$ and $\mathrm{A} 02$ respectively, which along with the QTL on A07 explained 68\% of the phenotypic variance in the DHLE population. Additive effect of the two QTL with alleles derived from L16 were 189.6 and $73.7 \mathrm{~mm}$ versus additive effect= $223.4 \mathrm{~mm}$ of alleles derived from Express617, which corresponds to position of parents in the frequency distribution in which L16 was significantly shorter than Express617 (see Figure 4.4.1 and Table 4.3.1). For shoot diameter, six QTL were identified on linkage groups A01, A06, A09, A10, C01 and C09 that together explained $48.4 \%$ of the phenotypic variance. For the appearance of buds three QTL were mapped to linkage groups A02, A07 and C09 that together explained $60.1 \%$ of the phenotypic variance with additive effect ranging from -8 to $-24 \%$. The two major QTL mapped to A02 and C09 explained individually $22.3 \%$ and $33.4 \%$ of the observed variance that corresponds to three contiguous groups in the frequency distribution for the percentage of visible buds in the spring sown environment (see Figure 4.4.1). 
Table 4.5.2: QTL mapped for the traits in the spring sown environment in the DHLE population ( $\mathrm{n}=151)$

\begin{tabular}{|c|c|c|c|c|c|c|c|c|}
\hline Trait & QTL.name & $\begin{array}{l}\text { Linkag } \\
\text { e group }\end{array}$ & $\begin{array}{l}\text { Position } \\
\text { (cM) }\end{array}$ & $\begin{array}{c}\mathrm{CI}^{a} \\
(\mathrm{cM})\end{array}$ & LOD & $\begin{array}{l}\text { Additive } \\
\text { Effect }^{b}\end{array}$ & $R^{2 c}$ & $T R^{2 d}$ \\
\hline \multirow{3}{*}{$\begin{array}{l}\text { Shoot } \\
\text { length }\end{array}$} & Sp-Len-1 & A02 & 52.7 & $44-52.7$ & 20.8 & 189.6 & 25.7 & 68 \\
\hline & Sp-Len-2 & A07 & 78.4 & $70.5-85.2$ & 3.03 & 73.7 & 6.8 & \\
\hline & Sp-Len-3 & C09 & 128.7 & $125-131$ & 8.35 & -223.4 & 35.5 & \\
\hline \multirow{6}{*}{$\begin{array}{c}\text { Shoot } \\
\text { diameter }\end{array}$} & Sp-Dim-1 & A01 & 3.74 & $3-8$ & 2.45 & -0.48 & 2.6 & 48.4 \\
\hline & Sp-Dim-2 & A06 & 62.93 & $59-66$ & 5.98 & -0.74 & 11.7 & \\
\hline & Sp-Dim-3 & A09 & 18.48 & $16-24.8$ & 4.36 & -0.65 & 10.7 & \\
\hline & Sp-Dim-4 & A10 & 14.2 & $13.3-17.5$ & 6.95 & 0.88 & 13.9 & \\
\hline & Sp-Dim-5 & $\mathrm{C} 01$ & 13.4 & $10.3-15.5$ & 3.82 & 0.58 & 6 & \\
\hline & Sp-Dim-6 & C09 & 31.9 & $29-35$ & 2.66 & -0.47 & 4.4 & \\
\hline \multirow[t]{3}{*}{ Buds } & Sp-Bud-1 & A02 & 52.9 & $52.3-54.1$ & 20.15 & 22 & 22.3 & 60.1 \\
\hline & Sp-Bud-2 & $\mathrm{A} 07$ & 90.26 & $80.8-91.3$ & 4.01 & -8 & 4.4 & \\
\hline & Sp-Bud-3 & C09 & 128.7 & $\begin{array}{l}127.5- \\
130\end{array}$ & 16.96 & -24 & 33.4 & \\
\hline
\end{tabular}

\footnotetext{
${ }^{a}:$ 1-LOD Confidence interval

${ }^{b}:\{+\}$ or $\{-\}$ indicates that the trait value is increased by the allele derived from L16 or Express617, respectively

${ }^{c}: R^{2}$ percentage of the phenotypic variance by each QTL

${ }^{d}: T R^{2}$ percentage of the phenotypic variance explained by all QTL
} 


\subsubsection{Greenhouse environment}

QTL analysis revealed 19 main QTL and 2 epistatic QTL for the studied traits in the different vernalization treatments in the greenhouse environment (Table 4.5.3). In the non-vernalization treatment, two QTL were found for shoot length on A06 and A09 with opposite additive effects of -2.29 and $2.4 \mathrm{~mm}$ which together accounted for $16.2 \%$ of the phenotypic variance. The two QTL for shoot diameter were found on linkage groups A03 and C07 that individually explained 7.1 and $10.9 \%$ of the phenotypic variance in the non-vernalization treatment. QTL analysis for shoot length in the four weeks vernalization treatment identified 5 main QTL which individually explained 4 to $21 \%$ of the phenotypic variance, which collectively with two epistatic QTL $\mathrm{A} 2 * \mathrm{C} 09$ and $\mathrm{C} 04 * \mathrm{C} 09$ explained $68.5 \%$ of the observed variance. The two QTL for shoot diameter were detected on linkage groups A02 and A09 that collectively explained $17.1 \%$ of the phenotypic variance in the four weeks vernalization treatment. In the eight weeks vernalization treatment, two QTL for shoot length with opposite additive effects were mapped on A10 and C04 that together contributed $13.3 \%$ to the phenotypic variance. For shoot diameter two QTL were found on A07 and C04. The QTL on C04 was a major QTL that determined 62.4\% of phenotypic variance for shoot diameter in the eight weeks vernalization treatment. For begin of flowering, four QTL were localized on linkage groups A10, C03(2) and C09, together explained $27.5 \%$ of the phenotypic variance in 8 weeks vernalization treatment.

Overlapping QTL confidence intervals were observed in the genomic regions of the DHLE population for the studied traits within and between the three mega environments. QTL Sp-Len-1 for shoot length in the spring sown environment overlapped with Gh-Len-H1 on A02 with positive additive effect, showing alleles derived from L16 increased shoot length in the spring sown and greenhouse environment with four weeks vernalization treatment. Strong correlation between shoot length and visible buds in the spring sown environment was supported (see Table 4.4.1) by overlapping QTL intervals on A02, A07 and C09, suggesting dependent pathways regulate the two traits. Confidence interval of major QTL Wi-Bflw-1 for begin of flowering coincided with QTL Sp-Len-1 and Wi-Het-1 on A02. This is in agreement with correlation coefficients found between the respective traits (see Table 4.4.1). The candidate gene BnA2.FT was identified within interval 48.5 to $50.7 \mathrm{cM}$ in the vicinity of major QTL Wi-Bflw-1 on linkage group A02. No overlapping confidence interval of QTL was found between shoot length before 
winter and shoot length in the spring sown and greenhouse environment with zero and 8 weeks vernalization treatment. Only on A08 QTL Win-Len-2 coincided with Gh-Len-H3 for shoot length in the four weeks vernalization treatment. Furthermore, no collocation of QTL were found between begin of flowering in the autumn sown environment and begin of flowering in the eight weeks vernalized plants. In contrast, confidence intervals of QTL Gh-Len-H-1 and Gh-Len-F-2 collocated with the two QTL for begin of flowering in the autumn sown environment on A02 and C04, respectively. No colocalizing QTL were found between shoot length and shoot diameter within the three mega environments suggesting independent genetic pathways for shoot length and shoot diameter in the DHLE population. 
Table 4.5.3: QTL mapped for the traits in the greenhouse environment in the DHLE population $(\mathrm{n}=151)$

\begin{tabular}{|c|c|c|c|c|c|c|c|c|c|}
\hline Treatment & Trait & QTL.name & $\begin{array}{l}\text { Linkage } \\
\text { group }\end{array}$ & $\begin{array}{c}\text { Position } \\
\text { (cM) }\end{array}$ & $\begin{array}{c}\mathrm{CI}^{a} \\
(\mathrm{cM})\end{array}$ & LOD & $\begin{array}{l}\text { Additive } \\
\text { Effect }^{b}\end{array}$ & $R^{2 c}$ & $T R^{2 d}$ \\
\hline \multirow{5}{*}{$\begin{array}{l}\text { Greenhous } \\
\text { e } \\
0 \text { week }\end{array}$} & \multirow{3}{*}{$\begin{array}{l}\text { Shoot } \\
\text { length }\end{array}$} & Gh-Len-N1 & A06 & 49.4 & 46.6- & 2.73 & -2.29 & 7.8 & \multirow[t]{3}{*}{16.2} \\
\hline & & & & & 55.5 & & & & \\
\hline & & Gh-Len-N2 & A09 & 3.35 & $1-11$ & 3.03 & 2.40 & 8.4 & \\
\hline & \multirow{2}{*}{$\begin{array}{c}\text { Shoot } \\
\text { diameter }\end{array}$} & Gh-Dim-N1 & A03 & 72.4 & $69-75$ & 2.67 & 0.08 & 7.1 & \multirow[t]{2}{*}{18} \\
\hline & & Gh-DimN2 & $\mathrm{C} 07$ & 46.7 & $42-51$ & 3.98 & -0.1 & 10.9 & \\
\hline \multirow[t]{9}{*}{$\begin{array}{l}\text { Greenhous } \\
\text { e 4weeks }\end{array}$} & \multirow[t]{7}{*}{$\begin{array}{l}\text { Shoot } \\
\text { length }\end{array}$} & Gh-Len-H1 & $\mathrm{A} 02$ & 45.8 & $\begin{array}{l}45.3- \\
48.4\end{array}$ & 7.36 & 31.7 & 14.6 & \multirow[t]{7}{*}{68.5} \\
\hline & & Gh-Len-H2 & A07 & 91.6 & $\begin{array}{c}85- \\
111\end{array}$ & 2.78 & 19.1 & 5.2 & \\
\hline & & Gh-Len-H3 & A08 & 37.5 & $35.2-$ & 3.6 & -23.2 & 6 & \\
\hline & & Gh-Len-H4 & $\mathrm{C} 04$ & 75.9 & $74-85$ & 2.8 & -19.4 & 4 & \\
\hline & & Gh-Len-H5 & $\mathrm{C} 09$ & 134.2 & $131.3-$ & 11.9 & -41.6 & 21 & \\
\hline & & Gh-Len-H6 & $\mathrm{A} 02 * \mathrm{C} 09$ & ----- & ----- & 3.7 & 2.18 & 9 & \\
\hline & & Gh-Len-H7 & $\mathrm{C} 04 * \mathrm{C} 09$ & ----- & ----- & 4.24 & -23.5 & 8.7 & \\
\hline & \multirow[t]{2}{*}{$\begin{array}{c}\text { Shoot } \\
\text { diameter }\end{array}$} & Gh-Dim-H1 & A02 & 52.9 & $\begin{array}{l}41.5- \\
52\end{array}$ & 4.21 & 0.97 & 10.3 & \multirow[t]{2}{*}{17.1} \\
\hline & & Gh-Dim-H2 & A09 & 25.24 & $20-35$ & 3.2 & 0.75 & 6.8 & \\
\hline \multirow[t]{8}{*}{$\begin{array}{l}\text { Greenhous } \\
\text { e } 8 \text { weeks }\end{array}$} & \multirow[t]{2}{*}{$\begin{array}{l}\text { Shoot } \\
\text { length }\end{array}$} & Gh-Len-F1 & A10 & 19.21 & $\begin{array}{l}15.4- \\
20\end{array}$ & 2.9 & 20.1 & 7 & \multirow[t]{2}{*}{13.3} \\
\hline & & Gh-Len-F2 & $\mathrm{C} 04$ & 82.67 & $\begin{array}{l}80.7- \\
92\end{array}$ & 2.75 & -18.6 & 6.3 & \\
\hline & \multirow[t]{2}{*}{$\begin{array}{r}\text { Shoot } \\
\text { diameter }\end{array}$} & Gh-Dim-F1 & A07 & 24.5 & $\begin{array}{l}15.2- \\
26\end{array}$ & 16.26 & -0.32 & 10.6 & \multirow[t]{2}{*}{73} \\
\hline & & Gh-Dim-F2 & $\mathrm{C} 04$ & 33.6 & $25-35$ & 28.1 & -2.8 & 62.4 & \\
\hline & \multirow[t]{4}{*}{$\mathrm{BOF}$} & Gh-Flw-F1 & A10 & 50.69 & $48-56$ & 3.19 & -2.7 & 6.3 & \multirow[t]{4}{*}{27.5} \\
\hline & & Gh-Flw-F2 & $\mathrm{C} 03$ & 63.3 & $\begin{array}{l}62.4- \\
64\end{array}$ & 2.7 & -2.86 & 2.9 & \\
\hline & & Gh-Flw-F3 & $\mathrm{C} 03$ & 92.87 & $\begin{array}{l}87.9- \\
93\end{array}$ & 4.94 & 4.04 & 9.5 & \\
\hline & & Gh-Flw-F4 & $\mathrm{C} 09$ & 133.2 & $\begin{array}{l}131- \\
134\end{array}$ & 3.2 & 2.8 & 8.8 & \\
\hline
\end{tabular}

\footnotetext{
${ }^{a}:$ 1-LOD Confidence interval
}

${ }^{b}:\{+\}$ or $\{-\}$ indicates that the trait value is increased by the allele derived from L16 or Express617, respectively

${ }^{c}: R^{2}$ percentage of the phenotypic variance explained by each QTL

${ }^{d}: T R^{2}$ percentage of the phenotypic variance explained by all QTL

BOF: begin of flowering (from sowing time) 


\subsubsection{Seed quality traits}

For the seed quality traits 64 QTL for the 10 studied traits were mapped to different linkage groups (Table 4.6.4). For oil content four QTL were mapped to linkage groups A07, C02(2) and C09 with additive effects ranging from 0.32 to $0.5 \%$, which together explained $41.8 \%$ of the phenotypic variance. The QTL mapped at position 46.5 on $\mathrm{C} 02$ individually accounted for $18.4 \%$ of the phenotypic variance that was bigger than the other QTL for oil content. Six QTL were identified for protein content of the defatted meal (PodM) that collectively accounted for 56\% of the phenotypic variance. For glucosinolate content, a major QTL on C02 explained individually $50 \%$ of the phenotypic variance with additive effect of $12.84 \mu \mathrm{mol} / \mathrm{g}$ derived from L16 that along with the five other QTL contributed $83.1 \%$ to the phenotypic variance. In total, 22 QTL were localized for the fatty acid profile on different linkage groups that explained $54.8 \%, 79.4 \%$ and $52.2 \%$ of the phenotypic variance for oleic acid (C18:1), linoleic acid (C18:2) and linolenic acid (C18:3), respectively. QTL mapping for thousand kernel weight (TKW) revealed six QTL with additive effects ranging from -0.08 to $0.22 \mathrm{~g}$ that explained $65.8 \%$ of the phenotypic variance. For seed fibre fraction, in total, 16 QTL found were distributed mainly over the C genome, contributed $52.7 \%, 49.1 \%$ and $32.7 \%$ to the observed variance for NDFm, ADFm and ADLm. The total additive effect of alleles coming from L16 was bigger than additive effect of alleles from Express617, which corresponds to higher means for NDFm, ADFm and ADLm in parent L16 (See Table 4.3.3). Multiple overlapping confidence intervals were found between QTL for fatty acid composition on A03, A04, A10, C01, C02 and C05 showing tight linkage between different genes or the pleiotropic effect of genes for the respective traits. Likewise, protein content of the defatted meal overlapped with opposite direction of additive effect for ADFm, NDFm and ADLm on A01, A07 and C02. Major QTL mapped for glucosinolates on C02 (Wi-Gsl-4 ) overlapped with Wi-oil3, Wi-Ndf-4 and Wi-Adf-5 with opposite effect suggesting that alleles derived from L16 increased GSL and simultaneously decreased oil content and the content of fiber fraction in defatted meal. The two mapped QTL for shoot length before winter overlapped with Wi-Oil-1 on A07 and Wi-Oil-4 on C09 in the same and opposite direction of additive effect, respectively. Furthermore, collocation of multiple QTL between NDFm, ADFm, ADLm and shoot length before winter and in greenhouse environment were found on A08, C01 and $\mathrm{C} 04$. 
Table 4.6.4: QTL mapped for seed quality traits in the DHLE population

\begin{tabular}{|c|c|c|c|c|c|c|c|c|}
\hline Trait & QTL.name & $\begin{array}{l}\text { Linkage } \\
\text { group }\end{array}$ & $\begin{array}{c}\text { Position } \\
(\mathrm{cM})\end{array}$ & $\begin{array}{c}\text { CI } \\
(\mathrm{cM})\end{array}$ & LOD & $\begin{array}{l}\text { Additive } \\
\text { Effect }\end{array}$ & $R^{2}$ & $T R^{2}$ \\
\hline \multirow[t]{4}{*}{ Oil } & Wi-Oil-1 & $\mathrm{A} 07$ & 56.2 & $55-69$ & 2.95 & 0.32 & 7.1 & 41.8 \\
\hline & Wi-Oil-2 & $\mathrm{C} 02$ & 48.4 & $37-58$ & 3.68 & -0.38 & 12 & \\
\hline & Wi-Oil-3 & $\mathrm{C} 02$ & 127.2 & $125-128.2$ & 8.9 & -0.5 & 18.4 & \\
\hline & Wi-Oil-4 & $\mathrm{C} 09$ & 46.5 & 41-50 & 2.84 & 0.5 & 4.3 & \\
\hline \multirow[t]{6}{*}{ PodM } & Wi-Pdm-1 & A01 & 14.5 & $10-17$ & 4.63 & -0.37 & 4 & 56 \\
\hline & Wi-Pdm-2 & A07 & 28.2 & $26-29$ & 8 & 0.95 & 17.6 & \\
\hline & Wi-Pdm-3 & $\mathrm{C} 02$ & 97.3 & $95-98$ & 6.32 & 0.57 & 8.8 & \\
\hline & Wi-Pdm-4 & $\mathrm{C} 04$ & 21.7 & $19-25$ & 3.1 & -0.45 & 6.8 & \\
\hline & Wi-Pdm-5 & $\mathrm{C} 05$ & 25 & $20-26$ & 3.3 & 0.38 & 8.7 & \\
\hline & Wi-Pdm-6 & $\mathrm{C} 08$ & 8.2 & $6-13$ & 6.3 & 0.54 & 10.1 & \\
\hline \multirow[t]{6}{*}{ GSL } & Wi-Gsl-1 & $\mathrm{A} 03$ & 109.1 & $109-123$ & 4.4 & -4.4 & 5.6 & 83.1 \\
\hline & Wi-Gsl-2 & A07 & 88.3 & 79-91 & 2.9 & -2.40 & 0.5 & \\
\hline & Wi-Gsl-3 & A08 & 51.1 & $41-60$ & 3.3 & 1.35 & 1 & \\
\hline & Wi-Gsl-4 & $\mathrm{C} 02$ & 123.4 & $123-124$ & 38 & 12.84 & 50 & \\
\hline & Wi-Gsl-5 & $\mathrm{C} 06$ & 29.9 & $26-32$ & 2.83 & 2.25 & 2 & \\
\hline & Wi-Gsl-6 & $\mathrm{C} 09$ & 28 & $27-29$ & 17 & 11 & 24 & \\
\hline \multirow[t]{6}{*}{ C18:1 } & Wi-C181-1 & $\mathrm{A} 03$ & 74 & 73-77 & 6.4 & 0.3 & 19 & 54.8 \\
\hline & Wi-C181-2 & A04 & 50 & $40-52$ & 5 & -0.27 & 5.2 & \\
\hline & Wi-C181-3 & A10 & 26.8 & $22-28$ & 10 & 0.2 & 8 & \\
\hline & Wi-C181-4 & $\mathrm{C} 02$ & 90 & 89-108 & 3 & 0.15 & 4 & \\
\hline & Wi-C181-5 & $\mathrm{C} 03$ & 36.7 & $20-37$ & 3.1 & 0.25 & 6.6 & \\
\hline & Wi-C181-6 & $\mathrm{C} 05$ & 61 & $57-62$ & 7 & 0.3 & 12 & \\
\hline \multirow[t]{8}{*}{ C18:2 } & Wi-C182-1 & A03 & 75 & $73-78$ & 6.3 & -0.34 & 16.2 & 79.4 \\
\hline & Wi-C182-2 & A06 & 1 & $0-3$ & 3.2 & -0.23 & 7.8 & \\
\hline & Wi-C182-3 & A07 & 6 & 5-9 & 3.3 & -0.24 & 8.4 & \\
\hline & Wi-C182-4 & A09 & 8.9 & $3.4-11.2$ & 3 & 0.24 & 8.2 & \\
\hline & Wi-C182-5 & $\mathrm{C} 02$ & 120 & $119-121$ & 3.5 & -0.26 & 9.6 & \\
\hline & Wi-C182-6 & $\mathrm{C} 03$ & 12 & 9-17 & 3.5 & -0.26 & 9.7 & \\
\hline & Wi-C182-7 & $\mathrm{C} 05$ & 75 & $73-81$ & 3 & -0.24 & 8.2 & \\
\hline & Wi-C182-8 & $\mathrm{C} 09$ & 42 & $31-47$ & 4 & -0.28 & 11.3 & \\
\hline \multirow[t]{8}{*}{ C18:3 } & Wi-C183-1 & A04 & 63.7 & $56-67$ & 3 & 0.12 & 3.8 & 52.2 \\
\hline & Wi-C183-2 & A06 & 59.3 & $57-63$ & 2.8 & 0.11 & 2.4 & \\
\hline & Wi-C183-3 & A09 & 75.4 & $65-79$ & 3.3 & -0.11 & 3 & \\
\hline & Wi-C183-4 & A10 & 26.7 & $25-28$ & 6 & -0.21 & 12 & \\
\hline & Wi-C183-5 & $\mathrm{C} 01$ & 52.6 & $45-54$ & 5.5 & 0.13 & 9 & \\
\hline & Wi-C183-6 & $\mathrm{C} 02$ & 73.1 & $70-89$ & 3.4 & -0.16 & 7.2 & \\
\hline & Wi-C183-7 & $\mathrm{C} 03$ & 12.1 & $5-28$ & 2.9 & -0.11 & 6.6 & \\
\hline & Wi-C183-8 & $\mathrm{C} 05$ & 59.6 & $55-63$ & 6 & -0.15 & 12 & \\
\hline \multirow[t]{6}{*}{ TKW } & Wi-Tkw-1 & A05 & 1 & $0-12$ & 10 & -0.22 & 23.7 & 65.8 \\
\hline & Wi-Tkw-2 & A06 & 48 & $46-49$ & 6 & -0.17 & 10 & \\
\hline & Wi-Tkw-3 & A09 & 73.4 & $64-75$ & 4.9 & -0.09 & 8.4 & \\
\hline & Wi-Tkw-4 & $\mathrm{C} 01$ & 13 & 5-15 & 4.5 & 0.12 & 11 & \\
\hline & Wi-Tkw-5 & $\mathrm{C} 02$ & 119 & $105-122$ & 4 & -0.08 & 6.1 & \\
\hline & Wi-Tkw-6 & $\mathrm{C} 09$ & 5.3 & 1-13 & 4 & -0.09 & 6.6 & \\
\hline \multirow[t]{6}{*}{ NDFm } & Wi-Ndf-1 & A07 & 28 & $15-30$ & 5 & -0.45 & 14 & 52.7 \\
\hline & Wi-Ndf-2 & $\mathrm{C} 01$ & 10 & $6-14$ & 3.7 & -0.34 & 6 & \\
\hline & Wi-Ndf-3 & $\mathrm{C} 01$ & 71 & $70-72$ & 8.6 & 0.47 & 9 & \\
\hline & Wi-Ndf-4 & $\mathrm{C} 02$ & 127 & $120-128$ & 3.9 & -0.3 & 8.5 & \\
\hline & Wi-Ndf-5 & $\mathrm{C} 04$ & 68 & $66-75$ & 3.2 & 0.2 & 5.2 & \\
\hline & Wi-Ndf-6 & $\mathrm{C} 06$ & 71 & $65-75$ & 3.2 & -0.4 & 10 & \\
\hline ADFm & Wi-Adf-1 & A01 & 14.5 & $11.7-17.3$ & 2.9 & 0.29 & 5.5 & 49.1 \\
\hline
\end{tabular}




\begin{tabular}{|c|c|c|c|c|c|c|c|c|}
\hline & Wi-Adf-2 & A08 & 43.1 & $40-50$ & 3.2 & -0.37 & 10.8 & \\
\hline & Wi-Adf-3 & $\mathrm{C} 01$ & 10.5 & $6-14$ & 7 & -0.4 & 11 & \\
\hline \multirow{8}{*}{ ADLm } & Wi-Adf-4 & C01 & 71 & $70-75$ & 3.3 & 0.3 & 5.2 & \\
\hline & Wi-Adf-5 & $\mathrm{C} 02$ & 125 & $120-128$ & 2.9 & -0.25 & 4.8 & \\
\hline & Wi-Adf- 6 & C04 & 66 & $60-76$ & 2.8 & 0.25 & 4 & \\
\hline & Wi-Adf-7 & $\mathrm{C} 05$ & 107 & $100-115$ & 3.1 & 0.34 & 7 & \\
\hline & Wi-Adl-1 & A03 & 42.8 & $36-45$ & 2.9 & 0.25 & 7.7 & 32.7 \\
\hline & Wi-Adl-2 & A08 & 43.1 & $42-50$ & 5 & -0.34 & 11.3 & \\
\hline & Wi-Adl-3 & $\mathrm{C} 02$ & 61.6 & $56-64$ & 5 & -0.38 & 7.7 & \\
\hline & Wi-Adl-4 & $\mathrm{C} 02$ & 100 & $99-105$ & 2.8 & 0.3 & 6 & \\
\hline
\end{tabular}

${ }^{a}$ : 1-LOD Confidence interval

${ }^{b}:\{+\}$ or $\{-\}$ indicates that the trait value is increased by the allele derived from L16 or Express617, respectively

${ }^{c}: R^{2}$ percentage of the phenotypic variance by each QTL

${ }^{d}: T R^{2}$ percentage of the phenotypic variance explained by all QT 


\subsection{Discussion}

\subsubsection{Phenotypic analysis}

Parent L16, in this study, is a semi-resynthesized line that significantly differed from Express617 for shoot length in the three mega environments, giving large phenotypic variance in the DHLE population. It is believed that some desired genes are lost due to selective bottlenecks for oil quality and oil content in modern oilseed rape varieties (Girke et al. 2012).Therefore, using of the artificially resynthesized B. napus is a breeding strategy to broaden genetic variability and introgression exotic genes in the current genepool of B. napus (Becker et al. 1995) Significant difference between L16 and Express617, also, was observed in the mean comparisons of 19 oilseed genotypes for shoot length in the autumn sown and spring sown environment (See Chapter 3). Importance of shoot growth in the autumn on winter survival is shown in the results of a study with different sowing dates (Darby et al. 2013). They discussed that very much growth prior to winter cessation can determine the overwintering of crop and causes killing of the crown and growth of disease in oilseed rape. That is, winter type crops with enhanced shoot length are very prone to frost damage due to less photosynthetic activity and less accumulated carbohydrates in shoot apex (Rapacz et al. 2001, Rapacz 2002b, Prásil et al. 2004, Velicka et al. 2010, Asghari et al. 2014, Balodis and Gaile 2015). Also, successful overwintering of oilseed rape plants was observed after they developed a root crown diameter of 8-10 mm and a height of apical bud not exceeding $30 \mathrm{~mm}$ in autumn (Cramer 1990). In the present study population mean for shoot length before winter was $42 \mathrm{~mm}$ that was longer than optimum shoot length suggested for the successful overwintering. However, no frost damage was observed during implementation of the project in years 2014 and 2015.

Heritability was higher than $70 \%$ for begin of flowering and plant height at end of flowering in the autumn sown environment, in contrast low heritability was observed for shoot length and shoot diameter before winter which is explained by high standard error due to measuring error, a few number of plants (five samples) or effect of sowing conditions (single seed drilling vs. normal seed drilling) and different sowing date at four locations. For instance, population mean for shoot length before winter was $72 \mathrm{~mm}$ at location Peine, sown on 21 August 2014, while 
population mean for shoot length was $26 \mathrm{~mm}$ at location Einbeck, sown on 4 September 2014. Velicka et al. (2010) explained that sowing date, autumnal growth and meteorological parameters such as air temperature and precipitation significantly influenced height and diameter of apical buds in oilseed cultivars.

Greenhouse results illustrated the all the DH lines flowered within 139 days after being incubated 8 weeks in the cold chamber (Table 4.3.2), while begin of flowering in the autumn sown delayed until other ambient cues were met in the following spring. The long gap between vernalization saturation and begin of flowering raises the question whether flowering time is a proper feature to measure vernalization requirement in the autumn sown field experiments or no? One alternative method to determine the vernalization requirement is, cultivation of winter oilseed rape in spring. This is done routinely by the German Federal Plant Variety Office (BSA, www.bundessortenamt.de) when testing varieties for Distinctness, Uniformity and Stability (DUS) in field plots. Inflorescence formation of winter oilseed rape cultivars in the year of spring sown field experiments is a much valued DUS-trait, because otherwise very similar cultivars usually can be distinguished by this trait (E. Thiemt, BSA Hannover, personal communication to C. Möllers). The tendency to form inflorescence in the year of spring sowing field experiments indicates that few cold days and nights at end of March and beginning of April are obviously sufficient for some winter oilseed rape genotypes. Obviously, increasing day length and temperatures in March/April positively influence bolting and flowering. The parents used for developing the DHLE population were selected from their contrasting characteristics that were in in compliance with results of the spring sown field experiments, where Express617 showed significant higher shoot length and low vernalization requirement than L16, giving a near bimodal distribution along with transgressive segregation for shoot length and visible buds. Quantitative nature of vernalization requirement is observed in most winter type crops (Hawkins et al. 2002).

\subsubsection{Correlation analysis}

Our results showed no significant phenotypic correlation between shoot length before winter and vernalization requirement, determined by shoot length in the spring sown environment. 
Likewise no significant correlation was observed between shoot length before winter with other traits influenced by vernalization such as begin of flowering in the autumn sown environment and tendency to form floral buds in the spring sown environment. Dechaine et al. (2013) observed no significant correlation between vegetative traits and reproductive traits in a recombinant inbred lines of Brassica rapa in the field and glasshouse due to different magnitude of genetic variation of traits in the different developmental stage. The lack of correlation between shoot length before winter as relevant trait for winter hardiness and vernalization requirement is in accordance with some published findings that illustrated there is no simple relationship between winter hardiness and the degree of vernalization (Fowler et al. 1966b, Teutonico et al. 1993, Markowski et al. 1994).

Negative correlation between vernalization requirement determined by shoot length in the spring sown environment and begin of flowering in the autumn sown and greenhouse environment $\left(\mathrm{r}_{s}=-0.54^{* *}\right.$ and $\left.\mathrm{r}_{s}=-0.33^{* *}\right)$ indicated that begin of flowering was accelerated in genotypes whose vernalization requirement is low. Hence, variation observed for elongation of shoot in the spring is influenced by different vernalization requirement and could be a more relevant trait than begin of flowering, which is routinely used by researchers, to measure vernalization requirement in the plant material. As a further evidence, highly positive correlation between shoot length, visible buds in the spring sown environment and shoot length of plants incubated for four weeks in the greenhouse environment $\left(\mathrm{r}_{s}=0.74^{* *}\right)$ proved that shoot length in the spring sown environment is strongly differentiated by the different vernalization requirement of DH lines. Therefore, shoot length in non-complete vernalized genotypes could be consider as a fast method to screen genotypes according to vernalization requirement. Positive correlation between plant height and begin of flowering in the autumn sown environment corresponds to the frequency distribution in which parent L16 with late flowering had longer plant height (See Figure 4.4.1). Mei et al. (2009) found positive correlation of $r_{s}=0.29^{* *}$ and $r_{s}=0.48^{* *}$ between plant height and flowering time in a segregating Brassica napus population with $145 \mathrm{~F}_{2: 3}$ lines in two growing seasons.

Highly broad sense heritability with significant variance for genotypes was observed for the seed quality traits in the DHLE population suggested that genetic gain could be achieved through phenotypic selection of the superior lines. However, complex relationship among seed quality traits impedes improvement of oil nutrition quality in oilseed rape varieties. Oil content had 
positive correlation with oleic acid $\left(\mathrm{r}_{\mathrm{s}}=0.55^{* *}\right)$ and negative correlation with poly unsaturated fatty acids linoleic $\left(\mathrm{r}_{s}=-0.38^{* *}\right)$ and linolenic $\left(\mathrm{r}_{s}=-0.41^{*}\right)$ that is promising for the development of "HOLLi', oilseed rape cultivars with a high content of oleic acid (18:1) and a low content of linolenic acid (18:3) in the seed oil (Abbadi and Leckband 2011). For human nutrition, negative correlation between oil content and polyunsaturated fatty acids and positive correlation between oil content and both oleic acid is beneficial due to better oxidative stability of the oil (Teh and Möllers 2016). Negative correlations were observed between fibre-related traits and protein content of defatted meal, while oil content was positively correlated with fibre traits in defatted meal and negatively correlated with protein content in the defatted meal. The results confirm that an increase of oil content in the seed leads to an increase fibre content in the defatted meal. The negative correlations between oil content and protein content of the defatted meal indicates that the increase in oil content occurred at the expense of protein content instead of fibre content. This interpretation is supported by positive correlations between fibre traits of defatted meal and oil content. Si et al. (2003) have also observed a negative correlation between oil and protein content of the defatted meal of canola quality material tested at 7 to 9 locations across 4 states in southern Australia. They suggested that direct selection for high seed oil content and high protein concentration of meal would reduce the proportion of seed residue (fibre content). Furthermore common carbon signaling pathway involved in the synthesis of oil and seed fibre fraction is described as main reason for positive correlation between oil and NDFm, ADFm and ADLm in oilseed rape (Suprianto 2015). Correlation between the seed quality traits and the studied traits in the three mega environment are not well known, only genetic correlation between flowering time and seed quality traits have been mainly investigated in a few studies (Zhao et al. 2006, Chen et al. 2010) but result shows no strong correlation between flowering time and seed quality traits in oilseed rape populations. Also in this study, no notable correlation was found between the seed related traits and begin of flowering in the autumn sown and greenhouse environment. Weak to moderate correlations were often found between shoot length in three environment and some quality traits such as oil content, protein content of defatted meal, NDFm, ADFm and ADLm content, suggesting that variation in vernalization requirement and shoot development before winter might influence genes regulating seed quality traits in oilseed rape. 


\subsubsection{QTL Mapping}

In total, 105 QTL were localized on 19 linkage groups for the 25 studied traits over three environments in the DHLE population. A general view of the position of all QTL on linkage groups demonstrated collocation of QTL for different traits were more frequently observed than individual isolated QTL. The overlapping QTL along with phenotypic correlation can shed light on genetic association between the traits measured in the different environments.

As already discussed, shoot length and visible buds in the spring sown environment are highly correlated with vernalization requirement. Therefore, QTL mapped for these traits are more likely linked to regulator genes for vernalization. It is shown in B. napus that the MADS box transcription factor gene FLOWERING LOCUS C $(F L C)$ is the key regulator of vernalization requirement and is down-regulated by vernalization, thus enabling promotion of flowering by FLOWERING LOCUS T (FT) (Zou et al. 2012, Raman et al. 2016). Two out of nine paralogues of FLC (BnFLC.C9a and BnFLC.C9b) were physically identified on chromosome C09 of B. napus (Zou et al. 2012). Physical position of a copy of FLC (BnFLC9b) was found in a genomic region from 125 to $131 \mathrm{cM}$ on CO9 that was within confidence intervals of the QTL for shoot length, visible buds in the spring sown environment, shoot length in four weeks vernalized plants and begin of flowering in eight weeks vernalized plants in greenhouse environment (Figure 4.5). Therefore, it can be speculated that BnFLC $9 b$ is the candidate gene controlling $35.5 \%$ of the phenotypic variance for shoot length in the spring sown environment. On linkage group A02 a QTL hotspot from 48.5 to $55.1 \mathrm{cM}$ encompassed QTL for begin of flowering and plant height in the autumn sown environment, shoot length and visible buds in the spring sown environment, shoot length and shoot diameter in the 4 weeks vernalization treatment in greenhouse (Figure 4.6). Surprisingly all the QTL were the largest or the second largest QTL for respective traits. The QTL on A02 is constantly reported in the flowering time-related studies, using informative molecular markers for genotyping, in oilseed rape segregating populations. Long et al. (2007) found a stable QTL for flowering time, budding time and bolting time on linkage group N02 across 11 field environments in B. napus. Lou et al. (2007) showed responsible QTL for flowering time, plant height, leaf number, turnip length on linkage R02 in three different segregating populations of $B$. rapa. A copy of gene $F T$ (BnA2.FT) was identified in a genetic position of $51.3 \mathrm{cM}$ within the hotspot on A02 (Figure 4.6). Our finding was in accordance with 
a FT paralogue (BnA2.FTa) associated with a major QTL for flowering time in the results reported by Wang et al. (2009) in B. napus. In Arabidopsis, the input from the vernalization and photoperiod pathway is integrated by floral integrator gene FLOWERING LOCUS T (FT) that is strong promoter of flowering (Michaels 2009). Multiple copies of FT, with different cis-intronic sequence, exist and appear to operate harmoniously within Brassica napus (AACC), a member of the same plant family as Arabidopsis (Wang et al. 2009). Kole et al. (2001) suggested that alleles affecting flowering time in oilseed Brassica species might also affect winter survival. In the present study, QTL Sp-Len-1 mapped on A02 for shoot length in the spring sown environment coincided with negative additive effect of QTL Wi-Bflw-1 detected for begin of flowering and QTL Wi-Het-1 for plant height in the autumn sown environment, indicating alleles derived from L16 on A02 caused lower vernalization requirement and earlier begin of flowering. This finding is in contrast with the finding that L16 with shorter shoot length in the spring sown environment showed stronger vernalization (Table 4.3.1), yet a glance to other QTL for shoot length and visible buds proved that the biggest QTL for shoot length in the spring sown environment was mapped at position $128.7 \mathrm{cM}$ on $\mathrm{C} 09$, overruling the additive effect of QTL mapped to A02 and A07. Interrelation between different loci affecting quantitative traits are studied in Arabidopsis. Caicedo et al. (2004) represented that in Arabidopsis thaliana, the FRI and FLC genes mechanistically interact to control flowering time and they showed that this epistatic interaction also contributes to genetic architecture of evolutionary diversification within the species. Epistatic relation between two candidate genes BnFLC9b and BnA2.FT in the vicinity of two major QTL with opposite additive effects on C09 and A02 for shoot length in the spring sown environment could be questionable. However, allelic combinations of flanking markers in the position of two major genes differentiated majority of genotypes into four genotypic classes (Figure 4.7), indicating that there is no apparent epistatic effect between the two major genes for shoot length in the spring sown environment.

Our results indicated that no overlapping QTL confidence interval was found between vernalization requirement and shoot length before winter as relevant trait for winter hardiness that was in accord with no significant correlation between them. Previous QTL mapping for freezing tolerance suggested that different linkage groups exist in both $B$. rapa and $B$. napus for capacity to attain freezing tolerance and vernalization (Ferreira et al. 1995, Teutonico et al. 1995). However, Chen et al. (2010) found three major QTLs controlling variation in 
developmental process, and each of them was tightly associated with a known flowering gene. QTL mapping, in our study, revealed that two QTL Wi-Len-1 and Wi-Len-6 were in the same linkage groups of QTL mapped for shoot length in the spring sown environment (A07 and C09). Furthermore, the QTL Win-Len-5 on linkage group C04 was at the same linkage group with the two QTL Gh-Len-H4 and Gh-Len-F2 for shoot length in the four and eight weeks vernalization treatment in greenhouse.

QTL for protein content of defatted meal (PodM), oil content, fatty acid composition, glucosinolate content, thousand kernel weight, NDFm and ADFm were cumulated on linkage group C02, in which QTL associated with oil content in a high-density map on Brassica napus also was reported in a different bi-parental population (Wang et al. 2013). Oil and protein synthesis in the seed share basic resources in the metabolic pathways and are partly controlled by the same genes, which causes significant negative correlation between the two traits (Zhao et al. 2006). Gül (2003) identified six QTL for seed oil content and four of them showed a close linkage with QTL for protein content. In three cases the allele increasing oil content was in coupling phase with the allele decreasing protein content and vice versa, explaining the negative correlation between the two traits. Interestingly, no QTL from the traits related to shoot elongation and vernalization requirement were found at this region which might be applicable for improved seed quality without significant impact on vegetative and generative traits. In this study, a major QTL explaining 50\% of the variance for the glucosinolate content was found on C02 that also was observed in oilseed rape populations (Howell et al. 2003, Liu et al. 2016). Brandes (2016) also reported a major QTL for glucosinolate content on C02 in the DHLE population. QTL mapping revealed linkage groups that comprised genetic regions influencing both morphological and seed quality traits in the DHLE population. Linkage groups A07 and C09 encompassed more QTL from the both categories. The QTL Wi-Len-1 in a genomic region from 10 to $27 \mathrm{cM}$ on A07 increased shoot length before winter while it was collocated with $\mathrm{Wi}$ Oil-1 for oil content with positive additive effect. In the second region from 67 to $79 \mathrm{cM}$ on A07, another overlapping QTL between shoot length in spring and glucosinolate content was discovered that led to a reduction of both vernalization requirement and GSL content. C09 was the second linkage group with overlapping genomic regions between oil content, shoot length before winter and oleic acid content with opposite effects. In other words, QTL at this region increased oil content and at the same time decreased shoot length before winter and oleic acid 
content. The two out of four QTL detected for oil content coincided with the QTL for shoot length before winter with positive and negative additive effects that should be taken in account, breeding for reduced shoot length before winter might influence oil profile. Rapacz and Markowski (1999) reported that modern double zero cultivars are characterized by lower frost resistance than traditional varieties. In addition, result of genetic variation in 19 oilseed genotypes (See chapter 3) revealed that the two resynthesized line R53 and L16 had a reduced shoot elongation, compared to the modern cultivars in the autumn sown and spring sown environment.

C09

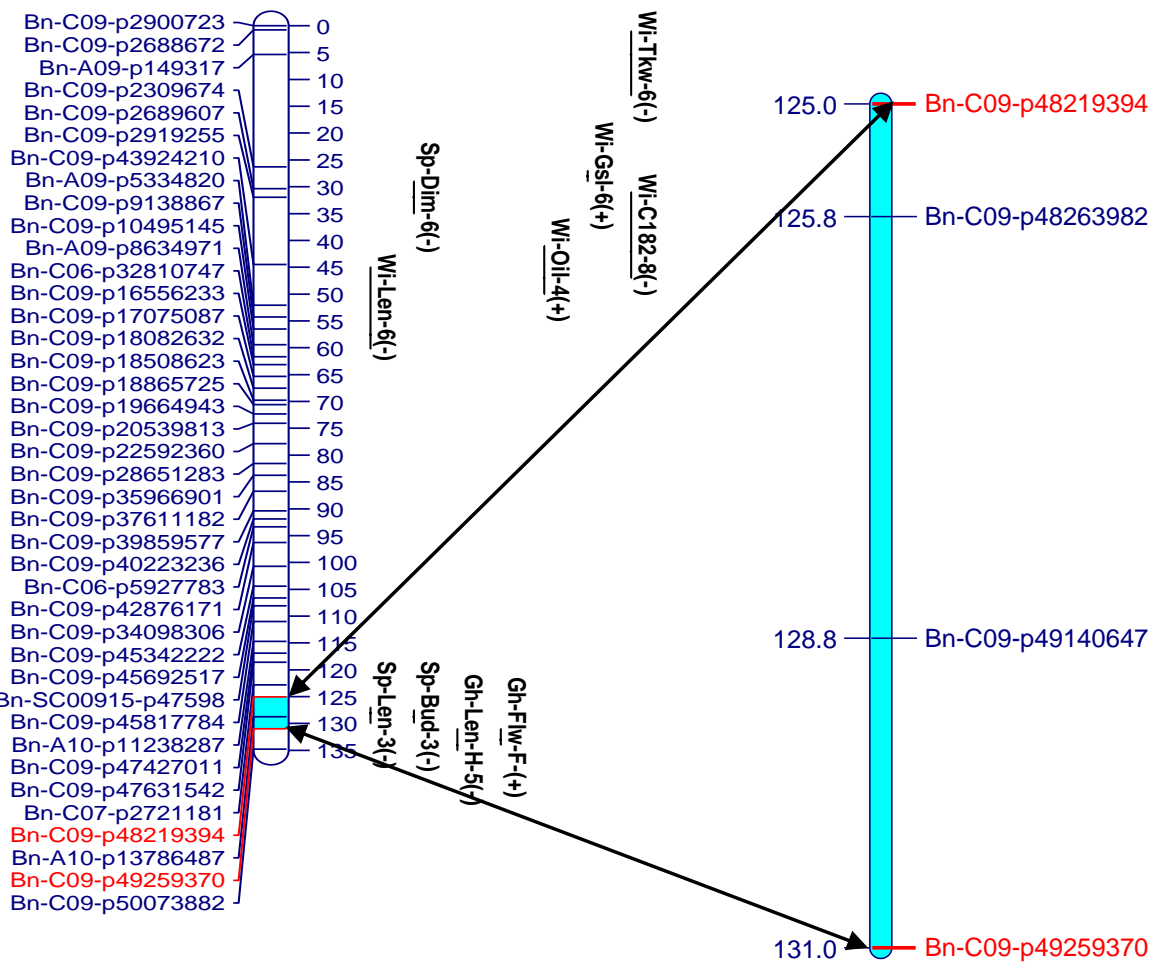

Physical map C09

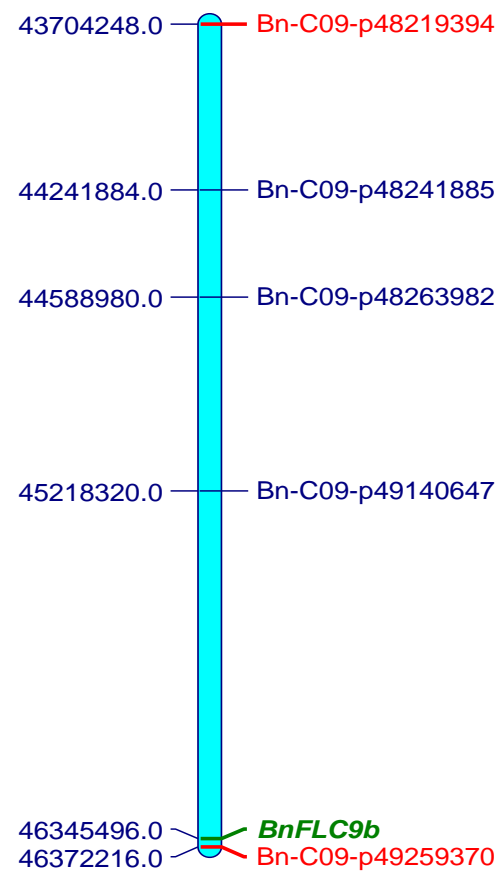

Figure 4.5: Genetic and physical map positions of markers within the QTL genomic region $(125-131 \mathrm{cM})$ on C09 in the DHLE. Left: QTL for shoot length and percentage of visible buds in the spring sown, shoot length and in the 4 week vernalization treatment and begin of flowering in the greenhouse with eight weeks vernalization treatment. Middle: Additional markers mapped within the QTL genomic region in the full map. Right: The corresponding physical positions of additional markers and the candidate gene (BnFLC9b) in B. napus genome 


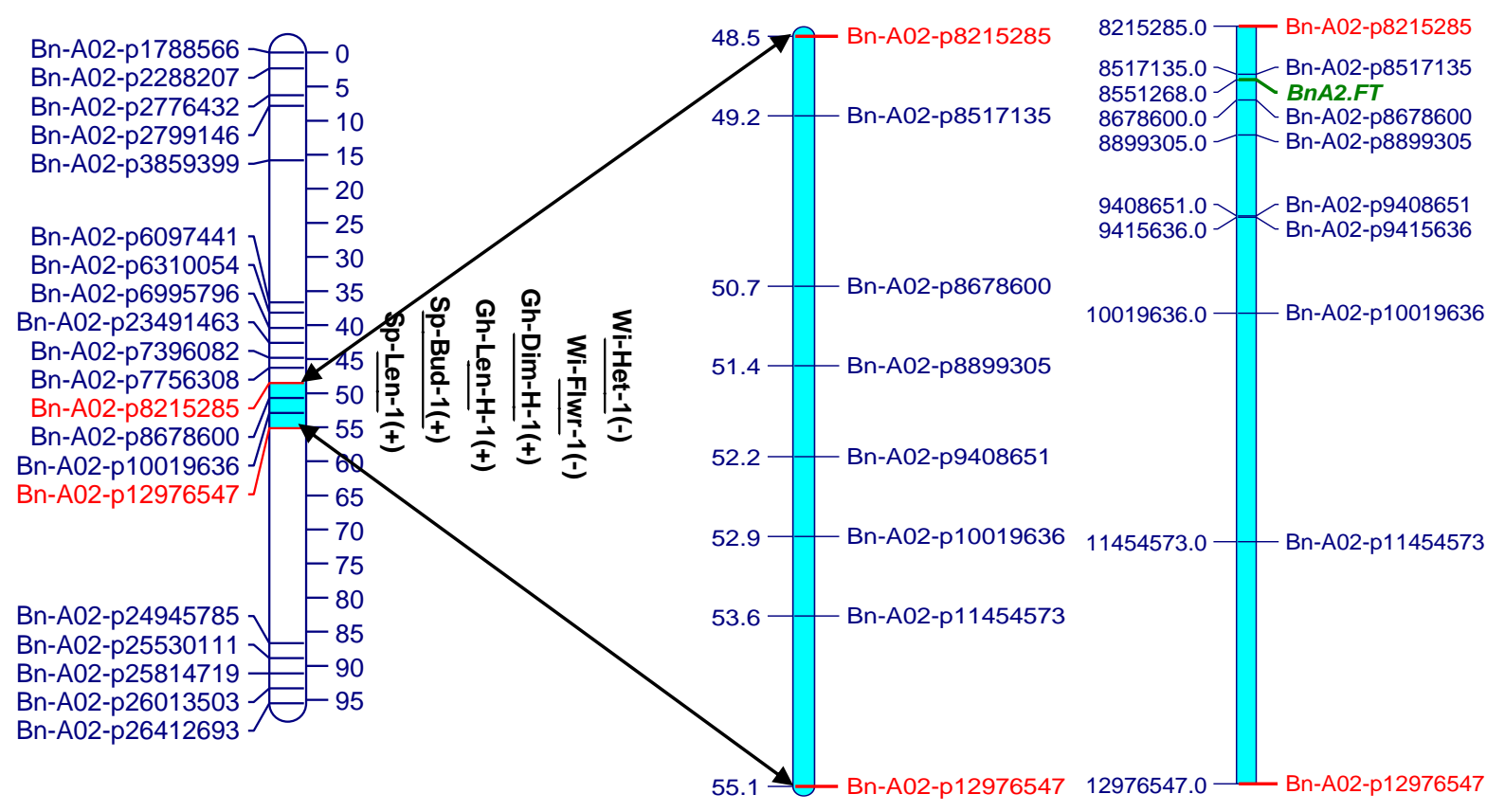

Figure 4.6: Genetic and physical map positions of markers within the QTL genomic region (48.5-55.1cM) on A02 in the DHLE. Left: QTL for begin of flowering and plant height at end of flowering in the autumn sown, shoot length Figure 4.7: Additive effect of two flanking markers Bn-A02-p8215285 and Bn-C09-p482119394 linked to the two major QTL on A02 and C09 for the shoot length in the spring sown environment in the DHLE population.

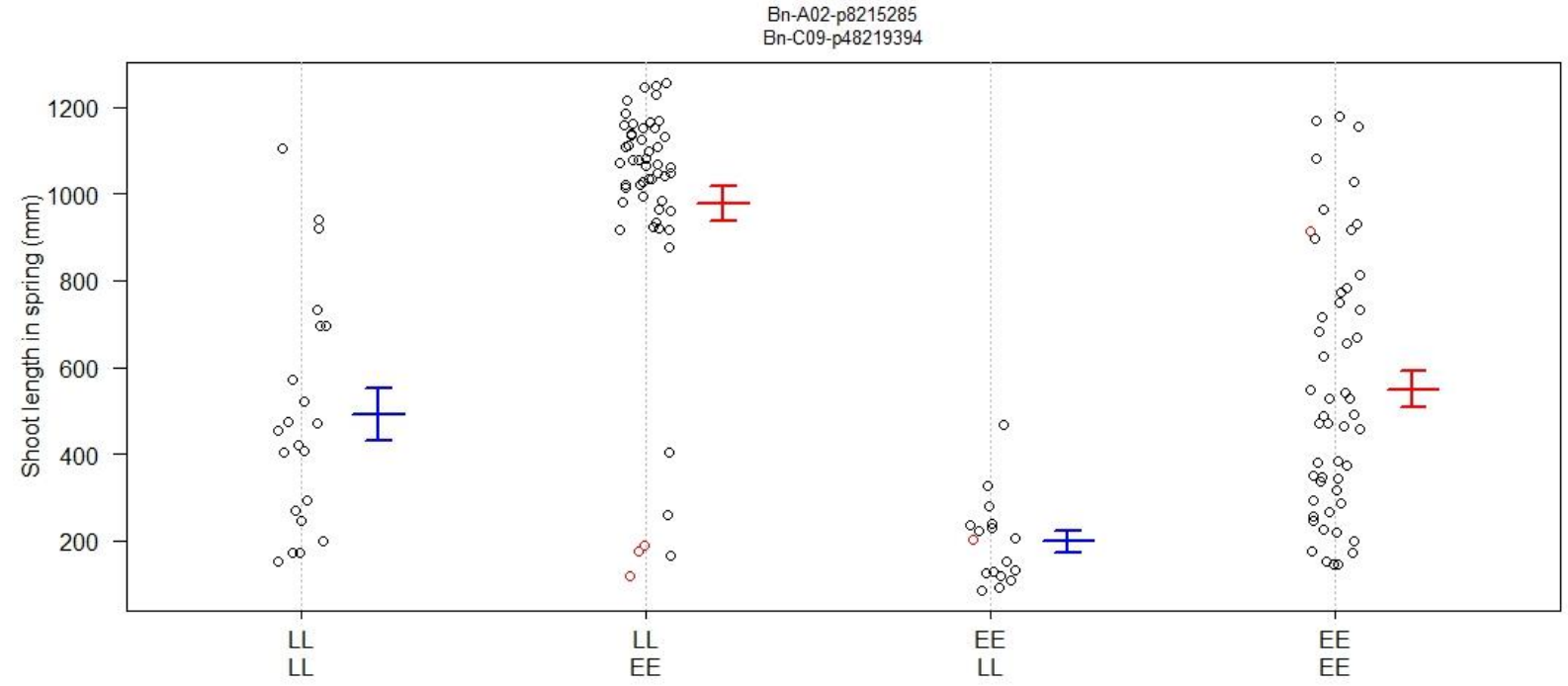

Figure 4.7: Additive effect of two flanking markers Bn-A02-p8215285 and Bn-C09-p482119394 linked to the two major QTL on A02 and C09 for the shoot length in the spring sown environment in the DHLE population. Red points indicate missing data. Red boxplot shows standard error and higher phenotypic mean and blue boxplot shows standard error and lower phenotypic mean for shoot length in the spring sown environment in each genotypic combination. 


\section{Chapter 5}

Genetic analysis and inheritance of shoot elongation before winter and its relation with other traits in a doubled haploid population Sansibar x Oase (Brassica napus L.) 


\subsection{Abstract}

Winter seasons are getting warmer with more rain due to global warming and increasing temperature. However, extreme freezing temperature are occasionally occurring in temperate regions, causing frost damage and yield loss. Cessation of shoot growth before and during winter in winter oilseed rape is a tolerance strategy to avoid winterkill by freezing temperatures. The present study aimed to analyze genetic architecture of shoot elongation before winter and its correlation with the other interacting traits in winter hardiness of oilseed rape. QTL mapping was performed in a segregating doubled haploid population derived from a cross of the two winter oilseed rape cultivars Sansibar and Oase, named DHSO population. The DHSO population and the parental lines were characterized in the three mega environments: autumn sown and spring sown and greenhouse. In the autumn sown environment, shoot length and shoot diameter were measured before winter, while begin, end, duration of flowering and plant height were measured in spring the following year. Likewise, shoot length, shoot diameter were measured around three months after sowing time in the spring sown environment. Non vernalized plants were cultivated in the greenhouse and shoot length and shoot diameter were measured three months after sowing time. High broad sense heritability was found for shoot length in the spring sown and greenhouse environment, in contrast shoot length before winter had medium heritability. Spearman's rank correlation revealed significant negative correlation between shoot length in the spring sown environment with begin of flowering, end of flowering and plant height in the autumn sown

environment. Positive correlation $\left(\mathrm{r}_{s}=0.31^{* *}\right)$ was found between shoot length before winter and vernalization requirement determined by shoot length in the spring sown environment. Multiple interval mapping detected five main QTL, explaining collectively $23.5 \%$ of the phenotypic variance for shoot length before winter. For shoot length in the spring sown environment a major QTL on A02 explained 70\% of the phenotypic variance. Three QTL for shoot length in greenhouse contributed $26 \%$ to the observed variance. The candidate gene BnFLC2 on linkage group A02 was identified in the confidence interval of the major QTL for shoot length in the spring sown and a minor QTL for begin of flowering and shoot length in the autumn sown environment. Furthermore, a copy of candidate gene FT (Bn.C6.FT.b) on linkage group C06 was identified in the vicinity of a major QTL for begin, end and duration of flowering in the autumn sown environment. 


\subsection{Introduction}

Oilseed rape varieties are cultivated in different regions across the world, including Central and Western Europe, Canada, China and other parts of the world. The large adaptation has been achieved by both spring and winter types, enabling genotypes to grow in diverse climates. (Downey 1990). This classification is based on vernalization requirement and not on their level of frost tolerance. However, winter types are generally assumed to have better winter survival (Teutonico et al. 1993). Winter survival is defined by Blum (1988) as "the final integrated plant response to a multitude of stresses involved during and after freezing stress, including both external-physical and biotic stresses.", therefore, even if plants are not winter-killed, they can be affected by freezing temperatures that may damage the leaf, causing reduction in leaf area, delayed growth, and plant debilitation (Sãulescu and Braun 2001). Selection for improved winter hardiness is a difficult task, because many interacting factors can vary greatly among regions causing winterkill at one location but having no impact at other locations. For instance, in the Ukraine, an analysis of data from the last 100 years showed that winterkill was caused by low temperatures in $35 \%$ of cases, by alternate freezing and thawing in $26 \%$ of cases, and by ice encasement in $22 \%$ of years when significant winter damage occurred (Poltarev et al. 1992). Shoot elongation before winter is one of the contributing factor in overwintering of plants which are sown in late summer or begin of autumn. It is shown that promotion of elongation growth leads to consumption of accumulated photosynthetic products, e.g. sugars and loss of frost tolerance (Levitt 1972). Rapacz et al. (2001) stated that decrease in frost tolerance observed in spring type plants was associated with the beginning of elongation growth of petioles and epicotyl and expansion of leaf area. With respect to the genetic basis of mechanisms regulating shoot development in winter type crops, few studies have been conducted. In the model plant Arabidopsis, the growth and development of the plant may be divided into the vegetative phase, the first-inflorescence phase and the second-inflorescence phase (Ratcliffe et al. 1998). These developmental phases are believed to be controlled by a group of flowering time genes comprising gibberellins, vernalization, photoperiod, and autonomous pathways (Ratcliffe et al. 1998, Sung and Amasino 2004). Therefore, understanding genetic mechanism controlling flowering time and vernalization requirement might be valuable to enhance level of winter hardiness in winter oilseed rape. The onset of flowering in plants is a critical life-history trait that 
has been shaped by natural and artificial selection to maximize reproductive success (Amasino 2010). Widespread researches have been launched to dissect genetic structure of flowering time in different growth types of oilseed rape, resulting in a general frame of flowering time pathway and its underlying genes (Ferreira et al. 1995, Long et al. 2007, Lou et al. 2007, Jung and Muller 2010, Luo et al. 2014, Schiessl et al. 2015). It is shown in Arabidopsis that some underlying genes in flowering time pathway contribute to developmental process and frost tolerance. For instance, FLOWERING LOCUS C (FLC) is a key gene in the onset of flowering time that is down regulated by vernalization in winter crops. However, it is shown that FLC binds to 505 DNA sites, mostly located in the promoter regions of genes, FLC targets are involved in developmental pathways throughout the life history of the plant, many of which are associated with reproductive development (Deng et al. 2011). Flowering-time gene SUPPRESSOR OF OVEREXPRESSION OF CONSTANS1 (SOCl) negatively regulates the expression of the cold induced genes $C B F \mathrm{~s}$ in Arabidopsis thaliana. As a results, overexpression of cold-inducible $C B F s$ caused late flowering through increased expression of $F L C$, an upstream negative regulator of SOC1. In B. napus correlation between floral related genes and the economic traits oil content and grain yield are questioned in natural or bi parental populations. It was suggested that selection of genes involved in post-transcriptional and epigenetic regulation of flowering time may play a potential role in adaptation of $B$. napus to highly divergent environments (Schiessl et al. 2015). However, due to complex network of flowering time function, gene effects are not stable over different environments and grain yield might not be increased with regard to flowering genes (Schiessl et al. 2015).

Correlation between flowering time and oil content in oilseed rape is contradictory and it varies greatly between populations. In a RIL population of B. napus, negative correlation was found ( $\mathrm{r}=$ -0.32) between oil content and days to flowering (Chen et al. 2010). In contrast, Javed et al. (2016) reported a positive phenotypic correlation $\left(\mathrm{r}=0.30^{* *}\right)$. The magnitude of the correlation was supported by collocation of two late flowering time QTL with QTL for oil, linoleic acid and linolenic acid content. In the present climate conditions with thermal fluctuations and warm winters, flowering time genes and especially vernalization related genes are gaining more importance, because winter oilseed rape has to be able to re-establish frost tolerance if freezing temperature follows after spring-like temperatures during winter. This situation has been observed in Northern Europe. For example, in 2012 following a rather normal winter, extreme 
low temperatures of up to $-25{ }^{\circ} \mathrm{C}$ occurred in February in North Western Germany (https://www.wunderground.com, site visited March 3, 2016). Since at that time crops were not covered by snow, this caused severe frost damage. Also in January 2016 after two weeks above $10{ }^{\circ} \mathrm{C}$ in Dec 2014 , suddenly temperature dropped to $-14{ }^{\circ} \mathrm{C}$ in January that damaged plants with enhanced shoot length (own personal observation). To date, little is known about the genetic basis of shoot elongation before winter and its relation to vernalization requirement, bolting and beginning of flowering in spring. Therefore, a DH population constructed from the two winter oilseed rape cultivars, Sansibar and Oase, was used in this study to investigate the inheritance of shoot elongation before winter and its relation to vernalization requirement, flowering time and seed quality traits. It is anticipated that by the use of the DHSO population whose parents differed in shoot length before winter, QTL mapping could detect quantitative traits loci that are involved in genetic regulation of shoot elongation before winter as a relevant trait for winter hardiness. 


\subsection{Materials and Methods}

\subsubsection{Plant material}

A doubled haploid bi-parental population consisting of 226 inbred lines, derived from a cross between the two winter oilseed rape cultivars Sansibar and Oase. The population was developed from F1-microspore culture technic in the Division of Plant Breeding at Georg-AugustUniversity Göttingen and was named DHSO population (Doubled Haploid of Sansibar and Oase; Teh and Möllers 2016). Both parents were characterized as "double low" quality in Europe and "canola" in Canada, meaning that they have less than $2 \%$ erucic acid in the oil and less than 25

$\mu \mathrm{molg}^{-1}$ glucosinolates in the seed. The two parents differed for shoot elongation before winter in which Sansibar is shorter shoot length before winter and Oase is longer shoot length before winter (See Figure 3.1.1 in Chapter 3).

\subsubsection{Field sown and greenhouse experiments}

The DHSO population and the parental lines were evaluated in field and greenhouse experiments. Field experiments were performed at two different seasons. Those included the normal sowing time at end of August/beginning of September and spring sowing time at end of March/beginning April. Since the greenhouse, autumn and spring sown experiments represented very different environments; they were called mega environments.

\subsubsection{Autumn sown environment}

The DHSO population and its parental inbred lines were sown at four locations in North Western Germany during growing seasons 2012/13 and 2015/16. In 2012/13 the locations were Einbeck (KWS Saat SE), sown on 1 September and Göttingen-Reinshof, sown on 3 September. In 2015/16 the locations were Peine (Limagrain GmbH), sown on 20 August, and GöttingenReinshof, sown on 28 August. Hundred seeds from each line were sown in small field-plots with 
double rows in Peine and Göttingen with $2 \mathrm{~m}$ length, $0.5 \mathrm{~m}$ space between plots and plant-toplant distance was $10 \mathrm{~cm}$. In Einbeck seeds were sown as one row with $3 \mathrm{~m}$ length and $8 \mathrm{~cm}$ space where plant-to-plant distance was $6 \mathrm{~cm}$. Three to four months after sowing, five representative plants were selected and harvested by cutting the stem below the root neck (crown). Harvesting time in 2012/13 for Einbeck and Göttingen were 5 and 8 January 2013, respectively and in 2015/16 for Peine and Göttingen were 30 November 2015 and 11 January 2016, respectively. Shoot length from root neck to apex and shoot diameter at the root neck were measured using a slide gauge and a metering rule and they were called shoot length and shoot diameter before winter. Additionally, mean data for begin of flowering, end of flowering, duration of flowering and plant height at end of flowering were kindly provided by Lishia Teh (Teh and Möllers 2016) for field experiments performed in 7 environments from 2011 and 2012.

\subsubsection{Spring sown environment}

The DHSO population and its parental inbred lines were sown at four spring sown locations in North Western Germany. Three locations were Göttingen-Reinshof sown on 19 April 2013, 30 April 2013 and 20 March 2014. The fourth experiment was in Einbeck (KWS Saat AG), sown on 4 April 2014. All plants were grown by sowing 100 seeds in $2 \mathrm{~m}$ long double rows and $50 \mathrm{~cm}$ space between plots and $10 \mathrm{~cm}$ between plants in the same row in Göttingen and $3 \mathrm{~m}$ single row and $80 \mathrm{~cm}$ space between plots and plant to plant distance was $6 \mathrm{~cm}$ in Einbeck. Three to four months after sowing (Göttingen 18.07.2013, 7/8.08.2013, 02/03.07.2014; Einbeck 25/26.06.2014), seven representative plants were selected and harvested by cutting the stem below the root neck (crown). Shoot length from root neck to apex and shoot diameter, at the root neck, were measured using metering rule and slide gauge. Tendency to form inflorescence was scored as $100 \%$ for visible buds or flower and $0 \%$ for lack of buds for each of the seven plants.

\subsubsection{Greenhouse environment}

The DHSO population and its parental lines were sown in 96-multipot trays, in compost soil. Four seeds, with one seed in each slot, were sown for each genotype. Three independent experiments were performed in non vernalization treatment. DH lines were sown on 5 October, 
18 October and 6 November 2012 and were kept constantly in the greenhouse at around $20{ }^{\circ} \mathrm{C}$ without vernalization treatment. The three experiments were respectively harvested on 18 January, 30 January and 11 February 2013 and four plants per genotype were harvested by cutting the stem below the root neck (crown). Shoot length from root neck to apex and shoot diameter at the root neck were measured using metering rule and slide gauge.

\subsubsection{Seed quality traits}

Data for six quality seed traits including oil content, protein of the defatted meal, oleic acid, linoleic acid and linoleic acid was kindly provided by Lishia Teh (Teh and Möllers 2016) to calculate Spearman's rank correlation between the seed quality traits and the studied traits in three mega environments.

\subsubsection{Linkage map}

Linkage map was constructed by Teh and Möllers (2016) using MAPMAKER/EXP 3.0 (Lincoln et al. 1992). The linkage map for the DHSO population has 1642 markers mapped to 23 linkage groups and covered $2350.2 \mathrm{cM}$ of linkage map with a mean interval distance of $2.0 \mathrm{cM}$ between markers (Table 5.1). The 23 linkage groups represented 19 chromosomes from A01 to C09 in B napus, additional four linkage groups (A08-II, C02-II, C0-II, and C04-II) were formed due to loose or no linkage to their main linkage groups. The map has an average density of 0.70 marker per $\mathrm{cM}$ with distribution of markers varied from 0.20 to 1.37 marker/cM across the linkage groups. The A genome comprised more markers (987) as compared to the $\mathrm{C}$ genome (655), with a mean interval distance between markers of $1.6 \mathrm{cM}$ in the $\mathrm{A}$ genome and $2.4 \mathrm{cM}$ in the $\mathrm{C}$ genome. The number of markers mapped in an individual linkage group ranged from 7 (A08-II) to 164 (C07). Also pairwise recombination and LOD scores indicted that markers were well allocated to linkage groups based on LOD and recombination frequency (Figure 5.1). For QTL mapping, a subset of 317 markers were manually selected from the high-fidelity markers with an average density about 1 marker per $7.4 \mathrm{cM}$. (Figure 5.2 and Figure 5.3). The term framework map was used to refer to the map used for QTL mapping. 
Table 5.1: Marker distribution, size and marker density between markers of each linkage group in the linkage map of DHSO population. (data taken from Teh and Möllers 2016)

\begin{tabular}{|c|c|c|c|c|c|c|c|c|c|c|}
\hline \multirow{2}{*}{$\begin{array}{l}\text { Linkag } \\
\text { e group }\end{array}$} & \multicolumn{8}{|c|}{ No. of markers per linkage group } & \multirow[b]{2}{*}{$\begin{array}{l}\text { Size } \\
(\mathrm{cM})\end{array}$} & \multirow{2}{*}{$\begin{array}{c}\text { Mark } \\
\text { er } \\
\text { Densi } \\
\text { ty }\left(\mathrm{cM}^{-}\right. \\
\left.{ }^{1}\right)\end{array}$} \\
\hline & $\begin{array}{l}\text { AFL } \\
\mathrm{P}\end{array}$ & $\mathrm{CG}^{a}$ & $\begin{array}{l}\text { DAR } \\
\mathrm{T}\end{array}$ & $\begin{array}{l}\text { KAS } \\
\mathrm{P}\end{array}$ & $\begin{array}{r}\text { Silico } \\
\text {-DART }\end{array}$ & SNP & SSR & Total & & \\
\hline A01 & 2 & & 6 & 1 & 58 & 4 & 4 & 75 & 98 & 0.77 \\
\hline A02 & 3 & & 5 & & 26 & 3 & & 37 & 40.7 & 0.91 \\
\hline A03 & 7 & & 19 & 3 & 107 & 15 & 1 & 152 & 224.1 & 0.68 \\
\hline A04 & 2 & & 14 & & 84 & 5 & 2 & 107 & 194.2 & 0.55 \\
\hline A05 & 2 & & 7 & 2 & 63 & 5 & 3 & 82 & 163.8 & 0.5 \\
\hline A06 & 4 & & 18 & 2 & 95 & 5 & & 124 & 128 & 0.97 \\
\hline A07 & 1 & 3 & 9 & 2 & 134 & 15 & & 164 & 133.7 & 1.23 \\
\hline A08 & 2 & & 9 & 1 & 31 & 2 & & 45 & 37.8 & 1.19 \\
\hline A08-II & & & 1 & & 6 & & & 7 & 9.7 & 0.72 \\
\hline A09 & 3 & & 8 & 2 & 49 & 2 & 1 & 65 & 130.2 & 0.5 \\
\hline A10 & 8 & & 11 & & 107 & 3 & & 129 & $94 . .1$ & 1.37 \\
\hline $\mathrm{C} 01$ & & & 4 & & 24 & 4 & 2 & 34 & 77.5 & 0.44 \\
\hline $\mathrm{C} 02$ & & & 1 & 1 & 11 & 1 & & 14 & 48.2 & 0.29 \\
\hline C02-II & 1 & & 1 & & 16 & 1 & 1 & 20 & 97.9 & 0.2 \\
\hline $\mathrm{C} 03$ & 2 & & 5 & 2 & 72 & 3 & & 84 & 111.3 & 0.75 \\
\hline C03-II & 3 & & 5 & 1 & 45 & 6 & 1 & 61 & 134.8 & 0.45 \\
\hline $\mathrm{C} 04$ & & & 1 & & 19 & 2 & 2 & 24 & 79.5 & 0.3 \\
\hline C04-II & 5 & & 3 & 4 & 75 & 6 & & 93 & 101 & 0.92 \\
\hline $\mathrm{C} 05$ & 2 & & 1 & 1 & 45 & 4 & & 53 & 92.1 & 0.58 \\
\hline C06 & 2 & & 5 & 1 & 49 & 7 & & 64 & 95.2 & 0.67 \\
\hline $\mathrm{C} 07$ & 8 & & 8 & 2 & 91 & 7 & 5 & 121 & 142.4 & 0.85 \\
\hline $\mathrm{C} 08$ & 4 & & & & 27 & 2 & & 33 & 52.5 & 0.63 \\
\hline C09 & 1 & 1 & 3 & & 44 & 4 & 1 & 54 & 63.5 & 0.85 \\
\hline $\begin{array}{c}\mathrm{A} \\
\text { genome }\end{array}$ & 34 & 3 & 107 & 13 & 760 & 59 & 11 & 987 & $\begin{array}{c}1254 . \\
3\end{array}$ & 0.79 \\
\hline $\begin{array}{c}\mathrm{C} \\
\text { Genome }\end{array}$ & 28 & 1 & 37 & 12 & 518 & 47 & 12 & 655 & $\begin{array}{c}1095 . \\
9\end{array}$ & 0.60 \\
\hline $\begin{array}{l}\text { Whole } \\
\text { Genome }\end{array}$ & 62 & 4 & 144 & 25 & 1278 & 106 & 23 & 1642 & $\begin{array}{c}2350 . \\
2\end{array}$ & 0.7 \\
\hline
\end{tabular}


${ }^{a}$ : Candidate Gene-based markers for phytosterol biosynthesis.

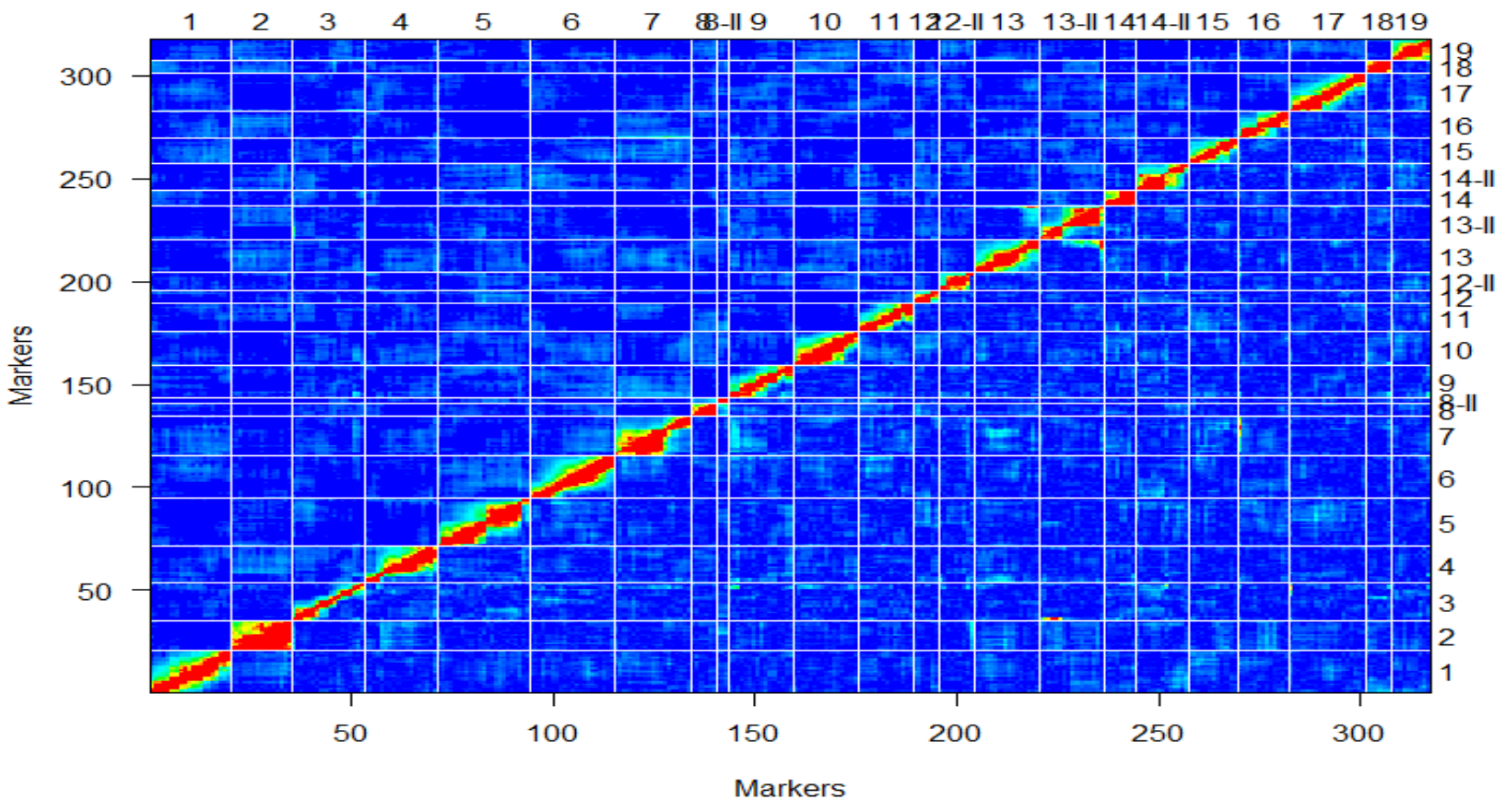

Figure 5.1: Estimated recombination fractions (upper left) and LOD scores (Lower right) for all pairs of markers in the DHSO population. Dark red indicates pairs of markers that appear to be tightly linked (very low recombination), dark blue indicates pairs that are not completely linked (very high recombination). Green points (combination of red and blue points) indicated marker's pairs ranging from very high recombination to very low recombination. 


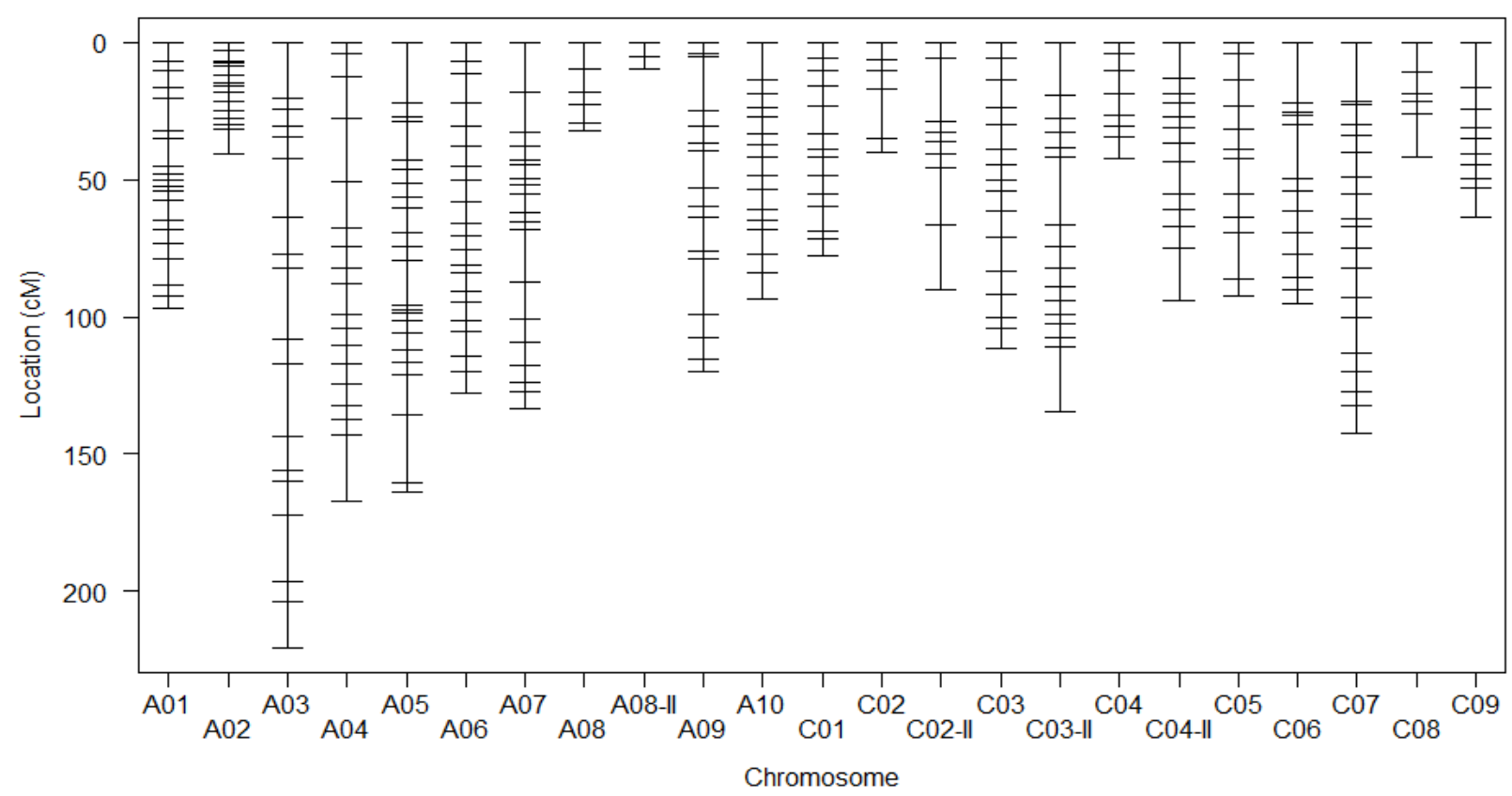

Figure 5.2: Genetic framework map of the DHSO population, with average density 1 marker per $7.4 \mathrm{cM}$

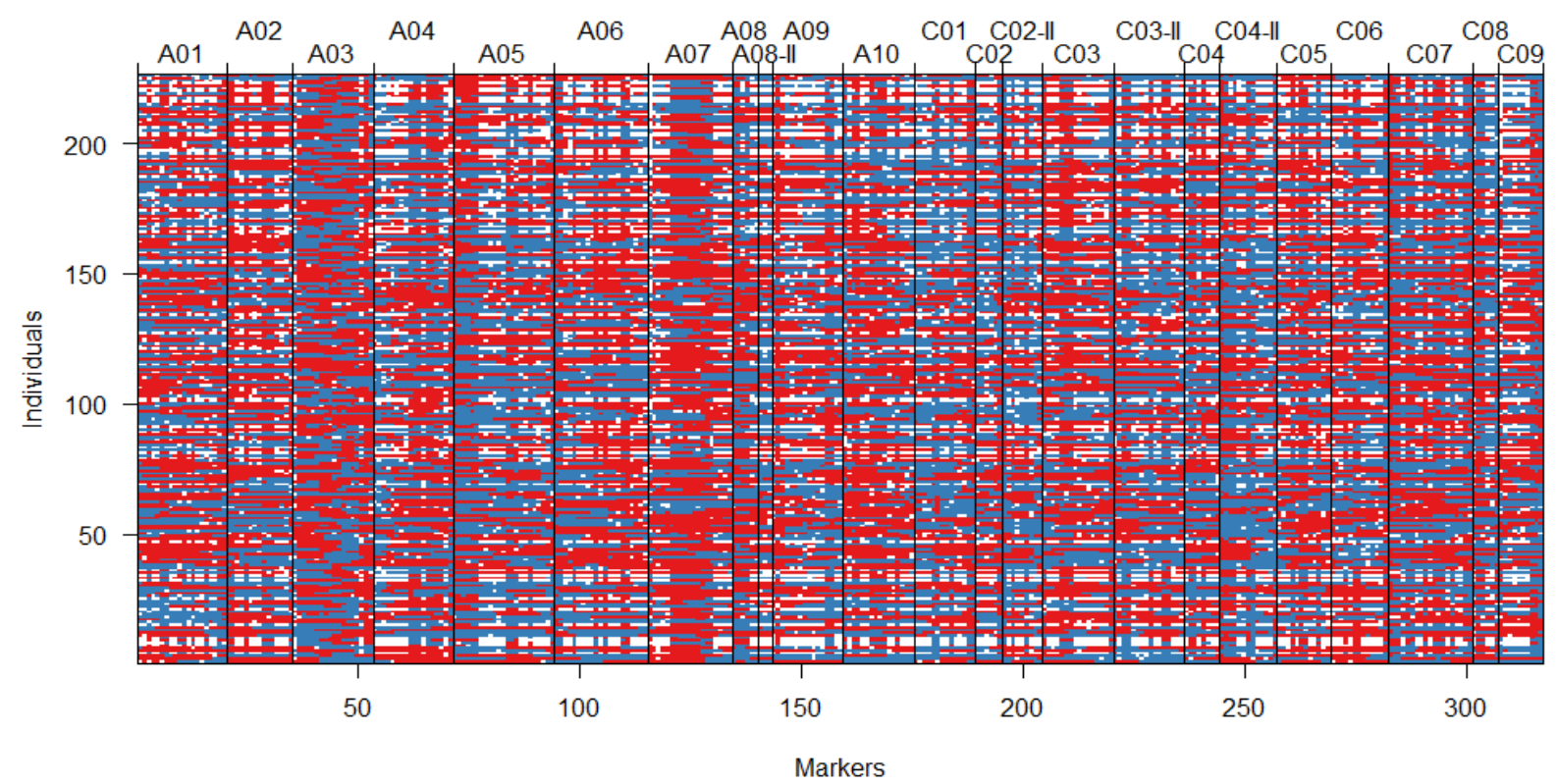

Figure 5.3: Genotype data for the DHSO population. Red and blue pixels correspond to alleles coming from Sansibar and Oase, respectively. White pixels indicate missing genotype data. 


\subsubsection{Statistical analysis}

Analysis of variance, descriptive statistic, frequency distribution and Spearman's rank correlation analysis were performed for the studied traits in the DHSO population as described for the DHLE population in section 4.3.5 in Chapter 4.

\subsubsection{QTL mapping and Identification of candidate genes}

QTL mapping and identification of candidate genes in the vicinity of major QTL for the some traits of interest were performed as described in section 4.3.6 in Chapter 4. 


\subsection{Results}

\subsubsection{Phenotypic analysis}

Analysis of variance represented highly significant genotypic effects for all traits recorded in the three mega environments: autumn sown, spring sown and greenhouse (Table 5.2.1). Furthermore, the variance components of the experiment (E) and interaction between genotype and experiment $(\mathrm{G} \times \mathrm{E})$ were significant and larger than genotypic variance for some traits in the three environment. Estimation of broad sense heritability classified traits in two groups. First group consisted of traits with high heritability ranging from 70 to $91 \%$ including plant height at end of flowering, begin and duration of flowering in the autumn sown environment, shoot length in the spring sown and greenhouse environment. Second group consisted of traits with weak to medium heritability ranging from 18 to $62 \%$ including shoot length, shoot diameter and end of flowering in the autumn sown experiments, shoot diameter in the spring sown and greenhouse environment. 
Table 5.2.1: Variance components and heritability of the DHSO population in the three mega environments.

\begin{tabular}{|c|c|c|c|c|c|}
\hline \multirow{2}{*}{ Environment } & \multirow{2}{*}{ Trait } & \multicolumn{3}{|c|}{ Variance components } & \multirow{2}{*}{$\begin{array}{l}\text { Heritability } \\
(\%)\end{array}$} \\
\hline & & Genotype (G) & Experiment (E) & $\mathrm{G} \times \mathrm{E}$ & \\
\hline \multirow[t]{6}{*}{ Autumn sown } & Shoot length ${ }^{a}$ & $14.7^{* *}$ & $202.7^{* *}$ & $65.65^{* *}$ & 46 \\
\hline & Shoot diameter ${ }^{a}$ & $0.22^{* *}$ & $0.067^{* *}$ & $2.59^{* *}$ & 18 \\
\hline & $\mathrm{BOF}$ & $4.1^{* *}$ & $259.4^{* *}$ & $3.5^{*}$ & 86 \\
\hline & EOF & $1.77^{* *}$ & $93.9^{* *}$ & $4.37^{* *}$ & 62 \\
\hline & DOF & $3.7^{* *}$ & $4.4^{* *}$ & $24.6^{* *}$ & 78 \\
\hline & $\begin{array}{l}\text { Plant height at } \\
\text { EOF }^{a}\end{array}$ & $82.4^{* *}$ & $162.9^{* *}$ & $54.9^{*}$ & 86 \\
\hline \multirow[t]{3}{*}{ Spring sown } & Shoot length ${ }^{a}$ & $898.1^{* *}$ & $257.8^{*}$ & $355.1^{*}$ & 90 \\
\hline & Shoot diameter ${ }^{a}$ & $2.68^{* *}$ & $12.4^{* *}$ & $10.9^{* *}$ & 43 \\
\hline & Buds $^{b}$ & $0.11^{* *}$ & $0.07^{*}$ & 0.06 & 87 \\
\hline \multirow{2}{*}{$\begin{array}{l}\text { Greenhouse } \\
0 \text { week } \\
\text { vernalization }\end{array}$} & Shoot length ${ }^{a}$ & $171.8^{* *}$ & $62.1 * *$ & $191.2^{* *}$ & 69 \\
\hline & Shoot diameter ${ }^{a}$ & $0.08^{* *}$ & $0.07^{* *}$ & $0.20^{* *}$ & 43 \\
\hline
\end{tabular}


In the autumn sown environment, parental differences for shoot length before winter, begin of flowering and end of flowering were significant and more pronounced than other traits (Table 5.3.1). Oase showed significant higher values for shoot length before winter and begin and end of flowering were almost four days earlier. Large phenotypic variation with normal or nearnormal distributions were found for shoot length before winter, shoot diameter before winter, begin, end and duration of flowering and plant height at end of flowering (Figure 5.4.1). Furthermore, transgressive segregation was observed for all the traits with extreme values at both ends of the distributions exceeding the mean values of both parents.

Table 5.3.1: Descriptive statistics of the parents and the DHSO population in the autumn sown environment

Parents

Doubled haploid population $(n=226)$

$\begin{array}{llll} & \text { Sansibar } & \text { Oase } \\ \text { Environment } & \text { Trait } & \end{array}$

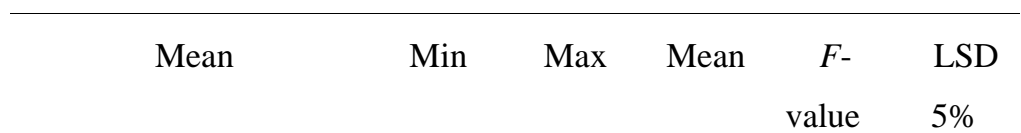

\begin{tabular}{|c|c|c|c|c|c|c|c|c|}
\hline \multirow[t]{6}{*}{ Autumn sown } & Shoot length $^{a}$ & 29 & 40 & 9 & 58 & 31 & $1.9^{* *}$ & 9.8 \\
\hline & Shoot diameter ${ }^{a}$ & 10 & 11 & 8 & 14 & 11 & $1.2^{* *}$ & 2.9 \\
\hline & BOF (days) & 128.4 & 124.4 & 120 & 130.6 & 125.4 & $7^{* *}$ & 2.3 \\
\hline & EOF(days) & 141 & 137.5 & 135.8 & 144.8 & 141 & $2.6^{* *}$ & 2.9 \\
\hline & DOF(days) & 26 & 26.5 & 25 & 34.5 & 29 & $4.4^{*}$ & 3 \\
\hline & Plant height at $\mathrm{EOF}^{a}$ & 1375 & 1425 & 950 & 1550 & 1337 & $7^{* *}$ & 100 \\
\hline
\end{tabular}

\footnotetext{
* and ${ }^{* *}$ denote significance at $\mathrm{P}<0.05$ and $\mathrm{P}<0.01$, respectively.

${ }^{a}$ and ${ }^{b}$ denote millimeter $(\mathrm{mm})$ and percentage $(\%)$, respectively.

LSD5\%: least significant difference at level of $\mathrm{P}<0.05$

BOF: begin of flowering (from first of January)

EOF: end of flowering (from firs of January)

DOF: duration of flowering
} 


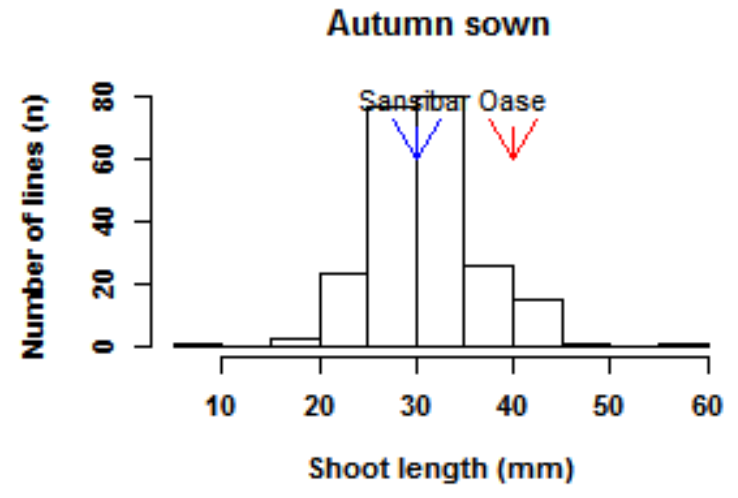

Autumn sown

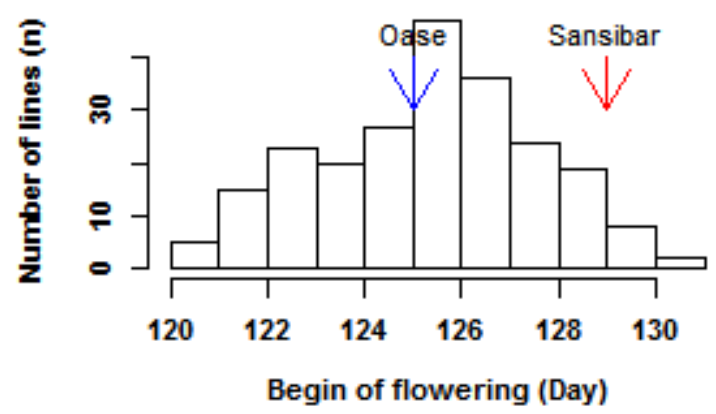

Autumn sown

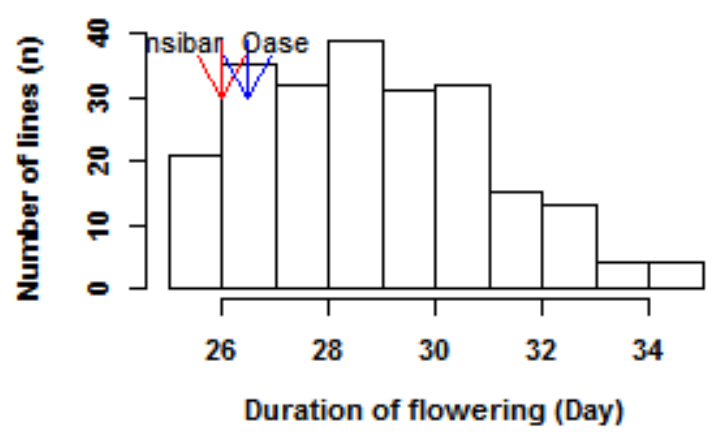

Autumn sown

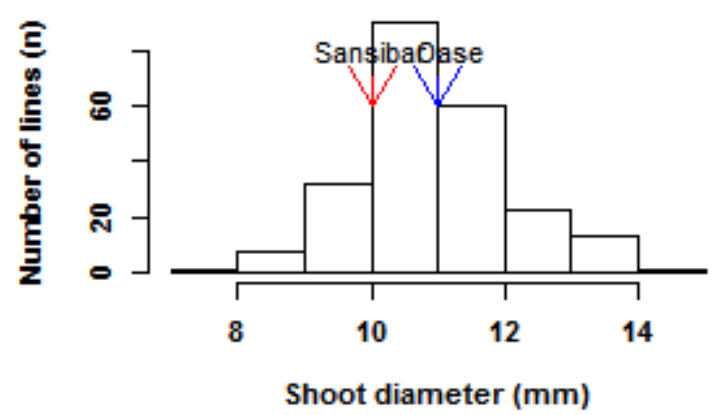

Autumn sown

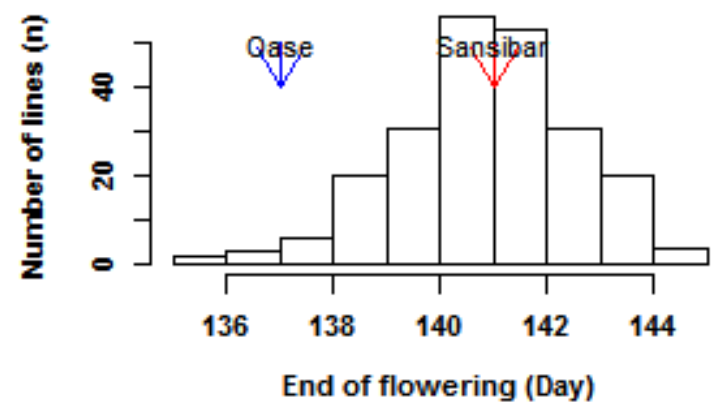

Autumn sown

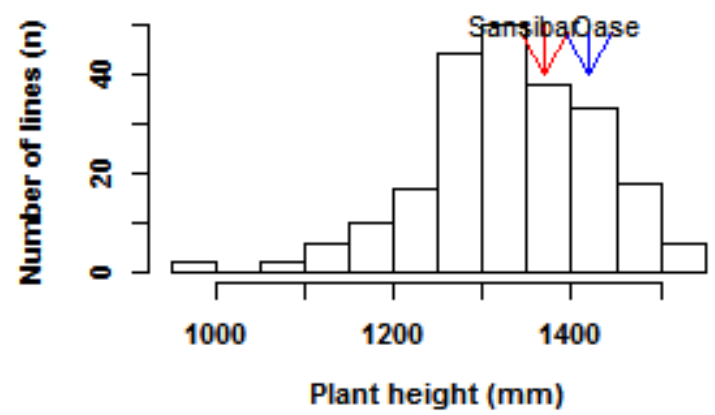

Figure 5.4.1: Frequency distribution of shoot length, shoot diameter, begin of flowering, end of flowering, duration of flowering and plant height at end of flowering in the autumn sown environment in the DHSO population. Parental mean values are indicated by arrows 
In the spring sown environment, large phenotypic variation was observed for shoot length which ranged from $209 \mathrm{~mm}$ to $1238 \mathrm{~mm}$, resulting in a bimodal distribution (Table 5.3.2 and Figure 5.4.2).The bimodal frequency distribution suggested involvement of one major gene in inheritance of this trait. Parent Sansibar was with $721 \mathrm{~mm}$ shoot length significantly longer than Oase with $442 \mathrm{~mm}$ shoot length. Visible buds was second trait with the bimodal distribution and the number of DH lines with 100\% visible buds were almost 4 times as many as number of DH lines with no visible buds, representing low vernalization requirement in majority DH lines. The two parents Sansibar and Oase showed almost the same values for buds percentage (Table 5.3.2). Comparison of frequency distributions between shoot length and visible buds indicated that shoot length in the spring sown environment was correlated to the appearance of buds and only 9\% of the DH lines (25 lines out of 226), whose shoot length was less than $300 \mathrm{~mm}$, didn't show any visible buds across the spring sown experiments.

In the greenhouse environment, in which genotypes were treated under non-vernalized conditions, normal frequency distribution was found for shoot length which ranged from 26 to $148 \mathrm{~mm}$ and ranged from 16 to $34 \mathrm{~mm}$ for shoot diameter (Figure 5.4.2). Parent Sansibar was shorter and thinner for shoot compared to Oase, however the difference was not significant (Table 5.3.2). Comparing the parental performance in the three mega environments showed that parent Oase was longer than Sansibar before winter and in the greenhouse, while it became shorter than Sansibar in spring. To find out the strange performance of parents the two parents were incubated under four and eight weeks vernalization conditions in the greenhouse environment. Results illustrated parent Oase was longer and had 3 days earlier begin of flowering under the eight weeks vernalization conditions, in contrast Sansibar was longer under four weeks vernalization treatment (data are not shown). The results confirmed that Sansibar has longer shoot length in the non-complete vernalization conditions i.e., spring sown and greenhouse environment with four weeks vernalization treatment 
Table 5.3.2: Descriptive statistics of the parents and the DHSO population $(n=226)$ in spring and greenhouse

Parents

Doubled haploid population $(\mathrm{N}=226)$

Environment
Trait


Spring sown

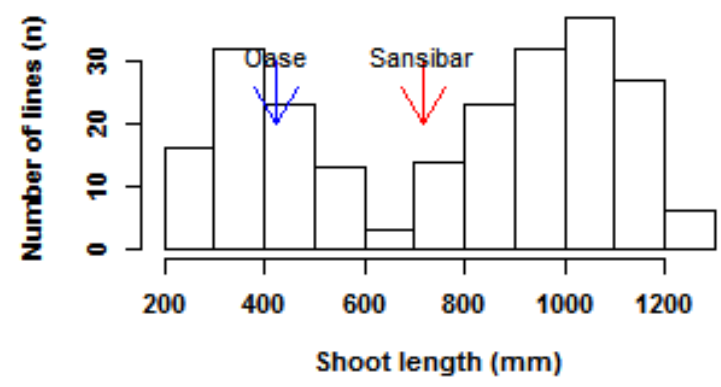

Spring sown

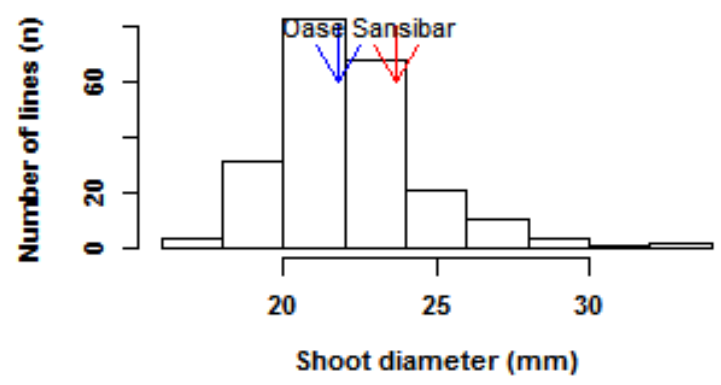

Greenhouse

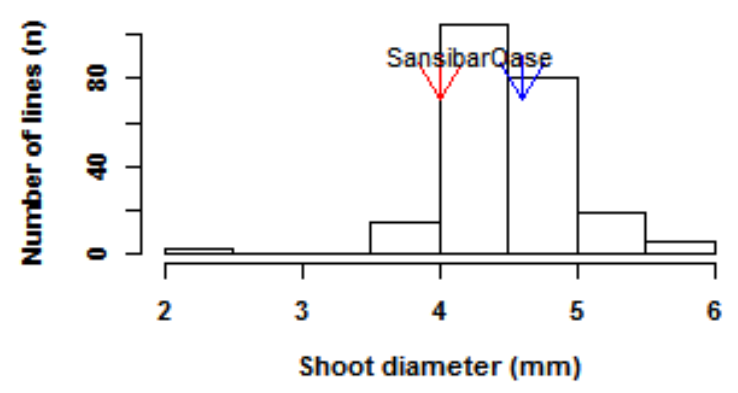

Spring sown

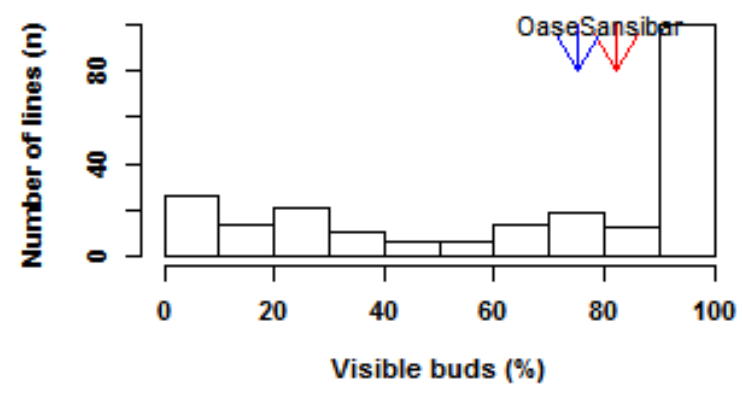

Greenhouse

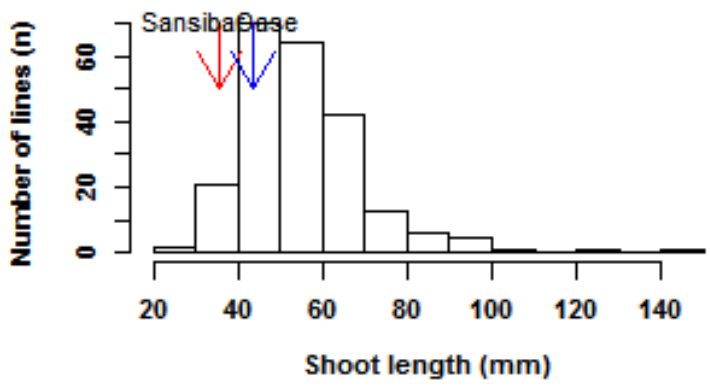

Figure 5.4.2: Frequency distribution of shoot length, visible buds and shoot diameter in the spring sown environment and shoot length, shoot diameter in the greenhouse environment in the DHSO population. Parental mean values are indicated by arrows 


\subsubsection{Correlation Analysis}

Correlations ranging from -0.07 to 0.90 were found for the studied traits in three different environments (Table 5.4.1). Shoot length before winter was positively correlated with shoot length in the spring sown $\left(\mathrm{r}_{s}=0.31^{* *}\right)$ and greenhouse environment $\left(\mathrm{r}_{s}=0.32^{* *}\right)$. Shoot length in the spring sown environment was positively correlated with the presence of visible buds $\left(\mathrm{r}_{s}=0.90^{* * *}\right)$, duration of flowering in autumn sown $\left(\mathrm{r}_{s}=0.46^{* *}\right)$ and shoot length of non-vernalized plants in the greenhouse environment $\left(\mathrm{r}_{s}=0.42^{* *}\right)$. Begin of flowering was negatively correlated with shoot length before winter $\left(\mathrm{r}_{s}=-0.29^{* * *}\right)$ and shoot length in the spring sown experiments $\left(\mathrm{r}_{s}=-0.52^{* *}\right)$ but had positive correlation with plant height at end of flowering $\left(\mathrm{r}_{s}=0.62^{* *}\right)$. Highly significant correlations were found among flowering time traits in which begin of flowering was highly positive correlated with end of flowering $\left(\mathrm{r}_{s}=0.93^{* *}\right)$ and negatively with duration of flowering $\left(\mathrm{r}_{s}=-0.91^{* *}\right)$. 
Table 5.4.1: Spearman's rank correlation of the studied traits in the DHSO population $(n=226)$

\begin{tabular}{|c|c|c|c|c|c|c|c|c|c|c|c|}
\hline \multirow{2}{*}{ Environment } & \multirow{2}{*}{ Trait } & \multicolumn{4}{|c|}{ Autumn sown } & \multicolumn{5}{|c|}{ Spring sown } & \multirow{2}{*}{$\begin{array}{l}\text { Greenhou } \\
\text { SL }\end{array}$} \\
\hline & & SL & $\mathrm{SD}$ & $\mathrm{BOF}$ & EOF & DOF & $\mathrm{PH}$ & SL & $\mathrm{SD}$ & Buds & \\
\hline \multicolumn{12}{|l|}{ Autumn sown } \\
\hline & SD & 0.13 & 1 & & & & & & & & \\
\hline & $\mathrm{BOF}$ & $-0.29^{* *}$ & -0.1 & 1 & & & & & & & \\
\hline & $\mathrm{EOF}$ & -0.19 & -0.07 & $0.93^{* *}$ & 1 & & & & & & \\
\hline & DOF & $0.31^{* *}$ & 0.16 & $-0.91^{* *}$ & $-0.74^{* *}$ & 1 & & & & & \\
\hline & $\mathrm{PH}$ & -0.08 & -0.05 & $0.62^{* *}$ & $0.50^{* *}$ & $0.60^{* *}$ & 1 & & & & \\
\hline \multirow[t]{3}{*}{ Spring sown } & SL & $0.31^{* *}$ & 0.1 & $-0.52^{* *}$ & $-0.51^{* *}$ & $0.46^{* *}$ & $-0.25^{*}$ & 1 & & & \\
\hline & $\mathrm{SD}$ & -0.2 & $0.26^{*}$ & 0.08 & 0.15 & -0.04 & 0.12 & -0.2 & 1 & & \\
\hline & Buds & $0.26^{*}$ & 0.09 & $-0.51^{* *}$ & $-0.50^{* *}$ & $0.5^{* *}$ & $-0.3^{*}$ & $0.9^{* *}$ & 0.09 & 1 & \\
\hline Greenhouse & SL & $0.32^{* *}$ & 0.12 & -0.17 & -0.12 & $0.23^{*}$ & -0.2 & $0.42^{* *}$ & -0.2 & $0.38^{* *}$ & 1 \\
\hline $\begin{array}{c}0 \text { week } \\
\text { vernalization }\end{array}$ & SD & 0.1 & -0.03 & -0.16 & -0.16 & 0.11 & -0.1 & 0.05 & 0.06 & 0.03 & $-0.3^{* *}$ \\
\hline
\end{tabular}

${ }^{*}$ and $^{* *}$ denote significance at $\mathrm{P}<0.05$ and $\mathrm{P}<0.01$, respectively.

SL: shoot length

BOF: begin of flowering (from first of January)

EOF: end of flowering (from first of January)

SD: shoot diameter

DOF: duration of flowering

PH: plant height at end of flowering 
The studied traits in three different mega environments were either not or only moderately correlated with seed quality traits (Table 5.4.2), suggesting no or little share of a regulatory pathways in the DHSO population. Nevertheless some correlation might be notable such as correlation between plant height and oil content $\left(\mathrm{r}_{s}=0.45^{* *}\right)$ and correlation between duration of flowering and thousand kernel weight $\left(\mathrm{r}_{s}=0.43^{* *}\right)$. Correlation between seed quality traits per se are well shown and discussed by Teh and Möllers (2016). 
Table 5.4.2: Spearman's rank correlation of seed quality traits in the DHSO population $(n=226)$

$$
\text { Autumn sown }
$$

Trait
BOF EOF

0.07

Oil

0.07

0.07

$-0.02$

0.18

0.07

$-0.10$

$-0.06$

$-0.07$

0.13

0.14

0.17

$-0.14$

$-0.15$

0.14

$-0.08$

$-0.11$

0.08

$-0.3^{* *}$

$-0.18$

$0.43^{* *}$

$-0.23^{*}$

$0.42 * *$

$-0.1$

$-0.36^{* *}$

0.27 and ${ }^{* *}$ denote significance at $\mathrm{P}<0.05$ and $\mathrm{P}<0.01$, respectively.

PodM: protein of the defatted meal

C18:1: oleic acid

C18:2: linoleic acid

C18:3: linolenic acid

TKW: Thousand kernel weight
SL: shoot length

SD: shoot diameter

BOF: begin of flowering (from first of January)

EOF: end of flowering (from first of January)

DOF: duration of flowering

PH: plant height at end of flowering
Greenhouse 0 week

vernalization 


\subsubsection{QTL Mapping}

To assess the utility of the DHSO population and linkage map for the genetic analysis of the traits, multiple interval mapping was performed from genotype's mean over the replicated experiments in each mega environment. In total 38 main QTL were detected for 11 traits in the three environments. (Table 5.5.1 and Table 5.5.2). The QTL were distributed over 18 linkage groups as shown in Figure 5.2. Collocation of QTL for different traits was observed more frequently than individual isolated QTL.

\subsubsection{Autumn sown environment}

In the autumn sown environment, 24 main QTL were mapped for shoot length, shoot diameter, begin, end and duration of flowering and plant height at EOD in the DHSO population (Table 5.5.1). Five main QTL identified for shoot length before winter were localized on linkage groups A02, A03, A05, A06 and C05 explaining collectively $23.5 \%$ of the observed variance. QTL WiLen-5 at position $4.1 \mathrm{cM}$ on C05 was the biggest QTL with alleles derived from Oase, contributing $9.4 \%$ to the shoot length variance. For shoot diameter, only one QTL with additive effect of $0.38 \mathrm{~mm}$ and coefficient of determination of $11.1 \%$ was found on linkage group A07. QTL mapping for begin of flowering identified one major QTL at position $27.5 \mathrm{cM}$ on C06 which along with 5 further QTL were distributed on linkage groups A02, A05, A10, C05, C06, and C09, accounting for $71.6 \%$ of the phenotypic variance. Around $65 \%$ of the phenotypic variance for end of flowering was explained by five mapped QTL on linkage groups A02, A03, A10, C06 and C09 with additive effects ranging from 0.3 to 1.04 days. Three and four QTL identified for duration of flowering and plant height at end of flowering were distributed on linkage groups A02, C04, C05, C06 and C09, explaining collectively 54.1 and 34\% of the phenotypic variance. The two QTL mapped to A02 and C06 were identical between plant height and flowering traits with the biggest additive effect for the respective traits. 
Table 5.5.1: QTL mapped for the studied traits in the autumn sown environment in the DHSO population.

\begin{tabular}{|c|c|c|c|c|c|c|c|c|}
\hline Trait & QTL name & $\begin{array}{l}\text { Linkage } \\
\text { group }\end{array}$ & $\begin{array}{l}\text { Position } \\
\text { (cM) }\end{array}$ & $\begin{array}{l}\mathrm{Cl}^{a} \\
(\mathrm{cM})\end{array}$ & LOD & $\begin{array}{l}\text { Additive } \\
\text { effect }^{b}\end{array}$ & $\begin{array}{l}R^{2 c} \\
(\%)\end{array}$ & $\begin{array}{c}T R^{2 d} \\
(\%)\end{array}$ \\
\hline \multirow[t]{5}{*}{ Shoot length ${ }^{d}$} & Wi-Len-1 & $\mathrm{A} 02$ & 18 & $15-25$ & 2.9 & 1.3 & 7 & 23.5 \\
\hline & Wi-Len-2 & A03 & 180 & $\begin{array}{l}176- \\
199\end{array}$ & 2.8 & 1.1 & 3.1 & \\
\hline & Wi-Len-3 & A05 & 46 & $42-51$ & 2.9 & -1.24 & 4 & \\
\hline & Wi-Len-4 & A06 & 60 & $58-68$ & 2.9 & -1.15 & 3 & \\
\hline & Wi-Len-5 & $\mathrm{C} 05$ & 4.1 & $0-13$ & 3.2 & -1.4 & 9.4 & \\
\hline $\begin{array}{c}\text { Shoot } \\
\text { diameter }^{\mathrm{d}}\end{array}$ & Wi-Dim-1 & $\mathrm{A} 07$ & 127 & $\begin{array}{l}124- \\
132\end{array}$ & 5.6 & 0.38 & 11.1 & 11.1 \\
\hline \multirow{6}{*}{$\begin{array}{l}\text { Begin of } \\
\text { flowering }\end{array}$} & Wi-BFlw-1 & A02 & 21 & $17-23$ & 8 & -0.8 & 12.7 & 71.6 \\
\hline & Wi-BFlw-2 & A05 & 126.1 & $\begin{array}{l}121- \\
135\end{array}$ & 4.3 & -0.4 & 5.4 & \\
\hline & Wi-BFlw-3 & A10 & 60.7 & $47-65$ & 3.9 & 0.4 & 3.7 & \\
\hline & Wi-BFlw-4 & $\mathrm{C} 05$ & 13.7 & $6-19$ & 2.8 & 0.28 & 1.8 & \\
\hline & Wi-BFlw-5 & $\mathrm{C} 06$ & 27.5 & $22-30$ & 28.7 & 1.5 & 46.9 & \\
\hline & Wi-BFlw-6 & $\mathrm{C} 09$ & 51.7 & $45-59$ & 3.2 & 0.3 & 2.2 & \\
\hline \multirow{5}{*}{$\begin{array}{c}\text { End of } \\
\text { flowering }\end{array}$} & Wi-EFlw-1 & A02 & 17.3 & $17-22$ & 13.5 & -0.64 & 13 & 64.4 \\
\hline & Wi-BFlw-2 & A03 & 88 & $68-104$ & 3 & 0.3 & 3.1 & \\
\hline & Wi-EFlw-3 & A10 & 53.5 & $48-60$ & 6.6 & 0.43 & 6.3 & \\
\hline & Wi-EFlw-4 & $\mathrm{C} 06$ & 28.5 & $20-30$ & 30.3 & 1.04 & 37.6 & \\
\hline & Wi-EFlw-5 & $\mathrm{C} 09$ & 49.7 & $47-52$ & 3.6 & 0.31 & 3.3 & \\
\hline \multirow{3}{*}{$\begin{array}{l}\text { Duration of } \\
\text { flowering }^{c}\end{array}$} & Wi-DFlw-1 & $\mathrm{A} 02$ & 16.9 & $15-19$ & 11.26 & 1.4 & 13.2 & 54.1 \\
\hline & Wi-DFlw-2 & $\mathrm{C} 05$ & 13.7 & $5.6-22$ & 3.22 & -0.3 & 2.9 & \\
\hline & Wi-DFlw-3 & C06 & 28.5 & $\begin{array}{l}26.7- \\
32\end{array}$ & 32.5 & -1.4 & 38 & \\
\hline \multirow{4}{*}{$\begin{array}{l}\text { Plant height }^{d} \\
\text { at EOD }\end{array}$} & Wi-Het-1 & A02 & 21.3 & $15-24$ & 4.8 & -265 & 7.1 & 34.1 \\
\hline & Wi-Het-2 & $\mathrm{C} 04$ & 19 & $17-23$ & 2.8 & -183 & 3 & \\
\hline & Wi-Het-3 & C06 & 27.5 & $16-32$ & 11.4 & 458 & 20.6 & \\
\hline & Wi-Het-4 & $\mathrm{C} 09$ & 27.2 & $15-30$ & 2.9 & 178 & 3.4 & \\
\hline
\end{tabular}

${ }^{a}$ 1-LOD Confidence interval

${ }^{b}\{+\}$ and $\{-\}$ indicate that the trait value is increased by the allele Sansibar and Oase, respectively.

${ }^{c}$ and ${ }^{d}$ denote days and millimeter for additive effects, respectively.

EOD: end of flowering

${ }^{c} R^{2}$ is the percentage of phenotypic variance explained by each QTL

${ }^{d} T R^{2}$ is the percentage of phenotypic variance explained by all QTL 


\subsubsection{Spring sown environment}

In the spring sown environment, 10 main QTL were mapped for shoot length, visible buds and shoot diameter in the DHSO population (Table 5.5.2). For shoot length Sp-Len-1 on A02 with $R^{2}=70 \%$ along with two minor QTL on A10 and C07 explained $75.7 \%$ of the phenotypic variance which is also reflected by the large and the bimodal frequency distribution for shoot length in the spring sown (Figure 5.4.2). Positive additive effect of Sp-Len-1, indicated that alleles coming from Sansibar had a notable increasing effect of $256 \mathrm{~mm}$ for shoot length which was in compliance with the descriptive statistics of the parents, showing longer plants for Sansibar compared to Oase in the spring sown environment (Table 5.3.1). QTL mapping for shoot diameter revealed three QTL that explained $24.5 \%$ of the phenotypic variance. Negative effect of Sp-Dim-1 mapped on A02 decreased shoot diameter, while alleles coming from Sansibar at position $74.3 \mathrm{cM}$ on A05 and at position $127.2 \mathrm{cM}$ on A07 increased shoot diameter in the spring sown environment. For the appearance of visible buds a major QTL with additive effect of $27 \%$ and coefficient of determination of $70 \%$ was localized on A02 that along with QTL mapped on A10, C06 and C09 together explained 76.1\% of the phenotypic variance.

\subsubsection{Greenhouse environment}

Three main QTL for shoot length and a QTL for shoot diameter in non-vernalized plants were mapped to different linkage groups (Table 5.5.2). Three QTL for shoot length were found on A02, A06 and A07 with additive effects ranging from -5 to $5.23 \mathrm{~mm}$ which together explained $26 \%$ of the phenotypic variance. In total, additive effects of alleles derived from Oase increased shoot length at two positions $61.2 \mathrm{cM}$, on A06, and $77 \mathrm{cM}$ on A07, whereas Sansibar allele increased shoot length in Gh-Len-N1 that might corresponds to the longer plants of Oase compared to Sansibar in the greenhouse experiment (Table 5.3.2). 
Table 5.5.2: QTL mapped for the studied traits in the spring sown and greenhouse environment in the DHSO population.

\begin{tabular}{|c|c|c|c|c|c|c|c|c|c|}
\hline Environment & Trait & QTL name & LG & $\begin{array}{l}\text { Position } \\
\text { (cM) }\end{array}$ & $\begin{array}{c}\mathrm{CI}^{a} \\
(\mathrm{cM})\end{array}$ & LOD & $\begin{array}{l}\text { Additive } \\
\text { effect }^{b}\end{array}$ & $\begin{array}{l}R^{2 c} \\
(\%)\end{array}$ & $T R^{2 d}$ \\
\hline \multirow[t]{10}{*}{ Spring sown } & \multirow[t]{3}{*}{$\begin{array}{l}\text { Shoot } \\
\text { length }^{\mathrm{d}}\end{array}$} & Sp-Len-1 & A02 & 16.9 & $\begin{array}{l}15- \\
17\end{array}$ & 16.9 & 256 & 70 & \multirow[t]{3}{*}{75.7} \\
\hline & & Sp-Len-2 & A10 & 59.7 & $\begin{array}{l}53- \\
64\end{array}$ & 3.26 & -48.1 & 3.1 & \\
\hline & & Sp-Len-3 & $\mathrm{C} 07$ & 93 & $\begin{array}{l}85- \\
96\end{array}$ & 3 & 34.7 & 2.5 & \\
\hline & \multirow{3}{*}{$\begin{array}{c}\text { Shoot } \\
\text { diameter } \\
d\end{array}$} & Sp-Dim-1 & A02 & 15 & $\begin{array}{l}8.7- \\
17\end{array}$ & 3 & -0.5 & 5.1 & \multirow[t]{3}{*}{24.5} \\
\hline & & Sp-Dim-2 & A05 & 74.3 & $\begin{array}{l}66- \\
79\end{array}$ & 3.6 & 0.6 & 5.5 & \\
\hline & & Sp-Dim-3 & A07 & 127.2 & $\begin{array}{l}122- \\
130\end{array}$ & 8.2 & 0.2 & 14 & \\
\hline & \multirow[t]{4}{*}{ Buds $^{c}$} & Sp-Bud-1 & A02 & 16.9 & $\begin{array}{l}16- \\
18\end{array}$ & 18 & 27 & 70 & \multirow[t]{4}{*}{76.1} \\
\hline & & Sp-Bud-2 & A10 & 82 & $\begin{array}{l}77- \\
91\end{array}$ & 2.8 & -0.5 & 2.2 & \\
\hline & & Sp-Bud-3 & $\mathrm{C} 06$ & 29 & $\begin{array}{l}23- \\
37\end{array}$ & 3.4 & -0.5 & 2.1 & \\
\hline & & Sp-Bud-4 & $\mathrm{C} 09$ & 48 & $\begin{array}{l}42- \\
52\end{array}$ & 2.8 & -0.4 & 1.2 & \\
\hline \multirow{4}{*}{$\begin{array}{l}\text { Greenhouse } \\
0 \text { week } \\
\text { vernalization }\end{array}$} & \multirow[t]{3}{*}{$\begin{array}{l}\text { Shoot } \\
\text { length }^{\mathrm{d}}\end{array}$} & Gh-Len-N1 & A02 & 18.3 & $\begin{array}{l}17- \\
20\end{array}$ & 7 & 5.23 & 11.2 & \multirow[t]{3}{*}{26} \\
\hline & & Gh-Len-N2 & A06 & 61.2 & $\begin{array}{l}55- \\
64\end{array}$ & 2.9 & -3.55 & 4.8 & \\
\hline & & Gh-Len-N3 & A07 & 77 & $\begin{array}{l}65- \\
90\end{array}$ & 5 & -5 & 10 & \\
\hline & $\begin{array}{r}\text { Shoot } \\
\underset{d}{\text { diameter }_{d}}\end{array}$ & Gh-Dim-N1 & A10 & 37 & $\begin{array}{l}30- \\
39\end{array}$ & 5.2 & -0.07 & 2.4 & 2.4 \\
\hline
\end{tabular}

${ }^{a} 1$-LOD Confidence interval

${ }^{b}\{+\}$ and $\{-\}$ indicate that the trait value is increased by the allele Sansibar and Oase, respectively.

${ }^{c}$ and ${ }^{d}$ denote percentage and millimeter for additive effects, respectively.

${ }^{c} R^{2}$ is the percentage of phenotypic variance explained by each QTL

${ }^{d} T R^{2}$ is the percentage of phenotypic variance explained by all QTL 


\subsubsection{Identification of candidate genes}

Overlapping of QTL confidence intervals were observed for the studied traits within and between the three mega environments (Table 5.5.1 and Table 5.5.2). A genomic region from 14.6 to $23.6 \mathrm{cM}$ was found on A02 with collocation of QTL for shoot length before winter ,shoot length in the spring and greenhouse environment, second biggest QTL for begin, end and duration of flowering and plant height in the autumn sown environment (Figure 5.5). The sequence of the two flanking Silico DArT markers linked at the position 14.6cM (3091433|F|0) and $23.6 \mathrm{cM}(3080289|\mathrm{~F}|$ 0) were blasted against complete genome sequence of B. napus (http://www.brassicadb.org/brad/) resulting in the roughly $50 \mathrm{kbp}$ interval between physical position of two flanking markers. Searching for flowering genes within the mentioned interval detected the candidate gene BnFLC2 (BnaA02g00370D) in the interval 15.3 to $15.9 \mathrm{cM}$ on A02. In addition, additive effect of the DArT marker 3110832|F|0 linked to BnFLC2 at position 15.9 cM showed that allele derived from Sansibar increased dramatically shoot length in the spring sown environment (Figure 5.6). Apart from A02, the overlapping QTL confidence intervals were observed on C06 between QTL $S p-B u d-3$ and the biggest corresponding QTL for begin, end, duration of flowering and plant height in the autumn sown environment (Figure 5.7). Physical positions of two flanking Silico DArT markers were used to search for relevant flowering time genes within the genomic region from 28542458 to $30304316 \mathrm{bp}$ (22.1 to $29.7 \mathrm{cM}$ ) on linkage group C06. The candidate gene Bn.C6.FTb (BnaC06g27090D) is a copy of FT gene found in the genetic interval 25.1 to $29.7 \mathrm{cM}$ on linkage group C06 that might be the causal gene for respective traits. For shoot length in the greenhouse environment, QTL mapped to A02 and A06 had overlapping confidence intervals with QTL for shoot length before winter which corresponds to moderate correlation between them $\left(\mathrm{r}_{s}=32^{* *}\right)$. 


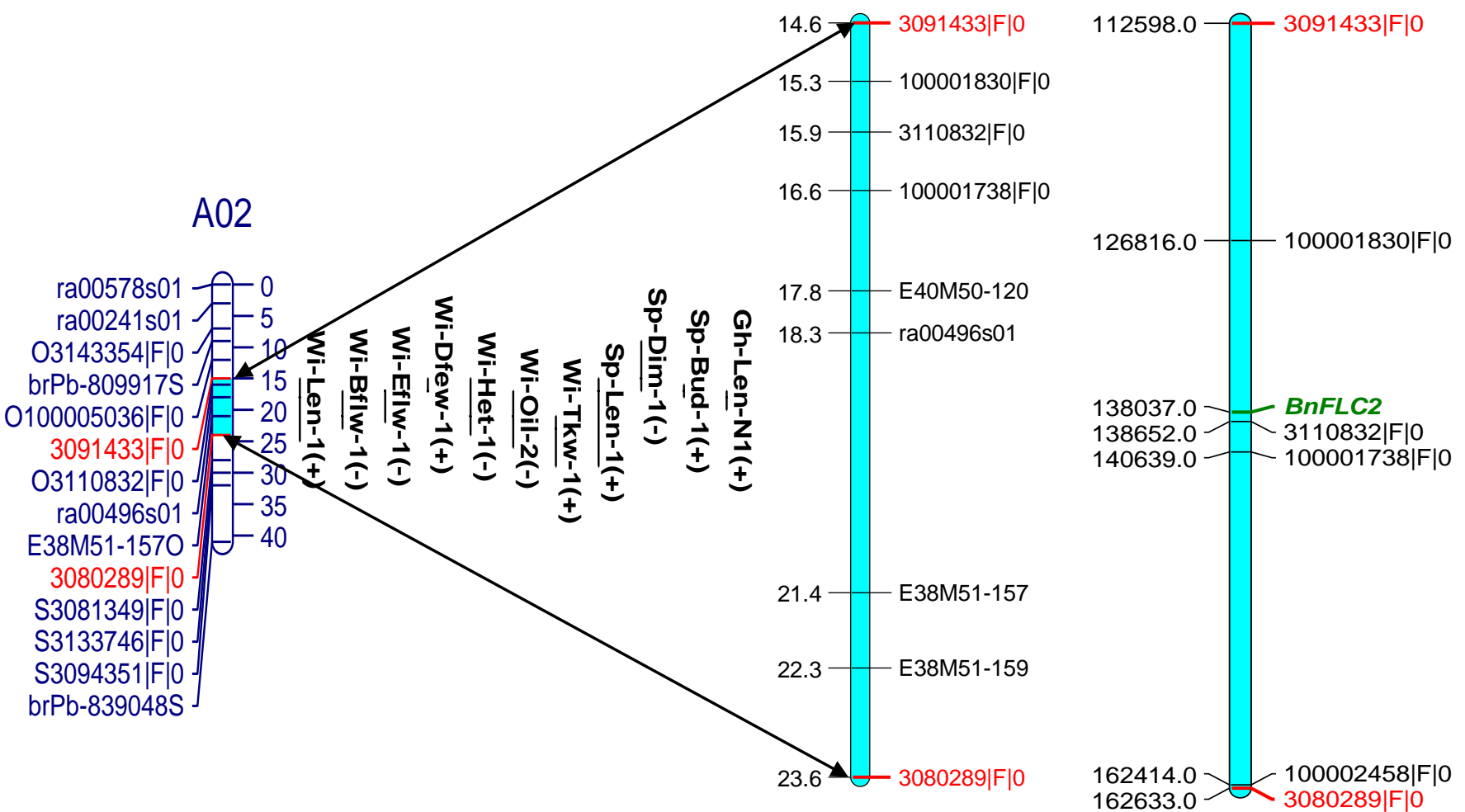

Figure 5.5: Genetic and physical map positions of markers within the QTL genomic region (14.6-23.6 cM) on A02. Left: QTL for shoot length, shoot diameter, begin of flowering, end of flowering, duration of flowering, plant height at end of flowering, percentage of visible buds, oil content and thousand kernel weight in the DHSO population. Middle: Additional markers mapped within the QTL genomic region in full map of the DHSO population Right: The corresponding physical positions of additional markers and the candidate gene (BnFLC2) in B. napus genome

$3110832|\mathrm{~F}| 0$

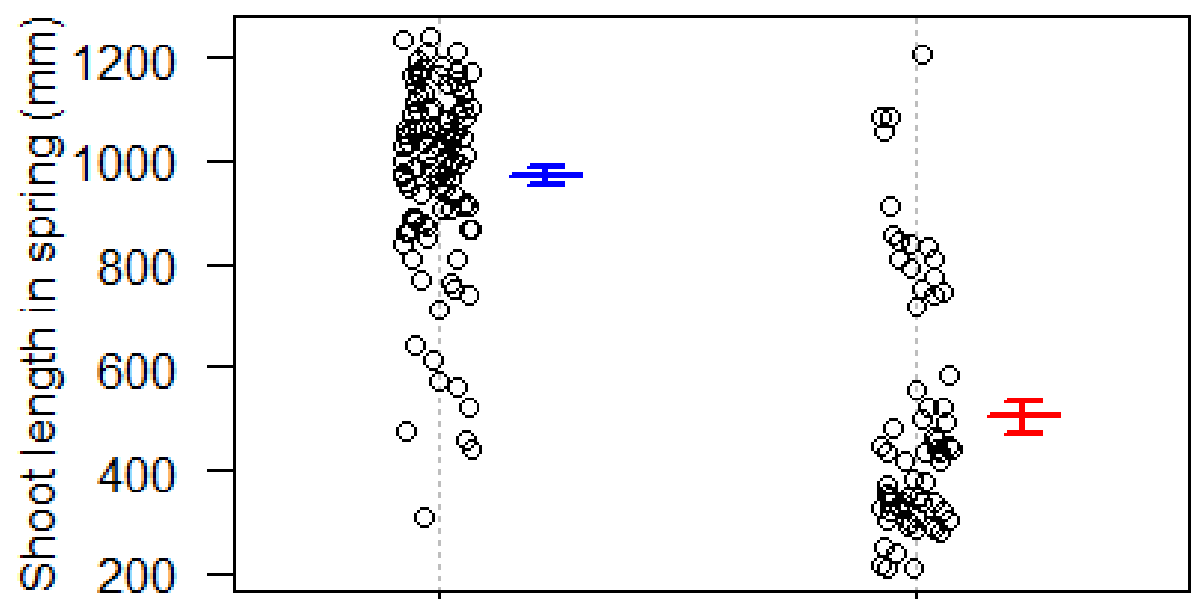

Figure 5.6: Additive effect of flanking marker 3110832|F|0 linked to the major QTL on A02 for the shoot length in the spring sown environment in the DHSO population. Red boxplot shows standard error and lower phenotypic mean and blue boxplot shows standard error and higher phenotypic mean for shoot length in the spring environment. 


\section{Genetic map C06}

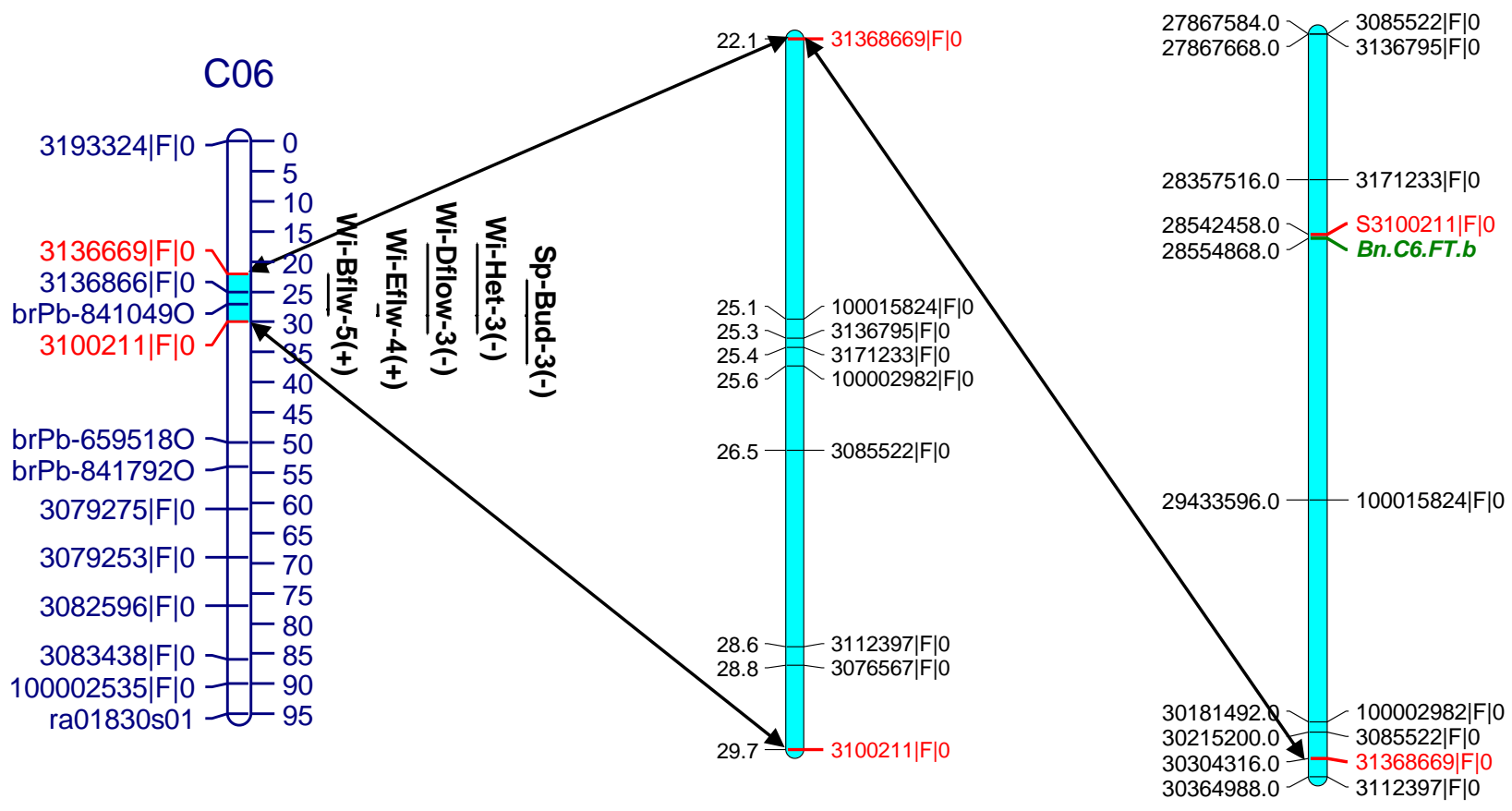

Figure 5.7: Genetic and physical map positions of markers within the QTL genomic region (22.1-29.7 cM) on C06. Left: QTL for begin of flowering, end of flowering, duration of flowering, plant height at end of flowering, percentage of visible buds in the DHSO population. Middle: Additional markers mapped within the QTL genomic region in full map of the DHSO population Right: The corresponding physical positions of additional markers and the candidate gene (Bn.C6.FT.b) in B. napus genome 


\subsection{Discussion}

\subsubsection{Phenotypic analysis}

Successful plant overwintering of oilseed rape depends on plant preparation before winter in two aspects: (1) meteorological conditions for oilseed rape growth during autumn and (2) plant condition (development and chemical composition) in autumn (Balodis et al. 2015). The meteorological conditions are not predictable and they are changing from year to year and location to location. But, plant development before winter can be optimized by breeding to reduce risk of frost damage in regions with freezing temperatures during winter. In the present study the population mean for shoot length and shoot diameter before winter were 31 and $11 \mathrm{~mm}$ that was within the optimum range recommended for successful overwintering (Cramer 1990). However, extreme cold temperature $\left(-22^{\circ} \mathrm{C}\right)$ was experienced in February 2012 in Göttingen (https://www.wunderground.com) which may have caused some frost damage in some genotypes of the DHSO population (Christian Möllers, personal communication). In addition, in growing season 2015-16 following the two warm weeks in December, leading to bud formation and elongation of shoot in some genotypes (own personal observation) suddenly temperature dropped down $-14{ }^{\circ} \mathrm{C}$ and it remained below $-10{ }^{\circ} \mathrm{C}$ for a few days (https://www.wunderground.com). As a result, frost damage was observed in some genotypes in Göttingen and Peine especially for those with enhanced shoot length (data not shown). In alfalfa, it was stated that warm temperatures during cold season causes genotypes to resume growth too early and these genotypes are prone to frost damage if temperature drops again below zero (Hesterman and Durling 1991). In the present study, population mean for shoot length was bigger at two locations Göttingen and Peine in growing season 2015-16 (data are not shown) that might be the reason for frost damage at the two-mentioned location. High heritability for flowering time traits indicated the precision of field trials at four locations and high genotypic stability despite ambient changes. The genetic stability for the flowering time traits is consistently reported by other researchers (Long et al. 2007, Wang et al. 2009, Raman et al. 2013). Comparison of frequency distribution between shoot length and the percentage of visible 
buds in the spring sown environment represented that only $9 \%$ of population didn't show any visible buds, while $65 \%$ of the population showed shoot length longer than $600 \mathrm{~mm}$ and more than $50 \%$ tendency to form inflorescence. Thus, although Sansibar and Oase are winter type cultivars, high tendency to form inflorescence in majority DH lines might be due to spring or semi winter alleles that exists in the parents' genome. The high tendency to form buds in spring sown environment raised up two hypothesis that either vernalization is partially met when night temperatures drop close to zero in March and April in Germany or vernalization competence does not necessarily rely on chilling treatment and just being under long days is enough to resume shoot growth in the $65 \%$ of DH lines. To get an answer, DHSO population was kept under non-vernalizing conditions in the greenhouse with $20{ }^{\circ} \mathrm{C}$ and 16 hours light. Results illustrated although large phenotypic variation was observed for shoot length ranging from 62 to $192 \mathrm{~mm}$, no tendency to form inflorescences was found in the non-vernalization condition, rejecting the assumption that day length alone induces flowering in winter oilseed rape. Waalen et al. (2014) reported that long day conditions don't affect plants that are not fully vernalized. Furthermore it has been found in model crops that vernalization requirement is essential mechanism for vegetative/reproductive transition and promoting reproductive growth in the spring (Kim et al. 2009, Zografos and Sung 2012).

\subsubsection{Correlation analysis}

Rather low correlation $\left(\mathrm{r}_{s}=31^{* *}\right)$ was observed between shoot length before winter and vernalization response determined by shoot length and the percentage of visible buds in the spring sown environment, suggesting that only a certain share of genetic regulation exists between vernalization requirement and shoot length before winter in the DHSO population. The certain share can be seen in wheat, in which genes controlling the development and growth operate in three pathways: vernalization, photoperiod, and earliness per se (Chen et al. 2009). Common genetic pathway between flowering time and vernalization is expected by the negative correlation between shoot length in the spring sown and begin and end of flowering in the autumn sown environment $\left(\mathrm{r}_{s}=-0.52^{* *}\right)$. The genetic analysis of flowering time pathway showed that vernalization and photoperiod are main inputs inducing development of shoot apex and acceleration of flowering in winter crops (Jung and Müller 2009). Weak correlation was found 
between shoot length before winter and shoot length in the greenhouse $\left(\mathrm{r}_{s}=0.32^{* *}\right)$ that means shoot length under natural (field) conditions is modulated by environmental cues that are likely to be absent or only partly relevant under controlled greenhouse conditions (El-Soda et al. 2014).

\subsubsection{QTL Mapping}

To date, no effort has been published regarding the QTL mapping for shoot length before winter in oilseed rape which marks the current study as first report of QTL mapped in association with shoot elongation before winter. We found five QTL that accounted for $23.5 \%$ of the phenotypic variance for this medium heritable trait. The data used for QTL mapping was mean of genotypes across four locations with $46 \%$ genetic variance $\left(h^{2}\right)$ for shoot length before winter, therefore it can be declared that QTL are constitutive QTL with consistent effects across environments. Constitutive QTL are the main targets for breeding programs because such QTL can be used to improve crop performance in all regions where the crop can be grown (El-Soda et al. 2014).

The QTL Wi-Len-1 on A02 overlapped with QTL for flowering time traits and a major QTL for shoot length in the spring sown environment. Positive additive effect of Wi-Len-1 and Sp-Len-1 indicated that allele coming from Sansibar yielded longer shoot length before winter and lower vernalization requirement. Candidate gene BnFLC.A2 was identified in the vicinity of a QTL hotspot on A02 that might be the causal gene affecting the regulation of respective traits in the DHSO population. The MADS box transcription factor gene FLOWERING LOCUS C (FLC) is the key regulator of vernalization requirement and is down-regulated by vernalization, enabling promotion of flowering by FT. In B. napus nine homologues of FLC were identified to six of 19 chromosomes that were relatively conserved in the coding region (Zou et al. 2012). Javed et al. (2016) reported a QTL on A2 that was in the vicinity of a known Brassica vernalization gene FLC explaining 43.2\% of the trait variation. Raman et al. (2013) found QTL associated with flowering time on A02, A03, A07, and C06 which may represent homologues of known flowering time genes in Arabidopsis.

Teh and Möllers (2016) reported two QTL (DE-Oil.2 and E-SW.1) for oil content and thousand kernel weight (TKW) in the DHSO population that coincided with the QTL hotspot on A02 in our study. A positive correlation between oil content and flowering time was supported by 
colocation of two late flowering time QTL with an oil content QTL in a DH population of $B$. napus (Javed et al. 2016). The candidate gene BnFLC2 on A02 may influence oil profile and TKW because of importance of FLC in biochemical pathways. Deng et al. (2011) demonstrated that FLC binds to more than 500 target sites in the Arabidopsis genome, potentially regulating genes involved in vegetative and reproductive pathways throughout the life history of the plant, many of these genes are associated with plant development.

C06 was the second linkage group with a genomic region from 22.1 to $29.7 \mathrm{cM}$ with the biggest QTL for begin and end of flowering in the autumn sown environment and a QTL for visible buds in the spring sown environment with opposite additive effects. No additional QTL for shoot length in the spring sown environment was found at this position. It can be speculated that candidate gene at this position is more related to flowering time and other ambient cues than vernalization. A copy of FLOWERING LOCOUS T (BnC6.FT.b) was identified within the hotspot on C06 in the DHSO population. Wang et al. (2009) reported two FT paralogues (BnA2.FTa and BnC6.FT.b) were associated with two major QTL clusters for flowering time in B. napus. FLOWERING LOCUS T (FT), along with SUPPRESSOR of OVEREXPRESSION of CONSTANS (SOC1) and LEAFY ( $L F Y)$ are the major integrators of flowering time in Arabidopsis thaliana (Bäurle and Dean 2006). FT induces flowering in response to long day and is a direct target of the nuclear protein CONTANS (CO) in leaves ( $\mathrm{Li}$ et al. 2008). It is well known in plants that FT is down regulated by FLC (Jung and Müller 2011), hence it can be speculated that two candidate genes reported on A02 (BnaA02g00370D) and C06 (BnaC06g27090D) are involved in flowering time pathways, in which vernalization is regulated by FLC on A02 and induces begin of flowering by FT on C06.

Overlapping QTL confidence intervals is an advantage when loci with desired alleles are linked, making breeding methods faster for QTL pyramiding but on the other hand, it is a threat when desired and undesired alleles are tightly linked. To conclude the chapter it should be pointed out that low vernalization requirement was observed in the DHSO population and in the parental lines. Furthermore, shoot elongation before winter is mainly regulated by independent genomic regions from flowering time and vernalization requirement and no strong correlation was found between vernalization and shoot elongation before winter. 


\section{Chapter 6}

\section{General discussion}

Long term meteorology data show tendency of winter warming in the regions with cold temperatures during winter, as a consequence of global warming (Intergovernmental Panel on Climate Change IPCC 2007). Despite increasing temperature in the northern hemisphere, nothing changed for the extreme low temperatures that occasionally occur during winter (Imai et al. 2012), for instance, in 2012 after a normal winter in Germany, temperature dropped to $-25{ }^{\circ} \mathrm{C}$, causing frost damage on winter crops (Europe Mars Bulletins 2012). Therefore, breeding for improved winter hardiness is still an important breeding aim in the current winter crop genotypes. Yet, complexity of winter hardiness and the hardship of field test implementation has slown down breeding programs for this goal (Sãulescu and Braun 2001). Plant development before winter and especially shoot elongation before winter, as an important organ for accumulation of essential assimilates, is considered by canola breeders as a relevant trait for the successful overwintering (Schulz 2007). Unfortunately, we did not find any report regarding the genetic variation and genetic regulation of shoot elongation before winter in oilseed rape or other winter crops. It seems that the trait has been neglected by researchers for improved winter hardiness. Therefore, the present study is the first report of genetic variation and inheritance of shoot length before winter in B. napus. The two DH populations and a collection of 19 winter oilseed rape genotypes were tested in replicated field and greenhouse trials in three different environments: autumn and spring sown field experiments and greenhouse trials.

\subsection{Phenotypic analysis}

In the all plant materials, large phenotypic variation with significant genotypic effect was found for shoot length in the autumn sown and spring sown environment. Shoot length before winter ranged from 23 to $66 \mathrm{~mm}$ among 19 winter oilseed genotypes that was relatively the same as the phenotypic variation observed in the two DH populations. This large variation among a small sample of winter oilseed genotypes shows large existing diversity in the genepool of B. napus. 
Segregating populations developed from the oilseed rape material are able to broaden the genetic variation for target traits. For instance, DH lines whose shoot length before winter were $71 \mathrm{~mm}$ in the DHLE populations and DH lines with $9 \mathrm{~mm}$ shoot length before winter in the DHSO population give large variation to select genotypes with desired shoot length for further breeding studies. Population mean for shoot length in the DHLE was $42 \mathrm{~mm}$ that was bigger than the DHSO population with $31 \mathrm{~mm}$. This difference can be due to different sowing time and different growing seasons during implementation of field trials in the two DH populations. Because results of genetic variation in 19 winter oilseed rape genotypes showed that mean for shoot elongation of two parents Sansibar and Oase $(36 \mathrm{~mm})$ was larger than mean of Express617 and L16 (31 $\mathrm{mm})$. The significant genotype $\mathrm{x}$ experiment effect for shoot length before winter becomes visible by the intermediate heritability ranging from 46 to $62 \%$ across the three plant materials.

Tendency to form inflorescence and shoot length in the spring sown environment represented significant variation for vernalization requirement. Results showed same phenotypic variation with high heritability for shoot length in the spring sown environment over the three plant materials. Bimodal or near bimodal frequency distribution was found in the both DH populations suggesting involvement of one or two major genes for shoot length and visible buds in the spring sown environment. The two parents L16 and Express617 showed clear differentiation for vernalization requirement, whereas Sansibar and Oase differed only slightly. Furthermore, among 19 oilseed rape genotypes, the two resynthesized lines were distinguished for strong vernalization requirement while traditional lines and cultivars showed large variation ranging from strong to week vernalization requirement.

Phenotypic variation and population mean for shoot length under the non-vernalized condition in the greenhouse environment was larger in the DHSO population $(55 \mathrm{~mm})$ compared to the DHLE population $(33 \mathrm{~mm})$.

Broad sense heritability was higher than $70 \%$ for beginning of flowering and plant height in the autumn sown environment in the both DH populations. Begin of flowering and plant height are well evaluated in oilseed rape and high heritability often has been reported for them in different breeding materials (Mei et al. 2009, Chen et al. 2010, Javed et al. 2016). Phenotypic variation for beginning of flowering was larger in the DHSO population, while larger phenotypic variation was found for plant height in the DHLE population. We noticed that in the two DH populations magnitude of parental variation for the related traits changed in different mega environments. For 
instance in the DHLE population, shoot length for parent L16 was halved of Express617 (34 mm versus $61 \mathrm{~mm}$ ) in the spring sown environment, but such a large variation was decreased between L16 and Express617 for plant height and begin of flowering in the autumn sown environment (See table 4.3.1). These oscillations are explained by effect of genotype $\mathrm{x}$ environments in phenotypic plasticity that are categorized in five genetic models; Overdominance, Pleiotropy, Epistasis, Epigenesis (El- Soda et al. 2014)

\subsection{Correlation analysis between traits}

Vernalization requirement along with shoot length before winter are involved in the complex architecture of winter hardiness. Hence, correlation between vernalization and shoot length before winter has been one of the main objectives in the three plant materials. Our results indicated that, no strong correlation was found between shoot length before winter and shoot length in the spring sown environment in the three studies. However, weak and medium correlations were found between the two traits in the DHSO population $\left(\mathrm{r}_{\mathrm{s}}=0.31^{* * *}\right)$ and among 19 oilseed genotypes $\left(r_{\mathrm{s}}=0.48^{* * *}\right)$, suggesting certain share of genetic pathway controlling shoot length before winter and vernalization requirement in winter oilseed rape. This changing correlations have also been reported between vernalization requirement and frost tolerance in cereals and oilseed rape (Prásil et al. 2004, Waalen et al. 2014). Begin of flowering showed negative correlation, around $r_{s}=-0.50^{* *}$, with shoot length in the spring environment in the two DH populations. This correlation was expected according to known genetic pathway of flowering time that is down regulated by vernalization genes in oilseed rape (Osborn and Lukens 2003).

\subsection{QTL mapping in the two DH populations}

QTL mapped for same traits in the three environments were compared between the two DH populations (Table 6.1). For shoot length before winter, six main QTL and one epistatic QTL explained $49.2 \%$ of the phenotypic variance in the DHLE population while $23.5 \%$ of the phenotypic variance was explained by five QTL in the DHSO population. Larger phenotypic difference between parent L16 as resynthesized line and parent Express617 could be the main 
reason for higher coefficient of determination for shoot length before winter in the DHLE population. The major QTL for shoot length and the percentage of visible buds in the spring sown experiment were localized on linkage group A02 in the both populations. Likewise, for shoot length in the non-vernalized conditions in the greenhouse environment a QTL on A06 was found in the both $\mathrm{DH}$ populations. For begin of flowering time and plant height in the autumn sown environment a QTL on A02 was found in the both DH populations, However, physical position of flanking markers linked to the mentioned QTL showed that no QTL with similar physical positions were found between the two DH populations, indicating different regulator genes are involved for the trait variation in the two DH populations

Table 6.1: Number of QTL mapped in the DHLE and DHSO for the studied traits in three mega environments.

\begin{tabular}{|c|c|c|c|c|}
\hline Environment & Trait & DHLE & DHSO & Total no. of $\mathrm{QTL}^{a}$ \\
\hline \multirow[t]{4}{*}{ Autumn sown } & Shoot length & 7 & 5 & 12 \\
\hline & Shoot diameter & 2 & 1 & 3 \\
\hline & Begin of flowering & 4 & 6 & 10 \\
\hline & $\begin{array}{l}\text { Plant height at } \\
\text { EOF }\end{array}$ & 6 & 4 & 10 \\
\hline \multirow[t]{3}{*}{ Spring sown } & Shoot length & 3 & 3 & 6 \\
\hline & Buds & 3 & 4 & 7 \\
\hline & Shoot diameter & 6 & 3 & 9 \\
\hline Greenhouse & Shoot length & 2 & 3 & 5 \\
\hline $\begin{array}{c}0 \text { week } \\
\text { vernalization }\end{array}$ & Shoot diameter & 2 & 1 & 3 \\
\hline
\end{tabular}


The two interesting QTL hotspots were found on A02 and C09 in the DHLE population and on linkage groups A02 and C06 in the DHSO populations. Identification of candidate genes on the QTL hotspots showed two different copies of candidate genes $F L C$ and $F T$ in the two DH populations. One copy of FLC (BnFLC.C9b) was mapped to the genomic region from 128 to 131 cM on C09 in the DHLE population. The second copy of FLC (BnFLC2) was in the DHSO population in the genomic region from 15.3 to $15.9 \mathrm{cM}$ on A02. One copy of candidate gene $F T$ (BnA2.FT) was identified in the genomic region from 49.2 to $50.7 \mathrm{cM}$ on A02 in the DHLE population. The second copy of FT (Bn.C6.FTb) was identified in the interval 25.6 to $29.7 \mathrm{cM}$ on linkage group C06 in the DHSO population.

In the both DH populations, candidate gene $F L C$ was found in the vicinity of major QTL for shoot length and visible buds in the spring sown environment, meaning $F L C$ has a decisive role in vernalization requirement. Whereas, candidate gene $F T$ was found in the genomic region of major QTL for begin of flowering and plant height in the autumn sown environment. Both FLC and $F T$ are responsible in the timing of flowering in B. napus. Candidate gene $F T$ is a central regulator whose protein product is a major component of the mobile signal that initiates flowering time in B. napus (Shavorskaya 2004). As soon as vernalization and photoperiod pathway allow, FT is translocated to the shoot apex, triggering flowering time (Schiessl et al. 2014). FLC and FRIGIDA (FRI) are important determinants of variation in the requirement for vernalization. FLC represses the initiation of flowering and prevents changes that convert the apical meristem to the reproductive structures (Shindo et al. 2005). Genome wide association mapping on big diversity set of canola $(n=188)$ for flowering time revealed that different homologues of FT and FLC are responding to vernalization and photoperiods and their effect may be seen only in some conditions (Raman et al. 2016).

Comparison of QTL mapped for seed quality traits in the vicinity of candidate gene FLC and FT in the two DH populations indicates that confidence intervals of QTL for oil and thousand kernel weight collocated with the genetic position of BnFLC.A2 in the DHSO population, while no QTL from seed quality traits were found in the vicinity of $F L C$ in the DHLE population. Pleotropic effects of $F L C$ and FT in pathway of different traits are described in some crops. Deng et al. (2011) showed that more than 500 genes for developmental pathways are potentially regulated by FLC in the Arabidopsis thaliana. In tomato and oilseed rape mutations within the paralogues of FT had large effects on fruit yield and yield components, showing FT protein binds 


\section{General discussion}

to pathways of seed traits (Kriege et al. 2010, Gou et al. 2014). Also tight linkage between underlying genes of oil content, thousand kernel weight and FLC might be the reason for overlapping confidence interval of the mapped QTL for the seed quality traits and the studied traits in three mega environments. 


\section{Chapter 7}

\section{Summary}

Oilseed rape (Brassica napus L.) is a major oilseed in many parts of the world with well adaptation to cold, dry and moist growing conditions. Despite large adaptation, winter survival is a major limiting factor to success of the crop in the regions with extreme freezing temperatures. Selection for improved winter hardiness is a difficult task, because firstly, efficient selection can only be performed in extreme winters, which in principle are not accessible and predictable in all regions. Secondly, winter hardiness is a complex trait, which consists of other interacting stresses. Cessation of shoot elongation before and during winter, has been considered one of the main requirements for successful overwintering in winter plants. Therefore, shoot length before and during winter is particularly considered by oilseed rape breeders as a contributing trait for selection of winter-hardy genotypes. Vernalization requirement, also, is a main winter survival mechanism that reduces the rate of shoot development and extend the vegetative phase to prevent frost damage by prohibiting floral transition during long warm periods before and during winter.

To analyze the genetic variation for shoot elongation before winter and vernalization requirement, field experiments were performed with a set of 19 European winter oilseed rape genotypes. Moreover, to understand the genetic architecture of shoot elongation before winter and its correlation with vernalization requirement in winter oilseed rape, QTL mapping was implemented in two bi-parental doubled haploid (DH) populations of Brassica napus (DHLE and DHSO). The DHLE population consists of 151 doubled haploid lines, derived from a cross between the resynthesized line L16 and the winter oilseed rape line Express617. The DHSO population consists of 226 doubled haploid lines, derived from a cross between the two winter oilseed rape cultivars Sansibar and Oase. The two DH populations and the parental lines were phenotypically characterized in series field and greenhouse experiments.

The two field environments included the normal sowing time at end of August/beginning of September, called autumn sown environment, and the spring sowing time at end of March/ beginning of April, called spring sown environment. Since the greenhouse, autumn and spring sown experiments represented very different environments; they were called three mega 
environments. Shoot length, shoot diameter were measured around three months after sowing time in the all three environments. In addition, data from flowering time, plant height, and seed quality traits were used to study their phenotypic and genetic association with the studied traits in the two DH populations.

In the set of 19 European winter oilseed rape genotypes, results showed large phenotypic variation with significant genotypic variance components for shoot length in the autumn sown and spring sown environment. Broad sense heritability was high for shoot length in the spring sown environment $\left(h^{2}=97 \%\right)$ while medium heritability $\left(h^{2}=62 \%\right)$ was observed for shoot length before winter. Spearman's rank correlation revealed a medium positive correlation $\left(\mathrm{r}_{s}=0.48^{*}\right)$ between shoot length before winter and shoot length in the spring sown environment. Scatter plot of spearmen's rank correlation distributed the 19 genotypes mainly in two clusters; first cluster consisted of genotypes with short shoot length in the autumn sown and spring sown environment, including R53 and L16, Mohican, Lorenz and Sollux, Zenith, Apex and Akela. Second cluster consisted of cultivars which were short before winter but long in the spring sown environment including Montego, Tenor, Adriana, Sansibar, Oase, Express 617, SGEDH13, SGDH14, King 10 and hybrid cultivar Visby. Gaoyou was the only cultivar with the longest shoot length in the both field environments. Low vernalization requirement was characterized in genotypes with significant elongation of shoot in the spring sown environment.

In the DHLE population, large and significant genotypic variance components were found for shoot length and shoot diameter in the all three mega environments. Express617 was significantly longer than L16 for shoot length before winter (61 vs. 34) and begin of flowering was around five days earlier in the autumn sown environment. In the spring sown environment, parent L16 was with $218 \mathrm{~mm}$ length significantly shorter than Express617 with $855 \mathrm{~mm}$ shoot length. A near bimodal frequency distribution was found for shoot length in the spring sown environment with large phenotypic variation that ranged from $87 \mathrm{~mm}$ to $1255 \mathrm{~mm}$. In addition, comparison of frequency distribution of shoot length and percentage of visible buds in the spring sown environment indicated that genotypes shorter than L16 almost did not show any tendency to form an inflorescence, whereas genotypes longer than Express617 showed almost 100\% tendency to form an inflorescence.

Correlation analysis in the DHLE population indicated no significant correlation between shoot length before winter and shoot length in the spring sown environment. Shoot length before 
winter was also not correlated with begin of flowering neither in the autumn sown nor in the greenhouse environment upon eight weeks vernalization treatment. Significant negative correlation of $\mathrm{r}_{s}=-0.54^{* * *}$ was found between begin of flowering in the autumn sown environment and shoot length, visible buds in the spring sown environment. Also, significant correlation was found between shoot length in non-vernalized plants in the greenhouse and shoot length in the autumn $\left(\mathrm{r}_{s}=0.31^{* *}\right)$ and spring sown environment $\left(\mathrm{r}_{s}=0.22^{* *}\right)$.

Multiple interval mapping in the DHLE population, detected six main QTL for shoot length before winter that contributed $49.2 \%$ to the phenotypic variance. For shoot length in spring sown environment a major QTL with $R^{2}=35.5 \%$ was localized on linkage group C09 which along with two QTL mapped to A02 and A07 explained 68\% of the phenotypic variance. In the nonvernalized greenhouse environment, two QTL were found for shoot length on A06 and A09 which together explained $16.2 \%$ of the phenotypic variance. No collocation of QTL was found between shoot length before winter, shoot length in the spring sown and non-vernalized greenhouse environment. Two candidate genes BnA2.FT and BnFLC9b were identified in the genomic regions with overlapping confidence intervals of QTL on A02 and C06. The candidate gene BnA2.FT is a paralogue of gene $F T$ that collocated with major QTL on A02 for begin of flowering and plant height in the autumn sown environment. The candidate gene BnFLC9b is a paralogue of gene $F L C$ found within a hotspot of linkage group C09 in which major QTL for shoot length and visible buds were localized in the spring sown environment.

In the DHSO population large and significant genotypic effects were found for shoot length in the three mega environments. High heritability was found for shoot length in the spring sown $\left(h^{2}=90 \%\right)$ and greenhouse environment with non-vernalized plants $\left(h^{2}=69 \%\right)$, in contrast shoot length before winter had rather medium heritability $\left(h^{2}=46 \%\right)$. Parent Oase showed significant higher value than Sansibar for shoot length before winter (40 ver. 29), while Sansibar was significantly longer than Oase in the spring sown field experiments (721 ver. 442). Tendency to form inflorescence in the spring sown environments was higher than $80 \%$ in Sansibar and Oase, showing low vernalization requirement in the parental lines. Spearman's rank correlation reveled negative correlation between shoot length in the spring environment and begin of flowering, $\left(r_{s}=-\right.$ $\left.0.52^{* *}\right)$, plant height $\left(\mathrm{r}_{s}=-0.25^{* *}\right)$ in the autumn sown environment. Shoot length in the spring sown environment was positively correlated with the appearance of visible buds $\left(\mathrm{r}_{s}=0.90^{* * *}\right)$ and shoot length in non-vernalized greenhouse environment $\left(\mathrm{r}_{s}=0.42^{* *}\right)$. Significant correlation was 
found between shoot length before winter and vernalization requirement determined by shoot length $\left(r_{s}=0.31^{* *}\right)$ and visible buds $\left(r_{s}=0.26^{*}\right)$ in the spring sown environment. Likewise, shoot length before winter was negatively correlated with begin of flowering $\left(\mathrm{r}_{s}=-0.29^{* * *}\right)$. In the DHSO population, multiple interval mapping detected five main QTL for shoot length before winter, explaining collectively $23.5 \%$ of the phenotypic variance. Three QTL were found for shoot length in the spring sown environment. The major QTL on A02 explained 70\% of the phenotypic variance for shoot length in the spring environment. Three QTL for shoot length in nonvernalized plants in the greenhouse contributed 26\% to the phenotypic variance. QTL mapping for begin of flowering identified one major QTL on C06 which along with 5 additional QTL accounted for $71.6 \%$ of the phenotypic variance. On linkage group A02 a hotspot was found with the QTL for shoot length before winter, begin of flowering, end of flowering, duration of flowering and plant height in the autumn sown environment and the major QTL for shoot length and visible buds in the spring sown environment. Surprisingly, all the QTL were the biggest or almost the biggest QTL of respective traits. A copy of candidate gene FLC (BnFLC2) was found on the genomic region from 15.3 to $15.9 \mathrm{cM}$ on A02. C06 was the second linkage group with overlapping confidence intervals of the biggest QTL for begin and end of flowering in the autumn sown environment and a QTL for visible buds in the spring sown environment with opposite additive effects in the DHSO population. A copy of FT (Bn.C6.FTb) was identified in the interval 25.6 to $29.7 \mathrm{cM}$ within the QTL hotspot on $\mathrm{C} 06$.

In the both populations, different copies of candidate genes $F L C$ were identified in the vicinity of major QTL for shoot length in the spring sown environment, indicating that elongation of shoot is significantly influenced by vernalization induced genes. Furthermore, different copies of candidate gene $F T$ were identified in the vicinity of the major QTL for flowering time, showing key role of $F T$ in regulation of flowering time. Identification of QTL mapped for some seed quality trait in the extent of $F L C$ in the DHSO population suggests pleiotropic effect of $F L C$ on different traits or tight linkage between genes involved in respective traits. 


\section{Bibliography}

Abbadi A, Leckband G (2011) Rapeseed breeding for oil content, quality, and sustainability. Eur J Lipid Sci Technol 113:1198-1206

Albani MC, Coupland G (2010) Comparative Analysis of Flowering in Annual and Perennial Plants. In: Timmermans MCP (ed) Plant development, vol 91. Academic Press, Amsterdam, pp 323-348

Amasino R (2010) Seasonal and developmental timing of flowering. Plant J 61:1001-1013. doi: 10.1111/j.1365-313X.2010.04148.x

Amasino RM, Michaels SD (2010) The timing of flowering. Plant Physiol 154:516-520. doi: 10.1104/pp.110.161653

Andersson G, Olsson G (1961) Winter raps-spezielle Auslese und Züchtungsmethodenwinterfestigkeit und Überwinterungsfragen. In: Th. Römer, and W. Rudorf (eds), Handbuch der Pflanzenzüchtung, Band V: H. Kappert, and W. Rudolf (eds), Züchtung der Sonderkulturpflanzen, pp. 37-40. Paul Parey, Berlin/Hamburg

Andrews JE, Horricks JS, Roberts DWA (1960) Interrelationship between plant age, root rot interaction and cold hardiness in winter wheat. Can. J. Bot. 38:601-611. doi: $10.1139 / \mathrm{b} 60-054$

Asghari A, Mohammadi SA, Moghaddam M, Mohammaddoost H (2014) Identification of QTL(s) Controlling Winter Survival in Brassica napus using RAPD Markers. Biotechnology \& Biotechnological Equipment 21:413-416. doi: 10.1080/13102818.2007.10817485

Balodis O, Gaile Z (2015) Changes of winter oilseed rape plant survival during vegetation. Proceedings of the Latvia University of Agriculture 33(1). doi: 10.1515/plua-2015-0005

Bäurle I, Dean C (2006) The timing of developmental transitions in plants. Cell 125:655664. doi: 10.1016/j.cell.2006.05.005

Becker HC, Engqvist GM, Karlsson B (1995) Comparison of rapeseed cultivars and resynthesized lines based on allozyme and RFLP markers. Theor Appl Genet 91:62-67. doi: 10.1007/BF00220859

Bergjord AK, Bakken AK, Skjelvåg AO (2009) The relationship between frost tolerance and generative induction in winter wheat (Triticum aestivum L.) under field conditions. Can. J. Plant Sci. 89:1031-1039. doi: 10.4141/CJPS08119

Blum A (1988) Plant breeding for stress environments. CRC Press, Boca Raton, Florida. 
Bothmer R (ed) (2003) Diversity in barley (Hordeum vulgare). Developments in Plant Genetics and Breeding, vol 7. Elsevier, Amsterdam, London.

Brandes H (2016) Variation und ererbung von glucosinolatgehalt und -muster in grünmasse und samen von raps (Brassica napus L.) und deren zusammenhang zum befall mit rapsstängelschädlingen. $\mathrm{PhD}$, Georg-August-Universität Göttingen (in German)

Britz W, Hertel TW (2011) Impacts of EU biofuels directives on global markets and EU environmental quality: An integrated PE, global CGE analysis. Agriculture, Ecosystems \& Environment 142:102-109. doi: 10.1016/j.agee.2009.11.003

Bundessortenamt (2014) Beschreibende Sortenliste. Getreide, Mais, Öl- und Faserpflanzen, Leguminosen, Rüben, Zwischenfrüchte URL http://www.bundessortenamt.de/internet30/ fileadmin/Files/PDF/bsl_getreide_2014.pdf

Caicedo AL, Stinchcombe, JR, Olsen KM, Schmitt J, Purugganan MD (2004) Epistatic interaction between Arabidopsis FRI and FLC flowering time genes generates a latitudinal cline in a life history trait. Proc Natl Acad Sci USA 101:15670-15675. doi: 10.1073/pnas.0406232101

Caradus JR, Christie BR (1998) Winter hardiness and artificial frost tolerance of white clover ecotypes and selected breeding lines. Can. J. Plant Sci. 78:251-255. doi: 10.4141/P96-147

Casao MC, Karsai I, Igartua E, Gracia MP, Veisz O, Am Casas (2011) Adaptation of barley to mild winters: a role for PPDH2. BMC Plant Biol 11:164. doi: 10.1186/1471-2229$11-164$

Chalhoub B, Denoeud F, Liu S, Parkin IAP, Tang H, Wang X, Chiquet J, Belcram H, Tong C, Samans B, Corréa M, Da Silva C, Just J, Falentin C, Koh CS, Le Clainche I, Bernard M, Bento P, Noel B, Labadie K, Alberti A, Charles M, Arnaud D, Guo H, Daviaud C, Alamery S, Jabbari K, Zhao M, Edger PP, Chelaifa H, Tack D, Lassalle G, Mestiri I, Schnel N, Le Paslier MC, Fan G, Renault V, Bayer PE, Golicz AA, Manoli S, Lee TH, Thi VHD, Chalabi S, Hu Q, Fan C, Tollenaere R, Lu Y, Battail C, Shen J, Sidebottom CHD, Wang X, Canaguier A, Chauveau A, Bérard A, Deniot G, Guan M, Liu Z, Sun F, Lim YP, Lyons E, Town CD, Bancroft I, Wang X, Meng J, Ma J, Pires JC, King GJ, Brunel D, Delourme R, Renard M, Aury JM, Adams KL, Batley J, Snowdon RJ, Tost J, Edwards D, Zhou Y, Hua W, Sharpe AG, Paterson AH, Guan C, Wincker P (2014) Early allopolyploid evolution in the post-Neolithic Brassica napus oilseed genome. Science 345:950-953

Chandler J, Dean C (1994) Factors influencing the vernalization response and flowering time of late flowering mutants of Arabidopsis thaliana (L.) Heynh. J Exp Bot 45:1279-1288. doi: $10.1093 / \mathrm{jxb} / 45.9 .1279$

Chandler J, Wilson A, Dean C (1996) Arabidopsis mutants showing an altered response to vernalization. The Plant Journal 10:637-644 
Chen Y, Carver BF, Wang S, Zhang F, Yan L (2009) Genetic loci associated with stem elongation and winter dormancy release in wheat. Theor Appl Genet 118:881-889. doi: $10.1007 / \mathrm{s} 00122-008-0946-5$

Chen G, Geng J, Rahman M, Liu X, Tu J, Fu T, Li G, McVetty PBE, Tahir M (2010) Identification of QTL for oil content, seed yield, and flowering time in oilseed rape (Brassica napus. L). Euphytica 175:161-174. doi: 10.1007/s10681-010-0144-9

Chen Y, Carver BF, Wang S, Cao S, Yan L (2010) Genetic regulation of developmental phases in winter wheat. Mol Breeding 26:573-582. doi: 10.1007/s11032-010-9392-6

Chinnusamy V, Zhu J, Zhu JK (2007) Cold stress regulation of gene expression in plants. Trends Plant Sci 12:444-451. doi: 10.1016/j.tplants.2007.07.002

Collard BCY, Jahufer MZZ, Brouwer JB, Pang ECK (2005) An introduction to markers, quantitative trait loci (QTL) mapping and marker-assisted selection for crop improvement: The basic concepts. Euphytica 142:169-196. doi: 10.1007/s10681-005-1681-5

Corbesier L, Vincent C, Jang S, Fornara F, Fan Q, Searle I, Giakountis A, Farrona S, Gissot L, Turnbull C, Coupland G (2007) FT protein movement contributes to long-distance signaling in floral induction of Arabidopsis. Science 316:1030-1033. doi: 10.1126/science. 1141752

Cramer N (1990) Raps: Anbau und Verwertung. Stuttgart, Deutschland. 148 S. (in German)

Crosatti C, Pagani D, Cattivelli L, Stanca AM, Rizza F (2008) Effects of growth stage and hardening conditions on the association between frost resistance and the expression of the cold-induced protein COR14b in barley. Environmental and Experimental Botany 62(2):93100. doi: 10.1016/j.envexpbot.2007.07.008

Danyluk J (2003) TaVRT-1, a Putative Transcription Factor Associated with Vegetative to Reproductive Transition in Cereals. Plant Physiol 132:1849-1860. doi: 10.1104/pp.103.023523

Darby H, Harvood H, Cummings E, Monahan S 2013 Winter canola survival. Retrieved at http://www.uvm.edu/extension/cropsoil (visited in May 2014).

Dechaine JM, Brock MT, Iniguez-Luy FL, Weinig C (2014) Quantitative trait loci x environment interactions for plant morphology vary over ontogeny in Brassica rapa. New Phytol 201:657-669. doi: 10.1111/nph.12520 
Dimov Z, Suprianto E, Hermann F, Möllers C (2012) Genetic variation for seed hull and fibre content in a collection of European winter oilseed rape material (Brassica napus L.) and development of NIRS calibrations. Plant Breed 131:361-368

Deng W, Ying H, Helliwell CA, Taylor JM, Peacock WJ, Dennis ES (2011) FLOWERING LOCUS C (FLC) regulates development pathways throughout the life cycle of Arabidopsis. Proc Natl Acad Sci USA 108:6680-6685. doi: 10.1073/pnas.1103175108

Doerge RW (2002) Mapping and analysis of quantitative trait loci in experimental populations. Nat Rev Genet 3:43-52. doi: 10.1038/nrg703

Dong MA, Farre EM, Thomashow MF (2011) Circadian clock-associated 1 and late elongated hypocotyl regulate expression of the C-repeat binding factor $(C B F)$ pathway in Arabidopsis. Proc Natl Acad Sci USA 108:7241-7246. doi: 10.1073/pnas.1103741108

Downey RK (1990) Brassica oilseeds breeding: Achievements and opportunities. Plant Breed Abstr 60:1165-1170

Downey RK, Rakow GF (1987) Rapeseed and Mustard. In Fehr, W. (Ed). Principles of cultivar development. MacMillan Publishing Co. New York.

Ecke W, Uzunova M, Weißleder K (1995) Mapping the genome of rapeseed (Brassica napus L.). II. Localization of genes controlling erucic acid synthesis and seed oil content. Theor Appl Genet 91:972-977

El-Soda M, Malosetti M, Zwaan BJ, Koornneef M, Aarts MG (2014) Genotype x environment interaction QTL mapping in plants: lessons from Arabidopsis. Trends Plant Sci 19:390-398. doi: 10.1016/j.tplants.2014.01.001

Europe Mars Bulletin (2012) Crop monitoring in Europe, vol 20, retrieved at https://ec.europa.eu/jrc/sites/jrcsh/files/mars_bulletin_vol20_no1.pdf

Ferreira ME, Satagopan J, Yandell BS, Williams PH, Osborn TC (1995) Mapping loci controlling vernalization requirement and flowering time in Brassica napus. Theor Appl Genet 90:727-732. doi: 10.1007/BF00222140

Finlayson AJ, Krzymanski J, Downey R K (1973) Comparison of chemical and agronomic characteristics of two Brassica napus L. cultivars, 'Bronowski' and 'Target'. Journal of the American Oil Chemists' Society 50: 407-410

Fletcher RS, Mullen JL, Heiliger A, McKay JK (2015) QTL analysis of root morphology, flowering time, and yield reveals trade-offs in response to drought in Brassica napus. $\mathrm{J}$ Exp Bot 66:245-256. doi: 10.1093/jxb/eru423 
Fowler DB, Gusta LV, Tyler NJ (1981) Selection for winter hardiness in Wheat. III. Screening Methods. Crop $\quad$ Science $21: 896 . \quad$ doi: 10.2135/cropsci1981.0011183X002100060023x

Fowler DB, Chauvin LP, Limin AE, Sarhan F (1996a) The regulatory role of vernalization in the expression of low-temperature-induced genes in wheat and rye. Theor Appl Genet 93:554-559. doi: 10.1007/BF00417947

Fowler DB, Limin AE, Wang S, Ward RW (1996b) Relationship between low-temperature tolerance and vernalization response in wheat and rye. Can. J. Plant Sci. 76:37-42. doi: 10.4141/cjps96-007

Fowler DB, Breton G, Limin AE, Mahfoozi S, Sarhan F (2001) Photoperiod and Temperature Interactions Regulate Low-Temperature-Induced Gene Expression in Barley. Plant Physiol 127:1676-1681. doi: 10.1104/pp.010483

Fujita M, Kawada N, Tahir M (1992) Relationship between cold resistance, heading traits and ear primordia development of wheat cultivars. Euphytica 64:123-130

Galiba G, Quarrie SA, Sutka J, Morgounov A, Snape JW (1995) RFLP mapping of the vernalization (Vrn1) and frost resistance (Fr1) genes on chromosome 5A of wheat. Theor Appl Genet 90:1174-1179. doi: 10.1007/BF00222940

Galiba G, Vágújfalvi A, Li C, Soltész A, Dubcovsky J (2009) Regulatory genes involved in the determination of frost tolerance in temperate cereals. Plant Science 176:12-19. doi: 10.1016/j.plantsci.2008.09.016

Geraldo N, Baurle I, Kidou S, Hu X, Dean C (2009) FRIGIDA delays flowering in Arabidopsis via a cotranscriptional mechanism involving direct interaction with the nuclear cap-binding complex. Plant Physiol 150:1611-1618. doi: 10.1104/pp.109.137448

Girke A, Schierholt A, Becker HC (2012) Extending the rapeseed genepool with resynthesized Brassica napus L. I: Genetic diversity. Genet Resour Crop Evol 59:14411447. doi: 10.1007/s10722-011-9772-8

Guo Y, Hans H, Christian J, Molina C (2014) Mutations in single FT-and TFL1-paralogs of rapeseed (Brassica napus L.) and their impact on flowering time and yield components. Front Plant Sci 5:282. doi: 10.3389/fpls.2014.00282

Gusta VA, Fowler DB (1977) Factors affecting the cold survival of winter cereals. Plant Sci. 57:213-219

Gusta LV, Wisniewski M (2013) Understanding plant cold hardiness: an opinion. Physiol Plant 147:4-14. doi: 10.1111/j.1399-3054.2012.01611.x 
Gül M (2003) QTL mapping and analysis of QTL of nitrogen interactions for protein and oil contents in Brassica napus Turk J Agric For 27: 71-76

Hawkins GP, Deng Z, Kubik TJ, Johnson-Flanagan AM (2002) Characterization of freezing tolerance and vernalization in Vern-, a spring-type Brassica napus line derived from a winter cross. Planta 216:220-226. doi: 10.1007/s00425-002-0850-1

Heterman OB, Durling JC (1991) Avoiding winter hardy to alfalfa. Michigan State University. Extension Bulletin E-2310.

Hill WG, Weir BS (1988) Variances and covariances of squared linkage disequilibria in finite populations. Theor Appl Genet 33:54-78

Howell PM, Sharpe AG, Lydiate DJ (2003) Homologous loci control the accumulation of seed glucosinolates in oilseed rape (Brassica napus). Genome 46:454-460

Hurry V, Strand A, Tobiiaeson M, Gardeström P, Gunner Öquist (1995) Cold Hardening of Spring and Winter Wheat and Rape Results in Differential Effects on growth, Carbon Metabolism, and Carbohydrate Content. Plant Physiol 109:697-706

Intergovernmental Panel on Climate Change IPCC (2007) Climate change 2007: Impacts, adaptation and vulnerability. In: Parry ML, Canziani OF, Palutikof JP, van der Linden PJ, Hanson CE (eds) Contribution of Working Group II to the Fourth Assessment Report of the Intergovernmental Panel on climate change. Cambridge University Press, Cambridge, p. 976

Irwin JA, Lister C, Soumpourou E, Zhang Y, Howell EC, Teakle G, Dean C (2012) Functional alleles of the flowering time regulator FRIGIDA in the Brassica oleracea genome. BMC Plant Biol 12:21. doi: 10.1186/1471-2229-12-21

Javed N, Geng J, Tahir M, McVetty PBE, Li G, Duncan RW (2016) Identification of QTL influencing seed oil content, fatty acid profile and days to flowering in Brassica napus L. Euphytica 207:191-211. doi: 10.1007/s10681-015-1565-2

Jiang C, Shi J, Li R, Long Y, Wang H, Li D, Zhao J, Meng J (2014) Quantitative trait loci that control the oil content variation of rapeseed (Brassica napus L.). Theor Appl Genet 127:957-968. doi: 10.1007/s00122-014-2271-5

Johanson U (2000) Molecular analysis of FRIGIDA, a major determinant of natural variation in Arabidopsis flowering time. Science 290:344-347. doi: $10.1126 /$ science.290.5490.344

Jung C, Muller AE (2009) Flowering time control and applications in plant breeding. Trends Plant Sci 14:563-573. doi: 10.1016/j.tplants.2009.07.005 
Kao CH, Zeng ZB, Teasdale RD (1999) Multiple Interval Mapping for Quantitative Trait Loci. Genetic Society of America 152:1203-1216

Kasperska-Palacz A (1978). Mechanism of Cold Acclimation in Herbaceous Plants. In: Plant Cold Survival and Freezing Stress (Li PH and Sakai A, eds.). Academic Press, New York, 139-152.

Kennard WC, Slocum MK, Fligdore SS, Osborn, TC 1994. Genetic analysis of morphological variation in Brassica oleracea using molecular markers. Theor. Appl. Genet. $87721-732$

Kim DH, Doyle, Sung S, Amasino RM (2009) Vernalization: winter and the timing of flowering in plants. Annu Rev Cell Dev Biol 25:277-299. doi: 10.1146/annurev.cellbio.042308.113411

Ko JH, Mitina I, Tamada Y, Hyun Y, Choi Y, Amasino RM, Noh B, Noh YS (2010) Growth habit determination by the balance of histone methylation activities in Arabidopsis. EMBO J 29(18):3208-3215. doi: 10.1038/emboj.2010.198

Kole C, Quijada P, Michaels SD, Amasino RM, Osborn TC (2001) Evidence for homology of flowering-time genes VFR2 from Brassica rapa and FLC from Arabidopsis thaliana. Theor Appl Genet 102(2-3):425-430. doi: 10.1007/s001220051663

Kole C, Thormann CE, Karlesson BH, Palta JP, Gaffney P, Zandell B, Osborn TC (2002) Comparative mapping of loci controlling winter survival and related traits in oilseed. Molecular Breeding 9:201-210

Krieger U, Lippman ZB, Zamir D (2010) The flowering gene SINGLE FLOWER TRUSS drives heterosis for yield in tomato. Nat. Genet. 42:459-463. doi: 10.1038/ng.550

Kuchel H, Hollamby G, Langridge P, Williams K, Jefferies SP (2006) Identification of genetic loci associated with ear-emergence in bread wheat. Theor Appl Genet 113:11031112. doi: 10.1007/s00122-006-0370-7

Lagunes LC, Huguet T, Julier B (2013) Multi-population QTL Detection for Flowering Time, Stem Elongation and Quality Traits in Medicago truncatula. In: Barth S, Milbourne D (eds) Breeding strategies for sustainable forage and turf grass improvement. Springer Netherlands, Dordrecht, pp 197-202

Laroche A, Geng X, Singh J (1992) Differentiation of freezing tolerance and vernalization responses in Cruciferae exposed to a low temperature. Plant Cell Environ 15(4):439-445. doi: 10.1111/j.1365-3040.1992.tb00994.x

Levitt J (1972) Plant responses to environmental stress. Academic Press, New York 
Levitt J (1980) Responses of plants to environmental stresses: chilling, freezing, and high temperature stresses. Vol. 1. Academic Press, New York, NY.

Levy YY, Dean C (1998) The Transition to Flowering. Plant Cell 10:1973. doi: $10.2307 / 3870778$

Li D, Liu C, Shen L, Wu Y, Chen H, Robertson M, Helliwell CA, Ito T, Meyerowitz E, Yu $\mathrm{H}$ (2008) A repressor complex governs the integration of flowering signals in Arabidopsis. Dev Cell 15:110-120. doi: 10.1016/j.devcel.2008.05.002

Li X, Liu Y (2010) The conversion of spring wheat into winter wheat and vice versa: False claim or Lamarckian inheritance? J Biosci 35:321-325. doi: 10.1007/s12038-010-0035-1

Lincoln S, Daly M, Lander E (1992) Mapping genetic mapping with MAPMAKER/EXP3. 0. Camb: Whitehead Inst Tech Rep

Liu J, Hua W, Yang HL, Zhan GM, Li RJ, Deng LB, Wang XF, Liu GH, Wang HZ (2012) The BnGRF2 gene (GRF2-like gene from Brassica napus) enhances seed oil production through regulating cell number and plant photosynthesis. J Exp Bot 63:3727-3740. doi: $10.1093 / \mathrm{jxb} / \mathrm{ers} 066$

Liu J, Hiran AH, Li Z, Wu C, McVetty P, Daayt F, Li G (2016) QTL controlling glucosinolates content in seeds of Brassica napus L. Australian Journal of Crop Science 10:152-160

Livingston DP, Henson CA (1998) Apoplastic sugars, fructans, fructan exohydrolase, and invertase in winter Oat: responses to second-phase cold hardening. Plant Physiol 116:403406

Long Y, Shi J, Qiu D, Li R, Zhang C, Wang J, Hou J, Zhao J, Shi L, Park BS, Choi, SR, Lim YP, Meng J (2007) Flowering time quantitative trait loci analysis of oilseed brassica in multiple environments and genome wide alignment with Arabidopsis. Genetics 177:24332444.doi:10.1534/genetics.107.080705

Lou P, Zhao J, Kim JS, Shen S, Del CDP, Song X, Jin M, Vreugdenhil D, Wang X, Koornneef M, Bonnema G (2007) Quantitative trait loci for flowering time and morphological traits in multiple populations of Brassica rapa. J Exp Bot 58:4005-4016. doi: 10.1093/jxb/erm255

Lu SX, Knowles SM, Andronis C, Ong MS, Tobin EM (2009) CIRCADIAN CLOCK ASSOCIATED1 and LATE ELONGATED HYPOCOTYL function synergistically in the circadian clock of Arabidopsis. Plant Physiol 150:834-843. doi: 10.1104/pp.108.133272

Luo YX, Luo CY, Du DZ, Fu Z, Yao YM, Xu CC, Zhang HS (2014) Quantitative trait analysis of flowering time in spring rapeseed (B. napus L.). Euphytica 200:321-335. doi: $10.1007 / \mathrm{s} 10681-014-1140-2$ 
Mahfoozi S (2001) Developmental regulation of low-temperature tolerance in winter wheat. Annals of Botany 87:751-757. doi: 10.1006/anbo.2001.1403

Mahfoozi S, Limin AE, Fowler DB (2001) Influence of vernalization and photoperiod responses on cold hardiness in Winter Cereals. Crop Science 41:1006. doi10.2135/cropsci2001.4141006x:

Mahfoozi S, Limin AE, Ahakpaz F, Roustaii M, Ketata H, Fowler DB (2005) Regulation of low-temperature tolerance in barley under field conditions in northwest Iran. Can. J. Plant Sci. 85:587-592. doi: 10.4141/P04-191

Mahfoozi S, Limin AE, Ahakpaz F, Fowler DB (2006) Phenological development and expression of freezing resistance in spring and winter wheat under field conditions in northwest Iran. Field Crops Research 97:182-187. doi: 10.1016/j.fcr.2005.09.012

Maibam P, Nawkar GM, Park JH, Sahi VP, Lee SY, Kang CH (2013) The influence of light quality, circadian rhythm, and photoperiod on the CBF-mediated freezing tolerance. Int J Mol Sci 14(6):11527-11543. doi: 10.3390/ijms140611527

Maltas E, Vural HC (2013) Comparison of winter and summer canola (Brassica napus) genotypes in Turkey. Genet Mol Res 12:408-415. doi: 10.4238/2013. 5

Markowski A, Rapacz M (1994) Comparison of vernalization requirements and frost resistance of winter rape lines derived from double haploids. J Agron Crop Sci 173:184-192. doi: 10.1111/j.1439-037X.1994.tb00553.x

Mei DS, Wang HZ, Hu Q, Li YD, Xu YS, Li YC (2009) QTL analysis on plant height and flowering time in Brassica napus. Plant Breeding 128:458-465. doi: 10.1111/j.14390523.2008.01528.x

Mei J, Ding Y, Lu K, Wei D, Liu Y, Disi JO, Li J, Liu L, Liu S, McKay J, Qian W (2013) Identification of genomic regions involved in resistance against Sclerotinia sclerotiorum from wild Brassica oleracea. Theor Appl Genet 126:549-556. doi: 10.1007/s00122-0122000-x

Melillo JM, Richmond T, Yohe GW (2014) Climate Change Impacts in the United States: The Third National Climate Assessment. U.S. Global Change Research Program

Michaels SD (2009) Flowering time regulation produces much fruit. Curr. Opin. Plant Biol. $12,75-80$

Mickelbart MV, Hasegawa PM, Bailey-Serres J (2015) Genetic mechanisms of abiotic stress tolerance that translate to crop yield stability. Nat Rev Genet 16:237-251. doi: $10.1038 / \mathrm{nrg} 3901$ 
Murelli C, Rizza F, Albini FM, Dulio A, Terzi V, Cattivelli L (1995) Metabolic changes associated with cold-acclimation in contrasting cultivars of barley. Physiologia Plantarum, 94: 87-93. doi: 10.1111/j.1399-3054.1995.tb00788.x

Nagata T, Tabata S (eds) (2003) Brassicas and legumes from genome structure to breeding. Biotechnology in agriculture and forestry, vol 52. Springer Berlin Heidelberg, Berlin, Heidelberg

Nelson MN, Rajasekaran R, Smith A, Chen S, Beeck CP, Siddique KH, Cowling WA (2014) Quantitative trait loci for thermal time to flowering and photoperiod responsiveness discovered in summer annual-type Brassica napus L. PLoS One 9(7):e102611. doi: 10.1371/journal.pone.0102611

Niewiadomski H (1990) Rapeseed- chemistry and technology. PWN, Warszawa/ Elsevier, Amsterdam, pp. 22-26.

Novickiene L, Gaveliene V, Miliuviene L, Kazlauskiene D, Pakalniskte L (2010) Comparison of winter oilseed rape varieties: cold acclimation, seed yield and quality. Žemdirbystè=Agriculture 97(3). 77-86

Osborn TC, Ko JH, Parkin IAP, Sharpe AG, Kuiper M, Lydiate DJ, Trick M (1997) Comparison of Flowering Time Genes in Brassica rapa, B. napus and Arabidopsis thulium. Genetic Society of America 146:1123-1129

Osborn TC, Lukens L (2003) The Molecular genetic basis of flowering time variation in Brassica Species. In: Nagata T, Tabata S (eds) Brassicas and Legumes From Genome Structure to Breeding, vol 52. Springer Berlin Heidelberg, Berlin, Heidelberg, pp 69-86

Öquist G, Hurry VM, Huner NPA (1993) Low temperature effects on photosynthesis and correlation with freezing tolerance in spring and winter cultivars of wheat and rye. Plant Physiol101: 245-250.

Parkin I, Sharpe A, Keith D, Lydiate D (1995) Identification of the A and C genomes of amphidiploid Brassica napus (oilseed rape). Genome 38:1122-1131

Palta JP (1991) Mechanisms for obtaining freezing Stress resistance in herbaceous plants. In: Plant Breeding in the1990s (Stalker HT and Murphy JP, eds.). CAB International, Wallingford, 219-250.

Poltarev EM, Borisenko LP, Ryabchun NI (1992) Diagnosis of winter wheat resistance to thawing and ice encasement as part of the complex evaluation of winter hardiness (methodological recommendations). (In Russian.) Ukrainian Academy of Agronomy Sciences, Harkov. 33 pp. 
Pomeroy MK, Fowler DB (1973) Use of lethal dose temperature estimates as indices of frost tolerance for wheat cold acclimated under nature and controlled environments. Can. J. Plant Sci. 53(3):489-494. doi: 10.4141/cjps73-093

Prásil IT, Prasilova P, Pankova K (2004) Relationships among vernalization, shoot apex development and frost tolerance in wheat. Annals of Botany 94:413-418. doi: 10.1093/aob/mch158

Qu CM, Li SM, Duan XJ, Fan JH, Jia LD, Zhao HY, Lu K, Li JN, Xu XF, Wang R (2015) Identification of Candidate Genes for seed glucosinolates content Using Association Mapping in Brassica napus L. Genes (Basel) 6(4):1215-1229. doi: 10.3390/genes6041215

R Core Team (2015). R: A language and environment for statistical computing. R Foundation for Statistical Computing, Vienna, Austria. URL https:/www.R-project.org/.

Raman H, Raman R, Eckermann P, Coombes N, Manoli S, Zou X, Edwards D, Meng J, Prangnell R, Stiller J, Batley J, Luckett D, Wratten N, Dennis E (2013) Genetic and physical mapping of flowering time loci in canola (Brassica napus L.). Theor Appl Genet 126:119132. doi: 10.1007/s00122-012-1966-8

Raman H, Raman R, Coombes N, Song J, Prangnell R, Bandaranayake C, Tahira R, Sundaramoorthi V, Killian A, Meng J, Dennis ES, Balasubramanian S (2016) Genome-wide association analyses reveal complex genetic architecture underlying natural variation for flowering time in canola. Plant Cell Environ 39:1228-1239. doi: 10.1111/pce.12644

Rapacz M (1998a) The after-effects of temperature and irradiance during early growth of winter oilseed rape (Brassica napus L. var. oleifera, cv. Górczański) seedlings on the progress of their cold acclimation. Acta Physiol Plant 20:73-78. doi: 10.1007/s11738-9980046-9

Rapacz M (1998b) The effects of day and night temperatures during early growth of winter oilseed rape (Brassica napus L. var. oleifera cv. Górczański) seedlings on their morphology and cold acclimation responses. Acta Physiol Plant 20:67-72. doi: 10.1007/s11738-9980045-X

Rapacz M, Janowiak F (1998) Physiological Effects of Winter Rape (Brassica napus var. oleifera) Pre-hardening to frost. I. Frost resistance and photosynthesis during cold acclimation. J Agron Crop Sci 181:13-20. doi: 10.1111/j.1439-037X.1998.tb00392.x

Rapacz M (1999) Frost resistance and cold acclimation abilities of spring-type oilseed rape. Plant Science 147:55-64. doi: 10.1016/S0168-9452(99)00098-9

Rapacz, M., Markowski, A. (1999) Winter hardiness, frost resistance and vernalization requirement of European winter Oilseed Rape cultivars within the Last 20 years. J Agron Crop Sci 183:243-253 
Rapacz M, Chilmonik E (2000) Does the lack of vernalization requirement interfere with winter survival of oilseed rape plants. Acta Physiol Plant 22:143-149. doi: 10.1007/s11738000-0069-3

Rapacz M, Tokarz K, Janowiak F (2001) The initiation of elongation growth during longterm low-temperature stay of spring-type oilseed rape may trigger loss of frost resistance and changes in photosynthetic apparatus. Plant Science 161:221-230. doi: 10.1016/S01689452(00)00341-1

Rapacz M (2002a) Regulation of frost resistance during cold de-acclimation and reacclimation in oilseed rape. A possible role of PSII redox state. Physiol Plant 115(2):236243. doi: 10.1034/j.1399-3054.2002.1150209.x

Rapacz M (2002b) Cold-deacclimation of oilseed rape (Brassica napus var. oleifera) in response to fluctuating temperatures and photoperiod. Annals of Botany 89:543-549. doi: 10.1093/aob/mcf090

Ratcliffe, OJ, Amaya I, Vincent CA, Rothstein S, Carpenter R, Coen ES, Bradley DJ (1998) A common mechanism controls the life cycle and architecture of plants. Development. 125:1609-1615

Ratcliffe OJ (2003) Analysis of the Arabidopsis MADS affecting flowering gene family: MAF2 prevents Vernalization by short periods of cold. The Plant Cell. 15:1159-1169. doi: 10.1105/tpc.009506

Rife CL and Salgado JP (1996) Selecting winter hardy oilseed rape for the great plants. In: J. Janick (ed.), progress in New Crops. Pp. 272-278. ASHS press, Alexandria, VA.

Sasani S, Hemming MN, Oliver SN, Greenup A, Tavakkol-Afshari R, Mahfoozi S, Poustini K, Sharifi HR, Dennis ES, Peacock WJ, Trevaskis B (2009) The influence of vernalization and day length on expression of flowering-time genes in the shoot apex and leaves of barley (Hordeum vulgare). J Exp Bot 60(7):2169-2178. doi: 10.1093/jxb/erp098

Sãulescu N, Braun HJ (2001) Cold stress. Application of Physiology in Wheat Breeding. Retrieved from http://books.google.com

Schaefer-Koesterke HL, Brandes H, Ulber B, Becker HC, Vidal S (2016) The potential of resynthesized lines to provide resistance traits against rape stem weevil in oilseed rape. $\mathrm{J}$ Pest Sci. doi: 10.1007/s10340-016-0742-y

Schiessl S, Samans B, Huttel B, Reinhard R, Snowdon RJ (2014) Capturing sequence variation among flowering-time regulatory gene homologs in the allopolyploid crop species Brassica napus. Front Plant Sci 5:404. doi: 10.3389/fpls.2014.00404 
Schmidt R, Bancroft I (2011) Genetics and Genomics of the Brassicaceae. Springer New York, New York, NY

Schilz RR (2007) Winterhärte am sproß erkennen. Raps Magazine, vol summer.pp2-5 (in German)

Seo E, Lee H, Jeon J, Park H, Kim J, Noh YS, Lee I (2009) Crosstalk between cold response and flowering in Arabidopsis is mediated through the flowering-time gene SOC1 and its upstream negative regulator FLC. Plant Cell 21(10):3185-3197. doi: $10.1105 /$ tpc. 108.063883

Shavorskaya O (2004) Identification of genes affecting flowering time variation in Brassica species. Acta Universitatis agriculturae Sueciae. Agraria, vol 453. Dept. of Plant Biology and Forest Genetics, Swedish Univ. of Agricultural Sciences, Uppsala

Shindo C, Aranzana MJ, Lister C, Baxter C, Nicholls C, Nordborg M, Dean C (2005) Role of FRIGIDA and FLOWERING LOCUS C in determining variation in flowering time of Arabidopsis. Plant Physiol 138(2):1163-1173. doi: 10.1104/pp.105.061309

Silva LC, Wang S, Zeng ZB (2012) Composite interval mapping and multiple interval mapping: procedures and guidelines for using Windows QTL Cartographer, vol 871

Smith LB, King GJ (2000) The distribution of BoCAL-a alleles in Brassica oleracea is consistent with a genetic model for curd development and domestication of the cauliflower Molecular Breeding 6(6):603-613. doi: 10.1023/A:1011370525688

Snowdon RJ, Wittkop B, Rezaidad A, Hasan M, Lipsa F, Stein A, Friedt W (2010) Regional association analysis delineates a sequenced chromosome region influencing antnutritive seed meal compounds in oilseed rape. Genome / National Research Council Canada = Génome / Conseil national de recherches Canada 53:917-928

Sotelo T, Soengas P, Velasco P, Rodriguez VM, Cartea ME (2014) Identification of metabolic QTLs and candidate genes for glucosinolates synthesis in Brassica oleracea leaves, seeds and flower buds. PLoS One 9:e91428. doi: 10.1371/journal.pone.0091428

Stanca AM, Romagosa I, Takeda K, Lundborg T, Terzi V, Cattivelli L (2003) Diversity in abiotic stress tolerances. In: Bothmer Rv (ed) Diversity in barley (Hordeum vulgare), vol 7. Elsevier, Amsterdam, London, pp 179-199

Sung S, Amasino RM (2004) Vernalization in Arabidopsis thaliana is mediated by the PHD finger protein VIN3. Nature 427:159-164. doi: 10.1038/nature02195

Suprianto E (2014) Genetic variation and inheritance of seed fibre content in winter oilseed rape (Brassica napus L.).PhD thesis, George august Göttingen University. 
Tasma IM, Lorenzen LL, Green DE, Shoemaker RC (2001) Molecular Breeding 8:25-35. doi: 10.1023/A:1011998116037

Teh L, Möllers C (2016) Genetic variation and inheritance of phytosterol and oil content in a doubled haploid population derived from the winter oilseed rape Sansibar x Oase cross. Theor Appl Genet 129:181-199. doi: 10.1007/s00122-015-2621-y

Teutonico RA, Osborn TC (1994) Mapping of RFLP and qualitative trait loci in Brassica rapa and comparison to the linkage maps of B. napus, B. oleracea, and Arabidopsis thaliana. Theor Appl Genet 89:885-894. doi: 10.1007/BF00224514

Teutonico RA, Osborn TC (1995) Mapping loci controlling vernalization requirement in Brassica rapa. Theor Appl Genet 91:1279-1283. doi: 10.1007/BF00220941

Teutonico RA, Palta JP, Osborn TC (1993) In vitro-freezing tolerance in relation to winter survival of rapeseed cultivars. Crop Science 33:103-107

Teutonico RA, Yandell B, Satagopan JM, Ferreira ME, Palta JP, Osborn TC (1995) Genetic analysis and mapping of genes controlling freezing tolerance in oilseed Brassica. Mol Breeding 1:329-339. doi: 10.1007/BF01248410

Theocharis A, Clement C, Barka EA (2012) Physiological and molecular changes in plants grown at low temperatures. Planta 235:1091-1105. doi: 10.1007/s00425-012-1641

Thies W (1971) Der Einfluß der Chloroplasten auf die Bildung von ungesättigten Fettsäuren in reifenden Rapssamen. Fette, Seifen, Anstrichmittel 73:710-715. doi: 10.1002/lipi.19710731202

Thurling N, Das VL, Vijendra DLD (1979) Genetic control of the pre-anthesis development of spring rape (Brassica napus L.). II. Identification of individual genes controlling developmental pattern. Aust. J. Agric. Res. 30:261. doi: 10.1071/AR9790261

Timmermans MCP (2010) Plant development. Current Topics in Developmental Biology, v. 91. Academic Press, Amsterdam

Tognetti JA, Salerno GL, Crespi MD, Pontis HG (1990) Sucrose and fructan metabolism of different wheat cultivars at chilling temperatures. Physiologia Plantarum 78:554 559.

Trischuk RG, Schilling BS, Low NH, Gray GR, Gusta LV (2014) Cold acclimation, deacclimation and re-acclimation of spring canola, winter canola and winter wheat: The role of carbohydrates, cold-induced stress proteins and vernalization. Environmental and Experimental Botany 106:156-163. doi: 10.1016/j.envexpbot.2014.02.013

Turck F, Fornara F, Coupland G (2008) Regulation and identity of florigen: FLOWERING LOCUS $T$ moves center stage. Annu Rev Plant Biol 59:573-594. doi: 10.1146/annurev.arplant.59.032607.092755 
Utz HF (2011) PLABSTAT a computer program for statistical analysis of plant breeding experiments Version 3A. Institute of Plant Breeding, Seed Science and Population Genetics, University of Hohenheim, Stuttgart, Germany

Wisniewski K, Zagdanska B, Pronczuk M (1997) Interrelationship between frost tolerance, drought and resistance to snow mould (Microdochium nivale). Acta Agronomica Hungarica 45(3):311-316.

Velicka R, Rimkeviciene M, Novickiene L, Anisimoviene N, Brazauskiene I (2005) Improvement of oil rape hardening and frost tolerance. Russ J Plant Physiol 52:473-480. doi: 10.1007/s11183-005-0070-1

Velicka R, Anisimoviene N, Puapalene R, Jankauskeine, Butkeviciene LM, Kriauciuniene $\mathrm{Z}$ (2010) Preparation of oilseed rape for over-wintering according to autumnal growth and cold acclimation period. Žemdirbyste்=Agriculture 97:69-76

Waalen W, Øvergaard SI, Åssveen M, Eltun R, Gusta LV (2013) Winter survival of winter rapeseed and winter turnip rapeseed in field trials, as explained by PPLS regression. European Journal of Agronomy 51:81-90. doi: 10.1016/j.eja.2013.06.004

Waalen WM, Stavang JA, Olsen JE, Rognli OA (2014) The relationship between vernalization saturation and the maintenance of freezing tolerance in winter rapeseed. Environmental and Experimental Botany 106:164-173. doi: 10.1016/j.envexpbot.2014.02.012

Wang S, Basten CJ. Zeng ZB (2012). Windows QTL Cartographer 2.5. Department of Statistics, North Carolina State University, Raleigh, NC.

Wang J, Long Y, Wu B, Liu J, Jiang C, Shi L, Zhao J, King GJ, Meng J (2009) The evolution of Brassica napus FLOWERING LOCUS T paralogues in the context of inverted chromosomal duplication blocks. BMC Evol Biol 9:271. doi: 10.1186/1471-2148-9-271

Wang N, Qian W, Suppanz I, Wei L, Mao B, Long Y, Meng J, Muller AE, Jung C (2011) Flowering time variation in oilseed rape (Brassica napus L.) is associated with allelic variation in the FRIGIDA homologue BnaA.FRI.a. J Exp Bot 62:5641-5658. doi: $10.1093 / \mathrm{jxb} / \mathrm{err} 249$

Wang X, Wang H, Long Y, Li D, Yin Y, Tian J, Chen L, Liu L, Zhao W, Zhao Y, Yu L, Li M (2013) Identification of QTLs associated with oil content in a high-oil Brassica napus cultivar and construction of a high-density consensus map for QTLs comparison in B. napus. PLoS One 8:e80569. doi: 10.1371/journal.pone.0080569

Wang XX, Wang HHH, Wang JJJ, Sun R, Wu J, Liu S, Bai Y, Mun JHJH, Bancroft I, Cheng F, Huang SS, Li X, Hua W, Freeling M, Pires JC, Paterson AH, Chalhoub B, Wang 
B, Hayward A, Sharpe AG, Park BS, Weisshaar B, Liu BB, Li B, Tong C, Song C, Duran C, Peng C, Geng C, Koh C, Lin C, Edwards D, Mu D, Shen D, Soumpourou E, Li F, Fraser F, Conant G, Lassalle G, King GJ, Bonnema G, Tang H, Belcram H, Zhou H, Hirakawa H, Abe H, Guo H, Jin H, Parkin IAP, Batley J, Kim JAJS, Just J, Li JJ, Xu J, Deng J, Yu J, Meng J, Min J, Poulain J, Hatakeyama K, Wu K, Wang L, Fang L, Trick M, Links MG, Zhao M, Jin M, Ramchiary N, Drou N, Berkman PJ, Cai Q, Huang Q, Li R, Tabata S, Cheng S, Zhang S, Sato S, Sun S, Kwon SJ, Choi SR, Lee TH, Fan W, Zhao X, Tan X, Xu X, Wang YY, Qiu Y, Yin Y, Li Y, Du Y, Liao Y, Lim Y, Narusaka Y, Wang ZZ, Li Z, Xiong Z, Zhang Z (2011b) The genome of the mesopolyploid crop species Brassica rapa. Nat Genet 43:10351039

Wanner LA (1999) Cold-induced freezing tolerance in Arabidopsis. Plant Physiol 120:391-400. doi: 10.1104/pp.120.2.391

Wardlaw IF (1972) Responses of plants to environmental stresses. Science 177(4051):786. doi: 10.1126/science.177.4051.786

Wei D, Mei J, Fu Y, Disi JO, Li J, Qian W (2014) Quantitative trait loci analyses for resistance to Sclerotinia sclerotiorum and flowering time in Brassica napus. Mol Breeding 34(4):1797-1804. doi: 10.1007/s11032-014-0139-7

Weinig C (2000a) Differing selection in alternative competitive environments: shadeavoidance responses and germination timing. Evolution 54: 124-136.

Weinig C (2000b) Plasticity versus canalization: population differences in the timing of shade- avoidance responses. Evolution 54: 441-451

Wittkop B, Snowdon RJ, Friedt W (2009) Status and perspectives of breeding for enhanced yield and quality of oilseed crops for Europe. Euphytica 170(1-2):131-140. doi: 10.1007/s10681-009-9940-5

Yuan YX, Wu J, Sun RF, Zhang XW, Xu DH, Bonnema G, Wang XW (2009) A naturally occurring splicing site mutation in the Brassica rapa FLCl gene is associated with variation in flowering time. J Exp Bot 60:1299-1308. doi: 10.1093/jxb/erp010

Zeng ZB (1994) Precision Mapping of Quantitative Trait Loci. Genetic Society of America.136:1457-1468

Zhang X, Wu J, Zhao J, Song X, Li Y, Zhang Y, Xu D, Sun R, Yuan Y, Xie C, Wang X (2006) Identification of QTLs Related to Bolting in Brassica rapa ssp. pekinensis (syn. Brassica campestris ssp. pekinensis). Agricultural Sciences in China 5:265-271. doi: 10.1016/S1671-2927(06)60048-5

Zografos BR, Sung S (2012) Vernalization-mediated chromatin changes. J Exp Bot 63:4343-4348. doi: 10.1093/jxb/ers157 
Zhao J, Becker HC, Zhang D, Zhang Y, Ecke W (2005) Oil Content in a Europeanx Chinese rapeseed population. Crop Sci 45:51-59

Zhao J, Becker HC, Zhang D, Zhang Y, Ecke W (2006) Conditional QTL mapping of oil content in rapeseed with respect to protein content and traits related to plant development and grain yield. Theor Appl Genet 113:33-38. doi: 10.1007/s00122-006-0267-5

Zou X, Suppanz I, Raman H, Hou J, Wang J, Long Y, Jung C, Meng J (2012) Comparative analysis of $F L C$ homologues in Brassicaceae provides insight into their role in the evolution of oilseed rape. PLoS One 7:e45751. doi: 10.1371/journal.pone.0045751 


\section{Acknowledgement}

I would like to express my deep gratitude to my supervisor Dr. Christian Möllers whose patient supervision, guidance, kindness, and encouragement throughout my study has made this thesis become a reality. I am grateful to Prof. Heiko C. Becker for giving me the opportunity to join Plant Breeding Division and for his support and constructive advices. I would like to express my words of gratitude to Prof. Dr. Konstantin V. Krutovsky and Dr. Wolfgang Ecke for agreeing to be my examiners in the final disputation.

I would like to show my thankfulness to the people who helped me during the research:

Madhuri Paul, Gunda Asselmeyer, Uwe Ammermann, Carmen Mensch, Birgit Olberg, Dr. Ujjal Kumar. My special thank goes to all PhD students in Plant Breeding Division for their great supports.

My sincere gratitude goes to Dr. Antje Schierholt for her kindness, help and generosity during my stay in Germany.

This study would not have been possible without financial support from Erasmus Mundus, SALAM 1 project, Therefore I would like to thank SALAM team at University of Warsaw in Poland and University of Göttingen in Germany.

I dedicate my deepest gratitude to my kind wife Farzaneh and my lovely daughter Sara for their limitless patience, support and encouragement during my study in Germany. I am grateful forever to my parents, Ruhollah and Banoo, for their continuous support, kindness and love. 


\section{Curriculum vitae}

\section{PERSONAL DETAILS}

Name

Mohammad Ghanbari

Place of birth

Zahedan, Iran

Date of birth

21 March 1981

Address

Roodaki 28, Zahedan9816944445

Email

Mghanbari.msc@gmail.com

Nationality

Iranian

Marital status

Married, one child

\section{Education Back ground}

Oct 2013 - May2016

Ph.D: Plant Breeding, Georg August University Götingen. Germany

Sep2003 - March 2006

Master: Plant Breeding, University of Tehran, Tehran, Iran

Sep 1999- April 2003

Bachelor: Agronomy and Plant Breeding, University of Zabol, Iran

\section{Work Experience}

Aug 2009- Sep 2013

Researcher \& Lecturer

Department of Biotechnology and Plant breeding.

University of Zabol, Zabol, Iran

Oct 2007 - Aug 2009

Plant breeder

Agriculture research institute

Ministry of agriculture, Iran. 


\section{Honours, Awards, Distinctions}

2013

PhD Fellowship at Göttingen University, Germany

Erasmus Mundus

2011

Outstanding Researcher

University of Zabol, Zabol, Iran

2010

Post-Graduate Fellowship

Ministry of Science, Research and Technology, Iran

2003

Fourth Rank Student Out of 804 candidates

Ministry of Science, Research and Technology, Iran

\section{Publication}

Ghanbari M, Molashahi M 2015 Study the response of mung bean to drought stress by multivariate analysis. International Journal of agriculture Innovations and Research. 3(4) 23191473.

Ghanbari M, Molashahi M 2014 Study the effects of super absorbent application on Maize Under drought stress condition. International Journal of agriculture Innovations and Research. 3(4) 2319-1473.

Ghanbari M, Mir B, 2013 Genetic analysis of pre-harvest sprouting resistance in wheat cultivars. International Journal of Agronomy and Plant protection .4(9)2260-2266.

Ghanbari M, Zaboli GR, Mir B 2013 Comparing Irrigation methods and weed control on yield of Garlic Cultivars. World of Science Journal. Vol 3.70-78

Ghanbari M, Ariafar S 2013 The study of different levels of zeolite application quantitative and qualitative parameters in Basil (Ocimum basilicum L.) under drought. International Journal of Agriculture, Research and Review .3(4)844-853.

Ghanbari M, Ariafar S 2013 The effects of water deficit and zeolite application on growth traits and oil yield of medicinal Peppermint. International Journal of Medicinal and Aromatic Plants .3(1)32-39. 


\section{Conferences}

Ghanbari M, Teh L, Paul M, Moellers C (2015) Genetic variation and inheritance of epicotyl elongation before winter and its correlation with winter hardiness and vernalization requirement in winter oilseed rape, $14^{\text {th }}$ international Rapeseed congress, Saskatoon, Canada.

Ghanbari M, Moellers C (2014) Inheritance of epicotyl elongation before winter as one component of winter hardiness in winter oil seed rape. GPZ international Congress, Kiel, Germany.

Ghanbari M (2012) Screening mung bean (Vigna radiate L.) genotypes for drought tolerance. International Symposium of Plant Biotechnology. Villa Clara. Cuba.

Ghanbari M (2011) Investigation of adaptability in rice (Oriza sativa L.) cultivars. The First National Conference of Modification in Consumption Patterns. Zabol. Iran.

Ghanbari M (2011) Investigation of adaptability in alfalfa (Medicago sativa .L.) ecotypes. The First National Conference of Modification in Consumption Patterns. Zabol. Iran.

Ghanbari M, Dahmarde M (2006) Estimation of variation, heritability and genetic behavior of wheat genotypes under drought Stress. $9^{\text {th }}$ Iranian Genetics Congress, Tehran-Iran.

Ghanbari M, Dahmarde M (2006) Study of diversity and genetic correlation between quantitative traits in mung bean lines under drought stress $.9^{\text {th }}$ Iranian Genetics Congress, Tehran-Iran.

\section{Workshop and practical course}

Next Generation Sequencing (NGS) - Analysis of RNAseq and ChIPseq data, Nov 2015. Göttingen University, Germany

Systematic review and Meta-analysis, Dec 2015. Göttingen University, Germany 
Linear statistical Model with R, Sep 2015. Göttingen University. Germany

Technique and teaching skills. Dec 2012. University of Zabol, Iran.

Application SPSS Software in Biometrical Analysis. May 2012. University of Zabol, Iran.

Molecular Markers Based PCR. Dec 2010. University of Zabol, Zabol, Iran.

Creativity and Innovation (invention). University of Zabol, Iran.

Introduction Research and Seed Propagation in Cotton. Mar 2009. Research Institute for Cotton and Fibrous Crops, Gorgan, Iran.

Familiarity with planning and value engineering and its application in drought management. Mars 2008. $1^{\text {th }}$ International Conference of water Crisis. Zabol, Iran. 